

\section{INSTITUTO DE PESQUISAS ENERGÉTICAS E NUCLEARES}

Autarquia associada à Universidade de São Paulo

\section{ESTUDO DE MATERIAIS ADSORVEDORES PARA O PREPARO DE GERADORES DE Ge-68/Ga-68}

Tânia de Paula Brambilla

Tese apresentada como parte dos requisitos para obtenção do Grau de Doutor em Ciências na Área de Tecnologia Nuclear - Aplicações

Orientador:

Prof. Dr. João Alberto Osso Júnior 
Dedico este trabalho aos meus pais Roberto e Dora, ao meu irmão Angelo e aos meus avós paternos Herminio e Adalgiza (em memória) 


\section{Agradecimentos}

A Deus, por ter me dado força e coragem para enfrentar mais este desafio.

Aos meus pais Dora e Roberto pelo amor, carinho e apoio que me deram ao longo de toda minha vida. Agradeço pelo incentivo aos estudos, dizendo sempre que o conhecimento é algo precioso, pois é a única coisa que ninguém pode nos tirar.

Ao meu irmão Angelo, que sempre torceu por mim, sendo além de irmão, um verdadeiro amigo.

Ao Dr. João Alberto Osso Júnior pela confiança em mim depositada para o desenvolvimento deste trabalho e durante esses oito anos no Centro de Radiofármacia. Além de orientador, é um grande amigo, por quem tenho profundo respeito e admiração. Admiro-o não só pelo profissionalismo e competência, mas também pela pessoa que ele é: extremamente humilde, sempre sorridente, disposto a ajudar, ensinar e incentivar. Agradeço imensamente por todos os ensinamentos transmitidos, pela paciência, compreensão, atenção, incentivo, ajuda e pela sincera amizade, contribuindo sempre para o meu crescimento profissional e pessoal.

Aos funcionários da Gerência de Pesquisa e Desenvolvimento do Centro de Radiofarmácia, Peterson, Lorena e Evandro. Agradecimento especial ao Peterson, por todos os ensinamentos transmitidos e realização das imagens no equipamento de $\mu \mathrm{PET}$.

Aos funcionários da Gerência de Produção de Radiofármacos que me ajudaram de alguma forma durante a realização deste trabalho, em especial a Regina Bezerra, Renato Benvenutti e Luis Alberto. Agradecimento especial ao Wagner Nieto por toda ajuda prestada na montagem das colunas e construção do desenho do gerador.

À Gerência do Controle de Qualidade de Radiofármacos onde foram realizadas algumas análises. Agradeço a todos seus funcionários, Patrícia, Zé, Marcelo, Vivian, Carlos, Natanael, Ideli e tantas outras pessoas que me ajudaram desde o início desta jornada. Um agradecimento mais que especial para a Patrícia, por toda paciência e boa vontade de querer ajudar durante todos esses anos, pela amizade e alegria transmitida.

Aos meus amigos Kátia, Carla, Graciela, Marcela, Josiane, Samanta, Rodrigo, Thais, Lorena e Daphne. Agradeço por todos os momentos compartilhados, pela ajuda em muitos momentos difíceis, pelo apoio e pela amizade.

Às minhas amigas Giceli, Pryscila e Marcela pelo apoio, incentivo e principalmente pelo carinho e amizade sincera. 
Às funcionárias da secretaria do CR, Fátima e Neli, por toda ajuda prestada durante todos esses anos de trabalho.

Aos funcionários da proteção radiológica, em especial ao Olavo e Eduardo, pela ajuda durante todo o desenvolvimento do projeto.

Ao Jorge, do setor de vendas do CR, pela ajuda prestada sempre que solicitado.

Ao pessoal da informática do CR, em especial ao Adolfo. Agradeço pela boa vontade de querer ajudar sempre que foi preciso.

À Dra. Elaine Bortoleti por ter me dado oportunidade de iniciar um novo trabalho junto a Garantia da Qualidade do Centro de Radiofarmácia. Agradeço também as minhas novas colegas de trabalho pelas palavras de incentivo.

À Dra. Ana Maria P. L. Gordon por ter me dado oportunidade de estagiar através do Programa PAE, por duas vezes, como monitora da sua disciplina, oferecida para graduação da USP. Agradeço por todos os ensinamentos transmitidos.

Ao Dr. Roberto Martinelli por toda ajuda prestada durante o desenvolvimento deste trabalho. Agradeço pelos ensinamentos transmitidos e a boa vontade de sempre querer ajudar.

Ao Dr. Genova pela ajuda e colaboração no desenvolvimento do trabalho.

Ao Dr. Nelson pela realização das análises de difração de raio-X e pelos conhecimentos transmitidos.

Ao Dr. Kenji pela ajuda prestada na realização das análises de BET.

À Dra. Fátima Maria (em memória), por quem sempre tive grande respeito e admiração. Agradeço pelos ensinamentos transmitidos e pela colaboração durante quase todos os anos do desenvolvimento deste trabalho. A Dra. Fátima foi, sem dúvida, uma pessoa admirável, tanto pela pesquisadora que era, quanto pela pessoa, sempre alegre e de bem com a vida, transmitindo alegria por onde passava. Deixo aqui os meus mais sinceros e profundos agradecimentos!

Ao Instituto de Pesquisas Energéticas e Nucleares, juntamente com o Centro de Radiofarmácia pela oportunidade concedida para a realização deste trabalho.

À Comissão Nacional de Energia Nuclear (CNEN) pela concessão da bolsa de doutorado.

A todos aqueles que, de alguma forma, contribuíram para a elaboração deste trabalho, quero expressar o meu mais sincero e profundo agradecimento. 
"Claro que devemos tentar atingir a perfeição, desde que tenhamos na mente que ela é inatingível."

Albert Einstein

"Tudo tem seu apogeu e seu declínio... É natural que seja assim; todavia quando tudo parece convergir para o que supomos o nada, eis que a vida ressurge, triunfante e bela!... Novas folhas, novas flores, na indefinida bênção do recomeço!..."

Francisco Cândido Xavier

"A persistência é o caminho do êxito."

Charles Chaplin

"The important thing in science is not so much to obtain new facts as to discover new ways of thinking about them."

Willian Lawrence Bragg 


\title{
Estudo de materiais adsorvedores para o preparo de geradores de ${ }^{68} \mathrm{Ge} /{ }^{68} \mathrm{Ga}$
}

\author{
Tânia de Paula Brambilla
}

\section{RESUMO}

O ${ }^{68} \mathrm{Ga}$ é um radionuclídeo promissor para a medicina nuclear, decaindo por emissão de pósitrons com abundância de $89 \%$, apresentando tempo de meia vida física de 68 minutos, o que é compatível com a farmacocinética de muitas biomoléculas e substratos de baixo peso molecular. Outra característica importante é a sua disponibilidade por um sistema de gerador, onde o radionuclídeo pai, ${ }^{68} \mathrm{Ge}\left(\mathrm{t}_{1 / 2}=270,95\right.$ dias) é adsorvido em uma coluna e o filho, ${ }^{68} \mathrm{Ga}$, é eluído na forma iônica ${ }^{68} \mathrm{Ga}^{3+}$. O desenvolvimento dos geradores de ${ }^{68} \mathrm{Ge} /{ }^{68} \mathrm{Ga}$ teve início na década dos anos 60 , mas o seu uso clínico começou a ser aceitável e relevante apenas recentemente. $O$ método de separação do ${ }^{68} \mathrm{Ge}$ do ${ }^{68} \mathrm{Ga}$ mais utilizado é o sistema cromatográfico de troca iônica, devido sua praticidade de operação, mas outros sistemas de geradores já foram propostos, como de extração por solvente e técnica de evaporação. Atualmente, os geradores de ${ }^{68} \mathrm{Ge} /{ }^{68} \mathrm{Ga}$ são disponíveis comercialmente tanto com colunas utilizando matrizes inorgânicas preparadas $\mathrm{com} \mathrm{TiO}_{2}$ ou $\mathrm{SnO}_{2}$ como também usando resina orgânica. A eficiência de eluição do ${ }^{68} \mathrm{Ga}$ varia de $70 \%$ a 80 \%, apresentando uma queda ao longo do tempo. Os níveis de contaminação do ${ }^{68} \mathrm{Ge}$ vão de $10^{-2}$ a $10^{-3} \%$, porém ocorre um aumento nos níveis de contaminação após longos períodos de uso. Mesmo com todos os avanços tecnológicos, ocorridos nas últimas décadas, no desenvolvimento dos geradores de ${ }^{68} \mathrm{Ge} /{ }^{68} \mathrm{Ga}$, o eluato de ${ }^{68} \mathrm{Ga}$ dos geradores comerciais ainda não é adequado para uso direto em seres humanos e algumas melhorias nos sistemas precisam ser feitas para diminuir os níveis de contaminação de ${ }^{68} \mathrm{Ge}$ e impurezas químicas. O objetivo principal deste trabalho foi desenvolver um sistema de gerador de ${ }^{68} \mathrm{Ge} /{ }^{68} \mathrm{Ga}$ com o qual se pudesse eluir ${ }^{68} \mathrm{Ga}$ com qualidade necessária para uso clínico. $\mathrm{O}$ comportamento químico do $\mathrm{Ge}$ e do $\mathrm{Ga}$ foi avaliado em vários materiais adsorvedores inorgânicos. Foram desenvolvidos dois tipos de sistemas de geradores de ${ }^{68} \mathrm{Ge} /{ }^{68} \mathrm{Ga}$ utilizando $0 \mathrm{TiO}_{2}$ como material adsorvedor: sistema de eluição com pressão manual e sistema de eluição a vácuo, controlado. As eficiências dos geradores foram similares às encontradas nos geradores comerciais, assim como os níveis de impurezas no eluato. Um novo método para o controle radionuclídico foi desenvolvido e apresentou resultados satisfatórios para determinação da contaminação do ${ }^{68} \mathrm{Ge}$ no eluato do gerador. Foi proposto um protótipo de gerador capaz de fornecer ${ }^{68} \mathrm{Ga}$ com a qualidade necessária para ser utilizado em aplicações médicas. 


\title{
Study of adsorber materials for preparing ${ }^{68} \mathrm{Ge} /{ }^{68} \mathrm{Ga}$ generators
}

\author{
Tânia de Paula Brambilla
}

\begin{abstract}
The ${ }^{68} \mathrm{Ga}$ is a promising radionuclide for nuclear medicine, decaying by positron emission with an abundance of $89 \%$, with physical half-life of 68 minutes, which is compatible with the pharmacokinetics of many biomolecules and low molecular weight substrates. Another important feature is its availability through a generator system, where the parent radionuclide, ${ }^{68} \mathrm{Ge}\left(\mathrm{t}_{1 / 2}=270.95\right.$ days) is adsorbed on a column and the daughter, ${ }^{68} \mathrm{Ga}$, is eluted in an ionic form ${ }^{68} \mathrm{Ga}^{3+}$. The development of ${ }^{68} \mathrm{Ge} /{ }^{68} \mathrm{Ga}$ generators began in the $60 \mathrm{~s}$, but its clinical use began to be acceptable and relevant only recently. The method of separation of ${ }^{68} \mathrm{Ge}$ and ${ }^{68} \mathrm{Ga}$ most used is the ion-exchange chromatographic system, due to its practical operation, but other generator systems have been proposed, such as solvent extraction and evaporation technique. Currently, ${ }^{68} \mathrm{Ge} /{ }^{68} \mathrm{Ga}$ generators are commercially available using inorganic matrices columns prepared with $\mathrm{TiO}_{2}$ or $\mathrm{SnO}_{2}$ as well using organic resin. The efficiency of ${ }^{68} \mathrm{Ga}$ elution ranges from $70 \%$ to $80 \%$, decreasing over time. The ${ }^{68} \mathrm{Ge}$ breakthrough varies from $10^{-2}$ to $10^{-3} \%$ or lower in a fresh generator, but there is an increase in the levels of contamination after long periods of use. Even with all the technological advances in the development of ${ }^{68} \mathrm{Ge} /{ }^{/ 8} \mathrm{Ga}$ generators in the past decades, the ${ }^{68} \mathrm{Ga}$ eluted from commercial generators is not suitable for direct use in humans and some improvements in the systems need to be made to reduce the ${ }^{68} \mathrm{Ge}$ breakthrough and chemical impurities levels. The main objective of this work was to develop a ${ }^{68} \mathrm{Ge} /{ }^{68} \mathrm{Ga}$ generator system is which ${ }^{68} \mathrm{G}$ a could be eluted with quality required for clinical use. The chemical behavior of $\mathrm{Ge}$ and $\mathrm{Ga}$ was evaluated on various inorganic adsorbents materials. Two types of ${ }^{68} \mathrm{Ge} /{ }^{68} \mathrm{Ga}$ generator systems were developed using $\mathrm{TiO}_{2}$ as adsorbent material: elution system with manual pressure and vacuum controlled. The efficiencies of the generators were similar to those found in commercial generators, as well as the impurity levels in the eluate. A new method for radionuclidic control was developed and showed good results for the determination of ${ }^{68} \mathrm{Ge}$ breakthrough in ${ }^{68} \mathrm{Ga}$ eluate. It was proposed a prototype ${ }^{68} \mathrm{Ga}$ generator capable of providing the quality needed for use in medical applications.
\end{abstract}




\section{SUMÁRIO}

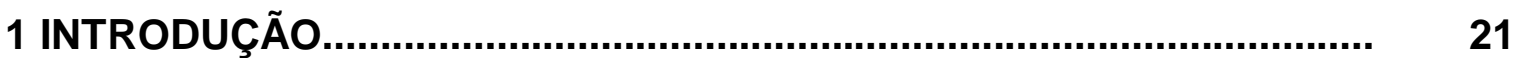

1.1 Medicina Nuclear....................................................................... 23

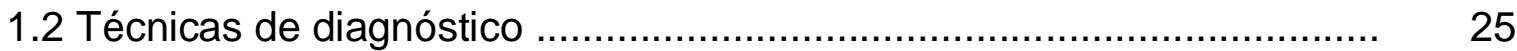

1.2.1 SPECT e os principais radionuclídeos emissores $\gamma \ldots \ldots \ldots \ldots \ldots \ldots \ldots \ldots . . . . . . . . . .26$

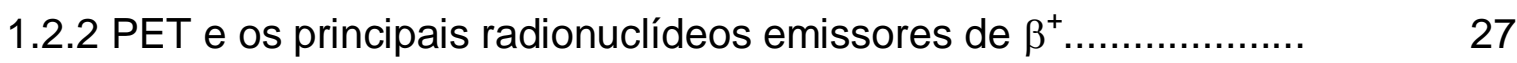

1.3 Geradores de radionuclídeos.......................................................... $\quad 30$

1.4 Propriedades físico-químicas do gálio................................................ 33

$1.5^{68} \mathrm{Ga}$ : característica de decaimento e uso clínico...............................

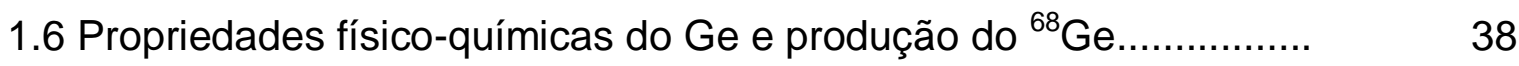

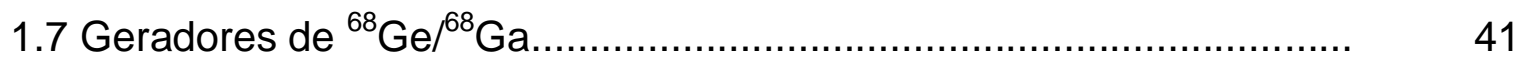

1.8 Revisão bibliográfica dos geradores de ${ }^{68} \mathrm{Ge} /{ }^{68} \mathrm{Ga}$ cromatográficos........................................................................ 46

1.9 Revisão bibliográfica sobre o controle radionuclídico do eluato de ${ }^{68} \mathrm{Ga}$.

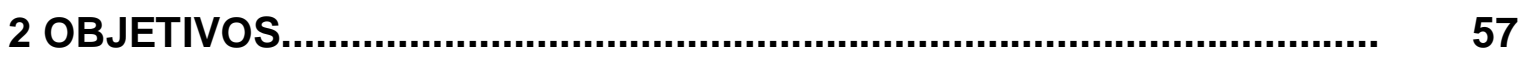

3 JUSTIFICATIVA A......................................................................... 58

4 MATERIAIS E MÉTODOS..............................................................

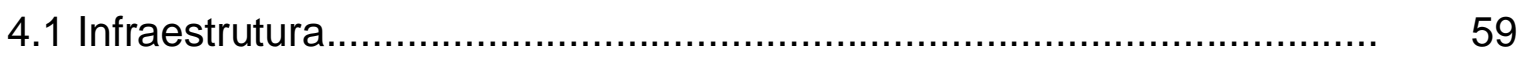

4.2 Materiais............................................................................ 59

4.2.1 Equipamentos e softwares....................................................... 59

4.2.2 Materiais em geral....................................................................... 60

4.2.3 Reagentes...................................................................... 60

4.2.4 Adsorvedores.................................................................... 61

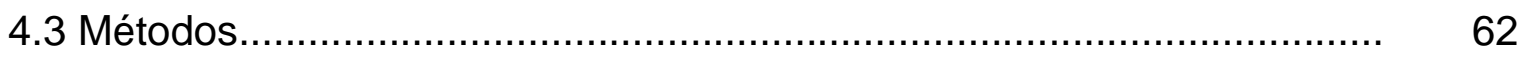

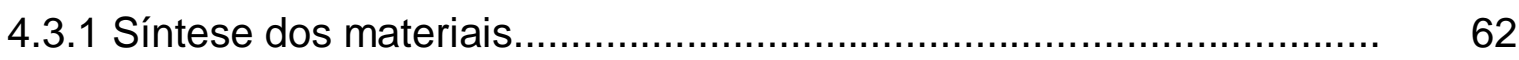

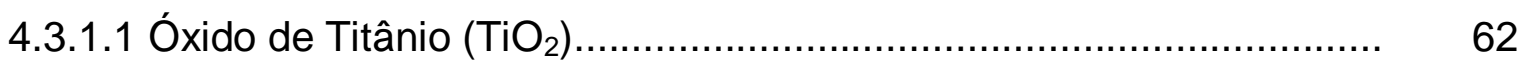

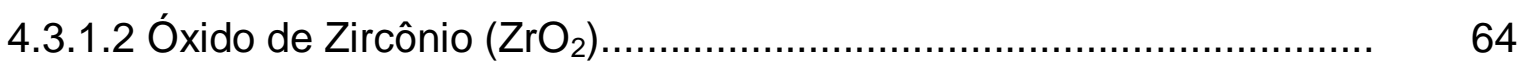

4.3.2 Estudo do comportamento químico do $\mathrm{Ge}$ e do $\mathrm{Ga}$ nos materiais

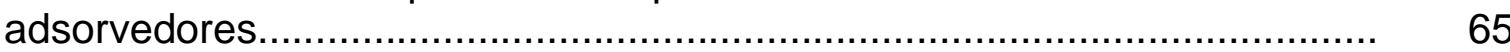

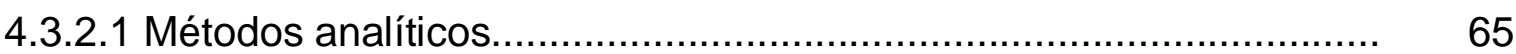

4.3.2.1.1 Espectrometria de emissão óptica com plasma indutivamente

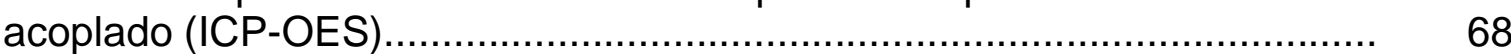

4.3.2.2 Colunas cromatográficas com $\mathrm{Al}_{2} \mathrm{O}_{3}, \mathrm{HZO}, \mathrm{ZrO}_{2}, \mathrm{TiO}_{2}$ e $\mathrm{SnO}_{2} \ldots \ldots . .69$ 
4.3.2.3 Colunas cromatográficas com microesferas

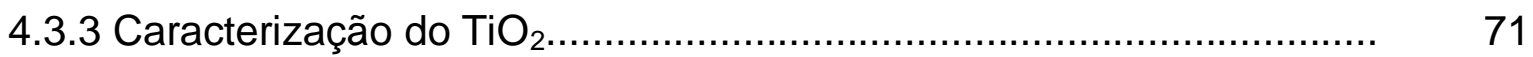

4.3.3.1 Distribuição granulométrica.......................................................

4.3.3.2 Microscopia eletrônica de varredura e análise elementar................. 72

4.3.3.3 Análise térmica (TG-DTA).......................................................

4.3.3.4 Difração de raios X................................................................

4.3.3.5 Análise da área superficial específica (B.E.T.)............................... 75

4.3.4 Preparo e avaliação dos geradores de ${ }^{68} \mathrm{Ge} /{ }^{68} \mathrm{Ga}$.............................. 75

4.3.5 Controle de qualidade do ${ }^{68} \mathrm{Ga}$...................................................... 81

4.3.5.1 Identificação dos fótons e identidade radionuclídica ........................ 82

4.3.5.2 Pureza radionuclídica ........................................................... 84

4.3.5.3 Pureza radioquímica................................................................ 88

4.3.5.4 Pureza química.................................................................... 91

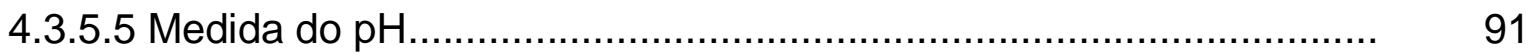

4.3.6 Determinação da pureza radionuclídica do ${ }^{68} \mathrm{Ga}$ por fitas cromatográficas

4.3.6.1 Seleção do sistema de separação................................................. 91

4.3.6.2 Análise da amostra de ${ }^{68} \mathrm{Ga}$........................................................ 95

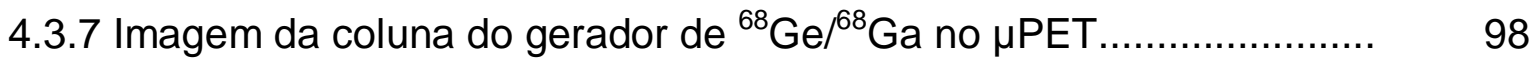

4.3.8 Projeto de gerador com sistema a vácuo para eluição e purificação.

5 RESULTADOS E DISCUSSÃo

5.1 Estudo do comportamento químico do $\mathrm{Ge}$ e do $\mathrm{Ga}$ nos materiais adsorvedores

5.2 Caracterização do $\mathrm{TiO}_{2}$

5.2.1 Distribuição granulométrica. 108

5.2.2 Microscopia eletrônica de varredura e análise elementar.

5.2.2.1 Microscopia eletrônica.

5.2.2.2 Análise elementar.

5.2.3 Análise termogravimétrica (TG e DTA).

5.2.4 Difração de raio $X$

5.2.5 Análise da área superficial específica (B.E.T.)

5.3 Preparo e avaliação dos geradores de ${ }^{68} \mathrm{Ge} /{ }^{68} \mathrm{Ga}$.

5.4 Controle de Qualidade dos geradores de ${ }^{68} \mathrm{Ge} /{ }^{68} \mathrm{Ga}$.

5.4.1 Identificação dos fótons e identidade radionuclídica. 


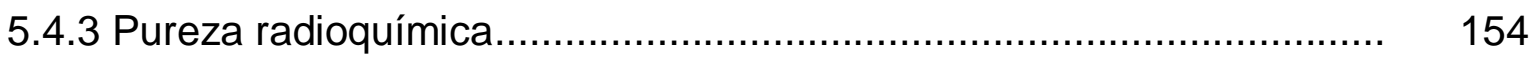

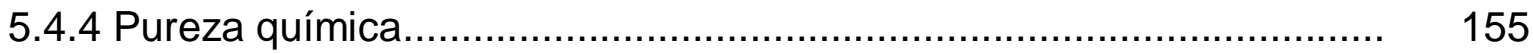

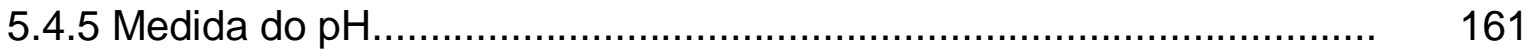

5.5 Determinação da pureza radionuclídia do ${ }^{68} \mathrm{Ga}$ por fitas cromatográficas

5.5.1 Seleção do sistema de separação..................................................... 161

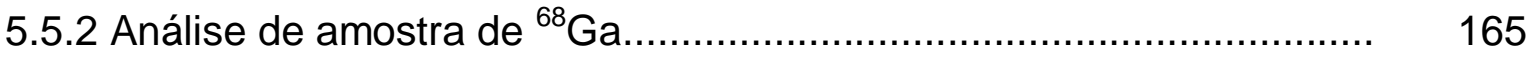

5.6 Imagem da coluna do gerador de ${ }^{68} \mathrm{Ge} /{ }^{68} \mathrm{Ga}$ no $\mu \mathrm{PET} \ldots \ldots \ldots \ldots \ldots \ldots \ldots \ldots \ldots . . . . . . . . . . . .170$

5.7 Projeto de gerador com sistema de purificação feita a vácuo.................. 172

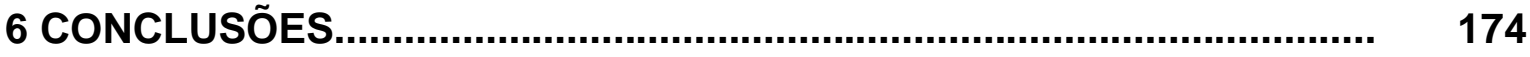

REFERÊNCIAS BIBLIOGRÁFICAS..................................................... 176 


\section{LISTA DE TABELAS}

TABELA 1.1 - Métodos de produção ou obtenção de radionuclídeos.

TABELA 1.2 - Principais radionuclídeos emissores de radiação gama com suas respectivas energias e tempos de meia-vidas físicas.

TABELA 1.3 - Radionuclídeos emissores de pósitrons utilizados na medicina com as respectivas meia-vidas físicas, abundância e energia máxima do $\beta^{+}$

TABELA 1.4 - Exemplos de sistemas de geradores de radionuclídeos usados para aplicação na medicina nuclear.

TABELA 1.5 - Isótopos do gálio, suas respectivas meias vidas físicas e modo de decaimento.

TABELA 1.6 - Radiofármacos com ${ }^{68} \mathrm{Ga}$ encontrados na literatura............. $\quad 37$

TABELA 1.7 - Principais reações nucleares para produção de ${ }^{68} \mathrm{Ge} . \ldots \ldots \ldots . . . \quad 40$

TABELA 1.8 - Geradores de ${ }^{68} \mathrm{Ge} /{ }^{/ 8} \mathrm{Ga}$ disponíveis comercialmente.......... $\quad 44$

TABELA 1.9 - Características dos geradores cromatográficos encontrados na literatura.

TABELA 4.1 - Parâmetros instrumentais e analíticos utilizados para determinação do Ge no ICP-OES.

TABELA 4.2 - Resumo dos parâmetros utilizados no preparo dos geradores.

TABELA 4.3 - Atividades de ${ }^{68} \mathrm{Ge}$ e as massas do carregador utilizadas nos geradores

TABELA 4.4 - Equações para determinação da eficiência $(\varepsilon)$ do detector de HPGe em seis posições

TABELA 4.5 - Sistemas cromatográficos estudados para separação do ${ }^{68} \mathrm{Ge} \mathrm{e}{ }^{68} \mathrm{Ga}$

TABELA 5.1 - Comportamento do Ge em diferentes materiais adsorvedores utilizando sistema manual de eluição com seringa...

TABELA 5.2 - Estudo da adsorção do $\mathrm{Ge}$ em diferentes tipos de microesferas. 
TABELA 5.3 - Volume de $\mathrm{TiCl}_{3}$ a $15 \%$ utilizado nas preparações dos lotes de $\mathrm{TiO}_{2}$, massa experimental do $\mathrm{TiO}_{2}$ e massa teórica do $\mathrm{TiO}_{2}$ calculada por estequiometria.

TABELA 5.4 - Porcentagem de perda da massa de $\mathrm{TiO}_{2}$ dos lotes 4, 5, 6, $7,8,9$ e 10 após calcinação a $420^{\circ} \mathrm{C}$ e as condições de cada material.......

TABELA 5.5 - Característica visual dos materiais obtidos nos 10 lotes......

TABELA 5.6 - Porcentagem média de $\mathrm{TiO}_{2}$ obtido em cada faixa granulométrica após o peneiramento do material.

TABELA 5.7 - Área superficial específica dos $\mathrm{TiO}_{2}$.

TABELA 5.8 - LD e LQ em seis posições do detector de germânio hiperpuro para a energia de $511 \mathrm{keV}$ com tempo de contagem de 20 minutos.

TABELA 5.9 - LD e LQ em seis posições do detector de germânio hiperpuro para a energia de $511 \mathrm{keV}$ com tempo de contagem de 60 minutos.

TABELA 5.10 - LD e LQ em seis posições do detector de germânio hiperpuro para a energia de $511 \mathrm{keV}$ com tempo de contagem de 120 minutos.

TABELA 5.11 - Concentração Ge, Ti, Fe, $\mathrm{Zn}$ e Al nas amostras das eluições do gerador $\mathrm{G} 2$ ( $\mathrm{TiO}_{2}$ não calcinado)

TABELA 5.12 - Concentração $\mathrm{Ge}, \mathrm{Ti}, \mathrm{Fe}, \mathrm{Zn}$ e Al nas amostras das eluições do gerador $\mathrm{G} 3$ ( $\mathrm{TiO}_{2}$ calcinado).

TABELA 5.13 - Concentração $\mathrm{Ge}, \mathrm{Ti}, \mathrm{Fe}, \mathrm{Zn}$ e $\mathrm{Al}$ nas amostras das eluições do gerador G5

TABELA 5.14 - Concentração Ge, Ti, Fe, Zn, Sn e Al nas amostras das eluições do gerador comercial 2 (iThemba).....

TABELA 5.15 - Rf do ${ }^{68} \mathrm{Ge}$ e do ${ }^{68} \mathrm{Ga}$ em diferentes sistemas cromatográficos

TABELA 5.16 - Limites de detecção (LD) do contador gama para energia de $511 \mathrm{keV}$ para diferentes tempos de contagem, utilizando para o cálculo o valor de BG informado pelo equipamento.

TABELA 5.17 - Limites de detecção (LD) do contador gama para energia de $511 \mathrm{keV}$ para diferentes tempos de contagem, utilizando para o cálculo o valor médio das medidas do BG. 
TABELA 5.18 - Porcentagem do crescimento do ${ }^{68} \mathrm{Ga}$ nos tempos utilizados para contagem das fitas.

TABELA 5.19 - Porcentagem de ${ }^{68} \mathrm{Ge}$ nos diferentes tempos analisados após o inicio da cromatografia... 


\section{LISTA DE FIGURAS}

FIGURA 1.1 - Alcance do pósitron no tecido em função da sua energia ....

FIGURA 1.2 - Formação de espécies químicas do Ga em solução aquosa com pH 3 a 8

FIGURA 1.3 - Número de publicações relacionadas ao ${ }^{68} \mathrm{Ga}$ encontradas no PubMed no período de 1965 a 2013 (Palavra-chave para pesquisa: $\mathrm{Ga}-68$ ou ${ }^{68} \mathrm{Ga}$ )

FIGURA 1.4 - Imagens diagnósticas de um paciente com tumores neuroendócrinos realizadas com três radiofármacos diferentes, $\mathrm{FDG}-{ }^{18} \mathrm{~F}$ (esquerda), Octreoscan ${ }^{111}$ In (centro) e DOTATOC $-{ }^{68} \mathrm{Ga}$ (direita)

FIGURA 1.5 - Dissociações do ácido germânico $\left(\mathrm{H}_{4} \mathrm{GeO}_{4}{ }^{0}\right)$

FIGURA 1.6- Esquema de decaimento do ${ }^{68} \mathrm{Ge}$

FIGURA 1.7 - Função de excitação para produção do ${ }^{68} \mathrm{Ge}$ através da reação ${ }^{\text {nat }} \mathrm{Ga}(\mathrm{p}, \mathrm{xn})^{68} \mathrm{Ge}$.

FIGURA 1.8 - llustração de ciclos de eluição com o crescimento da atividade do ${ }^{68} \mathrm{Ga}$ para um sistema de gerador de ${ }^{68} \mathrm{Ge} /{ }^{68} \mathrm{Ga}$.

FIGURA 1.9 - Geradores comerciais de ${ }^{68} \mathrm{Ge} /{ }^{68} \mathrm{Ga}: 1$ - Cyclotron Co Ltd; 2 - Eckert and Ziegler; 3 - ITG e 4 - iThemba.

FIGURA 1.10 - Esquema de montagem do gerador de ${ }^{68} \mathrm{Ge} /{ }^{68} \mathrm{Ga}$ proposto por Chakravarty et al em 2011

FIGURA $1.11-R_{f}$ do $\mathrm{Ga}$ e do $\mathrm{Ge}$ em HCl-acetona (1:1) na sílica gel (KSK)

FIGURA 4.1 - Solução de $\mathrm{TiCl}_{3}$ com $\mathrm{NH}_{4} \mathrm{OH}$ para síntese do $\mathrm{TiO}_{2}$. (A) Início da reação (B) Final da reação

FIGURA $4.2-\left(\right.$ A) $\mathrm{TiO}_{2}$ após a filtragem. (B) Material seco a $100^{\circ} \mathrm{C}$ no vidro de relógio.

FIGURA 4.3 - Gerador de ${ }^{68} \mathrm{Ge} /{ }^{68} \mathrm{Ga}$ (Obninsk-generator, Cyclotron Co. Ltd.).

FIGURA 4.4 - Calibrador de doses Capintec CRC-35R

FIGURA 4.5 - Espectrômetro de emissão óptica com plasma indutivamente acoplado (ICP-OES), Varian Vista - MPX, Varian Inc., EUA. 
FIGURA 4.6 - Esquema simplificado dos componentes de um equipamento de ICP-OES.

FIGURA 4.7 - Esquema de montagem das colunas cromatográficas e o procedimento experimental

FIGURA 4.8 - Microscópio eletrônico de varredura (MEV) de bancada, TM 3000, Hitachi.

FIGURA 4.9 - Difratômetro de raios-X Rigaku, modelo MultiFlex.

FIGURA 4.10 - Geradores G1, G2 e G3

FIGURA 4.11 - Geradores G4 e G5

FIGURA 4.12 - Frascos utilizados para eluição do gerador com sistema de eluição a vácuo.

FIG. 4.13 - Ilustração de um processo de eluição do Gerador de ${ }^{68} \mathrm{Ge} /{ }^{68} \mathrm{Ga}$ (iThemba).

FIGURA 4.14 - Detector de germânio hiperpuro (HPGe) da Canberra, modelo GX1518, acoplado a um sistema de aquisição multicanal e tratamento de dados via microcomputador contendo o programa GENIE-P

FIGURA 4.15 - llustração da estante do detector de HPGe com seis posições para contagem.

FIGURA 4.16 - Gaussiana.

FIGURA 4.17 - llustração gráfica do número de canais avaliados para o pico de $511 \mathrm{keV}(\mathrm{n}=20)$ e do número de canais para o $B G$ do pico $(\mathrm{m}=$ 4).

FIGURA 4.18 - Representação da fita cromatográfica utilizada no controle da pureza radioquímica

FIGURA 4.19 - Cubas de vidro com fitas cromatográficas.

FIGURA 4.20 - Curva de crescimento do ${ }^{68} \mathrm{Ga}$ mostrando a porcentagem da atividade em relação ao tempo.

FIGURA 4.21 - Representação da fita cromatográfica utilizada no controle da pureza radionuclídica.

FIGURA 4.22 - Equipamento micro PET Albira (Bruker Co.)

FIGURA 4.23 - Contador gama, modelo Cobra II ES5002 (PerkinElmer do Brasil Ltda.). 
FIGURA 5.1 - Curvas de calibração do ICP-OES para o Ge, utilizadas para a determinação dos limites de detecção e quantificação

FIGURA 5.2 - Porcentagem de Ge e de Ga nas simulações das eluições das colunas com $\mathrm{Al}_{2} \mathrm{O}_{3}$ ácida calcinada utilizando $\mathrm{pH} 1,5$ para soluções de condicionamento, carga e lavagem.

FIGURA 5.3 - Porcentagem de Ge e de Ga nas simulações das eluições das colunas com $\mathrm{Al}_{2} \mathrm{O}_{3}$ ácida calcinada utilizando $\mathrm{pH} 4$ para soluções de condicionamento, carga e lavagem.

FIGURA 5.4 - Porcentagem de Ge e de Ga nas simulações das eluições das colunas com $\mathrm{Al}_{2} \mathrm{O}_{3}$ ácida calcinada utilizando $\mathrm{pH} 1,5$ para soluções de condicionamento e lavagem e $\mathrm{pH} 4$ para carga.

FIGURA 5.5 - Porcentagem de Ge e de Ga nas simulações das eluições das colunas com $\mathrm{Al}_{2} \mathrm{O}_{3}$ básica utilizando $\mathrm{pH}$ 1,5 para soluções de condicionamento e lavagem e pH 4 para carga.

FIGURA 5.6 - Porcentagem de Ge e de Ga nas simulações das eluições das colunas com HZO utilizando $\mathrm{pH} 1,5$ para soluções de condicionamento, carga e lavagem.

FIGURA 5.7 - Porcentagem de Ge e de Ga nas simulações das eluições das colunas com HZO utilizando pH 4 para soluções de condicionamento, carga e lavagem.

FIGURA 5.8 - Porcentagem de Ge e de Ga nas simulações das eluições das colunas com HZO utilizando $\mathrm{pH} 4$ para as soluções do condicionamento e carga e $\mathrm{pH}$ 1,5 para lavagem.

FIGURA 5.9 - Porcentagem de Ge e de Ga nas simulações das eluições das colunas com $\mathrm{HZO}$ utilizando $\mathrm{pH}$ 1,5 para soluções de condicionamento e lavagem e $\mathrm{pH} 4$ para carga.

FIGURA 5.10 - Porcentagem de Ge nas simulações das eluições das colunas com $\mathrm{ZrO}_{2}$ utilizando $\mathrm{pH}$ 1,5 para soluções de condicionamento e lavagem e $\mathrm{pH} 4$ para carga

FIGURA 5.11 - Porcentagem de Ge e de Ga nas simulações das eluições das colunas com $\mathrm{TiO}_{2}$ utilizando $\mathrm{pH}$ 1,5 para soluções de condicionamento e lavagem e pH 4 para carga

FIGURA 5.12 - Estruturas cristalinas do $\mathrm{TiO}_{2}$

FIGURA 5.13 - Distribuição granulométrica de todos os lotes de $\mathrm{TiO}_{2}$ obtida após o peneiramento do material

FIGURA 5.14 - Distribuição granulométrica do $\mathrm{TiO}_{2}$ (lote 4) seco a $100^{\circ} \mathrm{C}$.. 
FIGURA 5.15 - Distribuição granulométrica do $\mathrm{TiO}_{2}$ (lote 4) calcinado a $420^{\circ} \mathrm{C}$.

FIGURA 5.16 - Micrografia do $\mathrm{TiO}_{2}$ lote 3 seco a $100^{\circ} \mathrm{C}$

FIGURA 5.17 - Micrografia do $\mathrm{TiO}_{2}$ lote 6 seco a $100^{\circ} \mathrm{C}$ e calcinado a $420^{\circ} \mathrm{C}$

FIGURA 5.18 - Micrografia do $\mathrm{TiO}_{2}$ lote 7 seco a $100^{\circ} \mathrm{C}$ e calcinado a $420^{\circ} \mathrm{C}$

FIGURA 5.19 - Micrografia do $\mathrm{TiO}_{2}$ lote 8 seco a $100^{\circ} \mathrm{C}$ e calcinado a $420^{\circ} \mathrm{C}$

FIGURA 5.20 - Micrografia do $\mathrm{TiO}_{2} \mathrm{P} 90$ da Evonik Degussa (300x)

FIGURA 5.21 - Micrografia do $\mathrm{TiO}_{2} \mathrm{P} 90$ da Evonik Degussa (4000x)

FIGURA 5.22 - Análise elementar do $\mathrm{TiO}_{2}$ lote $3\left(\right.$ seco a $\left.100^{\circ} \mathrm{C}\right)$ feita pelo sistema EDS do microscópio. A) Distribuição elementar. B) Espectro dos elementos encontrados na amostra.

FIGURA 5.23 - Quantificação elementar do $\mathrm{TiO}_{2}$ lote 3 (seco a $100^{\circ} \mathrm{C}$ ) feita pelo sistema EDS do microscópio. A) Mapeamento da área para quantificação. B) Porcentagem dos elementos encontrados na amostra.....

FIGURA 5.24 - Análise elementar do $\mathrm{TiO}_{2}$ lote 6 (seco a $100^{\circ} \mathrm{C}$ e calcinado a $420^{\circ} \mathrm{C}$ ) feita pelo sistema EDS do microscópio. A) Distribuição elementar. B) Espectro dos elementos encontrados na amostra

FIGURA 5.25 - Análise elementar do $\mathrm{TiO}_{2}$ lote 7 (seco a $100^{\circ} \mathrm{C}$ e calcinado a $420^{\circ} \mathrm{C}$ ) feita pelo sistema EDS do microscópio. A) Distribuição elementar. B) Espectro dos elementos encontrados na amostra

FIGURA 5.26 - Quantificação elementar do $\mathrm{TiO}_{2}$ lote 7 (seco a $100^{\circ} \mathrm{C}$ e calcinado a $420^{\circ} \mathrm{C}$ ) feita pelo sistema EDS do microscópio. A) Mapeamento da área para quantificação. B) Porcentagem dos elementos encontrados na amostra.

FIGURA 5.27 - Análise elementar do $\mathrm{TiO}_{2}$ lote 8 (seco a $100^{\circ} \mathrm{C}$ e calcinado a $420^{\circ} \mathrm{C}$ ) feita pelo sistema EDS do microscópio. A) Distribuição elementar. B) Espectro dos elementos encontrados na amostra.

FIGURA 5.28 - Quantificação elementar do $\mathrm{TiO}_{2}$ lote $8\left(\right.$ seco a $100^{\circ} \mathrm{C}$ e calcinado a $420^{\circ} \mathrm{C}$ ) feita pelo sistema EDS do microscópio. A) Mapeamento da área para quantificação. B) Porcentagem dos elementos encontrados na amostra. 
FIGURA 5.29 - Análise elementar do $\mathrm{TiO}_{2} \mathrm{P} 90$ da Evonik Degussa feita pelo sistema EDS do microscópio. A) Distribuição elementar. B) Espectro dos elementos encontrados na amostra.

FIGURA 5.30 - Quantificação elementar do $\mathrm{TiO}_{2} \mathrm{P} 90$ da Evonik Degussa feita pelo sistema EDS do microscópio. A) Mapeamento da área para quantificação. B) Porcentagem dos elementos encontrados na amostra.....

FIGURA 5.31 - Curva de TG e DTA do $\mathrm{TiO}_{2}$ lote 4 seco a $100{ }^{\circ} \mathrm{C} . . . \ldots \ldots \ldots . . . . . . \quad 131$

FIGURA 5.32 - Curva de TG e DTA do $\mathrm{TiO}_{2}$ lote 9 seco a $60{ }^{\circ} \mathrm{C} . . . . . . . . . . . . . . . . .132$

FIGURA 5.33 - Curva de TG e DTA do $\mathrm{TiO}_{2}$ lote 9 seco a $100{ }^{\circ} \mathrm{C} . . . . . . . . . . . . . . \quad 133$

FIGURA 5.34 - Curva de TG e DTA do $\mathrm{TiO}_{2}$ lote 10 seco a $100{ }^{\circ} \mathrm{C} \ldots \ldots \ldots \ldots . . .133$

FIGURA 5.35 - Difratograma do $\mathrm{TiO}_{2}$ lote 6 (seco a $100^{\circ} \mathrm{C}$ e calcinado a $420^{\circ} \mathrm{C}$ ) e difratograma padrão do $\mathrm{TiO}_{2} \mathrm{com}$ as fichas cristalográficas das fases anatase (JCPDS 21-1272) e rutilo (JCPDS 65-192)

FIGURA 5.36 - Difratogramas de diferentes amostras de $\mathrm{TiO}_{2}$. AEROXIDE $\mathrm{TiO}_{2} \mathrm{P} 90$ (Degussa), lote 3 e 4 secos a $100^{\circ} \mathrm{C}$, lote $4,6,7$ e 8 calcinados a $420^{\circ} \mathrm{C}$ e lote 5 calcinado a $420^{\circ} \mathrm{C}$ e $800^{\circ} \mathrm{C}$

FIGURA 5.37 - Difratogramas dos $\mathrm{TiO}_{2}$ dos lotes 9 e 10. Lote 9: seco a $60^{\circ} \mathrm{C}, 100^{\circ} \mathrm{C}$, calcinado a $420^{\circ}$ com resfriamento rápido (RR) e resfriamento lento $(R L)$. Lote 10 : seco a $100^{\circ} \mathrm{C}$, calcinado a $420^{\circ}(R R)$ e $420^{\circ} \mathrm{C}(\mathrm{RL})$.

FIGURA 5.37 - Eficiência de eluição dos geradores G1, G2, G3, G4 e G5 em relação aos dias decorridos após o carregamento do ${ }^{68} \mathrm{Ge}$ na coluna...

FIGURA 5.38 - Eficiência de eluição em relação à quantidade de eluições dos geradores preparados neste trabalho e dois geradores comerciais.

FIGURA 5.39 - Eficiência de eluição do gerador comercial 1 em relação aos dias decorridos do carregamento e a eficiência de eluição obtida com sistema de eluição a vácuo

FIGURA 5.40 - Perfis de eluição dos geradores G2 e G3.

FIGURA 5.41 - Porcentagem de rendimento de eluição dos geradores G2 e G3.

FIGURA 5.42 - Perfil de eluição do gerador comercial 1

FIGURA 5.43 - Porcentagem de rendimento de eluição do gerador comercial 1 . 
FIGURA 5.45 - Porcentagem de rendimento de eluição do gerador comercial 2 .

FIGURA 5.46 - Espectro obtido na contagem da amostra de eluição do gerador G5 no detector de germânio hiperpuro, mostrando os picos de energia dos fótons gama característicos ao ${ }^{68} \mathrm{Ga}(511 \mathrm{keV}$ e $1077 \mathrm{keV}) \ldots . .$.

FIGURA 5.47 - Desintegração radioativa do ${ }^{68} \mathrm{Ga}$ obtido na eluição do gerador G3, desenvolvido neste trabalho. A escala do eixo da atividade está representada de maneira mono-log, mostrando a redução da atividade em função do tempo.

FIGURA 5.48 - Desintegração radioativa do ${ }^{68} \mathrm{Ga}$ obtido na eluição do gerador G5, desenvolvido neste trabalho. A escala do eixo da atividade está representada de maneira mono-log, mostrando a redução da atividade em função do tempo.

FIGURA 5.49 - Desintegração radioativa do ${ }^{68} \mathrm{Ga}$ obtido na eluição do gerador comercial 2 (iThemba). A escala do eixo da atividade está representada de maneira mono-log, mostrando a redução da atividade em função do tempo

FIGURA 5.50 - Curva de decaimento do ${ }^{68} \mathrm{Ga}$ mostrando a porcentagem da atividade em relação ao tempo.

FIGURA 5.51 - Porcentagem de contaminação de ${ }^{68} \mathrm{Ge}$ no ${ }^{68} \mathrm{Ga}$ eluído dos geradores desenvolvidos neste trabalho e de dois geradores comerciais.

FIGURA 5.52 - Coluna utilizada no gerador comercial 1 (Obninsk) e coluna do gerador $\mathrm{G} 3$.

FIGURA 5.53 - Cromatograma do controle radioquímico do ${ }^{68} \mathrm{Ga}$ eluído do gerador G5.

FIGURA 5.54 - Cromatograma do ${ }^{68} \mathrm{Ge}$ utilizando fita TLC-SG-IB-F e solvente $\mathrm{HCl} 2 \mathrm{~mol} \mathrm{~L}^{-1} /$ acetona (1:1) para separação de ${ }^{68} \mathrm{Ge}$ e ${ }^{68} \mathrm{Ga}$

FIGURA 5.55 - Cromatograma do ${ }^{68} \mathrm{Ge}$ utilizando fita TLC-SG-IB-F com spot de $\mathrm{HCl} 3 \mathrm{~mol} \mathrm{~L}^{-1}$ e solvente acetona para separação de ${ }^{68} \mathrm{Ge} e{ }^{68} \mathrm{Ga}$..

FIGURA 5.56 - Imagens de fita cromatográfica mostrando a separação do ${ }^{68} \mathrm{Ge}$ e do ${ }^{68} \mathrm{Ga}$ pelo sistema: fita TLC-SG-IB-F com spot de HCl $3 \mathrm{~mol} \mathrm{~L}^{-1}$ e solvente acetona. Aquisição em 4 tempos distintos contados após 0 término da cromatografia: (A) 1:45h; (B) 3:50h; (C) 5:05h; (D) 5:55h 
FIGURA 5.57 - Amostra de ${ }^{68} \mathrm{Ga}$ do gerador comercial 2 (iThemba) analisada por cromatografia, utilizando fita TLC-SG-IB-F com spot de $\mathrm{HCl}$ $3 \mathrm{~mol} \mathrm{~L}^{-1}$ e solvente acetona para separação de ${ }^{68} \mathrm{Ge}$ e ${ }^{68} \mathrm{Ga}$. Medida da atividade feita no contador gama em 4 tempos diferentes contados após o inicio da cromatografia.

FIGURA 5.58 - Imagem da coluna do gerador de ${ }^{68} \mathrm{Ge} /{ }^{68} \mathrm{Ga}$ adquirida no equipamento $\mu$ PET (corte sagital).

FIGURA 5.59 - Imagem da coluna do gerador de ${ }^{68} \mathrm{Ge} /{ }^{68} \mathrm{Ga}$ adquirida no equipamento $\mu$ PET (corte axial).

FIGURA 5.60 - llustração do gerador $\mathrm{de}^{68} \mathrm{Ge}^{-68} \mathrm{Ga}$ com sistema a vácuo para eluição e purificação do ${ }^{68} \mathrm{Ga}$. 


\section{INTRODUÇÃO}

Os primeiros geradores de ${ }^{68} \mathrm{Ge} /{ }^{68} \mathrm{Ga}$ foram desenvolvidos no início da década de 60 , mesmo período em que surgiram os primeiros geradores de ${ }^{99} \mathrm{Mo} /{ }^{99 \mathrm{~m}} \mathrm{Tc}$, que acabaram se estabelecendo mundialmente como uma das ferramentas mais importantes na área da medicina nuclear, devido à disponibilidade de marcação de uma variedade de moléculas com o ${ }^{99 m} \mathrm{Tc}$, possibilitando inúmeros procedimentos diagnósticos na rotina clínica (DECRISTOFORO, 2012).

Nessa época os geradores de ${ }^{68} \mathrm{Ge} /{ }^{68} \mathrm{Ga}$ disponibilizavam o ${ }^{68} \mathrm{Ga}$ como um complexo EDTA ${ }^{68} \mathrm{Ga}$ (ácido etilenodiaminotetraacético) que era utilizado para imagens de tumores cerebrais (DECRISTOFORO, 2012; $\mathrm{ROSCH}, 2013$ ). A preparação de outros radiofármacos com $0{ }^{68} \mathrm{Ga}$ requer a dissociação desse complexo, que possui alta estabilidade, necessitando de várias etapas para que ocorra a dissociação, não sendo viável devido a meia-vida física do ${ }^{68} \mathrm{Ga}$ ser curta (68 minutos) (YANO e ANGER, 1964). Por essa razão, fez-se necessário o desenvolvimento de geradores de ${ }^{68} \mathrm{Ge} /{ }^{68} \mathrm{Ga}$ que fornecessem $0{ }^{68} \mathrm{Ga}$ como uma espécie iônica livre, ${ }^{68} \mathrm{Ga}^{3+}$.

Além dessa dificuldade química no preparo de outros radiofármacos com $\circ{ }^{68} \mathrm{Ga}$ eluído como um complexo EDTA- ${ }^{68} \mathrm{Ga}$, é importante mencionar que os equipamentos de Tomografia por Emissão de Pósitron (PET - positron emission tomography) só começaram a ser desenvolvidos na década de 70 , portanto as primeiras imagens de ${ }^{68} \mathrm{Ga}$ foram adquiridas por gama câmaras, que não são equipamentos apropriados para trabalhar com energia de $511 \mathrm{keV}$ (VALLABHAJOSULA, 2009; ROSCH, 2013).

A evolução dos equipamentos PET para PET/CT, que é uma tecnologia que proporciona a fusão da imagem metabólica do PET com a imagem anatômica da tomografia computadorizada (CT - computed tomography) sem dúvida contribuiu para o sucesso e o reconhecimento dessa técnica, em particular na área da oncologia, principalmente com o uso do $\mathrm{FDG}-{ }^{18} \mathrm{~F}$ (fluordeoxiglicose). 
Paralelo à evolução dos equipamentos para aquisição de imagem, novos sistemas de geradores de ${ }^{68} \mathrm{Ge} /{ }^{68} \mathrm{Ga}$ foram propostos e em meados de 2005, a empresa Cyclotron Co. da Rússia começou a comercializar um gerador que fornecia $0{ }^{68} \mathrm{Ga}$ na forma catiônica livre, ${ }^{68} \mathrm{Ga}^{3+}$, expandindo as possibilidades para procedimentos de radiomarcação, em particular para biomoléculas como os peptídeos (DECRISTOFORO, 2012; ROSCH, 2013).

O ${ }^{68} \mathrm{Ga}$ passou a ganhar destaque e parte disso é devido ao reconhecimento da importância clínica do PET com uma maior disponibilidade desse tipo de equipamento, mas o fator mais importante foi o desenvolvimento de peptídeos análogos a somatostatina marcados com ${ }^{68} \mathrm{Ga}$, que vem apresentando resultados superiores aos radiofármacos utilizados na tomografia computadorizada por emissão de fóton único (SPECT - single photon emission computed tomography), resultando em um grande impacto na conduta clínica com o paciente (DECRISTOFORO, 2012; ROSCH, 2013).

O IPEN começou a comercializar o $\mathrm{FDG}-{ }^{18} \mathrm{~F}$ em 1998 , nessa época ainda não existiam no país equipamentos PET. Os exames eram realizados com SPECT com circuito de coincidência. Apenas em 2003 o primeiro equipamento de PET dedicado foi instalado no país (SBMN, 2011).

Nos últimos anos tem se verificado uma rápida disseminação da tecnologia PET/CT pelo Brasil, assim como ocorreu em diversos outros países (SBMN, 2011). Hoje no país existem 84 equipamentos, entre PET e PET/CT, instalados e autorizados para o uso, fora os que estão em fase de licenciamento (REGO, 2013).

$\mathrm{O}{ }^{18} \mathrm{~F}$ é o único radionuclídeo emissor de pósitron produzido no país e os únicos radiofármacos disponíveis comercialmente para PET são o $\mathrm{FDG}-{ }^{18} \mathrm{~F}$ e o Fluoreto- ${ }^{18} \mathrm{~F}$. A disponibilidade de novos radiofármacos para PET certamente daria um novo impulso ao crescente uso de PET/CT em áreas como cardiologia e neurologia, além da oncologia (SBMN, 2011).

Em 2009 o IPEN adquiriu o primeiro gerador de ${ }^{68} \mathrm{Ge} /{ }^{68} \mathrm{Ga}$, Obniskgenerator da Cyclotron Co. (Rússia), distribuído pela empresa alemã Eckert \& Ziegler. Iniciaram-se então os estudos de marcação do peptídeo DOTATATO $\left(1,4,7,10\right.$-tetraazacyclododecane-N,N',N",N'”-tetraacetic acid - D-Phe ${ }^{1}-T y r^{3}-T h r^{8}$ octreotide) com ${ }^{68} \mathrm{Ga}$ e a partir de 2013 o IPEN passou a produzir semanalmente, 
em pequena escala, o DOTATATO- ${ }^{68} \mathrm{Ga}$ e o produto é doado para alguns hospitais de São Paulo para realização de pesquisas clínicas. Esse radiofármaco é indicado para diagnóstico de tumores neuroendrócrinos. Nos dois primeiros meses de estudos, onze pacientes foram avaliados com exames feitos com o DOTATATO- ${ }^{68} \mathrm{Ga}$ e o Octreotídeo-DTPA- ${ }^{-111}$ In (diethylenetriaminepentaacetic acid), que é um radiofármaco comercializado pelo IPEN e utilizado em SPECT. Em nove casos, dos onze estudados, os exames realizados com DOTATATO${ }^{68} \mathrm{Ga}$ mostraram mais lesões do que com o Octreotídeo-DTPA- ${ }^{-11} \mathrm{In}$, mostrando a importância clínica desse novo radiofármaco (YAMAGA, 2013).

\subsection{Medicina Nuclear}

A medicina nuclear é uma especialidade médica que utiliza materiais radioativos, denominados radiofármacos, para o diagnóstico e tratamento de doenças (VALLABHAJOSULA, 2009).

Radiofármaco pode ser apenas um radionuclídeo na sua forma mais simples, um composto químico ou uma biomolécula marcada com um radioisótopo. Esse composto ou biomolécula é escolhido por sua capacidade de ser captado num determinado órgão, num processo fisiológico ou fisiopatológico (SAHA, 1992).

No Brasil, a Agência Nacional de Vigilância Sanitária (ANVISA) definiu radiofármacos (BRASIL, 2009) como "preparações farmacêuticas com finalidade diagnóstica ou terapêutica que, quando prontas para o uso, contêm um ou mais radionuclídeos. Compreendem também os componentes não-radioativos para marcação e os radionuclídeos, incluindo os componentes extraídos dos geradores de radionuclídeos." O preparo dos radiofármacos deve cumprir com as Boas Práticas de Fabricação (BPF's), uma vez que são administrados em seres humanos.

Radiofarmácia é a seção dentro da área da medicina nuclear encarregada da pesquisa, produção e distribuição dos radiofármacos e devido às suas características especiais, o processo produtivo pode ocorrer em três tipos de instalação (FERREIRA e MARQUES, 2012): 
Radiofarmácia industrial: onde são preparadas moléculas marcadas ou sistemas de geradores de radionuclídeos, os quais são distribuídos aos usuários;

Radiofarmácia centralizada: são locais que compram produtos da radiofarmácia industrial, reprocessam ou fracionam os radiofármacos e distribuem o material para o usuário final;

Radiofarmácia hospitalar: local que além de adquirir os radiofármacos das instalações industriais e centralizadas, pode realizar alguns tipos de produção ou preparação, principalmente aquelas com a marcação de produtos utilizando radionuclídeos provenientes de geradores.

A produção dos radionuclídeos para utilização em medicina ou pesquisa médica e biológica é feita de forma artificial em reatores nucleares, aceleradores de partículas, como os cíclotrons ou, de forma indireta, em geradores de radionuclídeos, como geradores de ${ }^{68} \mathrm{Ge} /{ }^{68} \mathrm{Ga}$ e ${ }^{99} \mathrm{Mo} /{ }^{99 \mathrm{~m}} \mathrm{Tc}$. (OSSO e KNAPP, 2011; FERREIRA e MARQUES, 2012).

Na TAB.1.1 são apresentados métodos de produção e obtenção de alguns radionuclídeos.

TABELA 1.1 - Métodos de produção ou obtenção de radionuclídeos (OLIVEIRA et al., 2006).

\begin{tabular}{|c|c|c|}
\hline Fonte & Radionuclídeo & Reação nuclear \\
\hline \multirow{5}{*}{ Reator } & ${ }^{131} \mid$ & ${ }^{235} U(n, f)^{131}$ \\
\hline & & ${ }^{130} \mathrm{Te}(\mathrm{n}, \mathrm{Y}){ }^{131} \mathrm{Te} \stackrel{{ }^{\beta}}{\longrightarrow}{ }^{131} \mathrm{I}$ \\
\hline & ${ }^{177} \mathrm{Lu}$ & ${ }^{176} \mathrm{Lu}(\mathrm{n}, \mathrm{y})^{177} \mathrm{Lu} \longrightarrow$ \\
\hline & ${ }^{153} \mathrm{Sm}$ & ${ }^{152} \mathrm{Sm}(\mathrm{n}, \mathrm{v})^{153} \mathrm{Sm}$ \\
\hline & ${ }^{99} \mathrm{Mo}$ & ${ }^{235} \mathrm{U}(\mathrm{n}, \mathrm{f}){ }^{99} \mathrm{Mo} /{ }^{98} \mathrm{Mo}(\mathrm{n}, \mathrm{y})^{99} \mathrm{Mo}$ \\
\hline \multirow{7}{*}{$\begin{array}{l}\text { Acelerador } \\
\text { (Cíclotron) }\end{array}$} & $123 \mid$ & ${ }^{124} \mathrm{Xe}(\mathrm{p}, 2 \mathrm{n}){ }^{123} \mathrm{Cs} \rightarrow{ }^{123} \mathrm{Xe} \rightarrow{ }^{123} \mathrm{I}$ \\
\hline & ${ }^{67} \mathrm{Ga}$ & ${ }^{68} \mathrm{Zn}(p, 2 n){ }^{67} \mathrm{Ga}$ \\
\hline & ${ }^{111} \ln$ & ${ }^{111} \mathrm{Cd}(\mathrm{p}, \mathrm{n})^{111} \mathrm{In}$ \\
\hline & ${ }^{201} \mathrm{Tl}$ & ${ }^{203} \mathrm{TI}(\mathrm{p}, 3 \mathrm{n})^{201} \mathrm{~Pb} \rightarrow{ }^{201} \mathrm{Tl}$ \\
\hline & ${ }^{18} \mathrm{~F}$ & ${ }^{18} \mathrm{O}(\mathrm{p}, \mathrm{n})^{18} \mathrm{~F}$ \\
\hline & ${ }^{68} \mathrm{Ge}$ & ${ }^{n a t} \mathrm{Ga}(p, x n){ }^{68} \mathrm{Ge}(\mathrm{x}=2$ ou 4$)$ \\
\hline & ${ }^{64} \mathrm{Cu}$ & ${ }^{64} \mathrm{Ni}(\mathrm{p}, \mathrm{n}){ }^{64} \mathrm{Cu}$ \\
\hline \multirow{4}{*}{ Gerador } & ${ }^{99 \mathrm{~m}} \mathrm{Tc}$ & ${ }^{99} \mathrm{Mo} \stackrel{\beta}{\longrightarrow}{ }^{99 \mathrm{~m}} \mathrm{Tc}$ \\
\hline & ${ }^{68} \mathrm{Ga}$ & ${ }^{68} \mathrm{Ge} \stackrel{\text { CE }}{\longrightarrow}{ }^{68} \mathrm{Ga}$ \\
\hline & ${ }^{90} \mathrm{Y}$ & ${ }^{235} \mathrm{U}(\mathrm{n,f})^{90} \mathrm{Sr} \stackrel{\beta_{-}}{\longrightarrow}{ }^{90} \mathrm{Y}$ \\
\hline & $\begin{array}{l}{ }^{188} \mathrm{Re} \\
{ }^{213} \mathrm{Bi}\end{array}$ & ${ }^{186} \mathrm{~W}(2 \mathrm{n}, \mathrm{Y})^{188} \overrightarrow{\mathrm{W}} \rightarrow{ }^{\beta}-{ }^{188} \mathrm{Re}$ \\
\hline
\end{tabular}

NOTA: TI - transição isomérica; CE - captura eletrônica; $f$ - fissão; $d$ - dêuteron; $n$ - neutron; $p$ próton; nat - natural. 
Atualmente são conhecidos 116 elementos químicos e mais de 3000 nuclídeos e radionuclídeos desses elementos, porém para o uso em medicina nuclear é possível a utilização de um número restrito desses radionuclídeos, pois é necessário que apresentem alguns requisitos básicos (FERREIRA e MARQUES, 2012).

Do ponto de vista físico, os radionuclídeos precisam apresentar forma de decaimento, energia de radiação e meia-vida física adequadas à sua aplicação. Para finalidade diagnóstica, os radionuclídeos devem ser emissores de radiação gama $(\gamma)$ ou emissores de pósitron $\left(\beta^{+}\right)$, já que o decaimento desses radionuclídeos dá origem à radiação eletromagnética penetrante, que consegue atravessar os tecidos e pode ser detectada externamente. Os radionuclídeos para terapia devem ser emissores de partículas ionizantes, alfa $(\alpha)$, beta $\left(\beta^{-}\right)$ou elétrons Auger, pois a sua ação se baseia na destruição seletiva de tecidos (OLIVEIRA et al., 2006; FERREIRA e MARQUES, 2012).

Já do ponto de vista químico, tanto para o diagnóstico quanto para terapia, os radionuclídeos precisam apresentar purezas radionuclídica, radioquímica e química adequadas, baixa toxicidade e capacidade de serem ligados ao composto desejado, em reações estáveis (SAHA, 1992).

\subsection{Técnicas de diagnóstico}

A escolha da técnica a ser utilizada no diagnóstico por imagem está relacionada com o tipo de emissão eletromagnética e corpuscular do radionuclídeo durante seu decaimento radioativo (THRALL, 2003; VALLABHAJOSULA, 2009).

Existem dois métodos tomográficos para aquisição de imagens em medicina nuclear: tomografia computadorizada por emissão de fóton único (SPECT) e tomografia computadorizada por emissão de pósitron (PET).

As imagens de SPECT e PET são uma medida in vivo da fisiologia, metabolismo celular e perfusão de um órgão ou sistema. Entretanto esses estudos apresentam baixa resolução devido ao pequeno fluxo de fótons e a perda dos detalhes anatômicos. Por outro lado, as imagens da tomografia computadorizada 
(CT) ou da ressonância magnética (RM) fornecem excelente resolução espacial e detalhes anatômicos, mas com reduzida informação funcional (LIMA et al., 2012).

Portanto, para um melhor diagnóstico, com exata localização do metabolismo, é necessário que se faça a fusão da imagem metabólica e a imagem anatômica. Os equipamentos SPECT e PET, mais modernos, possuem um sistema de tomografia computadorizada acoplado aos seus sistemas, sendo chamados de SPECT/CT e PET/CT. Existem também os equipamentos de $\mathrm{PET} / \mathrm{RM}$. A utilização desses equipamentos híbridos permite a localização precisa das áreas hipermetabólicas e aumentam a eficácia do método.

\subsubsection{SPECT e os principais radionuclídeos emissores $\gamma$}

O sistema SPECT é uma gama câmara com uma ou mais cabeças de detectores de $\mathrm{Nal}(\mathrm{TI})$ montados em um gantry com um computador online para a aquisição e processamento dos dados (LIMA et al., 2012).

$O$ detector (geralmente $50 \mathrm{~cm} \times 50 \mathrm{~cm}$ ) é acoplado a um colimador com uma série de tubos fotomultiplicadores para amplificar os sinais. A cabeça do detector gira em torno do eixo do paciente em pequenos ângulos - por exemplo, incrementos de $3^{\circ}$ - para coletar dados entre $180^{\circ}$ ou $360^{\circ}$. Os dados são coletados na forma de pulsos em cada posição angular e são armazenados no computador para posterior reconstrução nos planos de interesse. Os pulsos são formados nas fotomultiplicadoras que convertem os fótons de luz produzidos pela interação da radiação $\gamma$, que sai do corpo do paciente, no cristal (THRALL, 2003; LIMA et al., 2012).

Em gama câmaras com múltiplas cabeças os dados podem ser coletados em várias projeções simultaneamente, reduzindo assim o tempo de estudo (LIMA et al., 2012).

Os radionuclídeos utilizados para SPECT devem emitir radiação eletromagnética com energia variando de 30 a $300 \mathrm{keV}$. Abaixo de 30 os raios $\gamma$ são absorvidos pelos tecidos e não são detectados pelos detectores de $\mathrm{Nal}(\mathrm{TI})$ e acima de $300 \mathrm{keV}$, além da eficiência do detector diminuir, a colimação se torna menos efetiva e os raios $\gamma$ são detectados com incidência inadequada, resultando em degradação da imagem. Os feixes de radiação $\gamma$ devem ser monoenergéticos e 
com abundância de fótons suficiente para reduzir o tempo de aquisição das imagens. Para os detectores baseados em cristais de iodeto de sódio, a melhor eficiência em conversão de energia em sinais elétricos ocorre para emissões próximas a $140 \mathrm{keV}$ (FERREIRA e MARQUES et al., 2012).

$\mathrm{Na}$ TAB 1.2 são mostrados os principais radionuclídeos utilizados em diagnóstico por SPECT, assim como as energias $\gamma$ emitidas e os respectivos tempos de meia-vidas físicas (FERREIRA e MARQUES et al., 2012, IAEA Nuclear Data Section, 2013).

TABELA 1.2 - Principais radionuclídeos emissores de radiação gama com suas respectivas energias e tempos de meia-vidas físicas.

\begin{tabular}{cccc|}
\hline Radioisótopos & Meia-vida física & $\begin{array}{c}\text { Principal modo de } \\
\text { decaimento }\end{array}$ & Energia $\gamma(\mathbf{k e V})$ \\
\hline${ }^{99 \mathrm{~m}} \mathrm{Tc}$ & $6,0 \mathrm{~h}$ & $\mathrm{TI}$ & $140(100 \%)$ \\
${ }^{67} \mathrm{Ga}$ & $3,3 \mathrm{~d}$ & $\mathrm{CE}$ & $93,3(39 \%)$ \\
& & $\mathrm{CE}$ & $184,7(21 \%)$ \\
${ }^{111} \mathrm{In}$ & $2,8 \mathrm{~d}$ & & $171(25 \%)$ \\
& & $\mathrm{CE}$ & $155(18 \%)$ \\
${ }^{123} \mathrm{I}$ & $13 \mathrm{~h}$ & & $364(83 \%)$ \\
${ }^{131} \mathrm{I}$ & $8,0 \mathrm{~d}$ & $\mathrm{CE}$ & $135(24 \%)$ \\
${ }^{201} \mathrm{TI}$ & $3,0 \mathrm{~d}$ & & $167(10 \%)$ \\
\hline
\end{tabular}

\subsubsection{PET e os principais radionuclídeos emissores de $\beta^{+}$}

A tomografia por emissão de pósitron é baseada na detecção em coincidência de dois fótons de $511 \mathrm{keV}$ que se originam da aniquilação pósitronelétron. Os pósitrons são originários de elementos radioativos e são aniquilados no tecido do paciente produzindo dois fótons que são emitidos em direções opostas de praticamente $180^{\circ}$. Os dois fótons são detectados em um intervalo de tempo, chamado de "janela de coincidência", por dois detectores conectados eletronicamente e opostos em $180^{\circ}$.

Os fótons são convertidos em fótons de luz no cristal cintilador e a formação do pulso elétrico ocorre em válvula fotomultiplicadora. Os detectores são montados em uma disposição de vários anéis de modo a ter o órgão de interesse no campo de visão correspondido pelos anéis. Os dados obtidos em 
$360^{\circ}$ simultaneamente ao longo do eixo do corpo do paciente são usados para a reconstrução da imagem da distribuição de atividade no corte de interesse (LIMA et al., 2012).

Como os dois fótons em oposição formam uma linha reta, chamada linha de resposta (line of response - LOR), nenhum colimador é necessário para limitar o campo de visão e a técnica é conhecida como colimação eletrônica (LIMA et al., 2012). Essa característica tem importância primordial para esse tipo de equipamento, pois resulta em um aumento significativo da sensibilidade da técnica quando comparada ao SPECT (IAEA, 2009).

Os primeiros equipamentos utilizados para aquisição de imagens com os emissores de pósitron não eram constituídos por um anel de detectores e sim por dois ou três detectores, igual aos equipamentos SPECT. Os detectores trabalhavam com sistema de coincidência e eram chamados de PET em coincidência. A nova configuração dos equipamentos com anéis de detectores é considerada como PET dedicado.

NA TAB. 1.3 são apresentados os principais radionuclídeos emissores de pósitrons utilizados na medicina nuclear, com as respectivas meia-vidas físicas, abundância e energia máxima do pósitron.

Uma diferença importante entre estes radionuclídeos, além do tempo de meia-vida física, é a energia com que o pósitron é ejetado dos seus núcleos, pois quanto maior for essa energia maior será a distância que ocorrerá a reação de aniquilação em relação ao local onde estava a molécula marcada com o radionuclídeo, podendo diminuir a resolução da imagem (FERREIRA e MARQUES, 2012). Outra diferença a ser considerada, que pode influenciar na imagem, é porcentagem com que o radionuclídeo decai por emissão de pósitron. Quanto maior a porcentagem de decaimento por pósitron menor será a quantidade de atividade necessária para obter a mesma qualidade de imagem.

Na FIG. 1.1 é informada a distância de alcance dos pósitrons no tecido, dos radionuclídeos ${ }^{18} \mathrm{~F},{ }^{64} \mathrm{Cu},{ }^{11} \mathrm{C},{ }^{68} \mathrm{Ga}$ e ${ }^{82} \mathrm{Rb}$, em relação à energia dos seus respectivos pósitrons. 
TABELA 1.3 - Radionuclídeos emissores de pósitrons utilizados na medicina com as respectivas meia-vidas físicas, abundância e energia máxima do $\beta^{+}$(IAEA Nuclear Data Section, 2013; VALLABHAJOSULA, 2011).

\begin{tabular}{|c|c|c|c|}
\hline Radioisótopos & Meia-vida física & Decaimento & $\mathrm{E}_{\text {máx. }} \beta^{+}(\mathrm{MeV})$ \\
\hline${ }^{68} \mathrm{Ga}$ & $68,1 \mathrm{~min}$ & $\begin{array}{l}\beta^{+}(89 \%) \\
\text { CE }(11 \%)\end{array}$ & 1,9 \\
\hline${ }^{18} \mathrm{~F}$ & $109,8 \mathrm{~min}$ & $\begin{array}{l}\beta^{+}(96,73 \%) \\
\operatorname{CE}(3,27 \%)\end{array}$ & 0,63 \\
\hline${ }^{11} \mathrm{C}$ & $20,4 \min$ & $\begin{array}{l}\beta^{+}(99,76 \%) \\
\operatorname{CE}(0,24 \%)\end{array}$ & 0,96 \\
\hline${ }^{13} \mathrm{~N}$ & $9,96 \min$ & $\beta^{+} / \mathrm{CE}(100 \%)$ & - \\
\hline 15o & $2,07 \min$ & $\begin{array}{l}\beta^{+}(99,9 \%) \\
\operatorname{CE}(0,1 \%)\end{array}$ & 1,73 \\
\hline${ }^{64} \mathrm{Cu}$ & $12,7 \mathrm{~h}$ & $\begin{array}{c}\beta^{+}(17,4 \%) \\
\operatorname{CE}^{-}(43,6 \%) \\
\beta^{-}(39 \%)\end{array}$ & 0,65 \\
\hline${ }^{82} \mathrm{Rb}$ & $1,26 \mathrm{~m}$ & $\begin{array}{l}\beta^{+}(96 \%) \\
\operatorname{CE}(4 \%)\end{array}$ & 3,36 \\
\hline${ }^{124} I$ & 4,18 dias & $\begin{array}{l}\beta^{+}(22,8 \%) \\
\operatorname{CE}(77,2 \%)\end{array}$ & 2,14 \\
\hline${ }^{89} \mathrm{Zr}$ & $78,41 \mathrm{~h}$ & $\begin{array}{l}\beta^{+}(23 \%) \\
\operatorname{CE}(77 \%)\end{array}$ & 0,89 \\
\hline
\end{tabular}

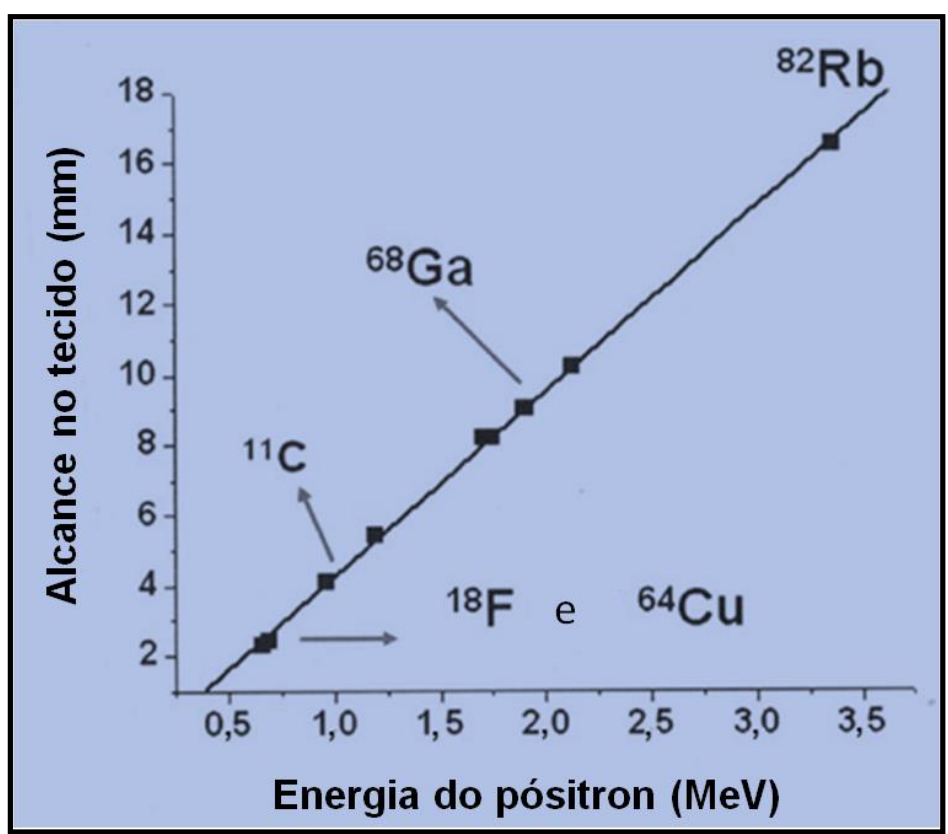

FIGURA 1.1 - Alcance do pósitron no tecido em função da sua energia (VALLABHAJOSULA, 2009). 
Os fatores que contribuem para uma maior dose para o paciente são: maior energia máxima do pósitron, maior meia-vida física, emissão de radiação $\gamma$ de alta energia.

\subsection{Geradores de radionuclídeos}

Os geradores são sistemas de produção de radionuclídeos baseados no princípio de decaimento de um radionuclídeo pai de meia-vida física longa a um radionuclídeo filho de meia-vida física mais curta (OSSO e KNAPP, 2011).

A vantagem desse sistema, quando comparado à produção de radionuclídeos em reatores ou cíclotrons, é que o sistema geralmente é pequeno, permite transporte fácil, tem prazo de utilização de semanas ou até anos, permitindo o uso em locais distantes de unidades de reatores e cíclotrons. No entanto, é importante ressaltar que o radionuclídeo pai precisa ser produzido em um reator ou cíclotron.

Outra característica importante é que os produtos obtidos, normalmente são isentos de carregadores, o que significa que o radionuclídeo tem alta atividade específica (radioatividade por unidade de massa) (FERREIRA e MARQUES, 2012). A presença de material carregador pode influenciar a eficiência do processo de radiomarcação e a biodistribuição, devido à competição por sítios de ligação biológicos.

Apesar das vantagens, a disponibilidade de tipos de geradores de radionuclídeos é limitada, uma vez que é necessário ter pares radionuclídeos paifilho que possam ser eficientemente separados, em um curto espaço de tempo, por um processo de extração do radionuclídeo filho onde não sejam extraídas impurezas ou outros componentes utilizados no preparo dos geradores. Além disso, para aplicações médicas, é necessário que o produto obtido seja estéril e apirogênico, para imediata utilização em pacientes (FERREIRA e MARQUES, 2012).

O sistema de geradores promove a separação do radionuclídeo filho do radionuclídeo pai. Vários métodos físico-químicos de separação podem ser utilizados: destilação, extração por solvente, deposição eletroquímica, precipitação, sublimação entre outros. Porém, o sistema cromatográfico baseado 
em um material adsorvedor, inorgânico ou orgânico, é o método mais prático para ser utilizado na rotina clínica (VALLABHAJOSULA, 2009; OSSO e KNAPP, 2011).

Outra característica importante dos geradores está relacionada com o equilíbrio que se estabelece entre a formação e decaimento do radionuclídeo filho. Em um gerador existem dois radionuclídeos obedecendo a lei das desintegrações radioativas, apresentadas nas equações 1.1 e 1.2. A integração dessas equações permite calcular a atividade a ser extraída de um gerador e demonstrar o momento em que o sistema atinge o equilíbrio, ou seja, quando a razão entre as atividades dos radionuclídeos pai e filho permanecem constantes (Eq. 1.3) (OSSO e KNAPP, 2011; FERREIRA e MARQUES, 2012).

$$
\left(A_{1}\right)_{t}=\left(A_{1}\right)_{0} \cdot e^{-\lambda 1 . t}
$$

Onde:

$\left(A_{1}\right)_{t}=$ número de átomos do elemento pai em determinado tempo $(t)$;

$\left(A_{1}\right)_{0}=$ número de átomos do elemento pai em tempo zero (0);

$\lambda_{1}=$ constante de decaimento do pai $=0,693 / t_{1 / 2}$

$t_{1 / 2}=$ tempo de meia-vida física

$$
\left(A_{2}\right)_{t}=\left(A_{2}\right)_{0} \cdot e^{-\lambda 2 . t}
$$

Onde:

$\left(A_{2}\right)_{t}=$ número de átomos do elemento filho em determinado tempo $(t)$;

$\left(A_{2}\right)_{0}=$ número de átomos do elemento filho em tempo zero (0);

$\lambda_{2}=$ constante de decaimento do filho $=0,693 / t_{1 / 2}$

$$
\left(A_{2}\right)_{t}=\left(A_{1}\right)_{t} \cdot\left(\frac{\lambda_{2}}{\lambda_{2}-\lambda_{1}}\right) \cdot\left[e^{-\left(\lambda_{1} \cdot t\right)}-e^{-\left(\lambda_{2} \cdot t\right)}\right]
$$

Dependendo da diferença entre as meia-vidas físicas dos radionuclídeos pai e filho, a condição de equilíbrio pode ser chamada de equilíbrio transiente ou secular (VALLABHAJOSULA, 2009; OSSO e KNAPP, 2011).

No equilíbrio transiente, a meia-vida física do radionuclídeo pai é maior que a meia-vida física do radionuclídeo filho $\left(t_{1 / 2(1)}>t_{1 / 2(2)}\right.$ ou $\left.\lambda_{1}<\lambda_{2}\right)$ e ao alcançar o equilíbrio, o radionuclídeo filho decai com a meia-vida física do radionuclídeo pai e a atividade do filho será maior que a atividade do pai. 
No equilíbrio secular, a meia-vida física do radionuclídeo pai é muito maior que a meia-vida física do radionuclídeo filho ( $t_{1 / 2(1)}>t_{1 / 2(2)}$ ou $\left.\lambda_{1}<<\lambda_{2}\right)$. Neste equilíbrio, a atividade do filho é igual à atividade do pai.

Na TAB. 1.4 são apresentados alguns tipos de geradores que podem ser utilizados para aplicações médicas e o tipo de equilíbrio formado pelos pares radioativos.

TABELA 1.4 - Exemplos de sistemas de geradores de radionuclídeos usados para aplicação na medicina nuclear (IAEA, 2010).

\begin{tabular}{cccc}
\hline $\begin{array}{c}\text { Tipo de } \\
\text { equilíbrio }\end{array}$ & Pai $\left(\mathrm{T}_{1 / 2}\right)$ & Pai $\left(\mathrm{T}_{1 / 2}\right)$ & $\begin{array}{c}\text { Modo principal de } \\
\text { decaimento do filho }\end{array}$ \\
\hline Secular & ${ }^{68} \mathrm{Ge}(271 \mathrm{~d})$ & ${ }^{68} \mathrm{Ga}(68 \mathrm{~min})$ & $\beta^{+}$ \\
& ${ }^{90} \mathrm{Sr}(28,6 \mathrm{a})$ & ${ }^{90} \mathrm{Y}(64,1 \mathrm{~h})$ & $\beta^{-}$ \\
& ${ }^{82} \mathrm{Sr}(25,6 \mathrm{~d})$ & ${ }^{82} \mathrm{Rb}(1,27 \mathrm{~min})$ & $\beta^{+}$ \\
& ${ }^{81} \mathrm{Rb}(4,58 \mathrm{~h})$ & ${ }^{81 \mathrm{~m}} \mathrm{Kr}(13 \mathrm{~s})$ & $\gamma$ \\
& ${ }^{188} \mathrm{~W}(69 \mathrm{~d})$ & ${ }^{188} \mathrm{Re}(16,9 \mathrm{~h})$ & $\beta^{-}$ \\
\hline Transiente & ${ }^{62} \mathrm{Zn}(9,19 \mathrm{~h})$ & ${ }^{62} \mathrm{Cu}(9,74 \mathrm{~min})$ & $\beta^{+}$ \\
\hline${ }^{99} \mathrm{Mo}(2,75 \mathrm{~d})$ & ${ }^{99 m} \mathrm{Tc}(6 \mathrm{~h})$ & $\gamma$ \\
\hline $\mathrm{T}_{1 / 2}$ = tempo de meia-vida física & & $\beta^{-}$ \\
\hline
\end{tabular}

Dos geradores apresentados, o gerador ${ }^{99} \mathrm{Mo} /{ }^{99 \mathrm{~m}} \mathrm{Tc}$ é o gerador mais importante para a medicina nuclear, uma vez que o ${ }^{99 \mathrm{~m}} \mathrm{Tc}$ é utilizado em mais de $80 \%$ dos procedimentos diagnósticos. Porém, nos últimos anos o gerador de ${ }^{68} \mathrm{Ge} /{ }^{68} \mathrm{Ga}$ tem ganho espaço na utilização em centros de diagnóstico PET (FERREIRA e MARQUES, 2012).

A Agência Internacional de Energia Atômica (IAEA - International Atomic Energy Agency) publicou em 2010 que os geradores de ${ }^{68} \mathrm{Ge} /{ }^{68} \mathrm{Ga}$ poderiam contribuir para o impacto clínico de diagnóstico na medicina nuclear para o PET tanto quanto o sistema de gerador de ${ }^{99} \mathrm{Mo} /{ }^{99 \mathrm{~m}} \mathrm{Tc}$ contribuiu para a técnica SPECT (IAEA, 2010). 


\subsection{Propriedades físico-químicas do gálio}

O gálio é um elemento químico de número atômico 31 , é um metal pertencente ao grupo $13(3 \mathrm{~A})$ da tabela periódica dos elementos (GREEN e WELCH, 1989).

O estado de oxidação +3 desse metal é o mais estável em soluções aquosas. $\mathrm{Ga}^{2+}$ pode existir na presença de altas concentrações de íons $\mathrm{Cl}^{-}$, mas é termodinamicamente instável sendo oxidado para $\mathrm{Ga}^{3+}$. O cátion $\mathrm{Ga}^{3+}$ é estável em soluções aquosas apenas em condições ácidas. Pode ser hidrolisado para trihidróxido insolúvel em pH 3 a 7, se sua concentração exceder nível nanomolar. Porém, essa precipitação pode ser evitada com a presença de agentes estabilizantes. A solubilidade do gálio em pH fisiológico é alta devido a formação quase exclusiva de íons [ $\left.\mathrm{Ga}(\mathrm{OH})_{4}\right]^{-}$(SCHUBIGER, 2007).

A principal espécie química do $\mathrm{Ga}$ em soluções aquosas com $\mathrm{pH}<1$ é $\left[\mathrm{Ga}(\mathrm{OH})_{4}\right]^{-}$. Já em soluções com pH 1 a aproximadamente 3, o Ga apresenta-se predominantemente na forma catiônica livre, $\mathrm{Ga}^{3+}$. A forma química $\left[\mathrm{Ga}(\mathrm{OH})_{2}\right]^{+}$é a principal espécie em soluções com $\mathrm{pH} 4$. A espécie $\left[\mathrm{Ga}(\mathrm{OH})_{3}\right]$ é predominante em pH 4,5 a 6. Em pH > 6 a espécie principal é $\left[\mathrm{Ga}(\mathrm{OH})_{4}\right]^{-}$(NEUMAIER e FANI, 2010; GREEN e WELCH, 1989; SCHUBIGER, 2007; ROESCH e RISS, 2010).

Na FIG. 1.2 são mostradas as espécies predominantes de Ga entre o pH 3 a 8 (NEUMAIER e FANI, 2010). 


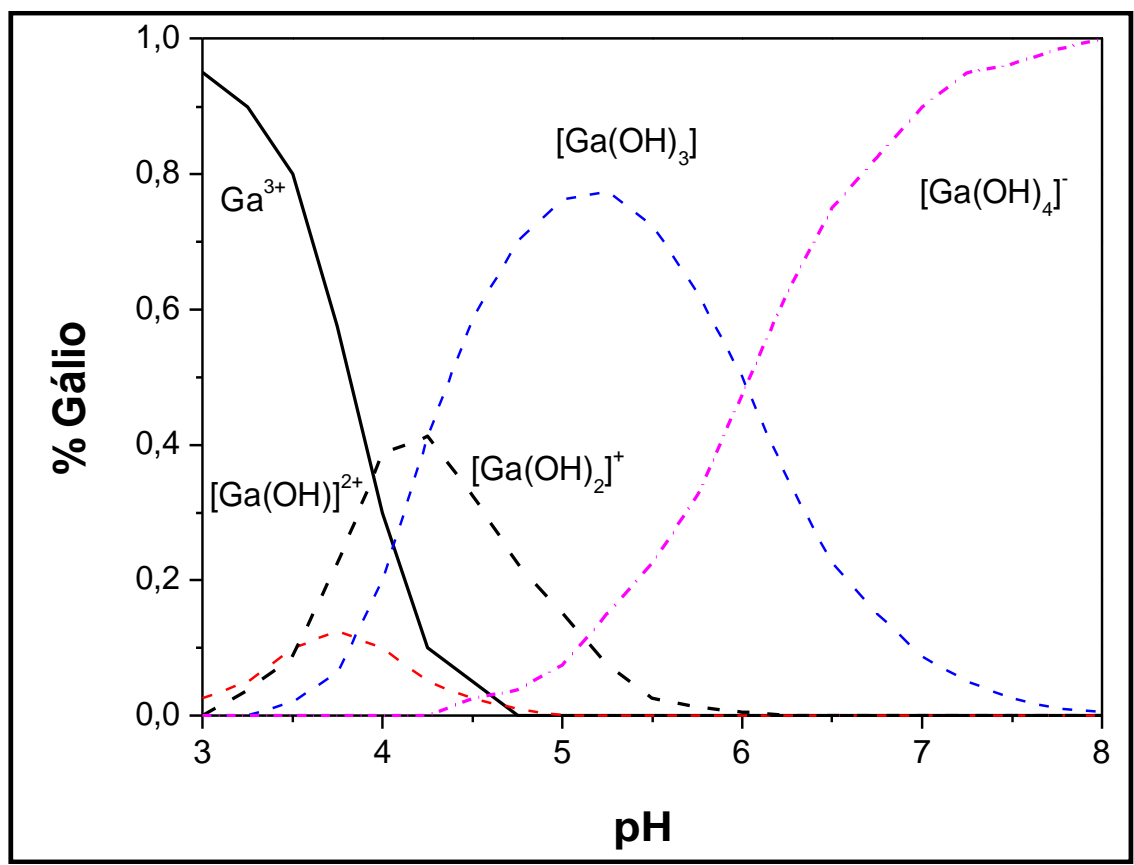

FIGURA 1.2 - Formação de espécies químicas do Ga em solução aquosa com pH 3 a 8 (NEUMAIER e FANI, 2010).

O Ga apresenta dois isótopos estáveis, ${ }^{69} \mathrm{Ga}$ e ${ }^{71} \mathrm{Ga}$ e vários isótopos radioativos (TAB. 1.5). $\mathrm{O}^{68} \mathrm{Ga}$ e ${ }^{67} \mathrm{Ga}$ são os mais importantes para uso clínico na medicina nuclear (GREEN e WELCH, 1989).

TABELA 1.5 - Isótopos do gálio, suas respectivas meia-vidas físicas e modo de decaimento.

\begin{tabular}{ccc}
\hline Simbolo & Meia vida & Decaimento \\
\hline${ }^{64} \mathrm{Ga}$ & $2,63 \mathrm{~min}$. & $\mathrm{CE} \mathrm{p} /{ }^{64} \mathrm{Zn}$ \\
${ }^{65} \mathrm{Ga}$ & $15,2 \mathrm{~min}$. & $\mathrm{CE} \mathrm{p} /{ }^{65} \mathrm{Zn}$ \\
${ }^{66} \mathrm{Ga}$ & $9,5 \mathrm{~h}$ & $\mathrm{CE} \mathrm{p} /{ }^{66} \mathrm{Zn}$ \\
${ }^{67} \mathrm{Ga}$ & $3,26 \mathrm{~d}$ & $\mathrm{CE} \mathrm{p} /{ }^{67} \mathrm{Zn}$ \\
${ }^{68} \mathrm{Ga}$ & $68 \mathrm{~min}$. & $\beta^{+} \mathrm{p} /{ }^{68} \mathrm{Zn}$ \\
& & $\mathrm{CE} \mathrm{p} /{ }^{68} \mathrm{Zn}$ \\
${ }^{69} \mathrm{Ga}$ & Estável & - \\
${ }^{70} \mathrm{Ga}$ & $21,1 \mathrm{~min}$. & $\mathrm{CE} \mathrm{p} /{ }^{70} \mathrm{Zn}$ \\
& & $\beta^{-} \mathrm{p} /{ }^{70} \mathrm{Ge}$ \\
${ }^{71} \mathrm{Ga}$ & Estável & - \\
${ }^{72} \mathrm{Ga}$ & $14,1 \mathrm{~h}$ & $\beta^{-} \mathrm{p} /{ }^{72} \mathrm{Ge}$ \\
${ }^{73} \mathrm{Ga}$ & $74,87 \mathrm{~h}$ & $\beta^{-} \mathrm{p} /{ }^{73} \mathrm{Ge}$ \\
${ }^{74} \mathrm{Ga}$ & $8,1 \mathrm{~min}$. & $\beta^{-} \mathrm{p} /{ }^{74} \mathrm{Ge}$ \\
${ }^{75} \mathrm{Ga}$ & $2,1 \mathrm{~min}$. & $\beta^{-} \mathrm{p} /{ }^{75} \mathrm{Ge}$ \\
\hline
\end{tabular}




\section{$1.5{ }^{68} \mathrm{Ga}$ : característica de decaimento e uso clínico}

O ${ }^{68} \mathrm{Ga}$ é um radionuclídeo emissor de pósitron que apresenta características adequadas para aplicações em PET. Decai 89 \% por emissão de pósitron $\left(E_{\text {máx }} 1,92 \mathrm{MeV}\right)$ e $11 \%$ por captura eletrônica para $0{ }^{68} \mathrm{Zn}$, que é um isótopo estável. $\mathrm{O}$ processo de decaimento é acompanhado pela emissão de fótons de 1077 keV com baixa abundância (3,22 \%).

O tempo de meia-vida física, relativamente curto, de 68 minutos, permite aplicação em PET com baixas doses para o paciente, sendo compatível com a farmacocinética de muitos peptídeos e moléculas pequenas, devido à rápida difusão, localização do alvo e rápido clareamento sanguíneo (NEUMAIER e FANI, 2010; ROESCH e RISS, 2010).

É obtido através de um sistema de gerador ${ }^{68} \mathrm{Ge} /{ }^{68} \mathrm{Ga}$, característica importante, que o torna independente de se ter um cíclotron próximo ao centro clínico, apresentando-se assim como uma alternativa interessante para $0{ }^{18} \mathrm{~F}$ (DECRISTOFORO, 2012).

Além das características físicas adequadas e praticidade de obtenção, a química do Ga é favorável para marcação de muitas moléculas. $\mathrm{O}^{68} \mathrm{Ga}^{3+}$ é estável e forma complexos com o ligante DOTA com alta afinidade, permitindo a radiomarcação com peptídeos ou outras biomoléculas conjugadas com o DOTA (NEUMAIER e FANI, 2010).

A eficácia dos radiofármacos preparados com ${ }^{68} \mathrm{Ga}$ é comparável com os marcados com ${ }^{18} \mathrm{~F}$ e tem estimulado muitos pesquisadores a investigar $\mathrm{o}$ potencial de novas moléculas marcadas com esse radionuclídeo para o uso clínico. O grande interesse no ${ }^{68} \mathrm{Ga}$ para aplicações médicas pode ser visto na FIG. 1.3, onde é ilustrado o número crescente de publicações sobre esse radionuclídeo nos últimos anos. 


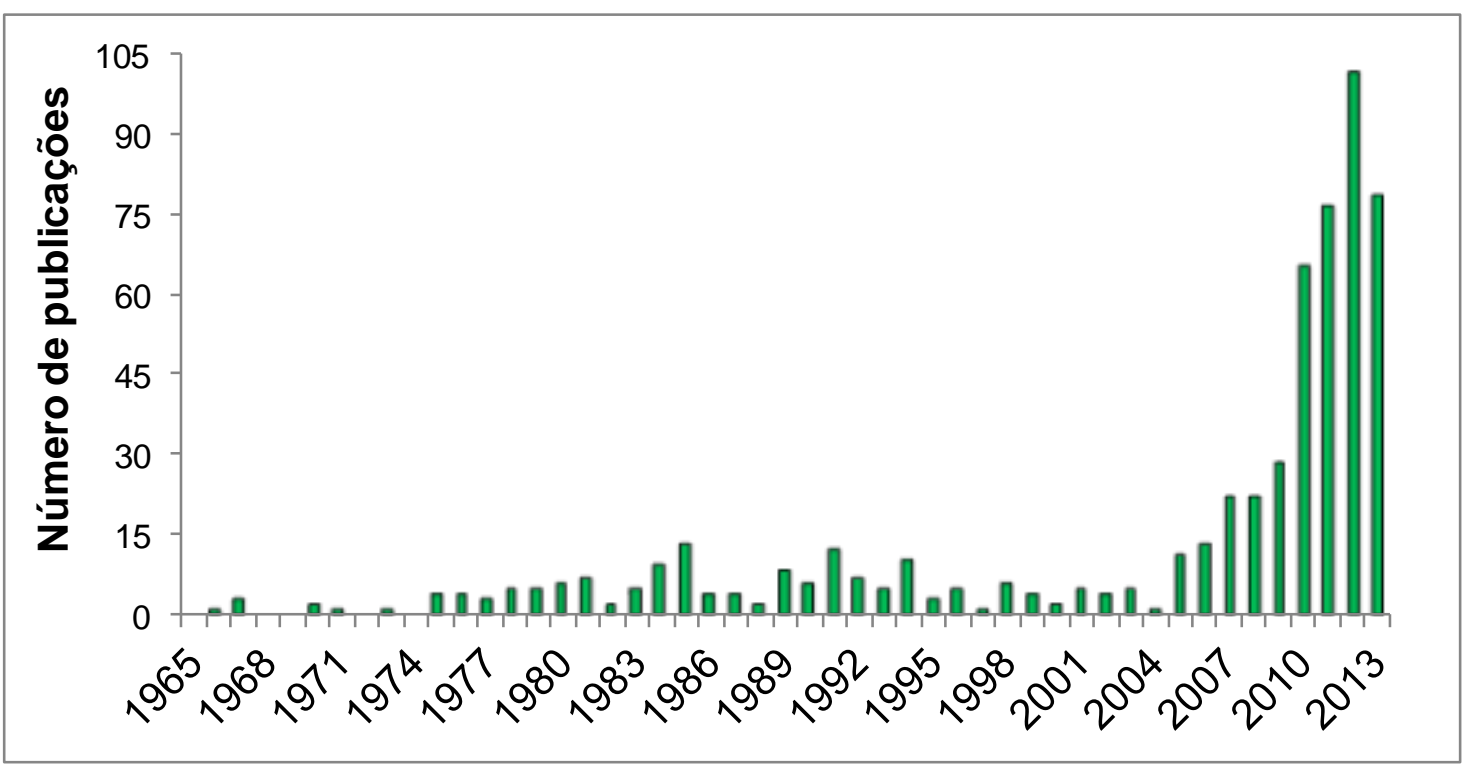

FIGURA 1.3 - Número de publicações relacionadas ao ${ }^{68} \mathrm{Ga}$ encontradas no PubMed no período de 1965 a 2013 (Palavra-chave para pesquisa: Ga-68 ou ${ }^{68} \mathrm{Ga}$ ) (PubMed, 2013).

Os compostos marcados com ${ }^{68} \mathrm{Ga}$ têm um potencial muito grande no diagnóstico de tumores e planejamento dosimétrico para radioterapia (KHAN et al., 2009).

Uma variedade de radiofármacos preparados com ${ }^{68} \mathrm{Ga}$ foi desenvolvida para estudos fisiológicos de diferentes órgãos, mas os que mais se destacaram foram os peptídeos análogos à somatostatina marcados com ${ }^{68} \mathrm{Ga}$, indicados para localização de tumores neuroendócrinos (NEUMAIER e FANI, 2010).

$\mathrm{Na}$ TAB. 1.6 estão apresentados alguns dos radiofármacos $\mathrm{com}^{68} \mathrm{Ga}$ encontrados na literatura (KHAN et al., 2009; YANG et al., 2009; ROESCH e RISS, 2010). 
TABELA 1.6 - Radiofármacos com ${ }^{68} \mathrm{Ga}$ encontrados na literatura.

\begin{tabular}{|c|c|}
\hline Radiofármaco & Aplicação \\
\hline${ }^{68} \mathrm{Ga}$-citrato & Processos inflamatórios e infecciosos \\
\hline $\begin{array}{l}{ }^{68} \mathrm{Ga}-\mathrm{Fe}(\mathrm{OH})_{3} \text { colóide } \\
{ }^{68} \mathrm{Ga} \text {-alizarina }\end{array}$ & Avaliação da função hepática \\
\hline $\begin{array}{l}{ }^{68} \mathrm{Ga} \text {-transferrina } \\
{ }^{68} \mathrm{Ga} \text {-DTPA albumina }\end{array}$ & $\begin{array}{l}\text { Avaliação do volume da proteína do } \\
\text { plasma }\end{array}$ \\
\hline${ }^{68} \mathrm{Ga}$-microesferas albumina & $\begin{array}{l}\text { Perfusão pulmonar, miocárdica e } \\
\text { cerebral }\end{array}$ \\
\hline${ }^{68} \mathrm{Ga}-\mathrm{EDTA}$ & $\begin{array}{l}\text { Detecção de anomalias na barreira } \\
\text { hemato-encefálica }\end{array}$ \\
\hline $\begin{array}{l}{ }^{68} \mathrm{Ga}-\mathrm{PLED} \\
{ }^{68} \mathrm{Ga}-\mathrm{EDTA} \\
{ }^{68} \mathrm{Ga}-\text { polimetafosfato } \\
{ }^{68} \mathrm{Ga} \text {-alizarina red S }\end{array}$ & Avaliação da função renal \\
\hline $\begin{array}{l}{ }^{68} \mathrm{Ga} \text {-t-butyl-HBED } \\
{ }^{68} \mathrm{Ga}-\mathrm{BP}-\text { IDA } \\
{ }^{68} \mathrm{Ga}-(3,4-D i P-L I C A M)\end{array}$ & Avaliação da função hepatobiliar \\
\hline $\begin{array}{l}{ }^{68} \mathrm{Ga}-E D T M P \\
{ }^{68} \mathrm{Ga} \text {-tripolifosfonato }\end{array}$ & Avaliação do sistema ósseo \\
\hline${ }^{68}$ Ga-glóbulos vermelhos & $\begin{array}{l}\text { Avaliação do volume de glóbulos } \\
\text { vermelhos }\end{array}$ \\
\hline${ }^{68} \mathrm{Ga}$-plaquetas & Localização de tromboses \\
\hline $\begin{array}{l}{ }^{88} \mathrm{Ga} \text {-peptídeos análogos à } \\
\text { somatostatina }\end{array}$ & $\begin{array}{l}\text { Localização de tumores } \\
\text { neuroendócrinos }\end{array}$ \\
\hline${ }^{68} \mathrm{Ga}-\mathrm{BAPEN}$ & Avaliação do miocárdio \\
\hline
\end{tabular}

Embora $0{ }^{18} \mathrm{~F}-\mathrm{FDG}$ (fluordeoxiglicose) seja o radiofármaco mais utilizado para imagens de PET em todo mundo, ele apresenta algumas limitações que incluem: (1) diagnóstico de algumas patologias, tais como, tumores neuroendócrinos, carcinoma de próstata e carcinoma hepatocelular, que não tem metabolismos glicolíticos; (2) dificuldade na avaliação de lesões que se encontram dentro ou ao redor de tecidos com alta atividade metabólica (cérebro) ou acumulação fisiológica (sistema urinário); (3) redução da especificidade em diferenciar tumores malignos de um processo inflamatório ou infeccioso. Além dessas limitações, ${ }^{18} \mathrm{~F}$ é produzido em cíclotrons e tem meia-vida física de 110 minutos, o que dificulta o fornecimento do radiofármaco, $\mathrm{FDG}-{ }^{18} \mathrm{~F}$, para regiões distantes do centro produtor (KHAN et al., 2009). 
Na FIG. 1.4 são apresentadas imagens diagnósticas de um paciente com tumores neuroendócrinos, realizadas com três radiofármacos diferentes: FDG- ${ }^{18} \mathrm{~F}$ (PET), Octreoscan $-{ }^{111}$ In (SPECT) e DOTATOC- ${ }^{68} \mathrm{Ga}$ (PET) (ROESCH e RISS, 2010; IAEA, 2010). O exame realizado com DOTATOC $-{ }^{68} \mathrm{Ga}$ mostrou nitidamente mais lesões do que os exames feitos com FDG- ${ }^{18} \mathrm{~F}$ e Octreoscan${ }^{111} \mathrm{In}$.

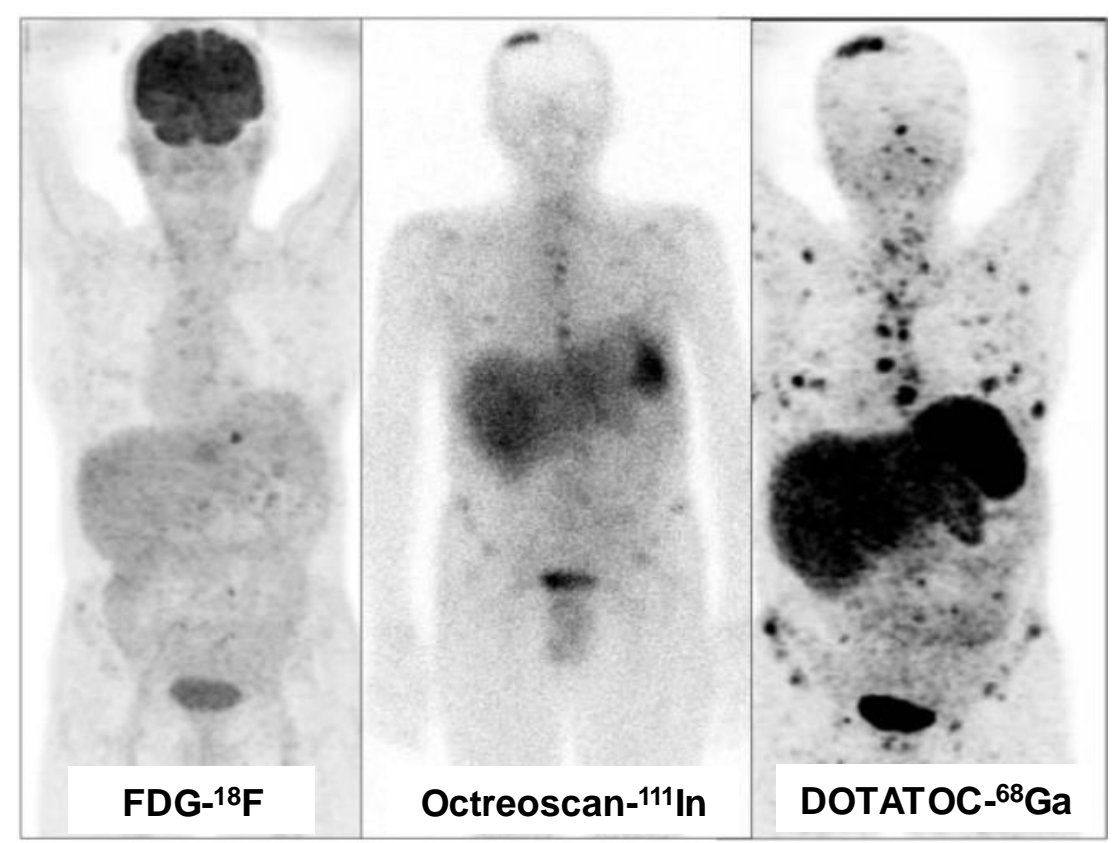

FIGURA 1.4 - Imagens diagnósticas de um paciente com tumores neuroendócrinos realizadas com três radiofármacos diferentes, $F D G-{ }^{18} \mathrm{~F}$ (esquerda), Octreoscan- ${ }^{111}$ In (centro) e DOTATOC $-{ }^{68} \mathrm{Ga}$ (direita) (ROESCH e RISS, 2010; IAEA, 2010).

\subsection{Propriedades físico-químicas do Ge e produção do ${ }^{68} \mathrm{Ge}$}

O germânio é um semi-metal com número atômico 34 , pertence ao grupo 4A dos elementos e seu estado de oxidação mais importante é o +4. $O$ íon $\mathrm{Ge}^{4+}$ raramente ocorre em soluções aquosas, porque é facilmente hidrolizado. As formas mais importantes do germânio em soluções aquosas são o ácido germânico $\left(\mathrm{H}_{4} \mathrm{GeO}_{4}{ }^{0}\right)$ e seus produtos de dissociação $\left(\mathrm{H}_{3} \mathrm{GeO}_{4}{ }^{-}\right.$e $\left.\mathrm{H}_{3} \mathrm{GeO}_{4}{ }^{2-}\right)$. A formação das espécies em relação ao pH da solução está ilustrada na FIG. 1.5 (WOOD e SAMSON, 2006; VIROLAINEN et al., 2013). 


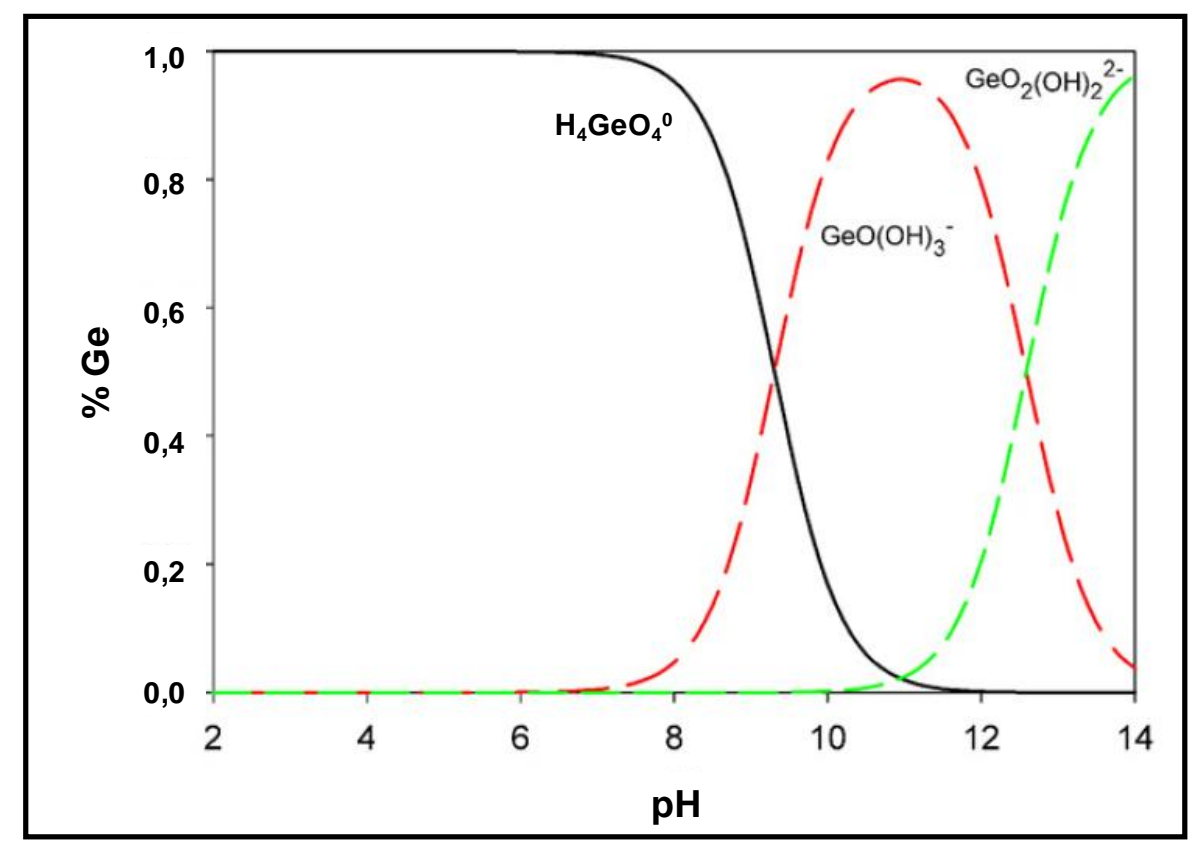

FIGURA 1.5 - Dissociações do ácido germânico $\left(\mathrm{H}_{4} \mathrm{GeO}_{4}{ }^{0}\right)$ (VIROLAINEN et al., 2013).

O Ge apresenta cinco isótopos estáveis, ${ }^{70} \mathrm{Ge}(20,55 \%),{ }^{72} \mathrm{Ge}(27,37$ $\%),{ }^{73} \mathrm{Ge}(7,67 \%),{ }^{74} \mathrm{Ge}(36,74 \%)$ e ${ }^{76} \mathrm{Ge}(7,67 \%)$ e vários isótopos radioativos, dos quais, $0{ }^{68} \mathrm{Ge}$ é o que apresenta meia-vida física mais longa, 271 dias, decaindo $100 \%$ por captura eletrônica para $0{ }^{68} \mathrm{Ga}$ (FIG. 1.6) (MIRZADEH e LAMBRECHT, 1996).

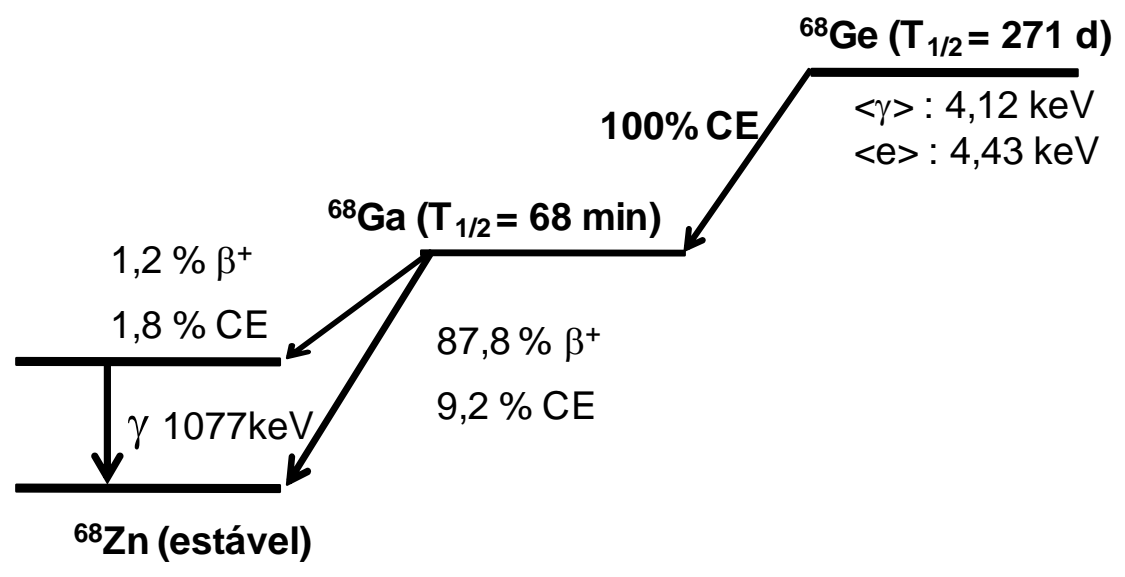

FIGURA 1.6 - Esquema de decaimento do ${ }^{68} \mathrm{Ge}$.

É produzido em aceleradores de partículas (cíclotrons) e as reações nucleares mais relevantes para sua produção estão descritas na TAB. 1.7 (IAEA, 2010). 
TABELA 1.7 - Principais reações nucleares para produção de ${ }^{68} \mathrm{Ge}$ (IAEA, 2010; ROESCH e RISS, 2010).

\begin{tabular}{ll}
\hline Núcleo Alvo & Reação Nuclear \\
\hline${ }^{69} \mathrm{Ga}$ & $(\mathrm{p}, 2 \mathrm{n})$ \\
& $(\mathrm{d}, 3 \mathrm{n})$ \\
${ }^{\mathrm{nat}} \mathrm{Ga}\left({ }^{69,71} \mathrm{Ga}\right)$ & $(\mathbf{p}, \mathrm{xn}), \mathbf{x}=\mathbf{2 , 4}$ \\
${ }^{n a t} \mathrm{Ge}$ & $(\mathrm{p}, \mathrm{pxn})$ \\
${ }^{66} \mathrm{Zn}$ & $(\mathrm{\alpha}, 2 \mathrm{n})$ \\
${ }^{66,67,68} \mathrm{Zn}$ & $\left({ }^{3} \mathrm{He}, \mathrm{xn}\right), \mathrm{x}=1,2,3$ \\
\hline
\end{tabular}

Dentre as reações nucleares descritas acima, a rota mais eficaz é a irradiação de alvos de Ga com feixe de prótons. Os altos valores de seção de choque para a reação ${ }^{69} \mathrm{Ga}(\mathrm{p}, 2 \mathrm{n}){ }^{68} \mathrm{Ge}$ permitem a irradiação do Ga natural sem o enriquecimento isotópico em ${ }^{69} \mathrm{Ga}$ para energias médias de prótons entre 20 e 30 $\mathrm{MeV}$ (FIG. 1.7). Além disso, se houver a presença de prótons com altas energias, a reação ${ }^{71} \mathrm{Ga}(\mathrm{p}, 4 \mathrm{n}){ }^{68} \mathrm{Ge}$ contribui para o rendimento de produção (IAEA, 2010).

A produção em larga escala $(3,7-37 \mathrm{GBq})$ do ${ }^{68} \mathrm{Ge}$ é limitada à aceleradores de partículas que apresentem alta corrente (de 40 a mais de 100 $\mu \mathrm{A})$ e disponibilidade de longos períodos de irradiação por vários dias.

Consequentemente, apenas um número limitado de aceleradores encontra-se disponível para este fim. A produção rotineira desse radionuclídeo é realizada principalmente pelos Estados Unidos (Brookhaven National Laboratory e Los Alamos National Laboratory), África do Sul (iThemba Laboratories/NAC) e Rússia (Cyclotron Co., Ltd, Obninsk). Esses centros produtores reportam capacidade de produção de aproximadamente 18,5 a $74 \mathrm{GBq}(0,5-2 \mathrm{Ci})$ de ${ }^{68} \mathrm{Ge}$ por irradiação (IAEA, 2010). 


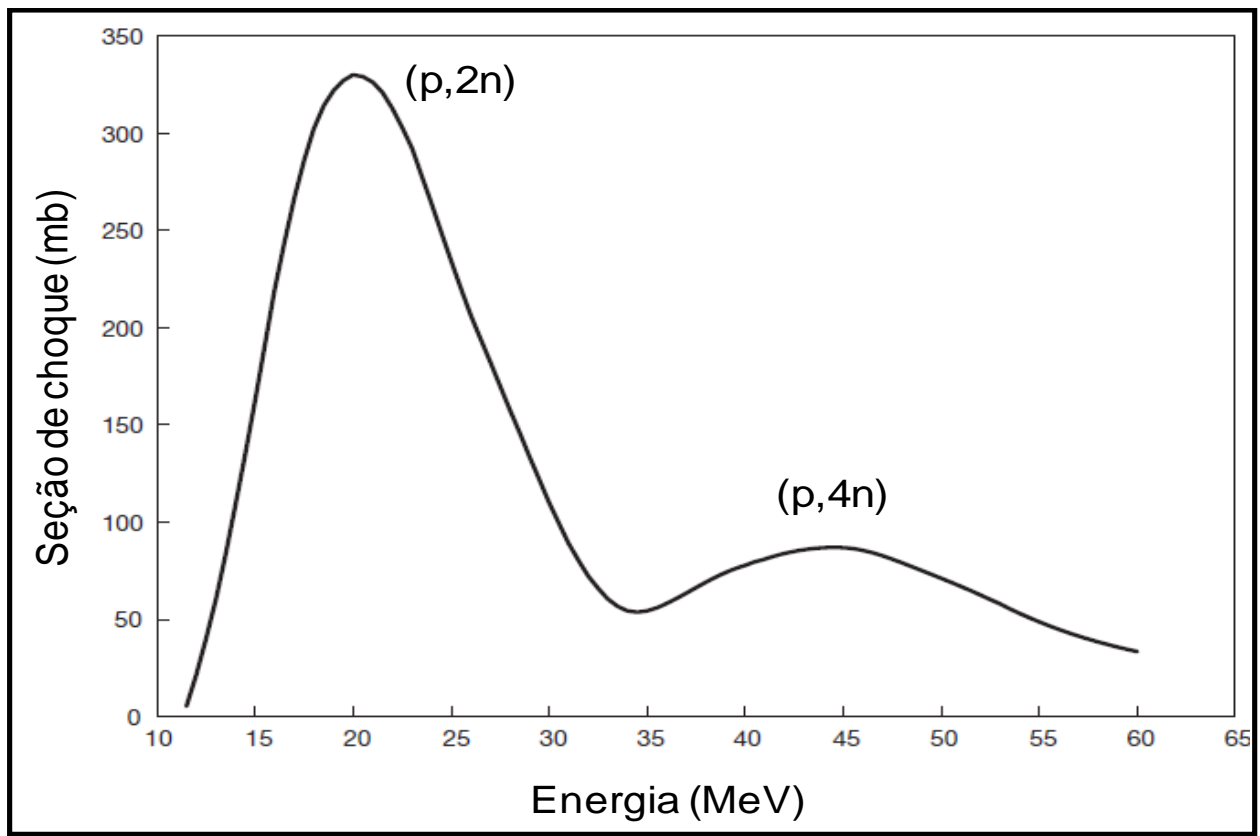

FIGURA 1.7 - Função de excitação para produção do ${ }^{68} \mathrm{Ge}$ através da reação ${ }^{\text {nat }} \mathrm{Ga}(\mathrm{p}, \mathrm{xn}){ }^{68} \mathrm{Ge}(\mathrm{IAEA}, 2010)$.

\subsection{Geradores de ${ }^{68} \mathrm{Ge} /{ }^{68} \mathrm{Ga}$}

Devido ao enorme interesse e importância clínica crescente da imagem de PET/CT, a viabilidade de sistemas de geradores de radionuclídeos que ofereçam emissores de pósitrons continua a estimular grande interesse.

$\mathrm{O}$ gerador ${ }^{68} \mathrm{Ge} /{ }^{68} \mathrm{Ga}$ tem um potencial muito grande para ser uma das mais importantes fontes de preparações radiofarmacêuticas para tomografia por emissão de pósitrons. Isso porque a longa meia-vida física de 271 dias do radionuclídeo pai, ${ }^{68} \mathrm{Ge}$, pode promover, por um longo período de tempo, várias doses diárias do radionuclídeo filho, ${ }^{68} \mathrm{Ga}$ (FIG. 1.8) (IAEA, 2010; OSSO e KNAPP, 2011). 


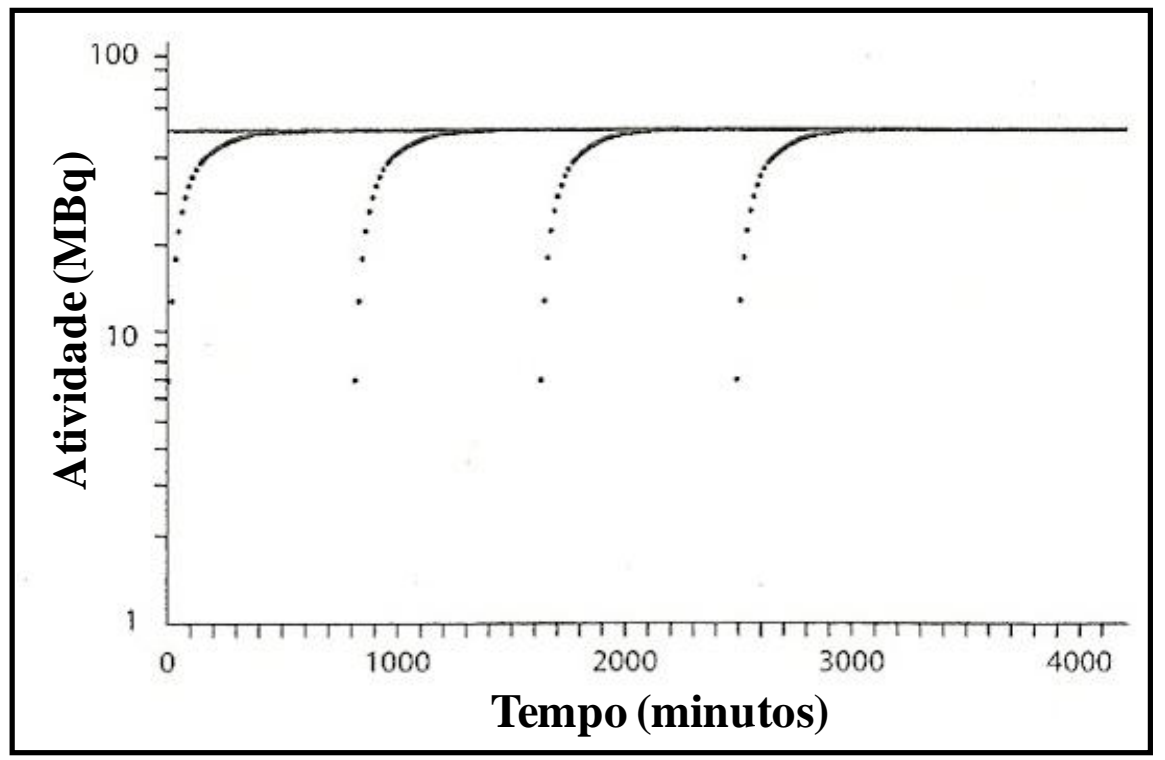

FIGURA 1.8 - Ilustração de ciclos de eluição com o crescimento da atividade do ${ }^{68} \mathrm{Ga}$ para um sistema de gerador de ${ }^{68} \mathrm{Ge} /{ }^{68} \mathrm{Ga}$ (OSSO e KNAPP, 2011).

Desde a concepção do primeiro gerador de ${ }^{68} \mathrm{Ge} /{ }^{68} \mathrm{Ga}$ na década de 60 , esforços contínuos estão sendo realizados no estudo para produção e otimização desse sistema. $\mathrm{O}$ método de separação do ${ }^{68} \mathrm{Ge}$ do ${ }^{68} \mathrm{Ga}$ mais utilizado, devido à praticidade de operação, é o de troca iônica em um sistema cromatográfico, mas sistemas de geradores com método de separação por extração por solvente e volatilização também foram propostos (GLEASON, 1960; EHRHARDT, 1978; MIRZADEH e LAMBRECHT, 1996; NEUMAIER e FANI, 2010).

Geradores com sistemas de troca iônica, basicamente, consistem em uma ou mais colunas carregadas com um material cromatográfico que tem o potencial de promover a separação química entre um radionuclídeo pai e o radionuclídeo filho, através da adsorção de um dos radionuclídeos na coluna e a eluição do outro por um determinado solvente. Esses materiais adsorvedores utilizados na coluna são sintéticos e podem ser inorgânicos ou orgânicos. A principal desvantagem dos geradores que utilizam materiais orgânicos é o efeito da radiólise nesses materiais que pode promover a quebra de moléculas e comprometer o desempenho do gerador (OSSO e KNAPP, 2011; NEUMAIER e FANI, 2010).

O primeiro gerador cromatográfico de ${ }^{68} \mathrm{Ge} /{ }^{68} \mathrm{Ga}$ foi proposto em 1961 por Green e Tucker. Neste sistema o radionuclídeo pai, ${ }^{68} \mathrm{Ge}$, ficava adsorvido em 
uma coluna de alumina e o radionuclídeo filho, ${ }^{68} \mathrm{Ga}$, era eluído com ácido etilenodiaminotetraacético 0,005 mol.L-1 (EDTA) (GREENE e TUCKER, 1961).

A solução de $E D T A-{ }^{68} \mathrm{Ga}$ foi usada diretamente na tentativa de se obter imagens tumorais. A grande limitação desse tipo de gerador é que a preparação de outros complexos marcados com ${ }^{68} \mathrm{Ga}$ requer a dissociação do complexo EDTA $-{ }^{68} \mathrm{Ga}$, que possui alta estabilidade, necessitando de várias etapas para que ocorra a dissociação, não sendo viável devido a meia-vida física do ${ }^{68} \mathrm{Ga}$ ser curta. Por essa razão, fez-se necessário o desenvolvimento de geradores de ${ }^{68} \mathrm{Ge} /{ }^{68} \mathrm{Ga}$ que fornecessem $0{ }^{68} \mathrm{Ga}$ como uma espécie iônica livre, ${ }^{68} \mathrm{Ga}^{3+}$ (MIRZADEH e LAMBRECHT, 1996; IAEA, 2010).

Em 1974 Kopecký et al. desenvolveram um dos primeiros sistemas de geradores de ${ }^{68} \mathrm{Ge} /{ }^{68} \mathrm{Ga}$ no qual ${ }^{68} \mathrm{Ga}$ era obtido em uma forma iônica livre. A base da coluna do gerador era de $\mathrm{Al}_{2} \mathrm{O}_{3}$ e a eluição do ${ }^{68} \mathrm{Ga}$ era realizada com $\mathrm{HCl} 0,2 \mathrm{~mol} \mathrm{~L}^{-1}$ (KOPECKÝ et al., 1974).

$A$ adsorção do ${ }^{68} \mathrm{Ge}$ foi avaliada em uma variedade de materiais inorgânicos, tais como: $\mathrm{Al}_{2} \mathrm{O}_{3}, \mathrm{SnO}_{2}, \mathrm{ZrO}_{2}, \mathrm{TiO}_{2}, \mathrm{Fe}_{2} \mathrm{O}_{3}, \mathrm{SiO}_{2}$. Resinas orgânicas também foram estudadas: 1,2,3-trihidroxibenzeno (pirogalol)-formaldeido (100200 mesh), AG1-X8 (200-400 Mesh) e a resina R-Mglu (Diaion CRB-02) (MIRZADEH e LAMBRECHT, 1996; OSSO e KNAPP, 2011).

O primeiro gerador disponível comercialmente (Cyclotron Inc, Obninsk, Rússia) foi desenvolvido com uma matriz inorgânica de $\mathrm{TiO}_{2}$, modificado com $\mathrm{ZrO}_{2}$ (DECRISTOFORO, 2012; ANDRONOV et al., 2008).

Atualmente, os geradores de ${ }^{68} \mathrm{Ge} /{ }^{68} \mathrm{Ga}$ são disponíveis comercialmente tanto com colunas utilizando matrizes inorgânicas preparadas com $\mathrm{TiO}_{2}$ ou $\mathrm{ZrO}_{2}$ como também usando resina orgânica (dodecil-3,4,5trihidroxibenzoato). A eficiência de eluição do ${ }^{68} \mathrm{Ga}$ varia de $70 \%$ a $80 \%$, apresentando uma queda ao longo do tempo. Os níveis de contaminação do ${ }^{68} \mathrm{Ge}$ vão de $10^{-2}$ a $10^{-3} \%$ ou até menores em geradores novos, porém ocorre um aumento nos níveis de contaminação após longos períodos de uso (RÖSCH, 2013; ITG, 2011).

Na FIG. 1.9 estão apresentados os geradores de ${ }^{68} \mathrm{Ge} /{ }^{68} \mathrm{Ga}$ disponíveis comercialmente e na TAB. 1.8 estão descritas as características de cada um deles. 

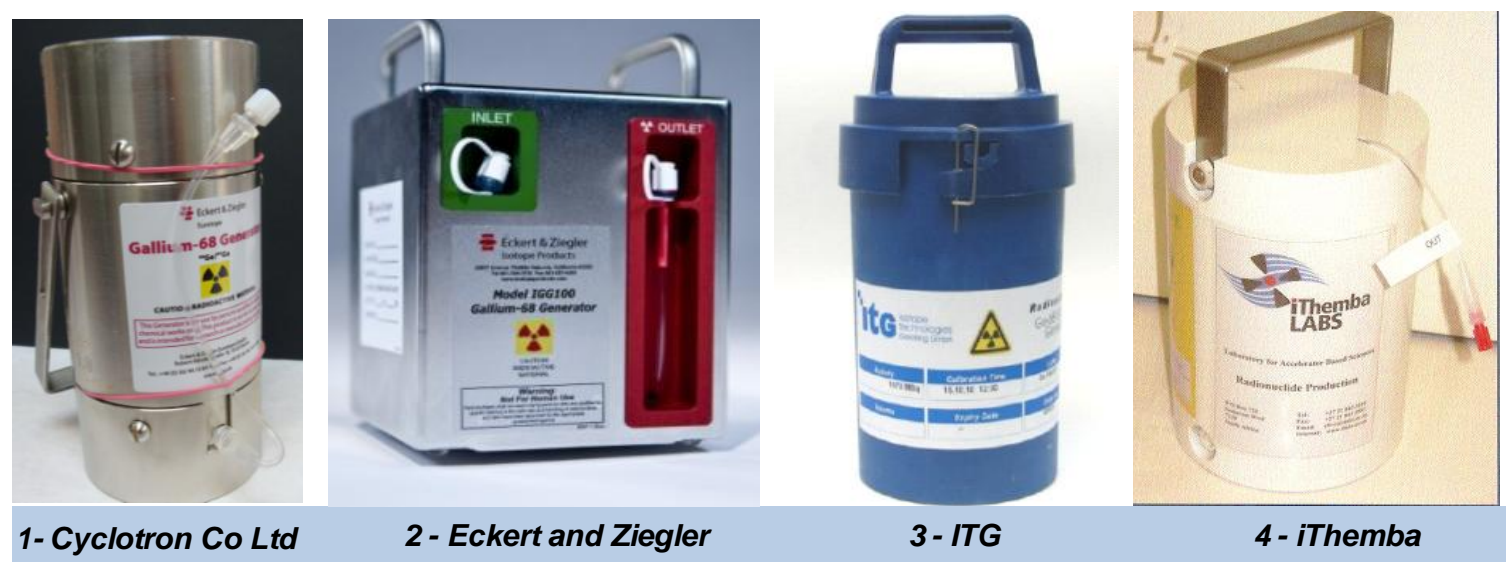

FIGURA 1.9 - Geradores comerciais de ${ }^{68} \mathrm{Ge} /{ }^{68} \mathrm{Ga}: 1$ - Cyclotron Co Ltd; 2 Eckert and Ziegler; 3 - ITG e 4 - iThemba (Technical Information Bulletin, 2013; IDB HOLLAND bv. iThemba LABS, 2010; ITG, 2011).

TABELA 1.8 - Geradores de ${ }^{68} \mathrm{Ge} /{ }^{68} \mathrm{Ga}$ disponíveis comercialmente (Technical Information Bulletin, 2013; IDB HOLLAND bv. iThemba LABS, 2010; ITG, 2011).

\begin{tabular}{|c|c|c|c|c|}
\hline $\begin{array}{l}\text { Características } \\
\text { do gerador }\end{array}$ & $\begin{array}{l}\text { Cyclotron } \\
\text { Co Ltd } \\
\text { (Rússia) }\end{array}$ & $\begin{array}{c}\text { Eckert and } \\
\text { Ziegler } \\
\text { (Alemanha/EUA) }\end{array}$ & $\begin{array}{l}\text { iThemba } \\
\text { (África do } \\
\text { Sul) }\end{array}$ & $\begin{array}{c}\text { ITG } \\
\text { (Alemanha) }\end{array}$ \\
\hline Matriz da coluna & $\begin{array}{c}\mathrm{TiO}_{2} \\
\text { Modificado }\end{array}$ & $\mathrm{TiO}_{2}$ & $\mathrm{SnO}_{2}$ & $\begin{array}{l}\text { Sílica/ } \\
\text { Orgânica }\end{array}$ \\
\hline $\begin{array}{l}\text { Concentração do } \\
\mathrm{HCl} \text { (eluente) }\end{array}$ & $0,1 \mathrm{~mol} \mathrm{~L}^{-1}$ & $0,1 \mathrm{~mol} \mathrm{~L}^{-1}$ & $0,6 \mathrm{~mol} \mathrm{~L}^{-1}$ & $0,05 \mathrm{~mol} \mathrm{~L}^{-1}$ \\
\hline $\begin{array}{l}\% \text { Eluição do } \\
{ }^{68} \mathrm{Ga}\end{array}$ & $60-75$ & $>65$ & $80 \%$ & $>80 \%$ \\
\hline $\begin{array}{l}\% \text { contaminação } \\
\text { de }{ }^{68} \mathrm{Ge}\end{array}$ & 0,005 & $<0,001$ & $\sim 0,002$ & $<0,005$ \\
\hline $\begin{array}{l}\text { Contaminantes } \\
\text { químicos }\end{array}$ & $\begin{array}{c}\mathrm{Pb}, \mathbf{Z n}, \mathbf{A l}, \\
\mathrm{Ni}, \mathbf{C u} \\
5-150 \mu \mathrm{g} \mathrm{L}{ }^{-1} \\
\text { (total) }\end{array}$ & $\begin{array}{c}\mathbf{P b}, \mathbf{Z n}, \mathbf{A l}, \mathbf{N i}, \\
\mathbf{C u} \\
<\underset{\text { (total) }}{2 \mu \mathrm{g} \mathrm{L}^{-1}}\end{array}$ & $?$ & $\begin{array}{c}\text { baixa } \\
\text { concentração } \\
\text { de metais }\end{array}$ \\
\hline $\begin{array}{l}\text { Vida útil } \\
\text { recomendada }\end{array}$ & $\begin{array}{c}1 \text { ano ou } 300 \\
\text { eluições }\end{array}$ & $\begin{array}{c}1 \text { ano ou } 300 \\
\text { eluições }\end{array}$ & $\begin{array}{c}1 \text { ano ou } 200 \\
\text { eluições }\end{array}$ & $1 / 2$ ano \\
\hline
\end{tabular}

Mesmo com todos os avanços tecnológicos, ocorridos nas últimas décadas, no desenvolvimento dos geradores de ${ }^{68} \mathrm{Ge} /{ }^{68} \mathrm{Ga}$, o eluato de ${ }^{68} \mathrm{Ga}$ dos geradores comerciais ainda não é adequado para uso direto em seres humanos e algumas melhorias nos sistemas precisam ser feitas para diminuir os níveis de contaminação de ${ }^{68} \mathrm{Ge}$ e impurezas químicas. Os radiofármacos com ${ }^{68} \mathrm{Ga}$ estão sendo sintetizados e usados rotineiramente de modo seguro, devido ao uso dos geradores estar associado à outras tecnologias de purificação $(\mathrm{RÖSCH}, 2013)$. 
Em paralelo, geradores comercialmente licenciados e com certificado de Boas Práticas de Fabricação são necessários para cumprir com as exigências das agências regulatórias (RÖSCH, 2013).

Recentes publicações descreveram o potencial de nanopartículas como ceria-poliacrilonitrilo (nanoceria-PAN) e nano zircônia no desenvolvimento de geradores de ${ }^{68} \mathrm{Ge} /{ }^{68} \mathrm{Ga}$, capazes de fornecer ${ }^{68} \mathrm{Ga}$ em condições adequadas para uso clínico, sem a necessidade de purificação (CHAKRAVARTY et al., 2010; CHAKRAVARTY et al., 2011). Porém, esses sistemas ainda não estão disponíveis comercialmente.

$\mathrm{Na}$ TAB. 1.9 apresenta-se um resumo dos geradores de sistema cromatográfico encontrados na literatura. 
TABELA 1.9 - Características dos geradores cromatográficos encontrados na literatura.

\begin{tabular}{|c|c|c|c|c|}
\hline \multirow{2}{*}{ Referência } & \multicolumn{2}{|c|}{ Sistema do Gerador } & \multirow{2}{*}{$\begin{array}{c}\text { \% Eluição } \\
\text { do }{ }^{68} \mathrm{Ga}\end{array}$} & \multirow{2}{*}{$\begin{array}{c}\text { \% Contaminação } \\
\text { de }{ }^{68} \mathrm{Ge}\end{array}$} \\
\hline & Adsorvedor & Eluente & & \\
\hline 1961-Greene et al. & $\mathrm{Al}_{2} \mathrm{O}_{3}$ & EDTA $0,005 \mathrm{~mol} \mathrm{~L}^{-1}$ & 70 & $<3 \times 10^{-4}$ \\
\hline 1964-Yano et al. & $\mathrm{Al}_{2} \mathrm{O}_{3}$ & EDTA $0,005 \mathrm{~mol} \mathrm{~L}^{-1}$ & 35 & $<1,4 \times 10^{-3}$ \\
\hline 1973-Kopecký et al. & $\mathrm{Al}_{2} \mathrm{O}_{3}$ neutra & EDTA $0,005 \mathrm{~mol} \mathrm{~L}^{-1}$ & 60 & Não detectado \\
\hline 1974-Kopecký et al. & $\mathrm{Al}_{2} \mathrm{O}_{3}$ básica & $\mathrm{HCl} 0,2 \mathrm{~mol} \mathrm{~L}^{-1}$ & 48,5 & $<2 \times 10^{-3}$ \\
\hline $\begin{array}{l}\text { 1975-Malyshev et } \\
\text { al. }\end{array}$ & Hidróxido de zircônio & $\mathrm{HCl} 0,1 \mathrm{~mol} \mathrm{~L}^{-1}$ & 35 & $3 \times 10^{-2}-6 \times 10^{-3}$ \\
\hline 1978-Arino et al. & ácido poliantimonico & $\begin{array}{l}\text { Oxalato de sódio } 2 \% \text {, } \\
\text { pH } 8,5\end{array}$ & 87 & $5 \times 10^{-2}$ \\
\hline \multirow[t]{3}{*}{ 1979-Neirinckx et al. } & $\mathrm{TiO}_{2}$ & $\mathrm{HNO}_{3}$ & * & * \\
\hline & $\mathrm{ZrO}_{2}$ & $\mathrm{HNO}_{3} 0,5-1,0 \mathrm{~mol} \mathrm{~L}^{-1}$ & * & * \\
\hline & $\mathrm{SiO}_{2}$ & $\mathrm{HNO}_{3} 6 \mathrm{~mol} \mathrm{~L}^{-1}$ & * & * \\
\hline 1980-Loc'h et al. & $\mathrm{SnO}_{2}$ & $\mathrm{HCl} 1 \mathrm{~mol} \mathrm{~L}^{-1}$ & $75-80$ & $2 \times 10^{-4}$ \\
\hline 1980-Neirinckx et al. & $\begin{array}{l}\text { AG1-X8 (200-400 } \\
\text { Mesh) }\end{array}$ & $\mathrm{HF} 0,01 \mathrm{~mol} \mathrm{~L}^{-1}$ & 90 & $1 \times 10^{-2}$ \\
\hline $\begin{array}{l}\text { 1980-Schuhmacher } \\
\text { et al. }\end{array}$ & $\begin{array}{l}\text { Resina Pirogalol/ } \\
\text { Resina troca aniônica } \\
\text { BioRad (100-200 } \\
\text { mesh) }\end{array}$ & $\mathrm{HCl} 0,5 \mathrm{~mol} \mathrm{~L}^{-1}$ & $75-80$ & $1 \times 10^{-4}$ \\
\hline 1982-Neirinckx et al. & $\begin{array}{l}\text { Resina Pirogalol- } \\
\text { formaldeido }\end{array}$ & $\mathrm{HCl} 0,3 \mathrm{~mol} \mathrm{~L}^{-1}$ & 60 & $<1 \times 10^{-2}$ \\
\hline 1988-Ambe et al. & $\alpha-\mathrm{Fe}_{2} \mathrm{O}_{3}$ & $\mathrm{HCl} 1 \mathrm{~mol} \mathrm{~L}^{-1}$ & $50-70$ & $6 \times 10^{-4}-2 \times 10^{-2}$ \\
\hline 1998-Benhong et al. & $\alpha-\mathrm{Fe}_{2} \mathrm{O}_{3}$ & $\mathrm{HCl} 0,05 \mathrm{~mol} \mathrm{~L}^{-1}$ & 90 & $1,8 \times 10^{-2}$ \\
\hline $\begin{array}{l}\text { 2000- Egamediev et } \\
\text { al. }\end{array}$ & $\mathrm{Al}_{2} \mathrm{O}_{3}$ & $\mathrm{HCl} 0,1 \mathrm{~mol} \mathrm{~L}^{-1}$ & 55 & $2 \times 10^{-4}$ \\
\hline 2000-Cheng et al. & $\mathrm{SnO}_{2}$ & $\mathrm{HCl} 1 \mathrm{~mol} \mathrm{~L}^{-1}$ & $\sim 70$ & $<6 \times 10^{-4}$ \\
\hline $\begin{array}{l}\text { 2002-Nakayama et } \\
\text { al. }\end{array}$ & $\begin{array}{l}\text { Resina R-Mglu } \\
\text { (Diaion CRB-02) }\end{array}$ & Citrato sódio $0,1 \mathrm{~mol} \mathrm{~L}^{-1}$ & $85-90$ & $4 \times 10^{-4}$ \\
\hline $\begin{array}{l}\text { 2005-Aardaneh et } \\
\text { al. }\end{array}$ & $\mathrm{SnO}_{2}$ & $\mathrm{HCl} 1 \mathrm{~mol} \mathrm{~L}^{-1}$ & 65 & $6,1 \times 10^{-4}$ \\
\hline $\begin{array}{l}2010 \text {-Chakravarty et } \\
\text { al. }\end{array}$ & $\mathrm{CeO}_{2}-\mathrm{PAN}$ & $\mathrm{HCl} 0,01 \mathrm{~mol} \mathrm{~L}^{-1}$ & $>80$ & $1 \times 10^{-5}$ \\
\hline $\begin{array}{l}\text { 2011-Chakravarty et } \\
\text { al. }\end{array}$ & $\mathrm{ZrO}_{2}$ & $\mathrm{HCl} 0,01 \mathrm{~mol} \mathrm{~L}^{-1}$ & $>80$ & $<1 \times 10^{-5}$ \\
\hline
\end{tabular}

\subsection{Revisão bibliográfica dos geradores de ${ }^{68} \mathrm{Ge} /{ }^{68} \mathrm{Ga}$ cromatográficos}

Em 1961, Greene e Tucker desenvolveram o primeiro gerador cromatográfico de ${ }^{68} \mathrm{Ge} /{ }^{68} \mathrm{Ga}$. O gerador consistia de uma coluna de vidro de 25 $\mathrm{mm}$ de diâmetro com $10 \mathrm{~g}$ de alumina. A coluna foi lavada com água e condicionada com solução de EDTA $0,005 \mathrm{~mol} \mathrm{~L}^{-1}, \mathrm{pH}$ igual a 7 , ajustado com 
$\mathrm{NaOH} . \quad O{ }^{68} \mathrm{Ge}$ foi carregado na coluna em uma solução igual à do condicionamento. A eluição do gerador era feita com $25 \mathrm{~mL}$ de EDTA 0,005 mol $\mathrm{L}^{-1}(\mathrm{pH}=7)$ com tempo de 3-4 minutos. O rendimento de eluição alcançado para o ${ }^{68} \mathrm{Ga}$ foi de $70 \%$ e a contaminação de ${ }^{68} \mathrm{Ge}$ no momento da eluição era menor que $3 \times 10^{-4} \%$. A coluna do gerador era mantida seca. Após a simulação de mil eluições, o rendimento de eluição e os níveis de contaminação de ${ }^{68} \mathrm{Ge}$ continuaram os mesmos (Greene e Tucker, 1961).

Em 1964, Yano e Anger prepararam um gerador utilizando a mesma metodologia descrita por Greene e Tucker em 1961. As eluições eram realizadas com $10 \mathrm{~mL}$ de EDTA $0,005 \mathrm{~mol} \mathrm{~L}^{-1}(\mathrm{pH}=7)$ e os níveis de impureza de ${ }^{68} \mathrm{Ge}$ encontrados foram menores que $1,4 \times 10^{-3} \%$. O rendimento do ${ }^{68} \mathrm{Ga}$ após um processo de dissociação do EDTA ${ }^{68} \mathrm{Ga}$ foi de $35 \%$ (YANO e ANGER, 1964).

Em 1973, Kopecký et al. estudaram a adsorção do ${ }^{68} \mathrm{Ge}$ e do ${ }^{68} \mathrm{Ga}$ na $\mathrm{Al}_{2} \mathrm{O}_{3}$, sendo preparadas duas colunas. Na primeira coluna, o condicionamento do material, percolação da solução carga de ${ }^{68} \mathrm{Ge}$ e eluição do ${ }^{68} \mathrm{Ga}$ foram realizados com solução de EDTA $0,005 \mathrm{~mol} \mathrm{~L}^{-1}(\mathrm{pH} 9,5-10)$. ${ }^{68} \mathrm{Ge}$ ficou adsorvido na coluna e $60 \%$ do ${ }^{68} \mathrm{Ga}$ foi eluído. Não foi detectada contaminação de ${ }^{68} \mathrm{Ge}$ no eluato. Na segunda coluna, a solução de EDTA $0,005 \mathrm{~mol} \mathrm{~L}^{-1}$ foi substituída por $\mathrm{NaCl} 0,9 \%$ em todas as etapas do preparo. ${ }^{68} \mathrm{Ge}$ ficou adsorvido na coluna, porém a eluição do ${ }^{68} \mathrm{Ga}$ foi nula (KOPECKÝ et al., 1973).

Kopecký e Mudrová em 1974 avaliaram a adsorção do ${ }^{68} \mathrm{Ge} \mathrm{e} \mathrm{do}{ }^{68} \mathrm{Ga}$ nos seguintes materiais: $\mathrm{Al}_{2} \mathrm{O}_{3}$ básica, $\mathrm{Al}(\mathrm{OH})_{3}$ e $\mathrm{Fe}(\mathrm{OH})_{3}$. Os melhores resultados foram obtidos com a $\mathrm{Al}_{2} \mathrm{O}_{3}$ básica. O rendimento de eluição do ${ }^{68} \mathrm{Ga}$ foi de $64 \%$ em HCl 0,2 mol L-1 e a contaminação do ${ }^{68} \mathrm{Ge}$ no eluato foi de $2 \times 10^{-3} \%$. Avaliouse a esterilização da coluna a $120{ }^{\circ} \mathrm{C}$ por 20 minutos. Após esse procedimento ocorreu uma redução da eluição de ${ }^{68} \mathrm{Ga}$, passando de $64 \%$ para 48,5 \%. Não foi observada alteração no nível de contaminação de ${ }^{68} \mathrm{Ge}$ no eluato (KOPECKÝ e MUDROVÁ, 1974).

Em 1975, Malyshev e Smirnov estudaram o comportamento químico do ${ }^{68} \mathrm{Ge}$ e do ${ }^{68} \mathrm{Ga}$ separadamente nos materiais adsorvedores hidróxido de zircônio, estanho e titânio. A adsorção do ${ }^{68} \mathrm{Ge}$ nos materiais foi estudada sob condições estáticas, onde uma solução de $10 \mathrm{~mL}$ contendo ${ }^{68} \mathrm{Ge}$ foi adicionada em 50 a $150 \mathrm{mg}$ de cada material adsorvedor. Como solução eluente foram 
utilizados $\mathrm{HCl}$ e ácido nítrico, variando o $\mathrm{pH}$ de 1 a 5 . O tempo de contato dos materiais adsorvedores com cada solução foi de três dias. O melhor resultado de adsorção do ${ }^{68} \mathrm{Ge}$ pelos materiais foi alcançado com pH 3 a 4 . O comportamento do ${ }^{68} \mathrm{Ga}$ nos materiais foi avaliado de modo dinâmico. $\mathrm{O}$ rendimento de eluição do ${ }^{68} \mathrm{Ga}$ em HCl $0,1 \mathrm{~mol} \mathrm{~L}^{-1}$ da coluna contendo zircônio foi de $35 \%$ e da coluna contendo estanho foi de $20 \%$. O material escolhido para o preparo do gerador de ${ }^{68} \mathrm{Ge} /{ }^{68} \mathrm{Ga}$ foi o zircônio. Foi utilizada uma coluna de teflon com $10 \mathrm{~mm}$ de diâmetro e $70 \mathrm{~mm}$ de altura, contendo $10 \mathrm{~g}$ de hidróxido de zircônio, que foi condicionado com $\mathrm{HCl} 0,1 \mathrm{~mol} \mathrm{~L}^{-1}$. A solução carga de ${ }^{68} \mathrm{Ge}$ foi preparada com 5 $\mathrm{mL}$ de $\mathrm{HCl} 0,1 \mathrm{~mol} \mathrm{~L}^{-1}$ e atividade de $3,7 \mathrm{MBq}$ ( 0,1 mCi). O tempo para percolação da solução na coluna foi de 1 hora. $\mathrm{O}$ rendimento de eluição do ${ }^{68} \mathrm{Ga}$ foi de $35 \%$ e a contaminação de ${ }^{68} \mathrm{Ge}$ no eluato foi de $3 \times 10^{-2}$ a $6 \times 10^{-3} \%$ (MALYSHEV e SMIRNOV, 1975).

Em 1978, Arino et al. preparam um sistema de gerador de ${ }^{68} \mathrm{Ge} /{ }^{68} \mathrm{Ga}$ utilizando ácido poliantiamônico como material adsorvedor. Em um recipiente de plástico foi colocado $0,5 \mathrm{~g}$ do material previamente lavado com água. Foi adicionado a esse recipiente, $5 \mathrm{~mL}$ de uma solução de ${ }^{68} \mathrm{GeCl}_{4}$ em HCl $3 \mathrm{~mol} \mathrm{~L}^{-1}$ contendo um reagente quelante ( $\mathrm{Na}_{2}$ EDTA \%, pH 8,5; citrato de amônia $2 \%, \mathrm{pH}$ $8,5$ ou oxalato de sódio $2 \%, \mathrm{pH} 8,5$; oxalato de amônia $2 \%, \mathrm{pH} 8,5) . \mathrm{O}$ pH das soluções foi ajustado com $\mathrm{NaOH}$. As soluções finais foram agitadas e ficaram reagindo até o dia seguinte. Colunas foram montadas com $15 \mathrm{mg}$ do material e o ${ }^{68} \mathrm{Ga}$ foi eluído com uma solução quelante. A solução quelante de oxalato de sódio foi a mais eficiente para promover a adsorção do ${ }^{68} \mathrm{Ge}(95 \%)$ e eluição do ${ }^{68} \mathrm{Ga}(87 \%)$. Neste sistema de gerador $0{ }^{68} \mathrm{Ga}$ é eluído como um complexo estável com o oxalato. A contaminação do ${ }^{68} \mathrm{Ge}$ no eluato foi de $5 \times 10^{-2} \%$ (ARINO et al., 1978).

Em 1979, Neirinckx e Davis avaliaram a separação do ${ }^{68} \mathrm{Ge}$ e do ${ }^{68} \mathrm{Ga}$ utilizando como materiais adsorvedores $\mathrm{TiO}_{2}$ (rutilo), $\mathrm{ZrO}_{2}$ e SiO 2 . Os coeficientes de distribuição para $\circ \mathrm{Ge}$ e $\circ \mathrm{Ga}$ nos três materiais foram determinados como uma função da concentração do reagente e duração do equilíbrio. $O$ coeficiente de distribuição (w/w) para o $\mathrm{Ge} \mathrm{no} \mathrm{SiO}_{2}$ foi de 250 em $\mathrm{HNO}_{3} 6 \mathrm{~mol} \mathrm{~L}^{-1}$, enquanto que o Ga não apresentou adsorção significativa no material, podendo ser coletado com um volume reduzido de $\mathrm{HNO}_{3} 6 \mathrm{~mol} \mathrm{~L} \mathrm{~L}^{-1}$. Nos estudos com o $\mathrm{ZrO}_{2}$ foram 
necessários volumes maiores de $\mathrm{HNO}_{3} 1 \mathrm{~mol} \mathrm{~L}^{-1}$ para coleta do ${ }^{68} \mathrm{Ga}$, que ainda assim apresentou coeficiente de distribuição de aproximadamente $50 . \mathrm{O}^{68} \mathrm{Ga}$ eluído do $\mathrm{TiO}_{2}$ ficou contaminado quimicamente com titanatos e necessitaria de procedimentos químicos adicionais para sua utilização (NEIRINCKX e DAVIS, 1979).

Em 1980, Loc'h e Comar prepararam um gerador de ${ }^{68} \mathrm{Ge} /{ }^{68} \mathrm{Ga}$ utilizando $\mathrm{SnO}_{2}$ como material adsorvedor. Foram montadas colunas com 2, 3 e 5 $\mathrm{g}$ de $\mathrm{SnO}_{2}$. A solução carga de ${ }^{68} \mathrm{Ge}$ percolada na coluna foi de $370 \mathrm{kBq}(10 \mu \mathrm{Ci})$ em $50 \mathrm{~mL}$ de $\mathrm{HCl} 1 \mathrm{~mol} \mathrm{~L}^{-1}$ contendo $100 \mu \mathrm{g}$ de carregador de Ge. A eficiência de eluição do gerador foi estudada variando a concentração do $\mathrm{HCl}$ de 1 a $8 \mathrm{~mol} \mathrm{~L}^{-1}$. $\mathrm{O}$ aumento da concentração do $\mathrm{HCl}$ melhorou a eficiência de eluição do ${ }^{68} \mathrm{Ga}$, porém resultou em uma maior contaminação de ${ }^{68} \mathrm{Ge}$. A eficiência de eluição das colunas contendo $3 \mathrm{~g}$ do material adsorvedor e eluídas com $\mathrm{HCl} 1 \mathrm{~mol} \mathrm{~L}^{-1}$ foi de aproximadamente $80 \%$. O rendimento de eluição obtido com $2,5 \mathrm{~mL}$ foi de $75 \%$. Foi realizada a simulação de 500 eluições feitas com $5 \mathrm{~mL}$ de $\mathrm{HCl} 1 \mathrm{~mol} \mathrm{~L}^{-1} \mathrm{e}$ após esse estudo o rendimento de eluição do ${ }^{68} \mathrm{Ga}$ permaneceu $>74 \%$. Foi realizada uma autoradiografia da coluna para avaliar a posição do ${ }^{68} \mathrm{Ge}$ após a simulação das 500 eluições e foi observado que a maior atividade permanecia nos dois terços superiores da coluna. A contaminação de ${ }^{68} \mathrm{Ge}$ no eluato foi de $10^{-4} \%$. Não foi observado mudança na eficiência de eluição ao deixar a coluna seca ou um mês sem ser eluída. O rendimento da eluição não foi influenciado pela vazão utilizada na eluição do ${ }^{68} \mathrm{Ga}$. A contaminação química do eluato foi avaliada por ativação neutrônica e os elementos quantificados foram: $\mathrm{Sn}, \mathrm{Ba}, \mathrm{Co}$, $\mathrm{Cr}, \mathrm{Fe}, \mathrm{Hg}, \mathrm{Sb}$ e Sn. Após a simulação das 500 eluições foi observada contaminação de $\mathrm{Sn}$ no eluato de $0,5 \mu \mathrm{g} \mathrm{mL}^{-1}$. Os valores encontrados para os outros elementos foram menores do que o valor encontrado para o $\mathrm{Sn}$ (LOC'H e COMAR, 1980).

Neirinckx e Davis em 1980 propuseram um gerador de ${ }^{68} \mathrm{Ge} /{ }^{68} \mathrm{Ga}$ utilizando uma resina orgânica de troca aniônica (AG1-X8) como material adsorvedor na coluna e solução de $\mathrm{HF} 0,01 \mathrm{~mol} \mathrm{~L}^{-1}$ como solução eluente. $\mathrm{O}$ rendimento de eluição do ${ }^{68} \mathrm{Ga}$ foi de $90 \%$ e a contaminação do ${ }^{68} \mathrm{Ge}$ foi de $10^{-2}$ $\%$ (NEIRINCKX e DAVIS, 1980). 
Schuhmacher e Maier-Borst em 1980 sintetizaram uma resina orgânica de troca iônica preparada com pirogalol e formaldeido, que são eficientes na adsorção do ${ }^{68} \mathrm{Ge}$ em soluções de $\mathrm{HCl}$. O gerador foi preparado com essa resina e eluído com $10 \mathrm{~mL}$ de $\mathrm{HCl}$ 4,5 mol L-1, apresentando rendimento de $75 \mathrm{a}$ $80 \%$ de eluição do ${ }^{68} \mathrm{Ga}$ durante um período de 200 dias. A contaminação de ${ }^{68} \mathrm{Ge}$ foi $<1 \times 10^{-4} \%$. A coluna do gerador foi acoplada em série com outra coluna contendo resina comercial (BioRad) de troca aniônica, onde o ${ }^{68} \mathrm{Ga}$ ficava retido e era eluído com $4 \mathrm{~mL}$ de $\mathrm{HCl}$ 0,5 mol L-1 (SCHUHMACHER e BORST, 1980).

Em 1982, Neirinckx et al. sintetizaram uma resina orgânica com pirogalol e formaldeído e prepararam um gerador de ${ }^{68} \mathrm{Ge} /{ }^{68} \mathrm{Ga}$. As constantes de distribuição entre a resina e a solução de $\mathrm{HCl} \mathrm{0,3} \mathrm{mol} \mathrm{L}^{-1}$ foram 0,5 para o ${ }^{68} \mathrm{Ga} e$ mais de 5000 para o ${ }^{68} \mathrm{Ge}$. O rendimento de eluição do ${ }^{68} \mathrm{Ga}$ foi de $60 \%$ com 3 a $6 \mathrm{~mL}$ de $\mathrm{HCl} \mathrm{0,3} \mathrm{mol} \mathrm{L}^{-1}$ e a contaminação do ${ }^{68} \mathrm{Ge}$ foi de $10^{-2} \%$ (NEIRINCKX et al., 1982).

Em 1988, Ambe avaliou a adsorção do ${ }^{68} \mathrm{Ge}$ em quatro materiais adsorvedores: $\alpha-\mathrm{Fe}_{2} \mathrm{O}_{3}$, oxido de cromo, carbono ativado e grafite. Apenas o $\alpha$ $\mathrm{Fe}_{2} \mathrm{O}_{3}$ foi considerado adequado para o preparo do gerador. $\mathrm{O}$ rendimento de eluição do ${ }^{68} \mathrm{Ga}$ foi de 50 a $70 \%$ com solução de $\mathrm{HCl}$ pH 2. A contaminação de ${ }^{68} \mathrm{Ge}$ foi de $6 \times 10^{-4}$ a $2 \times 10^{-2} \%$. Os níveis de contaminação por Fe foram menores que $0,03 \mu \mathrm{g} \mathrm{mL}^{-1}$ (AMBE, 1988).

Benhong et al. em 1998 estudaram a adsorção do ${ }^{68} \mathrm{Ge}$ e do ${ }^{68} \mathrm{Ga}$ em três tipos de óxido de ferro: óxido de ferro (I), oxido de ferro (II) e óxido de ferro (III). $\mathrm{O} \alpha-\mathrm{Fe}_{2} \mathrm{O}_{3}$ com estrutura cristalina trigonal apresentou melhor resultado para o preparo do gerador de ${ }^{68} \mathrm{Ge} /{ }^{68} \mathrm{Ga}$. O rendimento de eluição do ${ }^{68} \mathrm{Ga}$ foi de $90 \%$ em $1 \mathrm{~mL}$ de $\mathrm{HCl} 0,05 \mathrm{~mol} \mathrm{~L}{ }^{-1}$ e a contaminação de ${ }^{68} \mathrm{Ge}$ foi $<1,8 \times 10^{-2} \%$ (BENHONG et al., 1998).

Em 2000, Egamediev et al. estudaram a influência do tratamento térmico e do condicionamento da $\mathrm{Al}_{2} \mathrm{O}_{3}$ na adsorção do ${ }^{68} \mathrm{Ge}$ e ${ }^{68} \mathrm{Ga}$. As temperaturas de calcinação estudadas foram 400 e $1000{ }^{\circ} \mathrm{C}$. As soluções estudadas para o condicionamento do material foram $\mathrm{HCl} 0,1 \mathrm{~mol} \mathrm{~L}^{-1}, \mathrm{NaOH} 0,1$ mol $L^{-1}$ e a combinação de ambas soluções. O melhor resultado no estudo do tratamento térmico foi obtido com a $\mathrm{Al}_{2} \mathrm{O}_{3}$ calcinada a $1000{ }^{\circ} \mathrm{C}$. O rendimento de eluição do ${ }^{68} \mathrm{Ga}$ foi de $62 \%$ em $2 \mathrm{~mL}$ de $\mathrm{HCl} 0,1 \mathrm{~mol} \mathrm{~L}^{-1}$ e a adsorção do ${ }^{68} \mathrm{Ge}$ foi 
de $96 \%$, porém após a passagem de $300 \mathrm{~mL}$ de $\mathrm{HCl} 0,1 \mathrm{~mol} \mathrm{~L}^{-1}$ pela coluna, o nível de contaminação de ${ }^{68} \mathrm{Ge}$ no eluato permaneceu constante com o valor de $10^{-3} \%$. Nos experimentos que avaliaram as soluções utilizadas para o condicionamento da $\mathrm{Al}_{2} \mathrm{O}_{3}$, os melhores resultados para separação do ${ }^{68} \mathrm{Ge}$ e do ${ }^{68} \mathrm{Ga}$ foram obtidos com o condicionamento do material feito com $\mathrm{NaOH} 0,1 \mathrm{~mol}$ $\mathrm{L}^{-1}$ e em seguida $\mathrm{HCl} 0,1 \mathrm{~mol} \mathrm{~L}^{-1}$. O rendimento de eluição do ${ }^{68} \mathrm{Ga}$ foi de $55 \%$ em $3 \mathrm{~mL}$ e o nível de contaminação de ${ }^{68} \mathrm{Ge}$ foi de $2 \times 10^{-4} \%$. Após 100 eluições o rendimento obtido foi de $50 \%$ e o nível de contaminação de ${ }^{68} \mathrm{Ge}$ permaneceu igual. (EGAMEDIEV et al., 2000).

Em 2002, Nakayama et al. estudaram o comportamento químico do ${ }^{68} \mathrm{Ge}$ e do ${ }^{68} \mathrm{Ga}$ em sete resinas orgânicas diferentes, quatro eram comerciais e três foram sintetizadas em laboratório. Foram avaliadas doze soluções diferentes para eluição. A resina que apresentou melhor resultado no preparo do gerador de ${ }^{68} \mathrm{Ge} /{ }^{68} \mathrm{Ga}$ foi a resina Diaion CRB-02, que é um polímero orgânico contendo grupos N-metilglucamina (R-MGlu). Uma coluna de plástico com $5 \mathrm{~mm}$ de diâmetro foi carregada com $1 \mathrm{~mL}$ da resina (300 mg de resina seca) e $2 \mathrm{~mL}$ de tampão fosfato $0,01 \mathrm{~mol} \mathrm{~L}^{-1}$ contendo $370 \mathrm{kBq}(10 \mathrm{mCi})$ de ${ }^{68} \mathrm{Ge}(\mathrm{pH}=7)$. A vazão utilizada para percolação da solução carga de ${ }^{68} \mathrm{Ge}$ foi de $0,5 \mathrm{~mL} \mathrm{~min}{ }^{-1}$. Após lavagem da coluna com água deionizada, $0^{68} \mathrm{Ga}$ foi eluído com solução de citrato de sódio $0,1 \mathrm{~mol} \mathrm{~L}^{-1}$. O rendimento de eluição foi de $90 \%$ e a contaminação de ${ }^{68} \mathrm{Ge}$ foi de $4 \times 10^{-4} \%$ (NAKAYAMA et al., 2002).

Em 2005, Aardaneh e Walt estudaram a influência da temperatura de calcinação e tamanho de partícula do $\mathrm{SnO}_{2}$ para o preparo do gerador de ${ }^{68} \mathrm{Ge} /{ }^{68} \mathrm{Ga}$. Foi avaliado também a concentração do $\mathrm{HCl}$ utilizado para eluição $\left(0,5 ; 1,0 ; 2,0\right.$ e 4,0 mol L-1). Para realização dos experimentos foi utilizado $\mathrm{SnO}_{2}$ não calcinado e $\mathrm{SnO}_{2}$ calcinado a 450,700 e $900{ }^{\circ} \mathrm{C}$ (por 3 horas). $\mathrm{O}$ melhor rendimento de eluição do ${ }^{68} \mathrm{Ga}(65 \%)$ foi obtido com o gerador preparado com $\mathrm{SnO}_{2}$ calcinado a $900{ }^{\circ} \mathrm{C}$, utilizando $\mathrm{HCl} 1 \mathrm{~mol} \mathrm{~L}^{-1}$ como solução eluente. Foi observado que a variação no tamanho da partícula do óxido, alterou os nível de contaminação do ${ }^{68} \mathrm{Ge}$ no eluato. Quando o $\mathrm{SnO}_{2}(2 \mathrm{~g})$, contido na coluna, com granulometria de 100-300 $\mu \mathrm{m}$ foi substituído pelo óxido com 100-150 $\mu \mathrm{m}$, a contaminação de ${ }^{68} \mathrm{Ge}$ foi reduzida de $2,6 \times 10^{-2} \%$ para $6,1 \times 10^{-4} \%$. 
Em 2010, Chakravarty et al. desenvolveram um gerador de ${ }^{68} \mathrm{Ge} /{ }^{68} \mathrm{Ga}$ utilizando como material adsorvedor um composto nanocristalino de ceriapoliacrilonitrilo (nanoceria-PAN). O material foi sintetizado em laboratório. Para o preparo do gerador, foi utilizada uma coluna de vidro $(15 \mathrm{~cm} \times 0,4 \mathrm{~cm})$ contendo $0,5 \mathrm{~g}$ do adsorvedor, que foi condicionado com $100 \mathrm{~mL}$ de solução de $\mathrm{HCl} 0,001$ mol $\mathrm{L}^{-1}(\mathrm{pH}=3)$. A vazão para o condicionamento foi de $2 \mathrm{~mL} \mathrm{~min}^{-1}$. A solução carga $(20 \mathrm{~mL})$ contendo $370 \mathrm{MBq}(10 \mathrm{mCi})$ de ${ }^{68} \mathrm{Ge}$, em pH 3, foi percolada na coluna com vazão de $0,25 \mathrm{~mL} \mathrm{~min}{ }^{-1}$. A eluição do ${ }^{68} \mathrm{Ga}$ foi feita com $\mathrm{HCl} 0,01 \mathrm{~mol}$ $\mathrm{L}^{-1}(\mathrm{pH}=2)$ e o rendimento de eluição foi de $95 \%$ em $3 \mathrm{~mL}$. Após sete meses, o rendimento de eluição do ${ }^{68} \mathrm{Ga}$ foi de $82 \%$. O nível de impureza do ${ }^{68} \mathrm{Ge}$ no eluato durante os sete meses de estudo foi de $10^{-5} \%$. Os níveis de impurezas químicas foram $<0,1 \mu \mathrm{g} \mathrm{mL}^{-1}$ para Ce, Fe e Mn. Além de pureza radionuclídica e química, o eluato não apresentou nenhum produto orgânico (CHAKRAVARTY et al., 2010)

Sen et al. em 2011 avaliaram as propriedades de adsorção de alguns materiais adsorvedores inorgânicos, variando as concentrações de $\mathrm{HCl}$ e $\mathrm{HNO}_{3}$ para $\circ \mathrm{Ge}$ e $\circ \mathrm{Ga}$, com o objetivo de selecionar um material com potencial para o preparo de geradores de ${ }^{68} \mathrm{Ge} /{ }^{68} \mathrm{Ga}$. Os materiais avaliados foram o $\mathrm{TiO}_{2}, \mathrm{SnO}_{2}$, $\mathrm{Al}_{2} \mathrm{O}_{3}, \mathrm{SiO}_{2}, \mathrm{ZnO}$ e zeolitas. Foram realizados estudos de adsorção estáticos, onde $100 \mu \mathrm{L}$ de uma solução contendo Ge e $\mathrm{Ga}\left(0,1 \mu \mathrm{g} \mathrm{mL}^{-1}\right)$ foi adicionado em $100 \mathrm{mg}$ de cada material adsorvedor, previamente condicionados. Além da variação da concentração do $\mathrm{HCl}$ e do $\mathrm{HNO}_{3}$, para alguns materiais como $\mathrm{TiO}_{2} \mathrm{e}$ $\mathrm{SiO}_{2}$, foram estudadas as influências do tamanho da partícula e estrutura cristalina do material em relação ao seu poder de adsorção. Foi observado que a zeolita pode oferecer condições favoráveis para uso em sistemas de geradores de ${ }^{68} \mathrm{Ge} /{ }^{68} \mathrm{Ga}$ em solução de $\mathrm{HCl} \mathrm{pH}$ 1. Concluiu-se que o $\mathrm{TiO}_{2}$ (P-25 Degussa), que contem as fases cristalinas anatase e rutilo em proporção 3:1 pode promover a separação do $\mathrm{Ge}$ e do $\mathrm{Ga}$ em $\mathrm{HCl} \operatorname{com} \mathrm{pH}$ 1. Estudos individuais com $\mathrm{TiO}_{2}$ anatase e $\mathrm{TiO}_{2}$ rutilo não apresentaram bons resultados para serem utilizados no preparo do gerador (SEN et al., 2011).

Em 2011, Chakravarty et al. desenvolveram um gerador de ${ }^{68} \mathrm{Ge} /{ }^{68} \mathrm{Ga}$ utilizando nano-zircônia como material adsorvedor na coluna. Foi utilizada uma coluna de vidro com dimensões de $8 \times 0,6 \mathrm{~cm}$ contendo $1 \mathrm{~g}$ do material adsorvedor, que foi previamente condicionado com $\mathrm{HCl} 0,01 \mathrm{~mol} \mathrm{~L}^{-1}$. A ilustração 
do esquema de montagem do gerador está apresentada na FIG. 1.10. O gerador foi desenvolvido com um sistema fechado, utilizando-se tubos de conexão. Conexões de entrada e saída foram feitas com tubos de Teflon padrão com $1 \mathrm{~mm}$ de diâmetro interno e conectores. A coluna do gerador, tubos de conexão e conectores foram colocados dentro de uma blindagem de chumbo. Um filtro de $0,22 \mu \mathrm{m}$ foi conectado na saída da coluna do gerador por tubo de Teflon. A solução carga contendo $740 \mathrm{MBq}(20 \mathrm{mCi})$ de ${ }^{68} \mathrm{Ge}$, em pH 2, foi percolada na coluna com uma vazão de $0,25 \mathrm{~mL} \mathrm{~min}^{-1}$. A coluna carregada com ${ }^{68} \mathrm{Ge}$ foi seca sob vácuo por 1 minuto e lavada com $100 \mathrm{~mL}$ de $\mathrm{HCl} 0,01 \mathrm{~mol} \mathrm{~L}^{-1}$. A eluição do ${ }^{68} \mathrm{Ga}$ foi realizada regularmente com $2 \mathrm{~mL}$ de $\mathrm{HCl} \mathrm{0,01} \mathrm{mol} \mathrm{L}^{-1}$. O desempenho do gerador foi avaliado por aproximadamente 1 ano por eluições diárias, realizadas com intervalo de 24 horas e durante esse período a eficiência de eluição do ${ }^{68} \mathrm{Ga}$ foi $>80 \%$ e o nível de contaminação de ${ }^{68} \mathrm{Ge}$ no eluato foi $<10^{-5} \%$. O perfil de eluição foi avaliado pela coleta de frações de $0,5 \mathrm{~mL}$. Observou-se que menos de $2 \%$ do ${ }^{68} \mathrm{Ga}$ é eluído na fração de $1 \mathrm{~mL}$ e mais de $90 \%$ do ${ }^{68} \mathrm{Ga}$ é eluído nos próximos $2 \mathrm{~mL}$ de eluente. Com o propósito de se obter uma concentração radioativa maior de ${ }^{68} \mathrm{Ga}$, a primeira fração de $1 \mathrm{~mL}$, de todas as eluições, foi descartada. As impurezas químicas como $\mathrm{Zr}$, $\mathrm{Fe}$ e $\mathrm{Mn}$ foram $<0,1 \mu \mathrm{g} \mathrm{mL}^{-1}$. Como método de controle de qualidade do produto obtido, foi realizada marcação do DOTATATO com o ${ }^{68} \mathrm{Ga}$ eluído do gerador e o rendimento de marcação foi > 99 $\%$. 


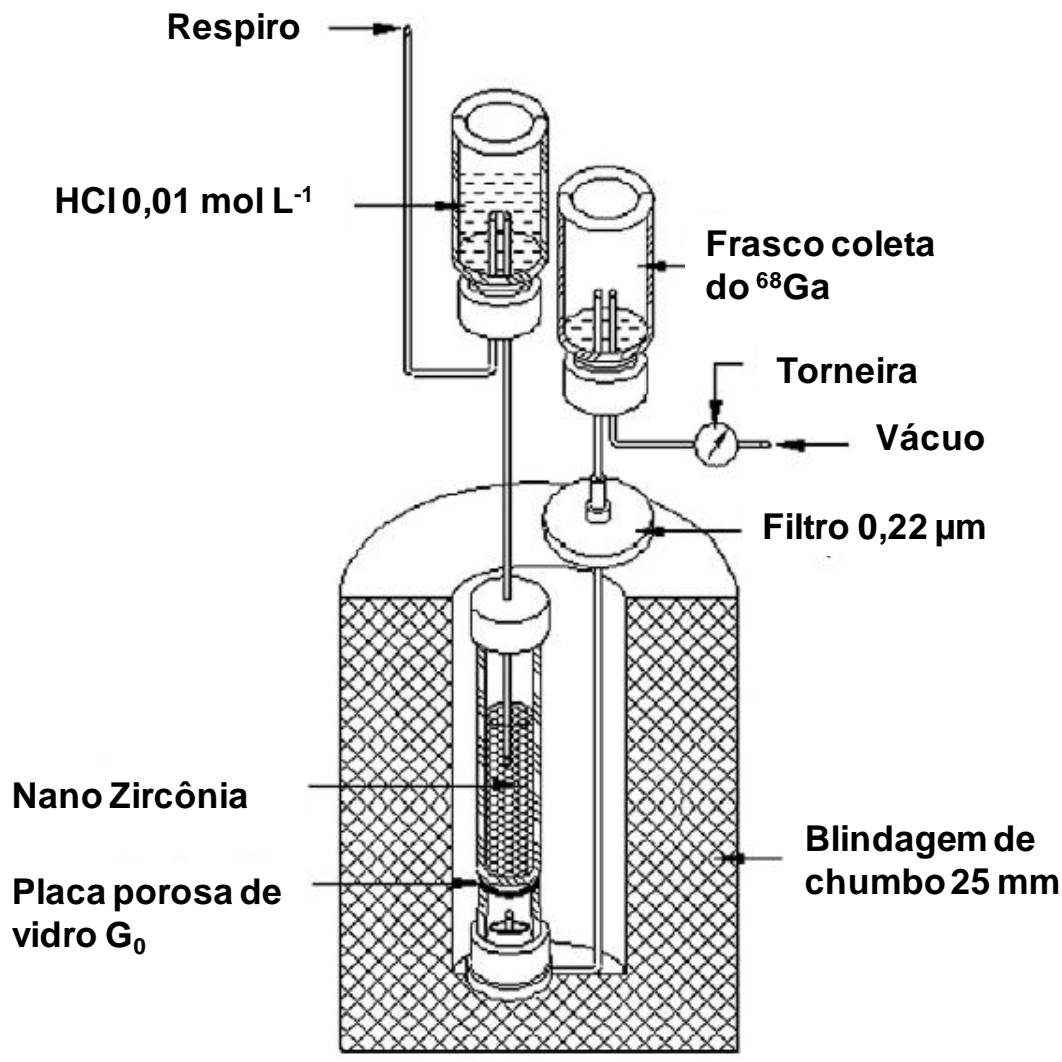

FIGURA 1.10 - Esquema de montagem do gerador de ${ }^{68} \mathrm{Ge} /{ }^{68} \mathrm{Ga}$ proposto por Chakravarty et al em 2011.

\subsection{Revisão bibliográfica sobre o controle radionuclídico do eluato de ${ }^{68} \mathrm{Ga}$}

Uma das análises para avaliar a qualidade do eluato de um sistema de geradores de radionuclídeo é a determinação da pureza radionuclídica do produto. Um dos primeiros trabalhos encontrados na literatura que estudou a determinação da pureza radionuclídica do ${ }^{68} \mathrm{Ga}$ eluído dos geradores de ${ }^{68} \mathrm{Ge} /{ }^{68} \mathrm{Ga}$ foi descrito por Barrall et al. em 1971. Amostras de eluições foram analisadas por espectrometria gama, utilizando detectores de $\mathrm{Nal}(\mathrm{Tl})$ e $\mathrm{Ge}(\mathrm{Li})$. O único radionuclídeo encontrado como impureza nas amostras foi o ${ }^{68} \mathrm{Ge}$. Como o processo de decaimento radioativo do ${ }^{68} \mathrm{Ge}$ não gera fótons de energias mensuráveis, as amostras das eluições foram analisadas dias após a eluição, para permitir o decaimento da atividade inicial do ${ }^{68} \mathrm{Ga}$. Através do equilíbrio secular do par radioativo foi possível avaliar a atividade de ${ }^{68} \mathrm{Ge}$ nas amostras pela determinação do ${ }^{68} \mathrm{Ga}$ (BARRALL et al., 1971).

Pesquisas estão sendo realizadas visando a criação de um novo método de avaliação mais rápida da impureza de ${ }^{68} \mathrm{Ge}$. 
A separação do $\mathrm{Ga}$ e do $\mathrm{Ge}$ pode ser feita por cromatografia em camada delgada, utilizando fita TLC como fase estacionária e $\mathrm{HCl}$-acetona (1:1) como fase móvel. $O \mathrm{R}_{\mathrm{f}}$ (fator de retardamento) de cada espécie nesse sistema está ilustrado na FIG 1.11 em função da concentração do HCl utilizado. Em 1996, Mirzadeh e Lambrecht já sugeriram o uso desse sistema como método de avaliação da pureza radionuclídica do eluato de ${ }^{68} \mathrm{Ga}$, em qualquer concentração de $\mathrm{HCl}$.
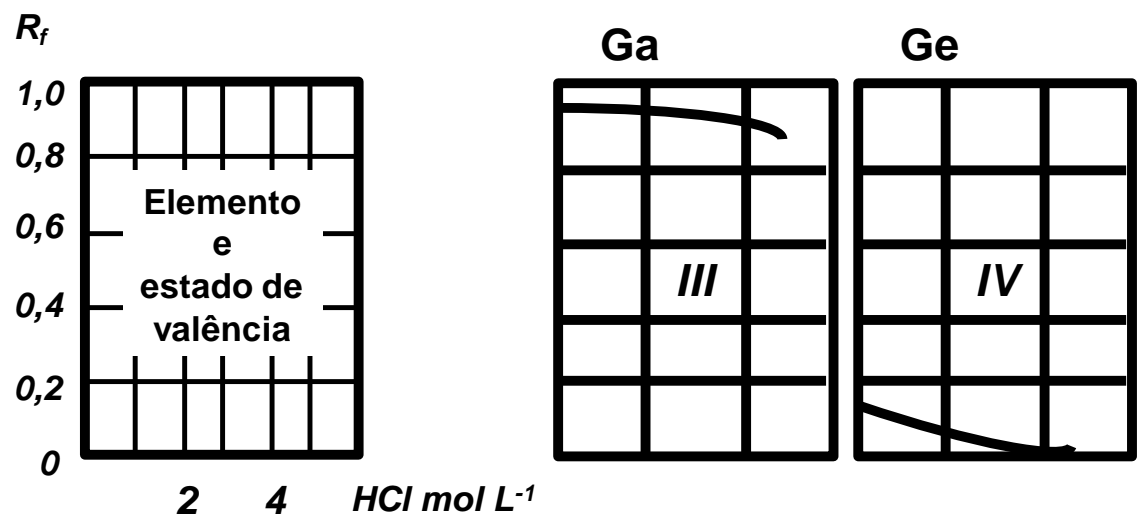

FIGURA 1.11 - $R_{f}$ do $\mathrm{Ga}$ e do $\mathrm{Ge}$ em $\mathrm{HCl}$-acetona (1:1) na sílica gel (KSK) (VOLYNETS et al., 1970).

Em 2012 Eppard et al. utilizaram sistemas de fitas cromatográficas para determinar a pureza radioquímica e radionuclídica do radiofármaco DOTATOC- ${ }^{68} \mathrm{Ga}$. Utilizaram fitas TLC com $\mathrm{HCl} 2 \mathrm{~mol} \mathrm{~L}-1 /$ acetona (1:1) como solvente e conseguiram separar $0{ }^{68} \mathrm{Ga},{ }^{68} \mathrm{Ge}$ e $\mathrm{o}$ produto marcado, com os seguintes Rf: ${ }^{68} \mathrm{Ge}=0,1 ;{ }^{68} \mathrm{Ga}=1$ e DOTATOC ${ }^{68} \mathrm{Ga}=0,4$.

Em 2013, a Farmacopeia Europeia determinou que a análise da pureza radionuclídica do ${ }^{68} \mathrm{Ga}$ deve ser feita por espectrometria gama e que a medida da atividade do ${ }^{68} \mathrm{Ga}$, vindo do decaimento do ${ }^{68} \mathrm{Ge}$, tem que ser feita 48 horas após a data da eluição. O limite permissível de atividade de ${ }^{68} \mathrm{Ge}$ é de $10^{-3} \%$ da atividade do ${ }^{68} \mathrm{Ga}$ (EUROPEAN DIRECTORATE FOR THE QUALITY OF MEDICINES AND HEALTHCARE, 2013). Não foi indicado em que tempo de calibração esse limite deve ser seguido.

Eppard et al. em 2013 propuseram um novo método para análise da pureza radionuclídica do eluato de ${ }^{68} \mathrm{Ga}$, que consiste na separação do ${ }^{68} \mathrm{Ga}$ e ${ }^{68} \mathrm{Ge}$, utilizando resinas de troca catiônica. $\mathrm{O}{ }^{68} \mathrm{Ga}$ é quantitativamente separado 
do ${ }^{68} \mathrm{Ge}$ e 0 nível de contaminação de ${ }^{68} \mathrm{Ge}$ no eluato do gerador pode ser quantificado em pouco tempo, através do crescimento da atividade do ${ }^{68} \mathrm{Ga}$ na fração de ${ }^{68} \mathrm{Ge}$ purificada pela resina (EPPARD et al., 2013). 


\section{OBJETIVOS}

O objetivo principal deste trabalho foi desenvolver um sistema de gerador de ${ }^{68} \mathrm{Ge} /{ }^{68} \mathrm{Ga}$ com o qual se pudesse eluir $0{ }^{68} \mathrm{Ga}$ com qualidade necessária para uso clínico.

Os objetivos específicos deste trabalho foram:

$\checkmark$ Estudar o comportamento químico do Ge e do Ga em diferentes materiais adsorvedores.

$\checkmark$ Escolher, dentre os materiais estudados, aquele com maior potencial para o desenvolvimento de geradores de ${ }^{68} \mathrm{Ge} /{ }^{68} \mathrm{Ga}$.

$\checkmark$ Estudar a eficiência dos sistemas de geradores desenvolvidos comparando com os comerciais.

$\checkmark$ Desenvolver um novo método para o controle radionuclídico do ${ }^{68} \mathrm{Ga}$. 


\section{JUSTIFICATIVA}

O Centro de Radiofarmácia do IPEN-CNEN/SP tem como missão a produção de radioisótopos e radiofármacos para uso em Medicina Nuclear. Além dos seus 38 produtos em catálogo, esforços são feitos para trazer à classe médica brasileira, novos radiofármacos, tanto para uso diagnóstico como terapêutico. O IPEN foi o pioneiro no Brasil na produção e distribuição dos primeiros radiofármacos para uso em diagnóstico pela técnica PET. Hoje são produzidos rotineiramente $\mathrm{FDG}-{ }^{18} \mathrm{~F}$ e Fluoreto- ${ }^{18} \mathrm{~F}$, sendo que $\mathrm{o}$ primeiro foi responsável pela implantação e sucesso dessa técnica no Brasil, levando inclusive à quebra do monopólio de produção de radioisótopos de meia vida menor que 2 horas. Os esforços agora estão voltados para a produção de novos radionuclídeos emissores de pósitron e novos radiofármacos preparados com eles. Neste sentido, $0{ }^{68} \mathrm{Ga}\left(\mathrm{t}_{1 / 2}=1,13 \mathrm{~h}\right)$ tem se apresentado no mundo inteiro como potencialmente o ${ }^{99 \mathrm{~m}} \mathrm{Tc}$ dos emissores de pósitrons, devido a sua facilidade de marcação de moléculas, principal desvantagem do ${ }^{18} \mathrm{~F}$, cuja química de marcação é complexa e de baixos rendimentos. $0{ }^{68} \mathrm{Ga}$ apresenta outra grande vantagem, ser produzido na forma de gerador, através do decaimento do seu pai radioativo, $0{ }^{68} \mathrm{Ge}\left(\mathrm{t}_{1 / 2}=271\right.$ dias$)$, o que compensa a sua meia-vida curta e permite o uso em clinicas nos mais diversos locais do país. Já existe uma demanda reprimida de biomoléculas marcadas $\mathrm{com}^{68} \mathrm{Ga}$, em particular análogos da somatostatina, como o octreotato, e outros peptídeos. O presente projeto visou a produção nacional deste gerador de ${ }^{68} \mathrm{Ge} /{ }^{68} \mathrm{Ga}$ com a qualidade necessária para marcação de biomoléculas. 


\section{MATERIAIS E MÉTODOS}

\subsection{Infraestrutura}

A parte experimental da pesquisa foi realizada nos laboratórios do Centro de Radiofarmácia (CR) do IPEN-CNEN/SP. As análises de caracterização dos materiais adsorvedores foram realizadas no Centro de Ciências e Tecnologia dos Materiais (CCTM) do IPEN-CNEN/SP e na Central Analítica do Instituto de Química da Universidade de São Paulo.

\subsection{Materiais}

\subsubsection{Equipamentos e softwares}

* Balança analítica, modelo AUW 220, Shimadzu, Japão

* Balança semi-analítica, modelo EB - 2200HU, Shimadzu, Japão

* Estufa, modelo Orion 515, Fanem São Paulo, Brasil

* Forno mufla, modelo EDG3P-S, EDG Equipamentos

* Chapa de aquecimento com agitador, modelo C-MAG H57, IKA

* pH-metro, modelo DM-20, DIGIMED, Brasil

* Peneira, Bertel Indústria Metalúrgica Ltda, Brasil

* Calibrador de dose, CRC - 10BC, Capintec Inc., EUA

* Espectrômetro de radiação gama constituído de um detector de germânio hiperpuro (HPGe), modelo GX1518, acoplado a um sistema de aquisição multicanal da Canberra Inc., EUA. Software: GENIE-PC

- Contador gama, modelo Cobra II ES5002, PerkinElmer do Brasil Ltda

* Equipamento $\mu \mathrm{PET}$ Albira, Bruker BioSpin Corp. Software: Albira Software Suite

* Espectrômetro de emissão óptica com plasma indutivamente acoplado (ICPOES), Varian Vista - MPX, Varian Inc., EUA 
* Capela com sistema de exaustão, Braslab Equipamentos para Laboratórios Ltda, Brasil

* Microscópio eletrônico de varredura (MEV) de bancada, TM 3000, Hitachi HighTechnologies Europe GmbH

- Difratômetro de raios X, MultiFlex, Rigaku

* Analisador de adsorção gasosa, modelo Nova 1000, Quantachrome Corp. USA

* Analisador granulométrico a laser, modelo CILAS 1064, CILAS

* Analisador térmico simultâneo, modelo STA 409 E, Netzsch

\subsubsection{Materiais em geral}

* Vidrarias

* Suporte universal

* Colunas de vidro com placa porosa, 6, 8, 10 e 12 mm de diâmetro (externo)

* Frascos a vácuo, IPEN-CNEN/SP

* Filtros 0,22 $\mu \mathrm{m}$ - Millex Filter units, Millipore Co., EUA

* Seringa hipodérmica - Embramac, Laboratórios Rymco S.A. Colombia

* Agulha hipodérmica, Nipro Medical Ltda, Brasil

* Agulha de parede fina hipodérmica, 100 Sterican, B.Braun Melsungen AG

* Pipetas automáticas - Pipetman, Gilson Inc., EUA

* Suporte cromatográfico - Papel 3 MM, Whatman International Ltda, UK

* TLC Silica Gel 60, Merck KGaA, Alemanha

* TLC Silica Gel IB-F, J.T. Baker Inc., Alemanha

* Papel indicador de pH, Merck KGaA, Alemanha

* Torneira de três vias, Wen Zhou K.L.F. Plastics Co. Ltd, China

* Cartucho de extração de fase sólida - SepPak Light

* Cartucho de resina catiônica - Strata X-C Phenomenex

* Gerador de ${ }^{68} \mathrm{Ge} /{ }^{68} \mathrm{Ga}$, Obninsk-generator, Cyclotron Co. Ltd., Rússia

- Gerador de ${ }^{68} \mathrm{Ge} /{ }^{68} \mathrm{Ga}$, iThemba Ltd., África do Sul

\subsubsection{Reagentes}

Dióxido de germânio $\left(\mathrm{GeO}_{2}\right)$, Merck KGaA, Alemanha 
* Ácido clorídrico ( $\mathrm{HCl}$ ) 37\%, Merck KGaA, Alemanha

* Ácido clorídrico suprapuro 30\%, Merck KGaA, Alemanha

* Hidróxido de sódio ( $\mathrm{NaOH}$ ), Merck KGaA, Alemanha

* Acetona, Merck KGaA, Alemanha

- Cloreto de zircônio hidratado $\left(\mathrm{ZrOCl}_{2} \cdot 8 \mathrm{H}_{2} \mathrm{O}\right)$, Carlo Erba Reagentes, Itália

* Hidróxido de amônio 25\% $\left(\mathrm{NH}_{4} \mathrm{OH}\right)$, Merck KGaA, Alemanha

* Tricloreto de titânio $\left(\mathrm{TiCl}_{3}\right)$ solução a $15 \%$ em HCl, Vetec, Sigma-Aldrich

* Dióxido de titânio $\left(\mathrm{TiO}_{2}\right)$, AEROXIDE $\mathrm{TiO}_{2} \mathrm{P}$ 90, Evonik Degussa Brasil Ltda

* Água purificada - Elix 10, Millipore Co., EUA

* Solução padrão de Ge, SpexCertiprep

* Solução padrão de Ge, Fluka Analytical

* Solução padrão de Ti, Fluka Analytical

* Solução padrão de Fe, SpexCertiprep

* Solução padrão de Zr, Fluka Analytical

* Solução padrão de Zn, Merck KGaA, Alemanha

* Solução padrão de Sn, Fluka Analytical

* Solução padrão de Al, SpexCertiprep

* Cloreto de ${ }^{67} \mathrm{Ga}\left({ }^{67} \mathrm{GaCl}_{3}\right)$ - IPEN-CNEN/SP

* Cloreto de ${ }^{68} \mathrm{Ge}\left({ }^{68} \mathrm{GeCl}_{4}\right)$, CMR Corporation Ltd./ Cyclotron Co. Ltd

\subsubsection{Adsorvedores}

Os materiais adsorvedores estudados no trabalho foram:

- $\mathrm{Al}_{2} \mathrm{O}_{3}$ ácida calcinada - preparada no IPEN-CNEN/SP para uso rotineiro dos geradores de ${ }^{99} \mathrm{Mo} /{ }^{99 \mathrm{~m}} \mathrm{Tc}$.

- $\mathrm{Al}_{2} \mathrm{O}_{3}$ básica - o óxido foi peneirado e a granulometria utilizada foi de 74 a 310 $\mu \mathrm{m}$ (200 - 48 mesh), Merck (Aluminium oxyde 90).

- $\mathrm{SnO}_{2}$ - o óxido foi calcinado a $900{ }^{\circ} \mathrm{C}$, peneirado e a granulometria utilizada foi de 149 a $310 \mu \mathrm{m}$ (100 - 48 mesh), Aldrich.

- HZO - Cristais de Óxido de Zircônio - 149 a 298 (100 - 50 mesh), BIO-RAD (HZO-1 lon Exchange Crystals).

- $\mathrm{ZrO}_{2}$ e $\mathrm{TiO}_{2}$ - preparação descrita no item 4.3.1. 
- Microesferas: $\mathrm{ZrO}_{2}$ e $\mathrm{AlO}_{3}$, preparadas no IPEN-CNEN/SP pelo Centro de Células Combustível a Hidrogênio - $\mathrm{CCCH}$.

- Microesferas: $\mathrm{ZrO}_{2}, \mathrm{ZrO}_{2} / \mathrm{Ti}$ (10\%), $\mathrm{ZrO}_{2} / \mathrm{Sn}$ (10\%), $\mathrm{Al}_{2} \mathrm{O}_{3} / \mathrm{Ti}(10 \%), \mathrm{Al}_{2} \mathrm{O}_{3} / \mathrm{Sn}$ (10\%) preparadas no IPEN-CNEN/SP pelo Centro de Ciências e Tecnologia dos Materiais - CCTM.

\subsection{Métodos}

A parte experimental deste trabalho foi dividida em etapas. Inicialmente, foram realizados estudos do comportamento químico do $\mathrm{Ge}$ e do $\mathrm{Ga}$ em diversos materiais adsorvedores. Foram utilizados trocadores iônicos comerciais $\left(\mathrm{Al}_{2} \mathrm{O}_{3}, \mathrm{SnO}_{2}, \mathrm{HZO}\right)$, materiais fornecidos por outros centros do IPENCNEN/SP (microesferas) e óxidos sintetizados no próprio laboratório do Centro de Radiofarmácia $\left(\mathrm{TiO}_{2}\right.$ e $\left.\mathrm{ZrO}_{2}\right)$. O estudo de materiais adsorvedores foi realizado durante todo o período do projeto. Paralelamente, outras etapas do trabalho foram desenvolvidas, como o preparo de geradores de ${ }^{68} \mathrm{Ge} /{ }^{68} \mathrm{Ga}$ utilizando $\mathrm{TiO}_{2}$ como material adsorvedor, com avaliação do perfil de eluição e do controle de qualidade do ${ }^{68} \mathrm{Ga}$ eluído, estudo de novos métodos para o controle radionuclídico do ${ }^{68} \mathrm{Ga}$ e a caracterização do $\mathrm{TiO}_{2}$ sintetizado em laboratório.

\subsubsection{Síntese dos materiais}

\subsubsection{1 Óxido de Titânio $\left(\mathrm{TiO}_{2}\right)$}

A síntese do $\mathrm{TiO}_{2}$ foi feita por precipitação homogênea, onde um precursor clorado de titânio (tricloreto de titânio) reagiu com uma base (hidróxido de amônio), formando hidróxido de titânio. Esse hidróxido foi convertido através da perda de moléculas de água em $\mathrm{TiO}_{2}$ amorfo, o qual, sob diferentes tratamentos térmicos deu origem às fases cristalinas anatase e rutilo. Essas reações estão representadas pelas equações 4.1 e 4.2 .

$$
\mathrm{TiCl}_{3}+3 \mathrm{NH}_{4} \mathrm{OH} \leftrightarrow \mathrm{Ti}(\mathrm{OH})_{3}+3 \mathrm{NH}_{4} \mathrm{Cl}
$$




$$
\mathrm{Ti}(\mathrm{OH})_{3} \stackrel{\Delta}{\Leftrightarrow} \mathrm{TiO}_{2}+\frac{1}{2} \mathrm{O}_{2} \uparrow+\frac{3}{2} \mathrm{H}_{2} \uparrow
$$

O preparo do material seguiu as seguintes etapas (AHMAD, 2010):

1) Adicionar lentamente $115 \mathrm{~mL}$ de $\mathrm{NH}_{4} \mathrm{OH} 2 \mathrm{~mol} \mathrm{~L}^{-1}$ em $50 \mathrm{~mL}$ de $\mathrm{TiCl}_{3}$, sob agitação;

2) Ajustar o pH a $7,5 \mathrm{com} \mathrm{NH} \mathrm{NH}_{4} \mathrm{Omol} \mathrm{L}{ }^{-1}$;

3) Agitar por 48 horas (FIG. 4.1);

4) Deixar decantar;

5) Retirar o sobrenadante e adicionar $100 \mathrm{~mL}$ de água deionizada;

6) Agitar por 20 minutos;

7) Repetir quatro vezes o processo de retirada do sobrenadante e adição de água;

8) Filtrar e secar na estufa a $100^{\circ} \mathrm{C}$ (FIG. 4.2);

9) Macerar;

10) Calcinar a $420^{\circ} \mathrm{C}$ por 3 horas (taxa de aquecimento: $5^{\circ} \mathrm{C} /$ minuto);

11) Peneirar.

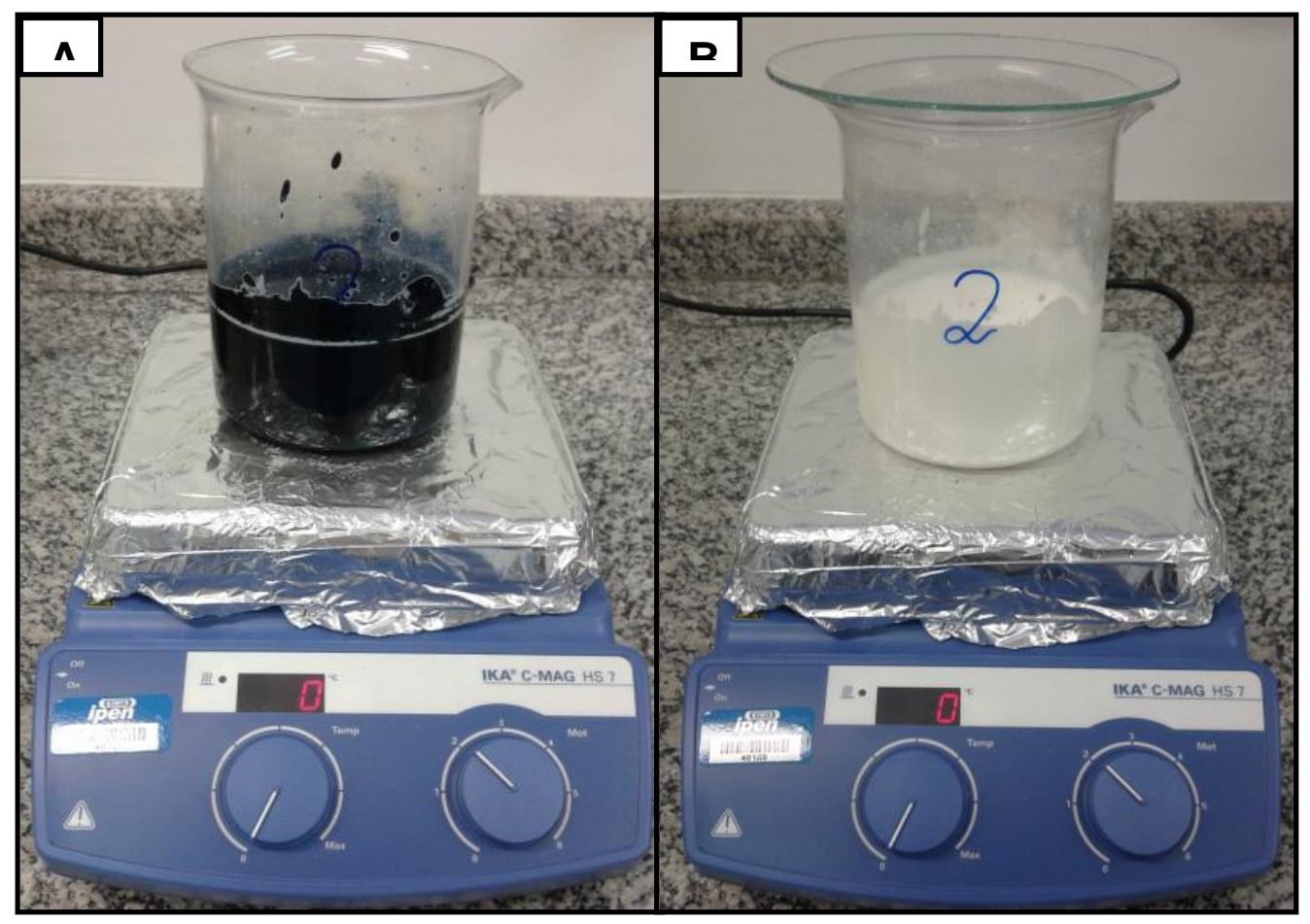

FIGURA 4.1 - Solução de $\mathrm{TiCl}_{3}$ com $\mathrm{NH}_{4} \mathrm{OH}$ para síntese do $\mathrm{TiO}_{2}$. (A) Início da reação (B) Final da reação. 


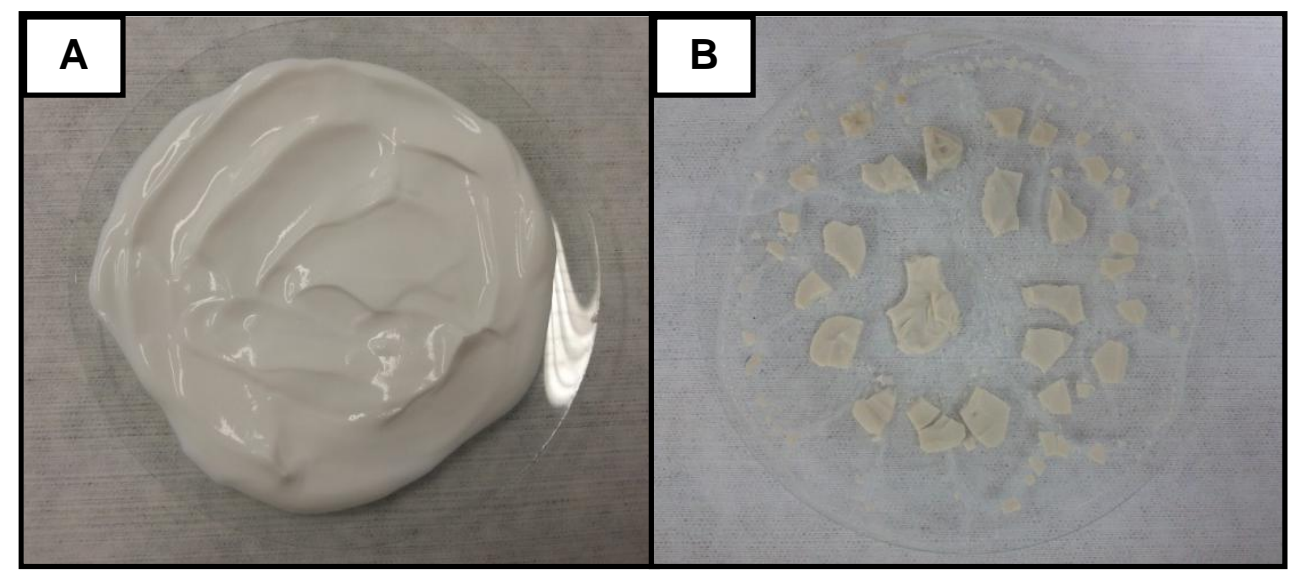

FIGURA 4.2 - (A) $\mathrm{TiO}_{2}$ após a filtragem. (B) Material seco a $100^{\circ} \mathrm{C}$ no vidro de relógio.

A granulometria utilizada para a realização dos experimentos foi 149 $\mu \mathrm{m}$ a $310 \mu \mathrm{m}$ (100 a 48 mesh). O material foi lavado com água deionizada para retirada de finos, condicionado com $\mathrm{HCl} 0,1 \mathrm{~mol} \mathrm{~L}^{-1}$ e então foi novamente seco a $100{ }^{\circ} \mathrm{C}$.

Algumas variáveis foram estudadas no preparo do material:

> Temperatura de secagem: 60 e $100^{\circ} \mathrm{C}$;

$>$ Material calcinado e não calcinado;

> Resfriamento "rápido": o material foi retirado do forno mufla logo após o término da calcinação;

> Resfriamento "lento": o material foi retirado do forno mufla após o mesmo apresentar temperatura menor que $110^{\circ} \mathrm{C}$.

\subsubsection{2 Óxido de Zircônio $\left(\mathrm{ZrO}_{2}\right)$}

$\mathrm{O} \mathrm{ZrO}_{2}$ foi preparado seguindo as seguintes etapas (FRÜH, 2007):

1) Dissolver $19 \mathrm{~g}$ de $\mathrm{ZrOCl}_{2} .8 \mathrm{H}_{2} \mathrm{O}$ em $45 \mathrm{~mL}$ de água;

2) Adicionar $70 \mathrm{~mL}$ de $\mathrm{NH}_{4} \mathrm{OH} 0,3 \mathrm{~mol} \mathrm{~L}^{-1}$. Ajustar a $\mathrm{pH} \geq 8 \mathrm{com} \mathrm{NH} \mathrm{N}_{4} \mathrm{OH} 2 \mathrm{~mol}$ $\mathrm{L}^{-1}$

3) Agitar por 30 minutos;

4) Deixar decantar por 12 horas;

5) Retirar o sobrenadante;

6) Adicionar $100 \mathrm{~mL}$ de água e agitar; 
7) Repetir o processo de retirada do sobrenadante e adição de água até a solução apresentar pH 6;

8) Filtrar;

9) Secar na estufa a $120^{\circ} \mathrm{C}$;

10) Macerar e peneirar.

A granulometria utilizada para a realização dos experimentos foi de 74 a $310 \mu \mathrm{m}$ (200 a 48 mesh).

\subsubsection{Estudo do comportamento químico do Ge e do Ga nos materiais adsorvedores}

\subsubsection{Métodos analíticos}

Inicialmente, para avaliar os adsorvedores, o comportamento químico do $\mathrm{Ge}$ e do $\mathrm{Ga}$ nesses materiais foi estudado separadamente, utilizando-se traçadores radioativo e químico. Essa metodologia foi uma alternativa para suprir a falta do radionuclídeo ${ }^{68} \mathrm{Ge}$ no início do projeto.

Para os estudos do comportamento do Ga nos materiais adsorvedores foram utilizados traçadores radioativos, ${ }^{67} \mathrm{Ga}$ e ${ }^{68} \mathrm{Ga}$. $\mathrm{O}{ }^{67} \mathrm{Ga}$, na forma de cloreto, foi produzido no IPEN-CNEN/SP e fornecido para pesquisa através do setor de produção do Centro de Radiofarmácia. $\mathrm{O}{ }^{68} \mathrm{Ga}$ foi eluído do gerador de ${ }^{68} \mathrm{Ge} /{ }^{68} \mathrm{Ga}$ comprado da Rússia, Obninsk-generator (FIG. 4.3). As amostras contendo ${ }^{67 / 68} \mathrm{Ga}$ foram analisadas através do calibrador de doses, Capintec (FIG. 4.4).

Calibrador de dose é um instrumento que consiste essencialmente de uma câmera de ionização do tipo poço e de um eletrômetro com mostrador digital que permite a leitura direta em unidades de atividade. A medição da atividade é feita utilizando-se uma condição fixa, pré-definida do instrumento, tal como uma tecla ou um fator de multiplicação ajustado eletronicamente para cada radionuclídeo em particular. A vantagem da câmera de ionização é que se pode medir a atividade de uma fonte com taxa de contagem muito alta sem cometer erros devido ao tempo morto (LIMA et al., 2012). 


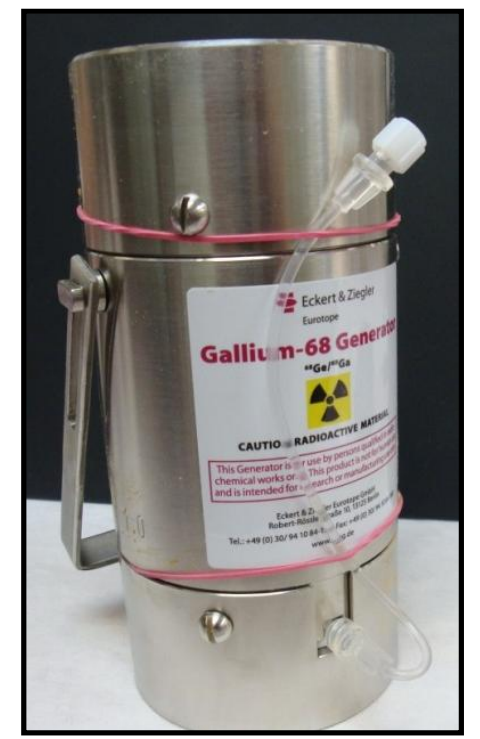

FIGURA 4.3 - Gerador de ${ }^{68} \mathrm{Ge} /{ }^{68} \mathrm{Ga}$ (Obninsk-generator, Cyclotron Co. Ltd.).

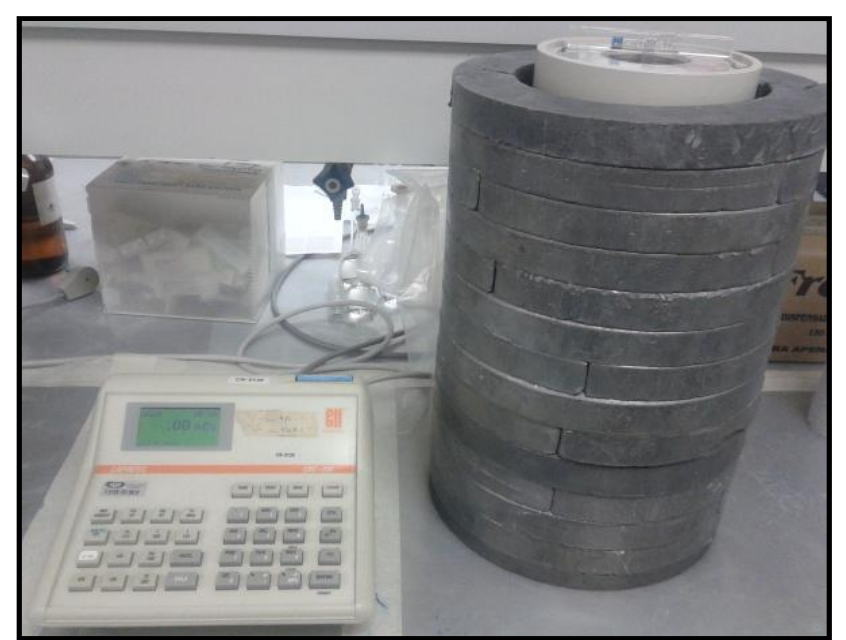

FIGURA 4.4 - Calibrador de doses Capintec CRC-35R.

O estudo da adsorção do Ge nos diferentes materiais adsorvedores foi realizado com um traçador químico, $\mathrm{GeCl}_{4}$. A solução foi preparada através da dissolução de 3,6 mg de $\mathrm{GeO}_{2}$ em $3 \mathrm{~mL}$ de $\mathrm{NaOH}$ 0,5 mol L ${ }^{-1}$ e diluição para 25 $\mathrm{mL}$ com $\mathrm{HCl} 0,1 \mathrm{~mol} \mathrm{~L}^{-1}$, apresentando $\mathrm{pH}=1,5$ (concentração final: $100 \mu \mathrm{g}$ de $\mathrm{Ge} / \mathrm{mL})$.

As amostras contendo Ge foram analisadas por um espectrômetro de emissão óptica com plasma indutivamente acoplado (ICP-OES), mostrado na FIG. 4.5. Os parâmetros instrumentais e analíticos utilizados estão apresentados na TAB. 4.1. 


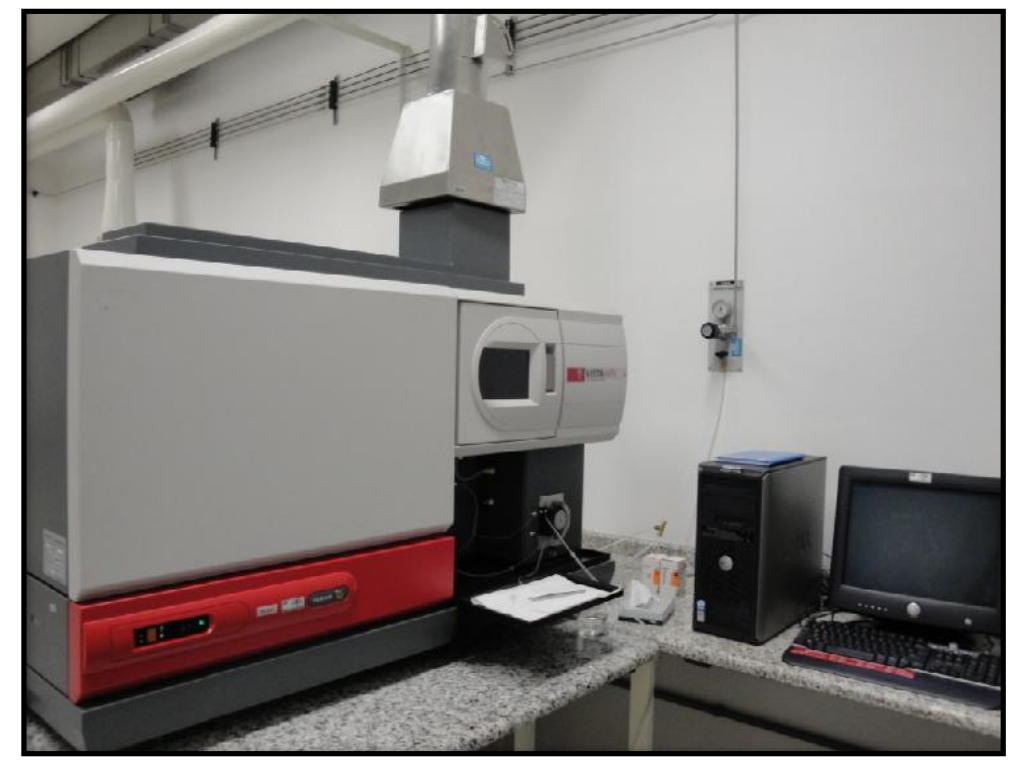

FIGURA 4.5 - Espectrômetro de emissão óptica com plasma indutivamente acoplado (ICP-OES), Varian Vista - MPX, Varian Inc., EUA.

TABELA 4.1 - Parâmetros instrumentais e analíticos utilizados para determinação do Ge no ICP-OES.

\begin{tabular}{ll}
\hline Potência $(\mathrm{W})$ & $1200 \mathrm{~W}$ \\
Gás para formação do plasma & Argônio \\
Tipo de nebulizador & concêntrico \\
Vazão do gás do Plasma & $15 \mathrm{~L} \mathrm{~min}^{-1}$ \\
Vazão do gás auxiliar & $1,5 \mathrm{~L} \mathrm{~min}^{-1}$ \\
Vazão do gás do nebulizador & $0,75 \mathrm{~L} \mathrm{~min}^{-1}$ \\
Linha de emissão para o Ge & $265,117 \mathrm{~nm}$ \\
\hline
\end{tabular}

Curvas de calibração para o Ge foram construídas com as seguintes concentrações: $0,02-0,04-0,06-0,08-1,0 \mu \mathrm{g} \mathrm{mL} \mathrm{m}^{-1}$. As soluções foram preparadas a partir de um padrão de Ge de concentração de $1000 \mu \mathrm{gL}^{-1}$ e diluídas em água deionizada.

Os limites de detecção (LD) e quantificação (LQ) do ICP-OES para o Ge foram determinados pelas equações 4.3 e 4.4, respectivamente. As curvas de calibração utilizadas para o cálculo de LD e LQ foram feitas com a mesma concentração das curvas utilizadas para análise das amostras.

$$
\mathrm{LD}=\frac{\mathrm{DPa} \cdot 3}{\mathrm{IC}}
$$




$$
\mathrm{LQ}=\frac{\mathrm{DPa} \cdot 10}{\mathrm{IC}}
$$

onde:

$\mathrm{DP}_{\mathrm{a}}=$ desvio padrão do intercepto com o eixo $\mathrm{Y}$ de no mínimo 3 curvas de calibração, construídas contendo concentrações próximas ao suposto limite de quantificação.

IC = valor médio das inclinações das curvas de calibração.

O limite de detecção consiste na menor quantidade do analito presente em uma amostra, que pode ser detectado e não necessariamente quantificado, em condições experimentais estabelecidas. O limite de quantificação consiste na menor quantidade do analito em uma amostra que pode ser determinada com precisão e exatidão.

\subsection{Espectrometria de emissão óptica com plasma indutivamente acoplado (ICP-OES)}

Essa técnica permite a determinação quantitativa de traços de metais e semi-metais em uma determinada amostra, sendo capaz de realizar análises simultâneas de vários elementos.

O princípio fundamental do ICP-OES consiste na ionização, atomização e excitação dos átomos de uma amostra pelo plasma indutivo. $O$ plasma é gerado pela ionização do gás argônio (ou xenônio). A ionização é iniciada por uma centelha formada pela bobina de indução, alimentada por um gerador de radiofrequência $(\mathrm{RF})$. Os íons e elétrons resultantes interagem então com o campo magnético oscilante (proveniente da fonte de RF) provocando mais ionização do gás, o qual sustenta o plasma.

A solução da amostra é convertida em um jato gasoso pelo nebulizador. A alta temperatura do plasma causa a evaporação do solvente, formando um aerossol, que é então vaporizado, dissociado e ionizado.

Átomos neutros ou íons quando excitados, termicamente ou eletricamente, emitem radiações com comprimentos de onda característicos nas regiões ultravioleta e visível do espectro eletromagnético. Portanto, após a 
atomização e excitação dos átomos da amostra, são produzidas as linhas de emissão específicas para cada elemento. A intensidade de cada linha é proporcional à concentração do elemento de interesse. A radiação emitida incide sobre um sistema óptico constituído por uma rede de difração e prisma. O sinal é conduzido a um detector de estado sólido, onde é amplificado e transformado em sinal elétrico, que é medido e registrado. A FIG. 4.6 mostra um esquema simplificado dos componentes do equipamento de ICP-OES.

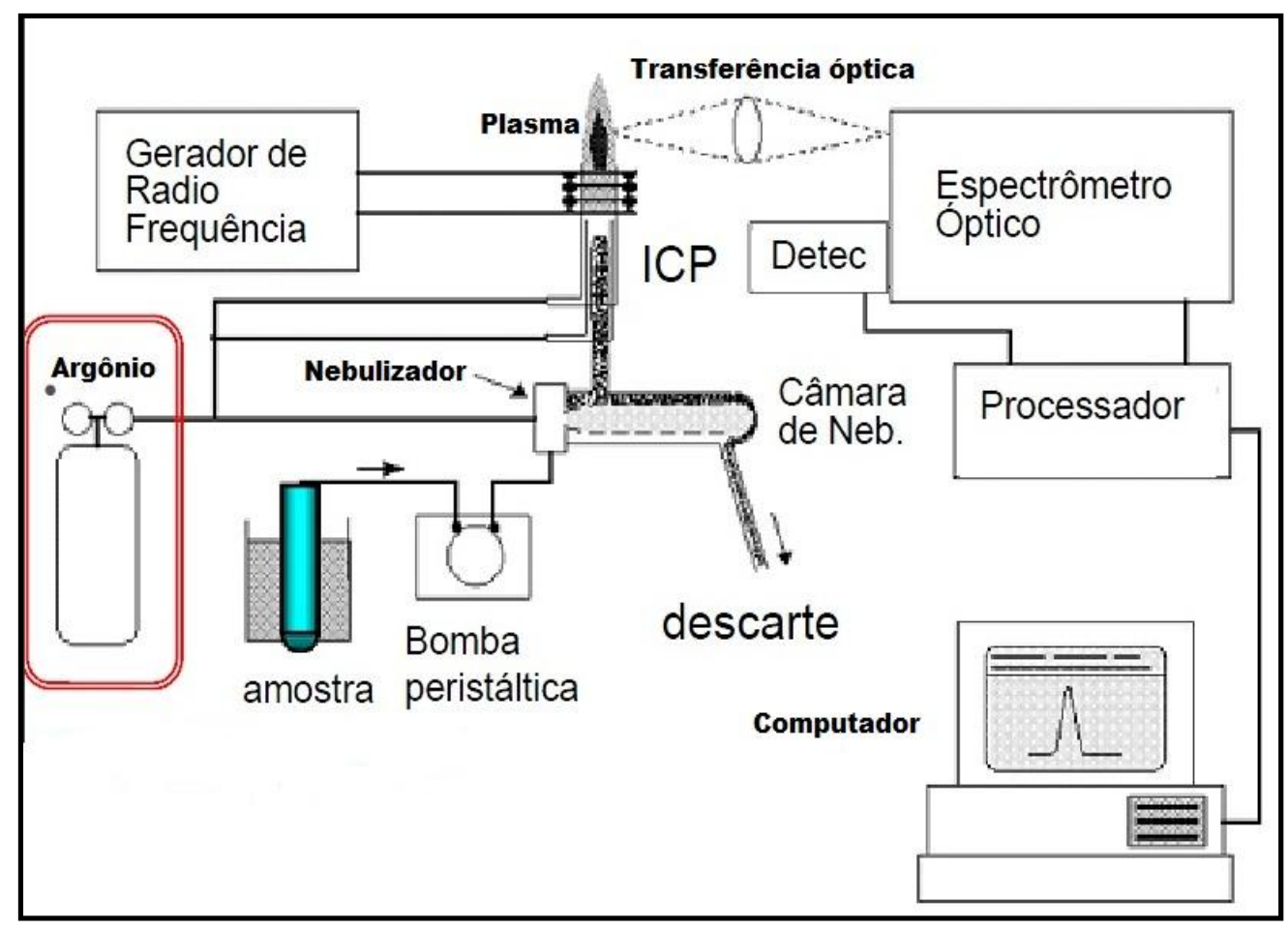

FIGURA 4.6 - Esquema simplificado dos componentes de um equipamento de ICP-OES.

\subsubsection{Colunas cromatográficas com $\mathrm{Al}_{2} \mathrm{O}_{3}, \mathrm{HZO}, \mathrm{ZrO}_{2}, \mathrm{TiO}_{2}$ e $\mathrm{SnO}_{2}$}

Para os experimentos com a $\mathrm{Al}_{2} \mathrm{O}_{3}$ (ácida calcinada e básica), $\mathrm{HZO}$, $\mathrm{ZrO}_{2}, \mathrm{TiO}_{2}$ e $\mathrm{SnO}_{2}$ foram utilizadas colunas de vidro com 8,10 e $12 \mathrm{~mm}$ de diâmetro contendo de 1 a $2 \mathrm{~g}$ dos materiais adsorvedores e as soluções foram percoladas utilizando-se vácuo ou pressão manual com seringa ( $3 \mathrm{~mL} / \mathrm{min}$.). As velocidades de escoamento para as colunas de 8,10 e $12 \mathrm{~mm}$ de diâmetro foram respectivamente de 0,35, 0,27 e 0,17 cm/ min.

As colunas foram previamente condicionadas com $\mathrm{HCl} 0,1 \mathrm{~mol} \mathrm{~L}^{-1} \mathrm{e}$ em seguida foram carregadas com solução de ${ }^{67 / 68} \mathrm{GaCl}_{3}(7,4$ a $55,5 \mathrm{MBq} / \mathrm{mL})$ ou 
$\mathrm{GeCl}_{4}$ (50-100 $\left.\mu \mathrm{g} \mathrm{Ge} / \mathrm{mL}\right)$, ambas soluções apresentando o mesmo pH (1,5 ou 4). Após a coleta da solução carga, foram realizadas lavagens das colunas para simular as eluições.

As colunas montadas com sistema a vácuo foram lavadas com $10 \mathrm{~mL}$

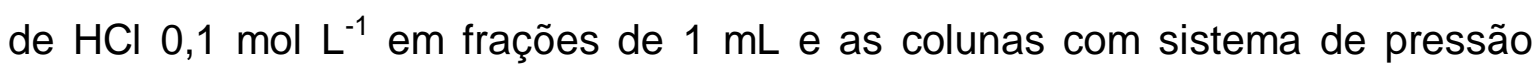
manual com seringa foram lavadas com $10 \mathrm{~mL}$ de $\mathrm{HCl}$ 0,1 mol L-1 em frações de 5 $\mathrm{mL}$. Foram estudados os pHs das soluções do condicionamento, da carga e de lavagem (1,5 e 4). O procedimento experimental está descrito na FIG. 4.7.

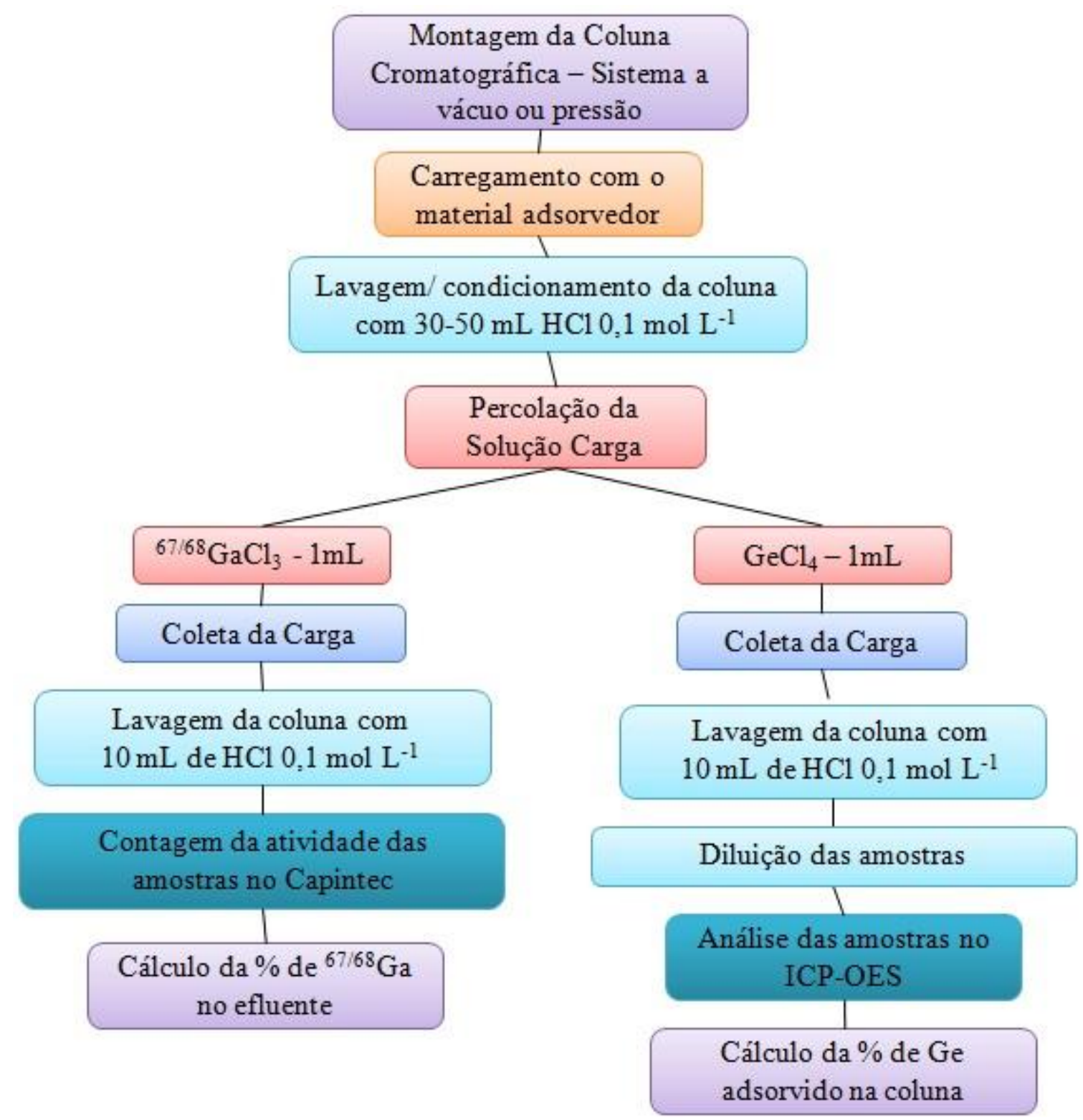

FIGURA 4.7 - Esquema de montagem das colunas cromatográficas e o procedimento experimental. 


\subsubsection{Colunas cromatográficas com microesferas}

O estudo da adsorção do Ge nas microesferas foi realizado pelo método dinâmico e estático. No estudo dinâmico, foram utilizadas colunas de vidro com 6 e $8 \mathrm{~mm}$ de diâmetro contendo $0,5 \mathrm{a} 1,0 \mathrm{~g}$ do material adsorvedor. Após o condicionamento da coluna com $\mathrm{HCl} 0,1 \mathrm{~mol} \mathrm{~L}^{-1}$, a solução carga $(\mathrm{pH} 1,5)$ foi percolada e então foi feita a lavagem com $\mathrm{HCl} 0,1 \mathrm{~mol} \mathrm{~L}^{-1}$.

Para estudar a adsorção do Ge nas microesferas pelo método estático, as microesferas foram colocadas em um becker com $1 \mathrm{~mL}$ da solução de $\mathrm{GeCl}_{4}$ (100 $\mathrm{mg} \mathrm{Ge} / \mathrm{mL}$ ) e foram aquecidas por volta de 4 minutos e permaneceram nessa solução durante 24 horas. Após esse período a solução foi retirada e o material foi lavado com $\mathrm{HCl} 0,1 \mathrm{~mol} \mathrm{~L}^{-1}$. A solução e lavagem foram analisadas para determinação do Ge.

Para o estudo do comportamento do ${ }^{68} \mathrm{Ga}$ utilizou-se colunas de vidro com $6 \mathrm{~mm}$ de diâmetro, que foram condicionadas com $\mathrm{HCl} \mathrm{0,1} \mathrm{mol} \mathrm{L}^{-1}$, percoladas com a solução de ${ }^{68} \mathrm{GaCl}_{3}(\sim 20 \mathrm{MBq} / \mathrm{mL})$ e eluídas com $\mathrm{HCl} 0,1 \mathrm{~mol} \mathrm{~L}^{-1}$. As soluções foram percoladas utilizando-se uma vazão constante $(1,4 \mathrm{~mL} / \mathrm{min}$.) e velocidade de escoamento de $0,23 \mathrm{~cm} / \mathrm{min}$.

A análise das amostras seguiu o mesmo esquema da FIG. 4.7.

\subsubsection{Caracterização do $\mathrm{TiO}_{2}$}

Foram preparados 10 lotes de $\mathrm{TiO}_{2}$ e para cada um foi feito o cálculo estequiométrico para verificar o rendimento da reação. Além disso, foi realizada uma avaliação visual dos lotes para verificar possíveis diferenças entre eles.

Para avaliar os materiais obtidos foram realizadas análises de caracterização, tais como:

* Distribuição granulométrica

* Microscopia eletrônica e análise elementar

* Análise térmica por duas técnicas simultâneas: termogravimetria (TG) e análise térmica diferencial (DTA)

* Difração de raios $X$

* Análise da área superficial específica pela técnica B.E.T. 


\subsubsection{Distribuição granulométrica}

A distribuição granulométrica foi analisada por duas técnicas distintas: peneiramento com agitação e espalhamento laser utilizando um analisador granulométrico CILAS.

No peneiramento com agitação foram utilizadas cinco peneiras com aberturas de $310 \mu \mathrm{m}$ (48 mesh), $149 \mu \mathrm{m}$ (100 mesh), $88 \mu \mathrm{m}$ (170 mesh), $74 \mu \mathrm{m}$ (200 mesh) e $60 \mu \mathrm{m}$ (250 mesh). O tempo de agitação para todos os materiais foi de 15 minutos.

A análise feita pela técnica de espalhamento laser utilizou um analisador granulométrico CILAS, modelo 1064. Foi utilizado como dispersante tetrapirofosfato de sódio dissolvido em água na razão 1:50 e foram aplicadas ondas de ultrassom durante 60 segundos antes e durante as medidas. Foi feita a determinação do diâmetro médio do material.

\subsubsection{Microscopia eletrônica de varredura e análise elementar}

A análise morfológica dos materiais foi feita por microscopia eletrônica de varredura (MEV) com um microscópio de bancada, modelo TM3000 da Hitachi (FIG. 4.8). As micrografias foram obtidas com aumento de 100 a 1800 vezes.

O microscópio utilizado possui sistema EDS (Energy Dispersive Spectrometer), espectrômetro de energia dispersiva, que permite a realização de um mapeamento elementar da amostra.

Foram analisados os lotes 3, 6, 7, 8 e o $\mathrm{TiO}_{2} \mathrm{P} 90$ comercial da Evonik Degussa. 


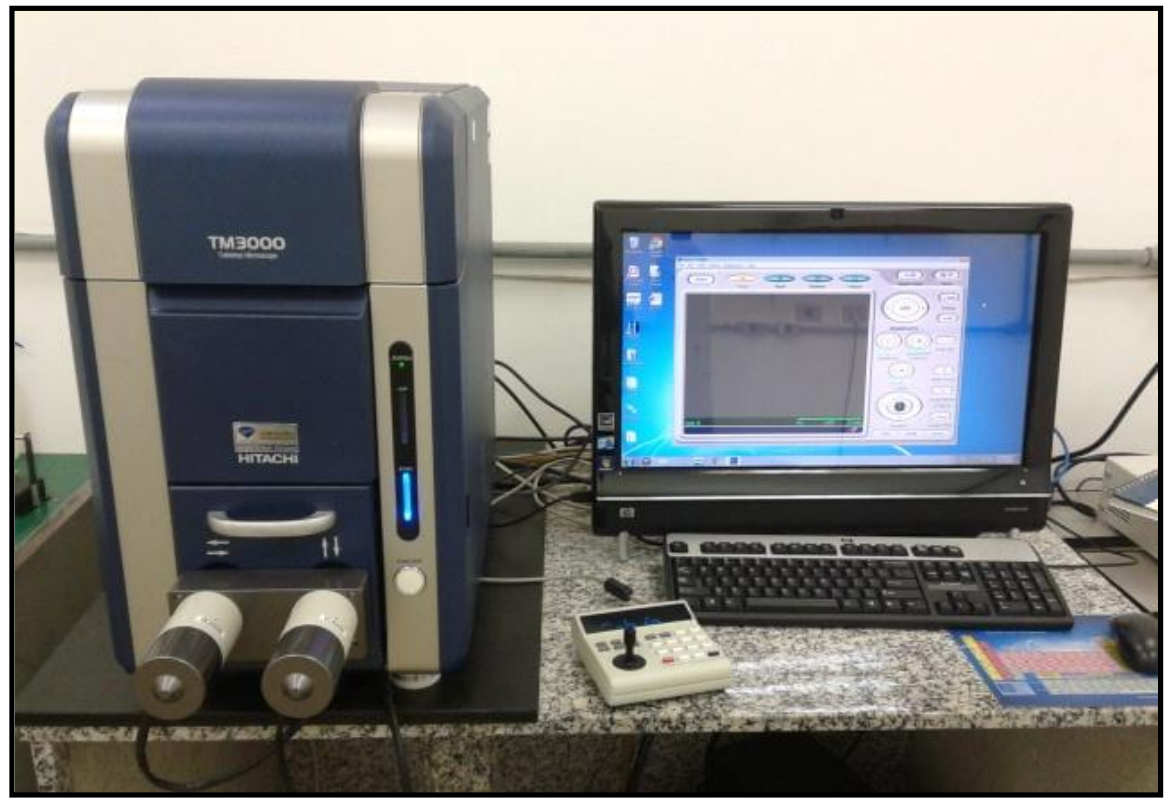

FIGURA 4.8 - Microscópio eletrônico de varredura (MEV) de bancada, TM 3000, Hitachi.

\subsubsection{Análise térmica (TG-DTA)}

A análise térmica do material foi feita por duas técnicas simultâneas, a termogravimetria (TG) e a análise térmica diferencial (DTA).

A termogravimetria é uma técnica de análise térmica onde a massa da amostra é registrada em função da temperatura ou do tempo. (VIEIRA, 2013) Pode ser:

- Isotérmica: a massa da amostra é registrada em função do tempo, a temperatura constante.

- Dinâmica: a massa da amostra é registrada sob condições onde a amostra é submetida a um programa de aquecimento ou resfriamento predeterminado, normalmente linear.

- Quasi-isotérmica: a massa da amostra é registrada sob condições de aquecimento numa série de patamares de temperatura.

A análise térmica diferencial é uma técnica que registra a diferença de temperatura entre a amostra a ser analisada e um material de referência termicamente inerte, como por exemplo, alumina ou carbeto de silício. O registro é feito em função da temperatura ou do tempo, à medida que a amostra é aquecida ou resfriada. Geralmente, os equipamentos que realizam esse tipo de 
análise permitem a circulação de um gás inerte, como o nitrogênio, ou um gás reativo, como o oxigênio e o ar (SKOOG et al., 1998).

As análises das amostras de $\mathrm{TiO}_{2}$ (lotes 4,9 e 10) foram feitas com um analisador térmico simultâneo, modelo STA 409 E da Netzsch. Foi realizada termogravimetria dinâmica, onde a massa da amostra foi registrada em função do aumento da temperatura. A faixa de temperatura utilizada foi de 20 a $800^{\circ} \mathrm{C} c o m$ velocidade de aquecimento de $10^{\circ} \mathrm{C} / \mathrm{min}$. Simultaneamente foi realizada a análise térmica diferencial que utilizou $\mathrm{Al}_{2} \mathrm{O}_{3}$ como amostra padrão. Para realizar a análise do lote 4 utilizou-se atmosfera de nitrogênio e para os lotes 9 e 10 foi utilizado ar sintético. Atmosfera de nitrogênio é inerte e a de ar sintético oxidante.

\subsubsection{Difração de raios $X$}

A microestrutura dos materiais obtidos nos diferentes lotes foi analisada por difração de raios $\mathrm{X}$, tendo como objetivo avaliar e identificar a formação de fases cristalinas características ao $\mathrm{TiO}_{2}$. As fases cristalinas anatase e rutilo foram identificadas por comparação com as fichas cristalográficas JCPDS 21-1272 e 65-192 do $\mathrm{TiO}_{2}$. Os ângulos varridos foram de $10^{\circ}$ até $80^{\circ}$, utilizando velocidade de varredura de $1 \%$ min. A radiação utilizada foi raio $\mathrm{X}$ de $30 \mathrm{keV}$, utilizando alvo de Cu e corrente de $15 \mathrm{~mA}$.

As análises dos lotes 3, 5, 6, 7 e 8 foram realizadas na Central Analítica do Instituto de Química da USP, assim como a análise do $\mathrm{TiO}_{2} \mathrm{P90}$ da Evonik Degussa.

Os lotes 4, 9 e 10 foram analisados no laboratório de difração de raios $X$ do Centro de Ciências e Tecnologia dos Materiais (CCTM) do IPEN-CNEN/SP. O equipamento utilizado foi o MultiFlex da Rigaku (FIG. 4.9). 


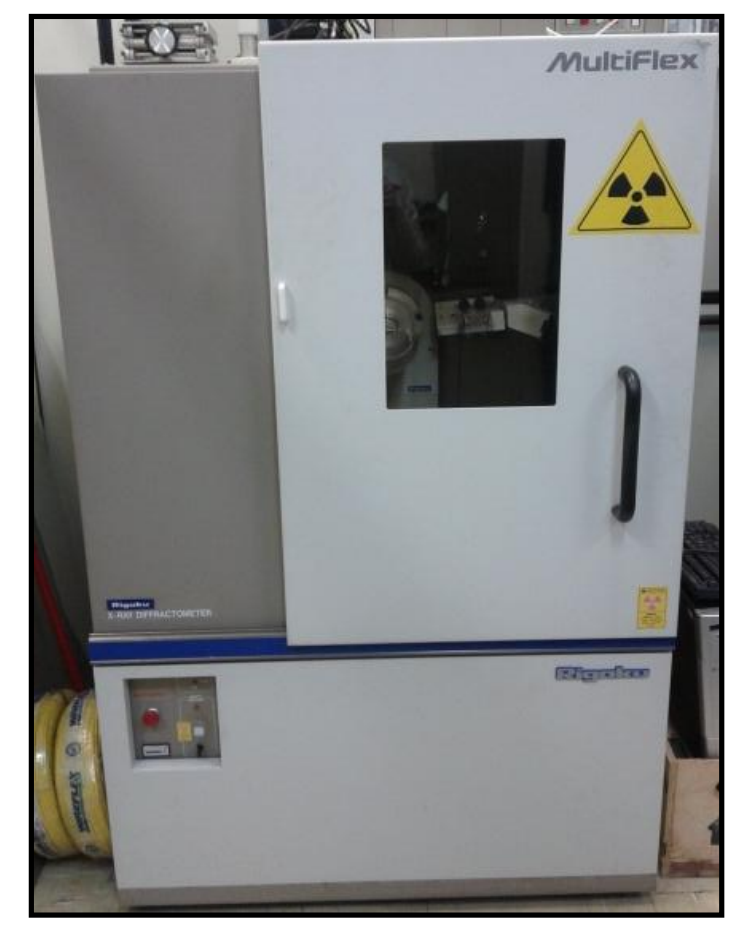

FIGURA 4.9 - Difratômetro de raios X Rigaku, modelo MultiFlex.

\subsubsection{Análise da área superficial específica (B.E.T.)}

A análise da área superficial específica do $\mathrm{TiO}_{2}$ foi realizada pela técnica B.E.T. com o objetivo de avaliar a relação entre a área e massa do material.

As medidas de área superficial são efetuadas por adsorção de gás no material. Esse gás normalmente é o nitrogênio, o qual, conduzido por diferença de pressão é adsorvido na superfície do material.

As análises foram realizadas por um analisador de adsorção gasosa, modelo Nova 1000, Quantachrome Corp. USA.

\subsubsection{Preparo e avaliação dos geradores de ${ }^{68} \mathrm{Ge} /{ }^{68} \mathrm{Ga}$}

Após o estudo do comportamento químico do Ge e do ${ }^{67 / 68} \mathrm{Ga}$ em diversos materiais adsorvedores, foram montadas colunas com ${ }^{68} \mathrm{Ge}$, na forma de cloreto, comprado da CMR Group, utilizando o $\mathrm{TiO}_{2}$ como material adsorvedor.

Foram preparados cinco geradores: G1, G2, G3, G4 e G5. Para montagem das colunas foram utilizados sistemas de eluição com pressão manual, 
feita através de seringa e sistema de eluição a vácuo, similar ao utilizado nos geradores de ${ }^{99} \mathrm{Mo} /{ }^{99 \mathrm{~m}} \mathrm{Tc}$.

Os geradores G1 e G2 foram feitos com sistema de eluição com pressão manual. $O$ gerador $\mathrm{G} 3$ foi preparado com o mesmo sistema de eluição que os geradores G1 e G2, porém na saída da coluna foi acoplada uma mangueira com torneira, com o objetivo de manter a coluna úmida (FIG. 4.10).

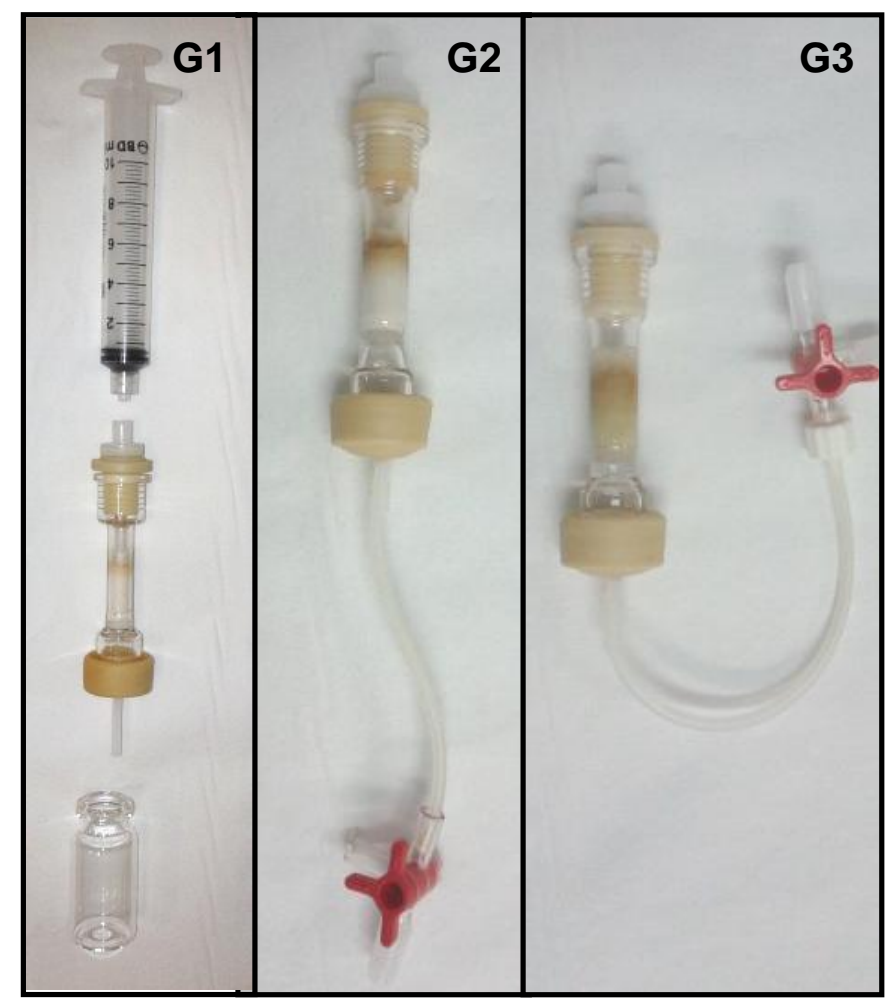

FIGURA 4.10 - Geradores G1, G2 e G3.

Após 12 eluições do gerador G2, o mesmo sistema de torneira, utilizado no gerador G3, foi acoplado à saída da coluna, para avaliar alguma alteração no desempenho do gerador ao manter-se a coluna úmida. A vazão utilizada nas eluições dos geradores G1, G2 e G3 foi de 2,5 a $3 \mathrm{~mL}$ por minuto.

Os geradores G4 e G5 foram preparados com sistema de eluição a vácuo (FIG. 4.11). Para controlar a vazão e manter as colunas úmidas, foram instalados dispositivos de equipo de soro e torneiras nas mangueiras de saída dos geradores. Foram adaptadas agulhas na entrada e na saída da coluna. A vazão utilizada foi de 1,5 a $4 \mathrm{~mL}$ por minuto. Após 5 eluições do gerador G4, o 
sistema a vácuo foi retirado e o gerador passou a ser eluído por pressão manual com a mesma vazão utilizada para os geradores G1, G2 e G3.

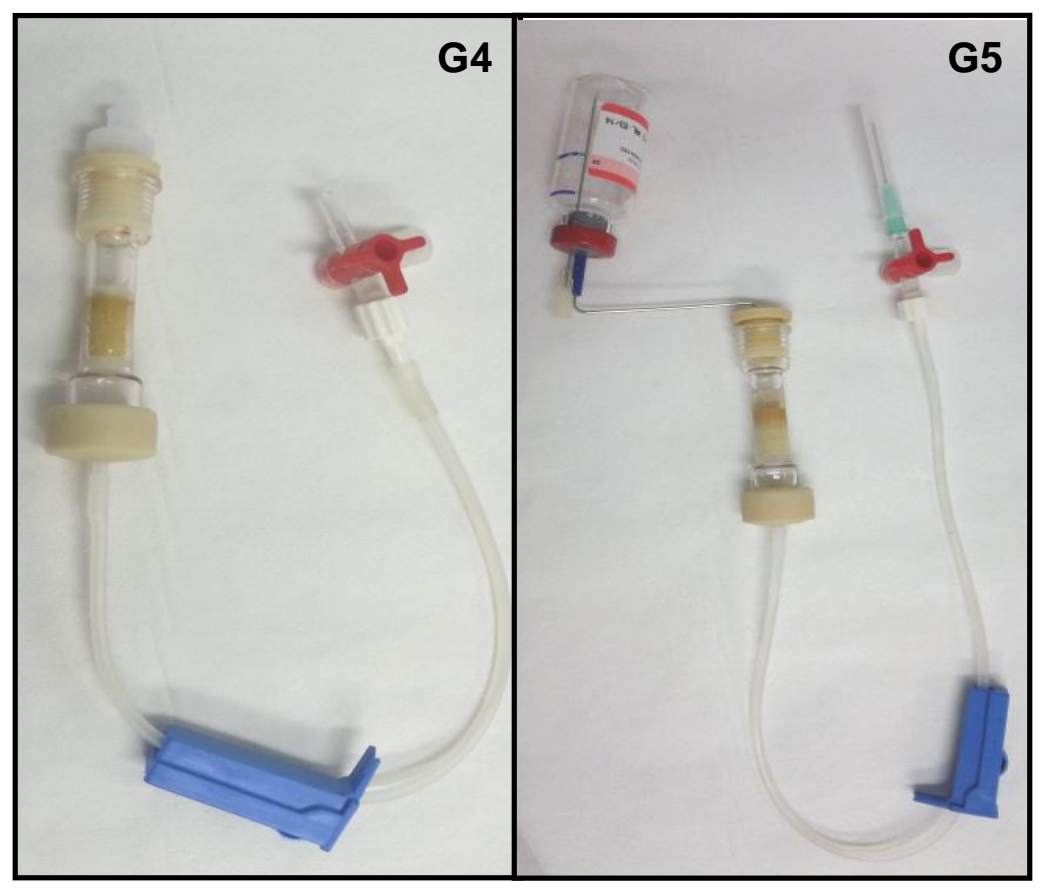

FIGURA 4.11 - Geradores G4 e G5.

A princípio foram utilizadas agulhas metálicas comuns, apenas para avaliar o desempenho do gerador em relação à sua eficiência de eluição utilizando-se o sistema a vácuo. A proposta é que as agulhas sejam substituídas posteriormente por outras agulhas feitas com algum material mais resistente à oxidação e corrosão e que não contenham ferro em sua composição, como por exemplo, agulhas de titânio ou nióbio.

Para o gerador G1 utilizou-se coluna de vidro com $6 \mathrm{~mm}$ de diâmetro externo contendo $0,5 \mathrm{~g}$ de $\mathrm{TiO}_{2}$ e para os geradores $\mathrm{G} 2, \mathrm{G} 3$, G4 e G5 foram utilizadas colunas com $8 \mathrm{~mm}$ de diâmetro externo carregadas com 0,85 g de $\mathrm{TiO}_{2}$. A granulometria do $\mathrm{TiO}_{2}$ utilizado para todos os geradores foi de 149 a $310 \mu \mathrm{m}$ (100 a 48 mesh). $\mathrm{O} \mathrm{TiO}_{2}$ utilizado em cada gerador, seco a $100{ }^{\circ} \mathrm{C}$ ou calcinado a $420{ }^{\circ} \mathrm{C}$, está descrito na TAB. 4.2. Todas as colunas foram lavadas e condicionadas com $30 \mathrm{~mL}$ de $\mathrm{HCl} 0,1 \mathrm{~mol} \mathrm{~L}^{-1}$. 
TABELA 4.2 - Resumo dos parâmetros utilizados no preparo dos geradores.

\begin{tabular}{ccccc}
\hline Gerador & $\begin{array}{c}\text { Sistema de } \\
\text { eluição }\end{array}$ & $\begin{array}{c}\text { Diâm. externo } \\
\text { da coluna de } \\
\text { vidro }(\mathbf{m m})\end{array}$ & $\begin{array}{c}\text { Massa do } \\
\text { adsorvedor } \\
\mathbf{( g )}\end{array}$ & $\mathrm{TiO}_{2}$ \\
$\mathbf{G 1}$ & $\begin{array}{c}\text { Pressão manual } \\
\text { sem torneira }\end{array}$ & 6 & 0,50 & $\begin{array}{c}\text { Lote } 6 / \mathrm{seco} \text { a } \\
100^{\circ} \mathrm{C}\end{array}$ \\
$\mathbf{G 2}$ & $\begin{array}{c}\text { Pressão manual } \\
\text { sem torneira/ com } \\
\text { torneira }\end{array}$ & 8 & 0,85 & $\begin{array}{c}\text { Lote } 6 / \text { seco a } \\
100^{\circ} \mathrm{C}\end{array}$ \\
$\mathbf{G 3}$ & $\begin{array}{c}\text { Pressão manual } \\
\text { com torneira }\end{array}$ & 8 & 0,85 & $\begin{array}{c}\text { Lote } 6 / \text { calcinado } \\
\text { a } 420^{\circ} \mathrm{C}\end{array}$ \\
$\mathbf{G 4}$ & $\begin{array}{c}\text { Vácuo e torneira/ } \\
\text { Pressão manual } \\
\text { com torneira }\end{array}$ & 8 & 0,85 & $\begin{array}{c}\text { Lote } 7 / \text { calcinado } \\
\text { a } 420^{\circ} \mathrm{C} \\
\text { G5 }\end{array}$ \\
Vácuo e torneira & 8 & 0,85 & $\begin{array}{c}\text { Lote } 6 / \text { calcinado } \\
\text { a } 420^{\circ} \mathrm{C}\end{array}$ \\
\hline
\end{tabular}

Para o carregamento, as tampas das colunas foram retiradas e as soluções foram percoladas por gravidade. $O$ volume utilizado para cada coluna foi de $1 \mathrm{~mL}$ de ${ }^{68} \mathrm{GeCl}_{4}\left(\mathrm{pH}\right.$ 4) mais $20 \mu \mathrm{L}$ de $\mathrm{GeCl}_{4}$ (concentração de $100 \mu \mathrm{g}$ de $\mathrm{Ge} / \mathrm{mL}$ ), com exceção do gerador $\mathrm{G} 1$ que não utilizou carregador. As atividades de ${ }^{68} \mathrm{Ge}$ utilizadas nos geradores estão descritas na TAB. 4.3. No dia seguinte ao carregamento, as colunas foram fechadas e eluídas com $6 \mathrm{~mL}$ de $\mathrm{HCl} 0,1 \mathrm{~mol} \mathrm{~L}^{-1}$.

$\mathrm{O}$ uso de carregador teve como objetivo simular a massa de $\mathrm{Ge}$ existente em geradores comerciais. A massa teórica de Ge existente em 1,85 GBq $(50 \mathrm{mCi})$ de ${ }^{68} \mathrm{Ge}$ é de $7,05 \mu \mathrm{g}$. O valor de massa utilizado neste trabalho foi extrapolado para uma atividade de aproximadamente 5,55 GBq (150 mCi).

TABELA 4.3 - Atividades de ${ }^{68} \mathrm{Ge}$ e as massas do carregador utilizadas nos geradores.

\begin{tabular}{ccc}
\hline Gerador & Atividade ${ }^{68} \mathbf{G e}(\boldsymbol{\mu C i})$ & Carregador $(\boldsymbol{\mu g})$ \\
G1 & $144(5,33 \mathrm{MBq})$ & 0 \\
G2 & $1200(44,40 \mathrm{MBq})$ & 20 \\
G3 & $1300(48,10 \mathrm{MBq})$ & 20 \\
G4 & $730(27,01 \mathrm{MBq})$ & 20 \\
G5 & $1819(67,30 \mathrm{MBq})$ & 20 \\
\hline
\end{tabular}

Para os geradores que utilizaram torneira, antes do fechamento da coluna com a tampa, foi adicionado por volta de $1,5 \mathrm{~mL}$ de $\mathrm{HCl} 0,1 \mathrm{~mol} \mathrm{~L}^{-1} \mathrm{na}$ 
coluna. Esse procedimento permitiu criar um volume morto dentro da coluna para mantê-la úmida, mesmo após as eluições.

Para realizar a eluição dos geradores com sistema de eluição a vácuo, frascos lacrados foram carregados com $8 \mathrm{~mL}$ de $\mathrm{HCl} 0,1 \mathrm{~mol} \mathrm{~L}^{-1}$, mas apenas 6 $\mathrm{mL}$ foram utilizados na eluição (FIG. 4.12). A interrupção da eluição sem permitir total esvaziamento do frasco da solução eluente evitou a secagem da coluna. Foi feita uma marca no frasco da solução eluente para o volume de $2 \mathrm{~mL}$, sendo uma indicação do fim da eluição.

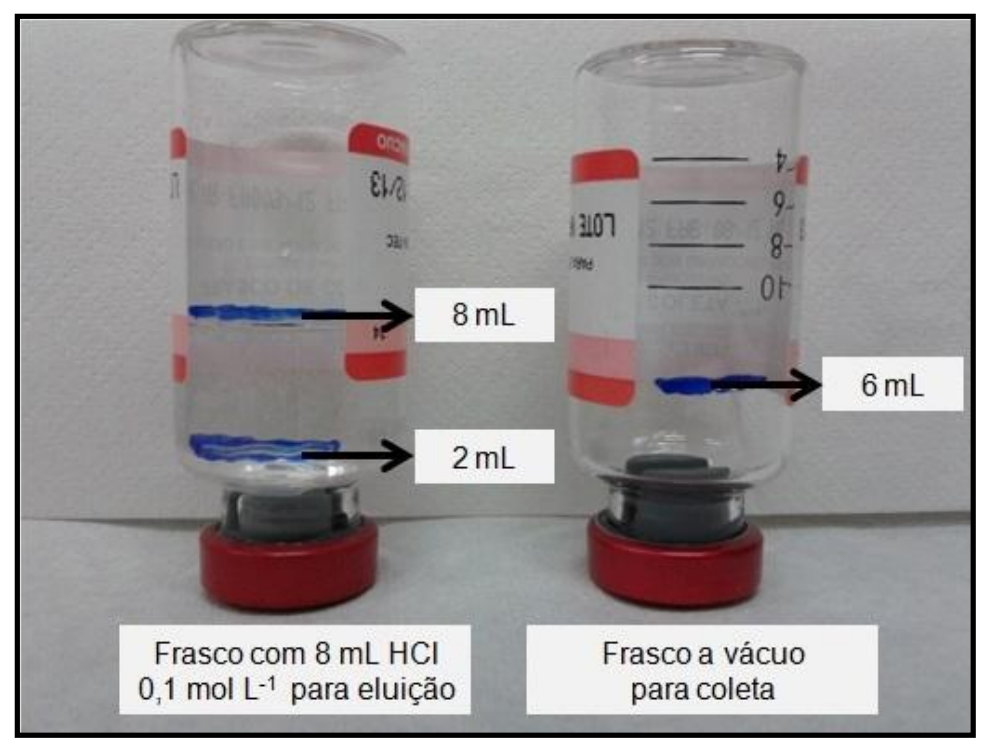

FIGURA 4.12 - Frascos utilizados para eluição do gerador com sistema de eluição a vácuo.

Nos geradores comerciais a eluição é feita com pressão manual. O gerador apresenta duas mangueiras, uma de entrada da solução eluente (inlet) e outra de saída (outlet). A mangueira de entrada possui um adaptador para seringa e a de saída apresenta uma torneira. Para realizar a eluição, a torneira da mangueira do gerador é aberta e colocada em um frasco de vidro para coleta, que deve estar dentro de um castelo de chumbo (FIG. 4.13). A eluição é feita com 5 a $10 \mathrm{~mL}$ de $\mathrm{HCl}$ com concentrações de $0,1 \mathrm{~mol} \mathrm{~L}^{-1}$, para o Gerador da Obninsk e 0,6 mol L ${ }^{-1}$ para o gerador da iThemba. 


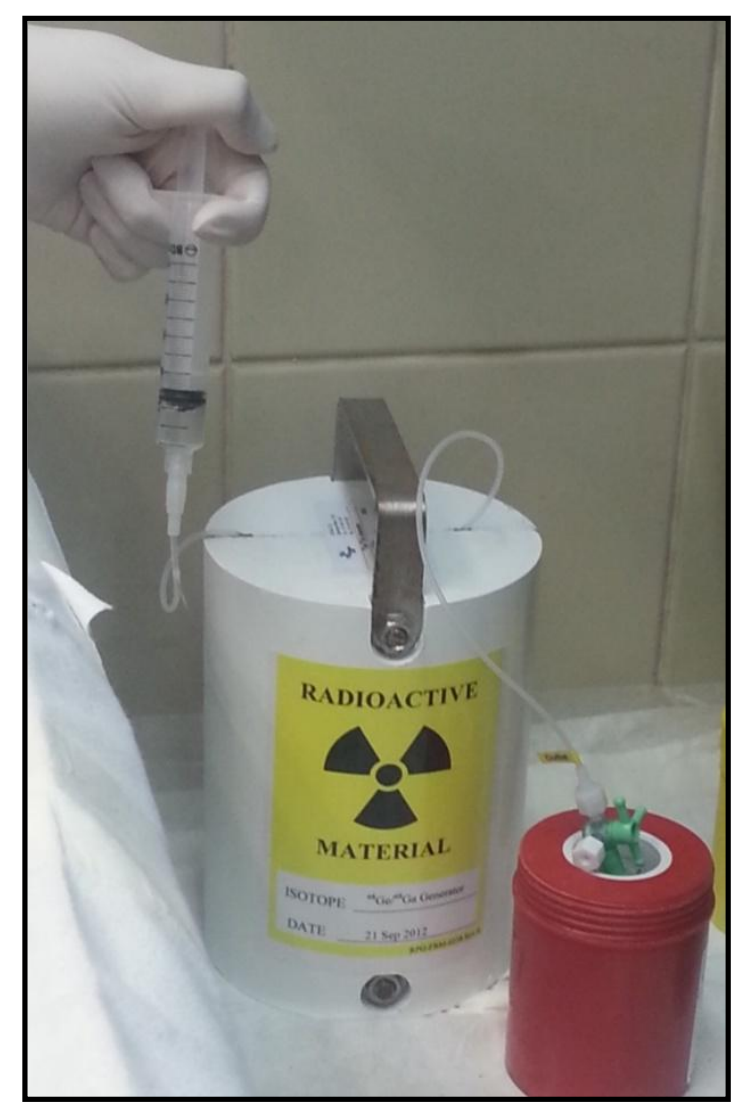

FIG. 4.13 - Ilustração de um processo de eluição do Gerador de ${ }^{68} \mathrm{Ge}-{ }^{68} \mathrm{Ga}$ (iThemba).

Neste trabalho, foram feitos geradores com sistema de eluição a vácuo com o propósito de se criar um sistema fechado, onde seja possível a utilização de solução estéril para eluição, maior praticidade de operação e diminuição da dose para o operador durante a realização das eluições, comparado ao sistema utilizado nos geradores comerciais. Além disso, o desenvolvimento de um sistema fechado facilitaria o preparo de geradores utilizando boas práticas de fabricação, o que poderia contribuir para aprovação desse sistema pelos órgãos regulatórios.

A medida da atividade das amostras obtidas ao longo das eluições de todos os geradores foi realizada no calibrador de dose, Capintec. A partir dos resultados obtidos, foram calculados a eficiência e rendimento de eluição do ${ }^{68} \mathrm{Ga}$.

A eficiência de eluição do gerador, geralmente dada em porcentagem, é determinada como a fração da atividade eluída de ${ }^{68} \mathrm{Ga}$ em relação à atividade teoricamente disponível no momento da eluição (Eq. 4.5). Para o cálculo da atividade teórica de ${ }^{68} \mathrm{Ga}$, considera-se a atividade de ${ }^{68} \mathrm{Ge}$ carregada na coluna (calibração) e o tempo decorrido (t) entre a carga e a eluição (Eq. 4.6). Se o 
sistema do gerador estiver em equilíbrio, a atividade teórica de ${ }^{68} \mathrm{Ga}$ pode ser considerada a mesma do ${ }^{68} \mathrm{Ge}$ e calculada pela equação 4.7 .

$$
\begin{aligned}
& \% \text { Eficiência do gerador }=\frac{A_{68} \text { Ga }(\text { experimental })}{A_{68} 8_{\text {Ga }} \text { (teórica) }} \cdot 100 \\
& A_{68_{G a}(t e o ́ r i c a)}=\mathrm{A}_{68_{\mathrm{Ge}}} \cdot\left(\frac{\lambda_{68_{\mathrm{Ga}}}}{\lambda_{68_{\mathrm{Ga}}}-\lambda_{68} \mathrm{Ge}}\right) \cdot\left[\mathrm{e}^{-\left(\lambda_{68} \mathrm{Ge} \cdot \mathrm{t}\right)}-\mathrm{e}^{-\left(\lambda_{68} \mathrm{Ga} \cdot \mathrm{t}\right)}\right] \\
& \mathrm{A}_{68_{\mathrm{Ga}} \text { (teórica) }}=\mathrm{A}_{68_{\mathrm{Ge}} \text { (inicial) }} \cdot \mathrm{e}^{-\lambda_{68} \mathrm{Ge}} \cdot{ }^{\mathrm{t}}
\end{aligned}
$$

Foram avaliadas as eficiências dos 5 geradores preparados neste trabalho e de dois geradores comerciais: gerador comercial 1 (Obninsk) e gerador comercial 2 (iThemba).

O rendimento percentual de eluição é definido a partir dos valores obtidos no perfil de eluição do gerador, onde a atividade extraída é avaliada por unidade de volume de solução eluída. Assim, é possível determinar por um único processo de eluição, o rendimento equivalente a cada mililitro coletado (Eq. 4.8). O rendimento total é obtido mediante a somatória das atividades eluídas em cada uma das alíquotas coletadas separadamente, considerada como $100 \%$.

$$
\% \text { Rendimento de eluição }=\frac{\Sigma \mathrm{A}_{68} \mathrm{Ga}(\text { experimental })(\mathrm{p} / \mathrm{mL})}{\Sigma \mathrm{A}_{68} \mathrm{Ge}(\text { experimental })} .100
$$

O desempenho e qualidade de um gerador são determinados tanto por sua eficiência e rendimento de eluição, quanto pela qualidade do eluato. Portanto, as amostras de ${ }^{68} \mathrm{Ga}$ de todos os geradores foram submetidas à análises de controle de qualidade descritas no item 4.3.5.

\subsubsection{Controle de qualidade do ${ }^{68} \mathrm{Ga}$}

Para o preparo de radiofármacos é necessário realizar o controle de qualidade do ${ }^{68} \mathrm{Ga}$ eluído do gerador, já que o produto será injetado em seres humanos. Segundo a Farmacopeia Europeia (EUROPEAN DIRECTORATE FOR 
THE QUALITY OF MEDICINES AND HEALTHCARE, 2013) são necessárias as seguintes análises:

$\checkmark$ Identificação dos principais fótons do ${ }^{68} \mathrm{Ga}, 511 \mathrm{keV}$ e $1077 \mathrm{keV}$

$\checkmark$ Identidade radionuclídica

$\checkmark$ Pureza radionuclídica

$\checkmark$ Pureza radioquímica

$\checkmark$ Pureza química

$\checkmark \mathrm{pH}$ do eluato

$\checkmark$ Esterilidade e apirogenicidade

Neste trabalho foram realizadas todas as análises com exceção do microbiológico (esterilidade e apirogenicidade).

\subsubsection{Identificação dos fótons e identidade radionuclídica}

A identificação dos fótons característicos ao decaimento do ${ }^{68} \mathrm{Ga}(511$ $\mathrm{keV}$ e $1077 \mathrm{keV}$ ) foi feita por espectrometria gama, utilizando um detector de germânio hiperpuro (HPGe) (FIG.4.14). As medidas foram realizadas com tempo de contagem de 1 minuto.

O detector de germânio hiperpuro é um detector semicondutor com boa resolução para medidas qualitativas de raios $X$ e raios gama. Possui uma estrutura diodo $n-i-p$, onde a camada-p e a camada-n estão separadas por uma zona de transição $p, n$. Sobre os dois lados criam-se cargas especiais com sinais opostos que formam uma camada de condução, na qual a largura poderá variar através da tensão aplicada. As vantagens dos detectores semicondutores são a boa resolução e uma larga região onde se verifica linearidade entre energia e altura do pulso. A desvantagem para as partículas com energia muito alta ou ionização específica baixa, é que não são absorvidas totalmente nos cristais. Além disso, altas doses de radiação podem alterar a eficiência de contagem por causa da danificação na rede do cristal e as medidas não podem ser realizadas a temperaturas mais altas, sendo necessária a refrigeração do cristal (SUZUKI, 2009).

O detector de germânio tem calibração de energia $\gamma$ feita por meio de fontes calibradas de ${ }^{60} \mathrm{Co},{ }^{152} \mathrm{Eu}$ e ${ }^{137} \mathrm{Cs}$. 


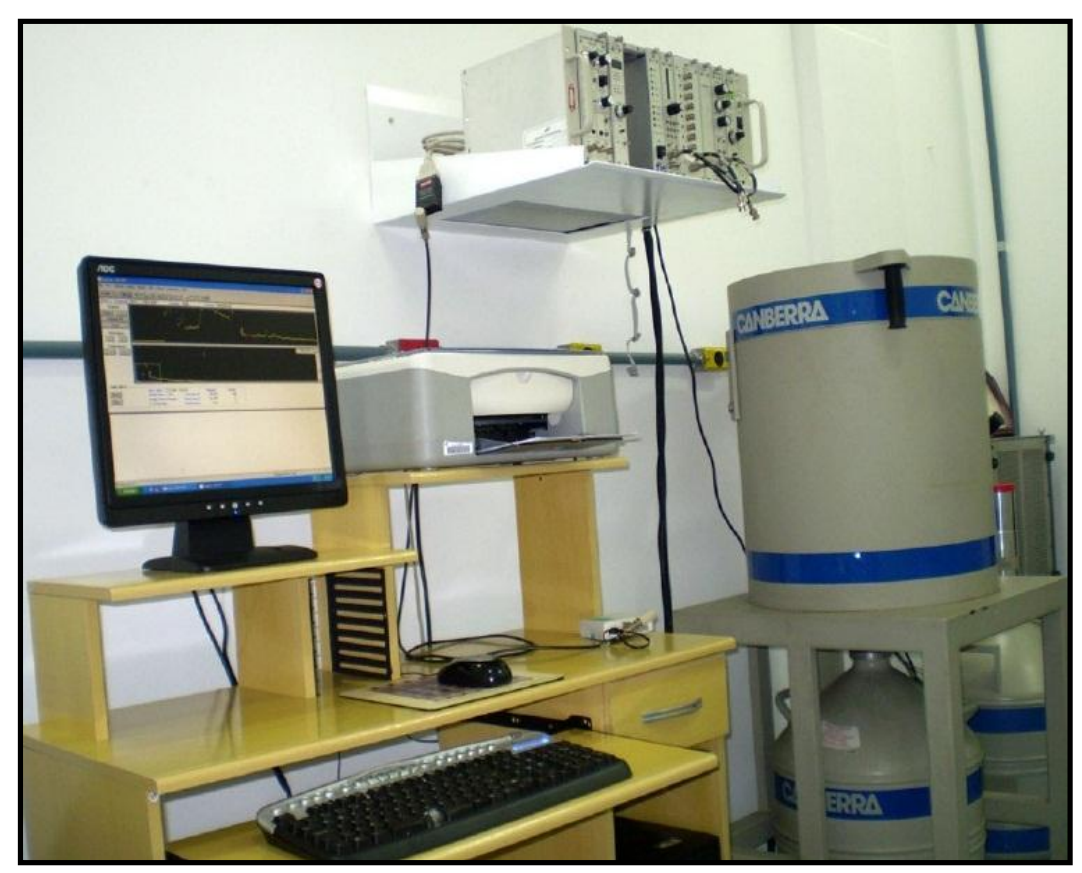

FIGURA 4.14 - Detector de germânio hiperpuro (HPGe) da Canberra, modelo GX1518, acoplado a um sistema de aquisição multicanal e tratamento de dados via microcomputador contendo o programa GENIE-PC.

A identidade radionuclídica é o tempo de meia-vida física $\left(\mathrm{t}_{1 / 2}\right)$ do radionuclídio, que pode ser determinado graficamente a partir da equação da reta da curva de decaimento, $\ln (\mathrm{A})$ versus o tempo. No gráfico do decaimento, 0 coeficiente angular da reta (a) corresponde em valor absoluto à constante de decaimento $(\lambda)$, portanto através da eq. 4.9 é possível determinar $0 t_{1 / 2}$ do elemento analisado.

$$
\mathrm{T}_{1 / 2}=\frac{0,693}{\lambda}
$$

Foram realizadas análises da identidade radionuclídica do ${ }^{68} \mathrm{Ga}$ eluído dos geradores G3, G5 e do gerador comercial da iThemba utilizando o calibrador de doses, Capintec. A Farmacopeia Europeia recomenda a realização de no mínimo três medidas da atividade da amostra em tempos distintos e determina que o resultado encontrado esteja entre 62 a 74 minutos. 


\subsubsection{Pureza radionuclídica}

A pureza radionuclídica é a fração do total de radioatividade da amostra que corresponde ao radionuclídio de interesse.

Nos geradores de ${ }^{68} \mathrm{Ge} /{ }^{68} \mathrm{Ga}$, o possível contaminante radionuclídico do ${ }^{68} \mathrm{Ga}$ é o próprio ${ }^{68} \mathrm{Ge}$. Como $0{ }^{68} \mathrm{Ge}$ decai $100 \%$ por captura eletrônica, a análise para verificar sua presença nas amostras das eluições é feita através da medida da atividade do ${ }^{68} \mathrm{Ga}(511 \mathrm{keV})$, proveniente do decaimento do ${ }^{68} \mathrm{Ge}$, em um detector de radiação gama.

$\mathrm{O}$ método de análise da pureza radionuclídica do ${ }^{68} \mathrm{Ga}$ descrito em vários trabalhos na literatura e na Farmacopeia Europeia, consiste na contagem de uma amostra de ${ }^{68} \mathrm{Ga}$ em um detector de radiação gama e a repetição da contagem da mesma amostra pelo menos 24 horas após a eluição, para que ocorra o decaimento completo do ${ }^{68} \mathrm{Ga}$. A Farmacopeia Europeia preconiza que a segunda contagem seja feita 48 horas após a eluição e que o limite de contaminação de ${ }^{68} \mathrm{Ge}$ seja inferior a $10^{-3} \%$ da atividade do ${ }^{68} \mathrm{Ga}$.

A atividade calculada na segunda contagem é referente ao ${ }^{68} \mathrm{Ga}$ proveniente do ${ }^{68} \mathrm{Ge}$, presente como contaminante na amostra. A relação entre as duas atividades de ${ }^{68} \mathrm{Ga}$ corresponde à porcentagem de ${ }^{68} \mathrm{Ge}$ presente no ${ }^{68} \mathrm{Ga}$.

A relação da porcentagem de ${ }^{68} \mathrm{Ge}$ no ${ }^{68} \mathrm{Ga}$ aumenta com o decorrer do tempo por conta do decaimento do ${ }^{68} \mathrm{Ga}$, ou seja, a cada 68 minutos a contaminação de ${ }^{68} \mathrm{Ge}$ no ${ }^{68} \mathrm{Ga}$ duplica. Portanto, é importante estabelecer para qual momento essa contaminação de ${ }^{68} \mathrm{Ge}$ será calculada. A Farmacopeia Europeia não determina para qual tempo deve-se calcular os níveis de contaminação de ${ }^{68} \mathrm{Ge}$. Neste trabalho, foi utilizada a hora da eluição como tempo referência.

Foi utilizado um detector de germânio hiperpuro (HPGe) para a contagem das amostras e o cálculo da atividade foi feito através da equação 4.10.

$$
\operatorname{dps}=\frac{\mathrm{cps}}{\mathrm{a}_{\gamma} \cdot \varepsilon}
$$

onde:

dps = atividade em desintegrações por segundo $(\mathrm{Bq})$ 
$\mathrm{cps}=$ área do pico de interesse $(511 \mathrm{keV})$ dividida pelo tempo de contagem, em segundos

$\mathrm{a} \gamma=$ abundância gama do pico de energia de interesse

$\varepsilon=$ eficiência do detector para a energia gama de interesse $(511 \mathrm{keV})$

Foram analisadas as amostras dos geradores G2, G3, G4, G5 e de dois geradores comerciais: Obninsk (gerador comercial 1) e iThemba (gerador comercial 2). Para todas as amostras analisadas, a primeira contagem para medir a atividade do ${ }^{68} \mathrm{Ga}$ foi feita com tempo de 1 minuto de contagem e o valor da atividade foi corrigido para a hora da eluição, através da Eq. 4.11.

$$
A=A_{0} \cdot e^{-\lambda \cdot t}
$$

Onde:

$\mathrm{A}=$ atividade

$\mathrm{A}_{0}=$ atividade inicial (neste caso, na hora da eluição)

$\lambda=\ln 2 / \mathrm{t}_{1 / 2}$

$\mathrm{t}_{1 / 2}=$ meia-vida física do ${ }^{68} \mathrm{Ga}=68$ minutos

$\mathrm{t}=$ tempo do decaimento (diferença entre o horário da contagem e o horário da eluição).

A segunda contagem foi realizada a partir de 24 horas da eluição com tempo de 20 minutos. Todas as medidas foram realizadas na posição 3 da estante do detector, que está a $11,7 \mathrm{~cm}$ do mesmo (FIG. 4.15). 


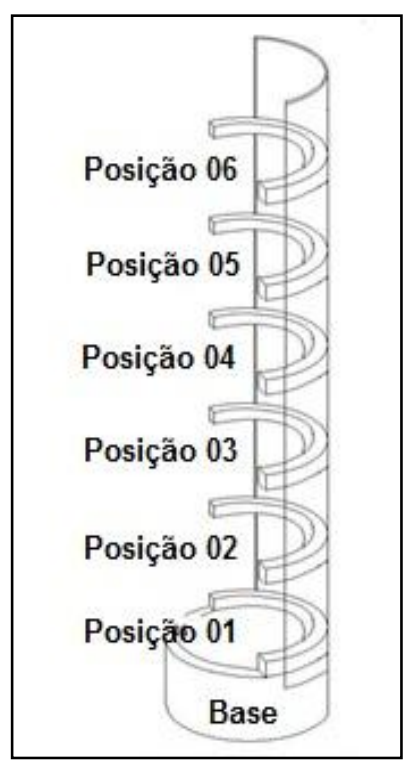

FIGURA 4.15 - Ilustração da estante do detector de HPGe com seis posições para contagem.

A eficiência do detector em função da energia do ${ }^{68} \mathrm{Ga}(511 \mathrm{keV})$ foi determinada para as seis posições da estante do equipamento, utilizando-se as equações descritas na TAB. 4.4 .

TABELA 4.4 - Equações para determinação da eficiência $(\varepsilon)$ do detector de HPGe em seis posições.

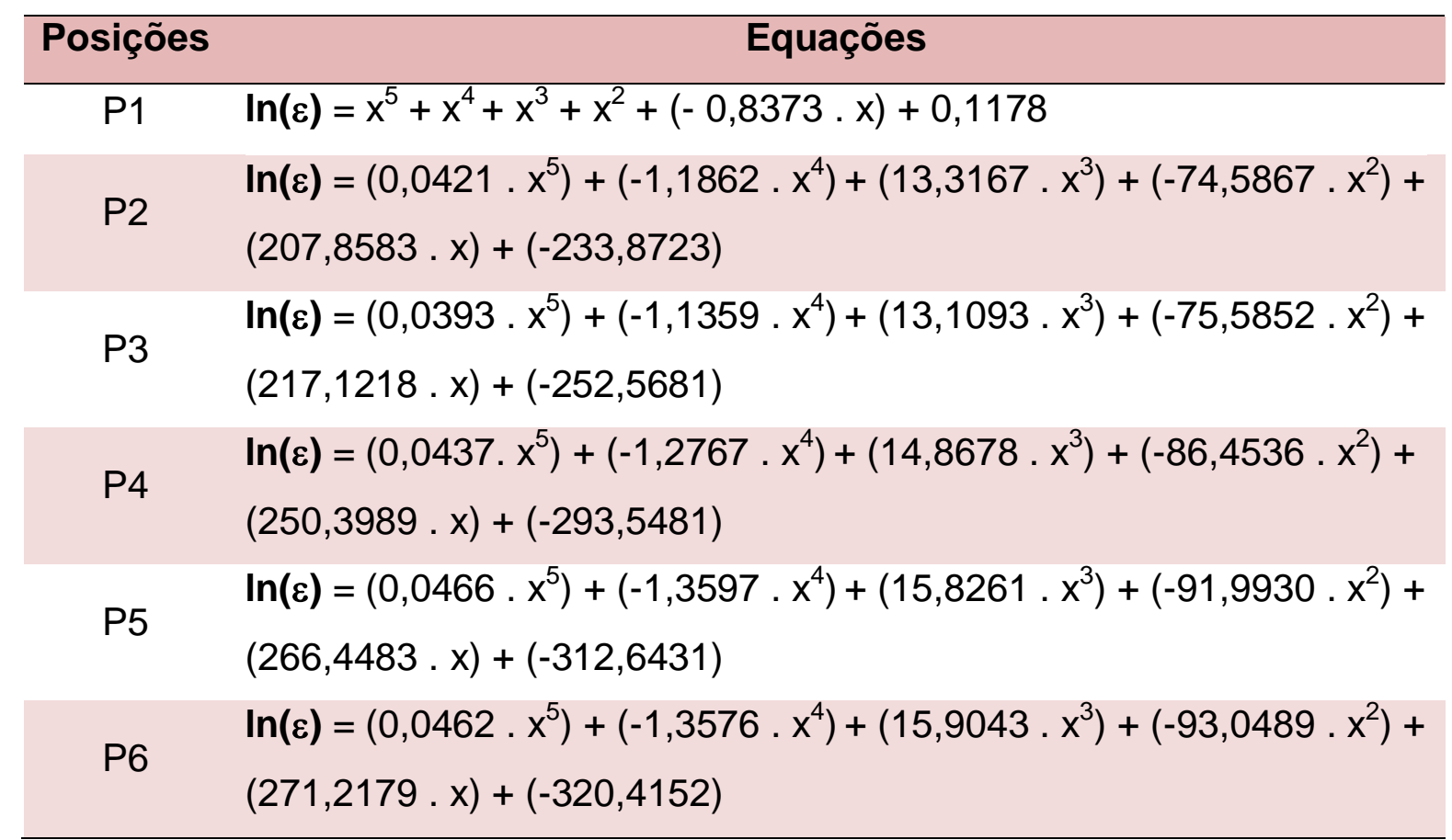


Durante o desenvolvimento deste trabalho notou-se a importância de se calcular os limites de deteç̧ão (LD) e limites de quantificação (LQ) do detector de HPGe para o ${ }^{68} \mathrm{Ga}$, com o objetivo de avaliar qual atividade mínima de ${ }^{68} \mathrm{Ga}$ é necessária na amostra para que seja possível a detecção de $10^{-3} \%$ de ${ }^{68} \mathrm{Ge}$.

Os cálculos para determinação do $L D$ e $L Q$ foram realizados através das equações 4.12 e 4.13 (IAEA-TECDOC, 2004).

$$
\begin{aligned}
& \mathrm{LD}=\mathrm{k}^{2}+\mathrm{k} \sqrt{\mathrm{C}_{\mathrm{BG}} \times\left(1+\frac{\mathrm{n}}{2 \mathrm{~m}}\right)} \\
& \mathrm{LQ}=\left(\frac{1}{\alpha}\right)^{2} \times \sqrt{1+\left(\frac{\mathrm{C}_{\mathrm{BG}}}{\left(\frac{1}{\alpha}\right)^{2}}\right)}
\end{aligned}
$$

onde:

$\mathrm{k}=$ fator de abrangência, sendo $\mathrm{k}=\sigma$ se $o \mathrm{n} \cong \infty$

$\sigma=$ erro

$\mathrm{C}_{\mathrm{BG}}=$ média das contagens do $\mathrm{BG}$ - background (radiação de fundo) (Contagem integral - contagem líquida NET)

$\mathrm{n}=$ número de canais do pico avaliado

$\mathrm{m}=$ número de canais do $\mathrm{BG}$ do pico

$\alpha=$ falso positivo $10 \%$

Segundo a IAEA (IAEA-TECDOC, 2004), deve-se utilizar o maior intervalo de confiança (99,73\%) para determinação do limite de detecção (LD), portanto o valor utilizado para o "k" na equação 4.12 foi igual a 3 (FIG. 4.16).

Foram utilizados 20 canais para as contagens do pico de $511 \mathrm{keV}(\mathrm{n}=$ 20), tanto para as amostras quanto para a contagem do BG. Esse parâmetro é selecionado manualmente no sistema do equipamento. O número de canais referente ao $B G$ do pico é um parâmetro automático do sistema e o valor utilizado foi o de 4 canais ( $m=4)$ (FIG. 4.17). 


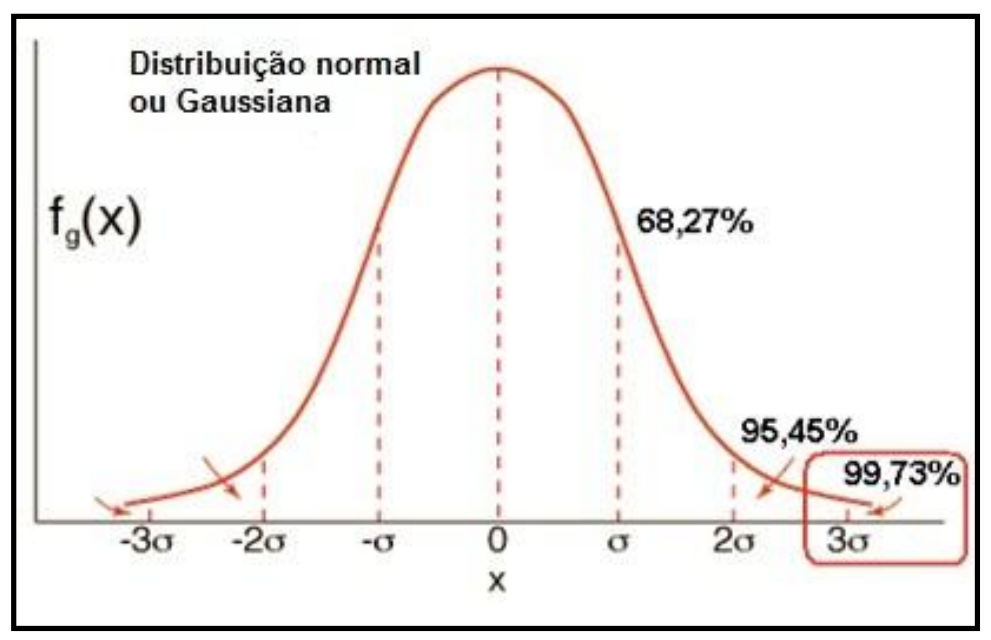

FIGURA 4.16 - Gaussiana.

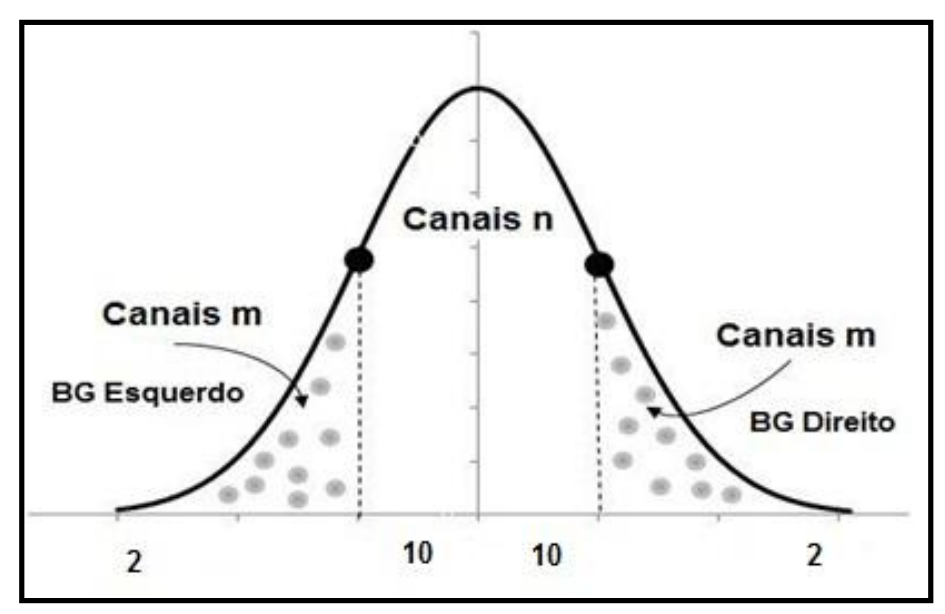

FIGURA 4.17 - Ilustração gráfica do número de canais avaliados para o pico de $511 \mathrm{keV}(\mathrm{n}=20)$ e do número de canais para o BG do pico $(\mathrm{m}=4)$.

Os valores de LD e LQ foram calculados para 20, 60 e 120 minutos de contagem. Para 20 minutos foram realizadas 10 contagens do BG e para os tempos de 60 e 120 minutos foram feitas 3 contagens. O valor do BG foi determinado através da subtração da contagem líquida (NET) da contagem do contínuo (integral). Foram calculadas as médias dos valores obtidos em cada tempo para serem então utilizadas nas equações 4.12 e 4.13 .

\subsubsection{Pureza radioquímica}

A pureza radioquímica é a fração da radioatividade total na forma química desejada presente no eluato. De acordo com a Farmacopeia Europeia, a 
pureza radioquímica do ${ }^{68} \mathrm{Ga}$, na forma iônica ${ }^{68} \mathrm{Ga}^{3+}$, tem que ser no mínimo 95 $\%$ da atividade total eluída.

O método descrito na Farmacopeia Europeia para determinação da pureza radioquímica é feito por cromatografia em camada delgada, utilizando fita ITLC (Instant Thin Layer Chromatography) como fase estacionária e como fase móvel a mistura de acetato de amônia $1 \mathrm{~mol} \mathrm{~L}^{-1}$ e metanol (50:50 v/v). Para a realização da cromatografia é necessário o preparo de soluções referência $(A)$ e (B) com o eluato de ${ }^{68} \mathrm{Ga}$, através do seguinte procedimento:

$>\mathrm{O}$ eluato de ${ }^{68} \mathrm{Ga}$ é ajustado para uma concentração de $\mathrm{HCl}$ de aproximadamente $0,3 \mathrm{~mol} \mathrm{~L}^{-1}$, que passa a ser chamada de "solução teste".

$>A$ solução referência $(A)$ é preparada com a adição de $0,3 \mathrm{~mL}$ de $\mathrm{NaOH} 0,1$ mol L $\mathrm{L}^{-1}$ em $0,2 \mathrm{~mL}$ da solução teste. A cromatografia é realizada após 30 minutos do preparo da solução. O Rf (fator de retardamento) para o pico principal da cromatografia obtido com essa solução não pode ser maior que 0,1 .

> A solução referência (B) é preparada com a adição de $1 \mathrm{~mL}$ da solução teste em $1 \mathrm{~mL}$ de solução de DTPA ( $0,1 \mathrm{~mol} \mathrm{~L}^{-1}$, preparada com solução de $\mathrm{NaOH} 0,1 \mathrm{~mol} \mathrm{~L}^{-1}$. O Rf para o pico principal da cromatografia obtido com essa solução não pode ser menor que 0,7 .

Neste trabalho, a análise da pureza radioquímica foi avaliada segundo as recomendações da Farmacopeia Europeia, porém foi realizada a cromatografia utilizando-se apenas a solução referência $A$.

As fitas foram cortadas com $1,5 \mathrm{~cm}$ de largura por $12 \mathrm{~cm}$ de altura. Foram marcadas linhas com lápis, sendo a primeira a $1,5 \mathrm{~cm}$ da base e as outras em segmentos de $1 \mathrm{~cm}$ depois desta marca (FIG. 4.18). O solvente foi colocado em cuba de vidro em quantidade suficiente para cobrir o fundo (FIG. 4.19).

Uma amostra de aproximadamente $5 \mu \mathrm{L}$ da solução referência $(A)$ foi aplicada com micropipeta no centro da marca de origem da fita. Depois da secagem da amostra, a fita foi colocada na cuba. Após o término da corrida do solvente e secagem da fita, a mesma foi cortada em segmentos e a atividade de cada segmento foi contada no detector de Germânio hiperpuro, utilizando o pico de $511 \mathrm{keV}$ do ${ }^{68} \mathrm{Ga}$. 
A porcentagem da pureza radioquímica (\% PR) corresponderá a porcentagem de atividade encontrada no segmento 1 da fita em relação a somatória da atividade de todos os segmentos da fita, calculada pela eq. (4.14).

$\% \mathrm{PR}=\frac{\text { contagem do segmento } 1}{\Sigma \text { contagem dos } 10 \text { segmentos }} \cdot 100$

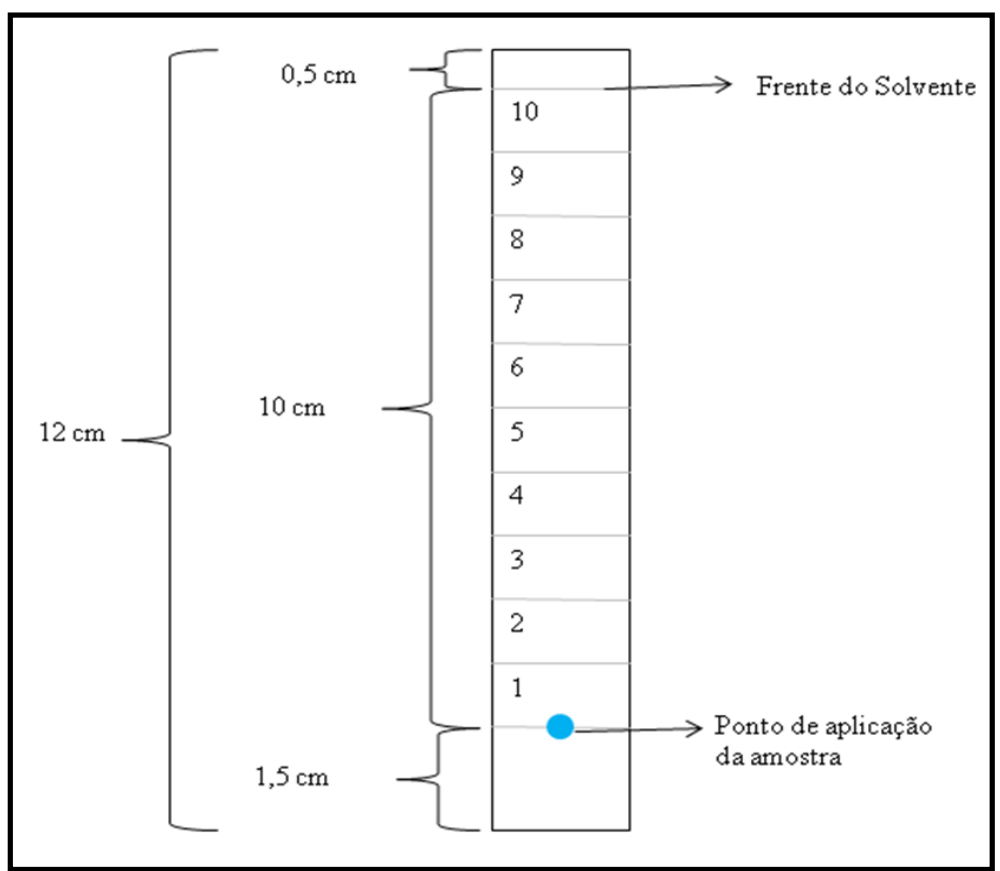

FIGURA 4.18 - Representação da fita cromatográfica utilizada no controle da pureza radioquímica.

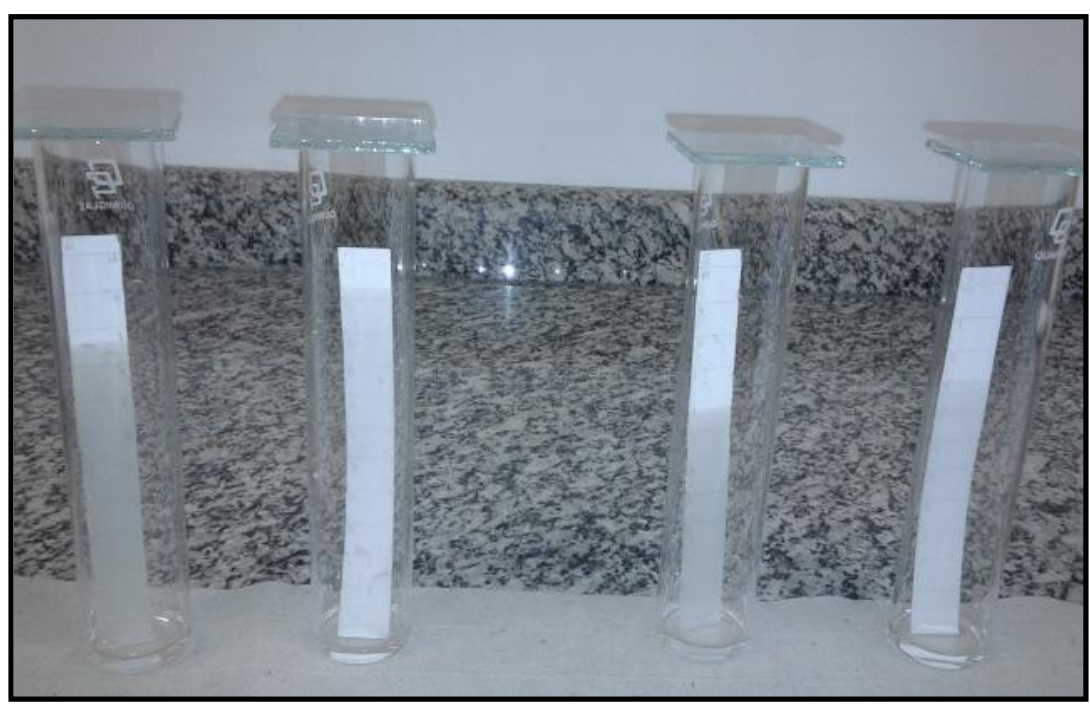

FIGURA 4.19 - Cubas de vidro com fitas cromatográficas. 


\subsubsection{Pureza química}

Os metais analisados nas amostras das eluições foram o Ti, $\mathrm{Fe}, \mathrm{Zn}$ e o próprio Ge. A possível contaminação de Ti pode ocorrer por causa do material adsorvedor da coluna $\left(\mathrm{TiO}_{2}\right)$. O Fe pode estar presente em todas as soluções utilizadas durante o processo de preparo do material adsorvedor, preparo de soluções e montagem da coluna. A principal fonte de contaminação de Zn é o próprio decaimento radioativo do ${ }^{68} \mathrm{Ga}$, que decai para o $\mathrm{Zn}$ estável, além de ser um contaminante comum em reagentes e soluções.

As amostras das eluições foram analisadas por espectrometria de emissão óptica com plasma indutivamente acoplado (ICP-OES) (Varian VistaMPX) (FIG.4.6). Para o Ti, Fe e Zn foram construídas curvas de calibração na faixa de concentração de 0,2 a $1,0 \mu \mathrm{g} \mathrm{mL}^{-1}$ e para o Ge de 0,02 a $0,1 \mu \mathrm{g} \mathrm{mL}^{-1}$.

\subsubsection{Medida do $\mathrm{pH}$}

$\mathrm{O} \mathrm{pH}$ das amostras das eluições foi medido através de papel indicador de $\mathrm{pH}$ (Merck KGaA). O limite permitido segundo a Farmacopeia Europeia é de no máximo 2,0.

\subsubsection{Determinação da pureza radionuclídica do ${ }^{68} \mathrm{Ga}$ por fitas cromatográficas}

\subsubsection{Seleção do sistema de separação}

O método tradicional de análise da pureza radionuclídica que necessita do decaimento total da atividade do ${ }^{68} \mathrm{Ga}$ para uma posterior recontagem da atividade da amostra é eficiente, mas outros métodos que forneçam uma resposta mais rápida precisam ser desenvolvidos.

Nesta etapa do trabalho foi estudado um novo método para análise da pureza radionuclídica. Esse método consiste na utilização de um sistema 
cromatográfico utilizando fitas de ITLC (Instant Thin Layer Chromatography), TLC ou papel para separação do ${ }^{68} \mathrm{Ge}$ do ${ }^{68} \mathrm{Ga}$.

Um sistema eficiente que separe esses dois radionuclídeos pode proporcionar uma análise da contaminação do ${ }^{68} \mathrm{Ge}$ mais rápida, comparada ao método tradicional, levando-se em conta que o crescimento da atividade do ${ }^{68} \mathrm{Ga}$ alcança equilíbrio (> 95\%) com o ${ }^{68} \mathrm{Ge}$ em aproximadamente 5 horas (FIG. 4.20). Torna-se assim possível avaliar a pureza radionuclídica depois de 1 ou 2 horas após a separação das espécies pelos sistemas de fitas cromatográficas.

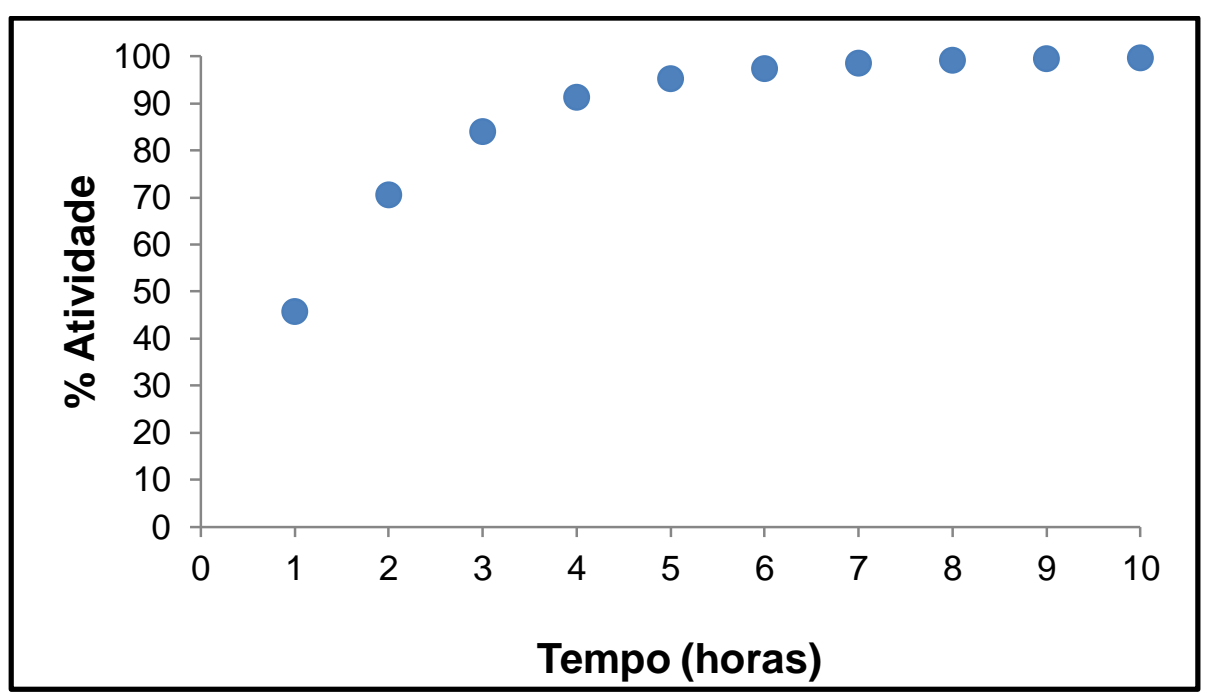

FIGURA 4.20 - Curva de crescimento do ${ }^{68} \mathrm{Ga}$ mostrando a porcentagem da atividade em relação ao tempo.

Vários sistemas cromatográficos foram avaliados para a separação do ${ }^{68} \mathrm{Ge}$ do ${ }^{68} \mathrm{Ga}$, utilizando-se diferentes tipos de fitas e solventes. Inicialmente, para avaliar melhor a separação dos radioisótopos, foram utilizadas amostras do próprio ${ }^{68} \mathrm{Ge}$.

Durante a realização desse estudo, foi encontrado na literatura um trabalho que estudou a determinação das purezas radionuclídica e radioquímica do DOTATOC $-{ }^{68} \mathrm{Ga}$ por fitas cromatográficas (EPPARD et al., 2012). Eppard et al. utilizaram fitas TLC com $\mathrm{HCl} 2 \mathrm{~mol} \mathrm{~L}^{-1} /$ acetona (1:1) e conseguiram separar 0 ${ }^{68} \mathrm{Ga},{ }^{68} \mathrm{Ge}$ e o produto marcado, com os seguintes $\mathrm{R}_{\mathrm{f}}:{ }^{68} \mathrm{Ge}=0,1 ;{ }^{68} \mathrm{Ga}=1 \mathrm{e}$ DOTATOC $-{ }^{68} \mathrm{Ga}=0,4$. No presente trabalho, esse sistema utilizado por Eppard et al. foi avaliado para determinação da pureza radionuclídica do eluato de ${ }^{68} \mathrm{Ga}$. 
Na TAB. 4.5 estão apresentados todos os sistemas cromatográficos estudados neste trabalho.

TABELA 4.5 - Sistemas cromatográficos estudados para separação do ${ }^{68} \mathrm{Ge}$ e ${ }^{68} \mathrm{Ga}$.

\begin{tabular}{|c|c|c|}
\hline Suporte & Spot na fita & Solvente \\
\hline Whatman 3 & EDTA $0,1 \mathrm{~mol} \mathrm{~L}^{-1}$ & $\mathrm{CCl}_{4}$ saturado com $\mathrm{HCl} 6 \mathrm{~mol} \mathrm{~L}^{-1}$ \\
\hline Whatman 3 & EDTA $0,1 \mathrm{~mol} \mathrm{~L}^{-1}$ & Acetona \\
\hline Whatman 3 & - & Acetona \\
\hline TLC-SG-AI & - & Acetona \\
\hline Whatman 3 & EDTA $0,1 \mathrm{~mol} \mathrm{~L}^{-1}$ & $\mathrm{NaCl} 0,9 \%$ \\
\hline Whatman 3 & - & EDTA $0,1 \mathrm{~mol} \mathrm{~L}^{-1}$ \\
\hline TLC-SG-IB-F & - & EDTA $0,1 \mathrm{~mol} \mathrm{~L}^{-1}$ \\
\hline Whatman 3 & - & $\mathrm{HCl} 3 \mathrm{~mol} \mathrm{~L}^{-1} /$ butanol $(1: 1)$ \\
\hline Whatman 3 & - & Citrato de sódio $1 \mathrm{~mol} \mathrm{~L}^{-1}$ \\
\hline Whatman 3 & - & $\mathrm{HCl} 2 \mathrm{~mol} \mathrm{~L}^{-1} /$ acetona $(1: 1)$ \\
\hline Whatman 3 & EDTA $0,1 \mathrm{~mol} \mathrm{~L}^{-1}$ & $\mathrm{HCl} 2 \mathrm{~mol} \mathrm{~L}^{-1} /$ acetona $(1: 1)$ \\
\hline TLC-SG-IB-F & - & $\mathrm{HCl} 2 \mathrm{~mol} \mathrm{~L}^{-1} /$ acetona $(1: 1)$ \\
\hline ITLC & - & $\mathrm{HCl} 2 \mathrm{~mol} \mathrm{~L}^{-1} /$ acetona $(1: 1)$ \\
\hline Whatman 3 & - & $\mathrm{HCl} 2 \mathrm{~mol} \mathrm{~L}^{-1} / \mathrm{etanol}(1: 1)$ \\
\hline TLC-SG-IB-F & - & $\mathrm{HCl} 2 \mathrm{~mol} \mathrm{~L}^{-1} / \mathrm{etanol}(1: 1)$ \\
\hline TLC-SG-IB-F & - & $\mathrm{HCl} 2 \mathrm{~mol} \mathrm{~L}^{-1} /$ metanol $(1: 1)$ \\
\hline TLC-SG-IB-F & $\mathrm{HCl} 3 \mathrm{~mol} \mathrm{~L}^{-1}$ & Acetona \\
\hline TLC-SG-IB-F & - & Acetona \\
\hline TLC-SG-IB-F & - & $\mathrm{HCl} 0,02 \mathrm{~mol} \mathrm{~L}^{-1} \mathrm{em}$ acetona \\
\hline
\end{tabular}

As fitas e as cubas foram preparadas conforme explicado no item 4.3.5.3, sobre pureza radioquímica.

Uma amostra de ${ }^{68} \mathrm{Ge}(\sim 3 \mu \mathrm{L})$ foi colocada com micropipeta no centro da marca de origem da fita. Para alguns sistemas foi aplicado um determinado solvente ou complexante na origem da fita antes de se colocar a alíquota de ${ }^{68} \mathrm{Ge}$, com o objetivo de reagir com uma das espécies, ${ }^{68} \mathrm{Ge}$ ou ${ }^{68} \mathrm{Ga}$, para mantê-las na origem (FIG. 4.21).

O EDTA $0,1 \mathrm{~mol} \mathrm{~L}^{-1}$ foi utilizado no spot da fita com o objetivo de complexar com $0^{68} \mathrm{Ga}$ e mantê-lo na origem. Os primeiros geradores de ${ }^{68} \mathrm{Ge} /{ }^{68} \mathrm{Ga}$ utilizavam EDTA como solução eluente e a informação encontrada na literatura é que o Ga forma um complexo de difícil dissociação com este reagente. 
O spot de $\mathrm{HCl} 3 \mathrm{~mol} \mathrm{~L}^{-1}$ foi utilizado para alterar a espécie química do ${ }^{68} \mathrm{Ga}$, que se encontra como uma forma catiônica de ${ }^{68} \mathrm{Ga}^{3+}$, mudando para uma espécie aniônica ${ }^{68} \mathrm{GaCl}_{4}$. Este sistema busca uma otimização do sistema utilizado por Eppard et al., que conseguiram a separação do ${ }^{68} \mathrm{Ge}$ e do ${ }^{68} \mathrm{Ga}$ utilizando como solvente $\mathrm{HCl} 2 \mathrm{~mol} \mathrm{~L}^{-1} /$ acetona. A vantagem de se usar apenas a acetona como solvente é a diminuição no tempo de ascensão do solvente na fita.

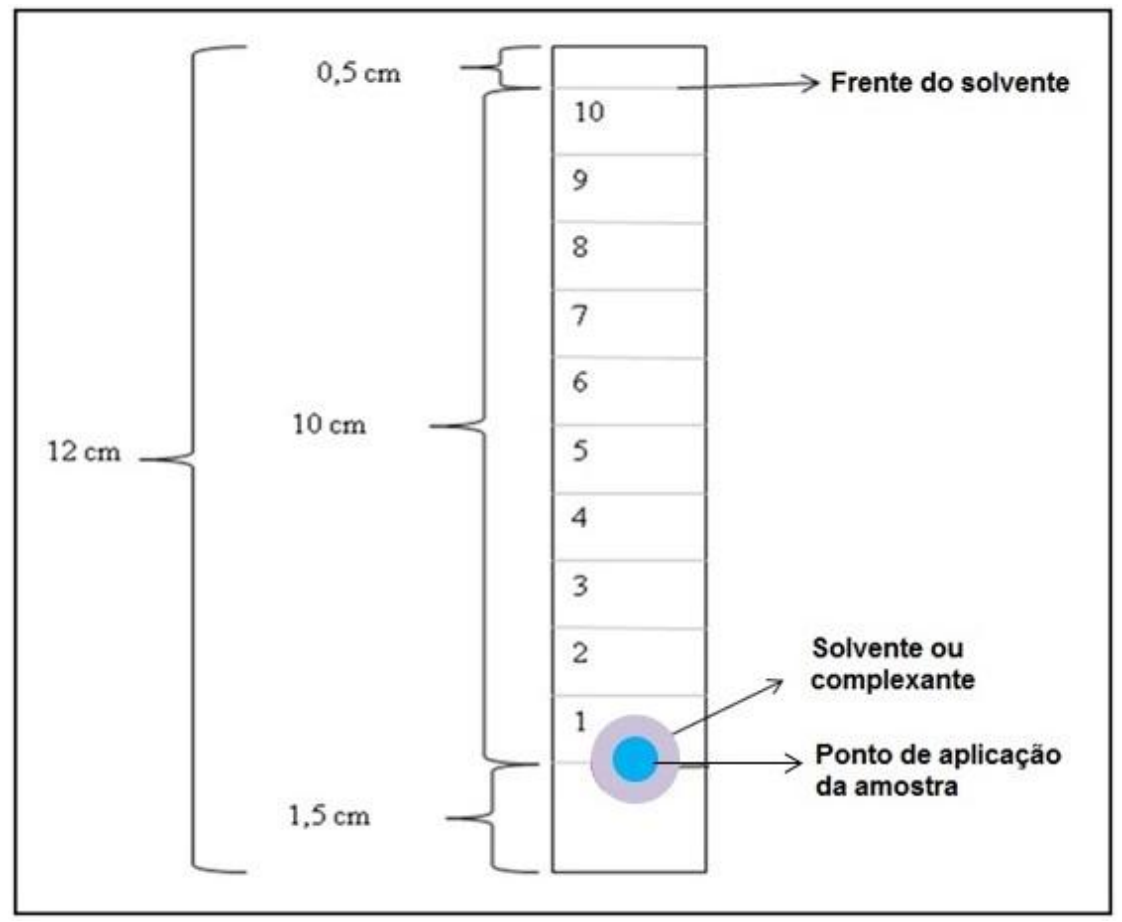

FIGURA 4.21 - Representação da fita cromatográfica utilizada no controle da pureza radionuclídica.

Após o término da corrida do solvente e secagem da fita, a mesma foi cortada em segmentos e a atividade de cada segmento foi contada no detector de Germânio hiperpuro utilizando o pico de 511 keV do ${ }^{68} \mathrm{Ga}$.

Foram realizadas duas contagens para cada fita com tempo de contagem de 1 minuto. A primeira contagem foi feita após a secagem da fita e a segunda contagem foi realizada depois de 24 horas, para avaliar se houve uma separação efetiva do ${ }^{68} \mathrm{Ge}$ e do ${ }^{68} \mathrm{Ga}$.

Para o sistema que apresentou melhor resultado de separação das espécies, foram adquiridas imagens da fita cromatográfica no equipamento $\mu \mathrm{PET}$ (FIG. 4.22). $O \mu$ PET é um equipamento de tomografia por emissão de pósitron com dimensões apropriadas para estudo com animais pequenos, como ratos e 
camundongos. O princípio de funcionamento do equipamento é igual a um equipamento PET utilizado no diagnóstico de seres humanos.

O campo de visão (FOV - field of view) do equipamento é de $9 \mathrm{~cm}$. Devido ao tamanho da fita $(12 \mathrm{~cm})$, foram necessárias duas aquisições de imagem com deslocamento da mesa e posterior reconstrução, feitas automaticamente pelo sistema do equipamento.

As imagens foram adquiridas em 4 tempos distintos, contados após a corrida do solvente na fita (1:15 h; 3:20 h; 4:35 h; 5:25 h).

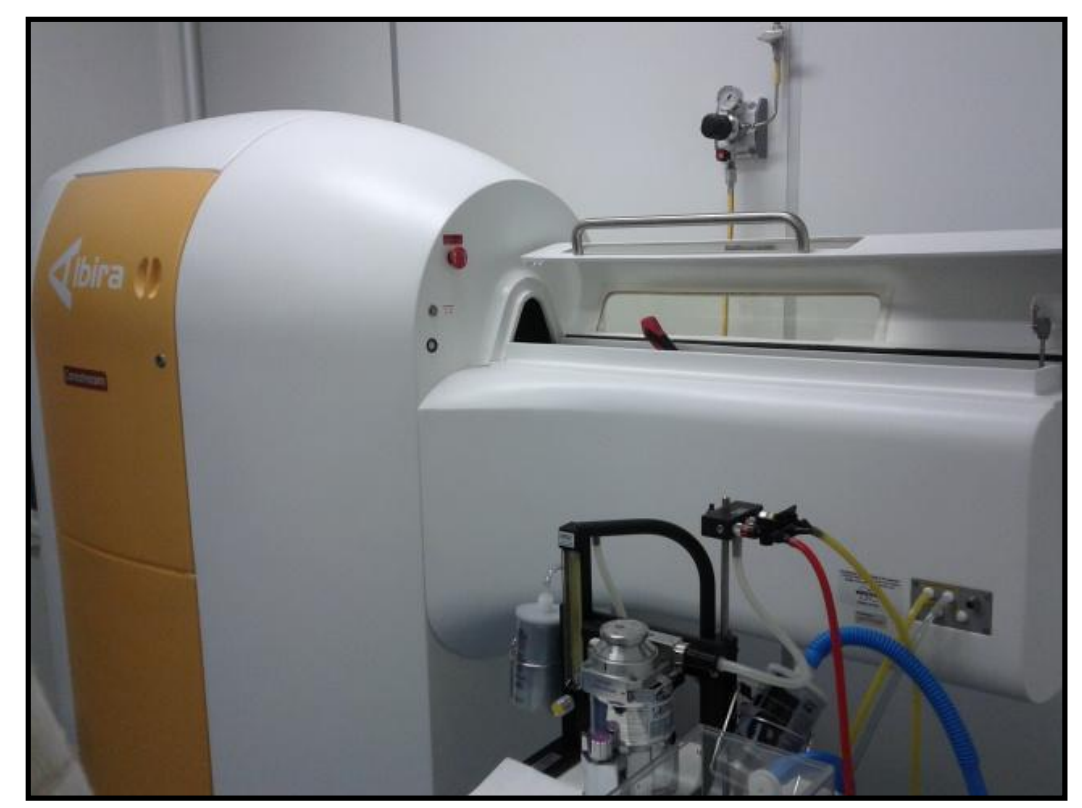

FIGURA 4.22 - Equipamento micro PET Albira (Bruker Co.).

\subsubsection{Análise da amostra de ${ }^{68} \mathrm{Ga}$}

O sistema cromatográfico que apresentou melhor resultado na separação do ${ }^{68} \mathrm{Ge}$ e do ${ }^{68} \mathrm{Ga}$ foi utilizado para avaliação da pureza radionuclídica do ${ }^{68} \mathrm{Ga}$. Devido a amostra utilizada ser da ordem de microlitros $(\sim 3 \mu \mathrm{L})$, utilizouse amostra de ${ }^{68} \mathrm{Ga}$ eluído do gerador comercial da iThemba, que apresentou concentração radioativa de aproximadamente $70 \mathrm{MBq} / \mathrm{mL}(1,9 \mathrm{mCi} / \mathrm{mL})$. Para contagem da atividade dos segmentos da fita foi utilizado um contador gama (FIG. 4.23). A contagem dos segmentos foi realizada em quatro tempos diferentes, contados a partir do início da corrida do solvente na fita, que corresponde ao momento da separação das duas espécies, ${ }^{68} \mathrm{Ge} \mathrm{e}{ }^{68} \mathrm{Ga}$. 
As atividades obtidas nos segmentos referentes ao ${ }^{68} \mathrm{Ga}$ foram corrigidas para a hora da eluição, utilizando a eq. 4.11. Para esse cálculo foram utilizados os valores obtidos no primeiro tempo de contagem.

A atividade encontrada no segmento da fita correspondente ao ${ }^{68} \mathrm{Ge}$ foi analisada nos quatro tempos distintos de contagem. Para cada tempo foi calculado a porcentagem do crescimento do ${ }^{68} \mathrm{Ga}$, correspondente ao decaimento do ${ }^{68} \mathrm{Ge}$ (Eq. 4.6), considerando-se o horário de início da realização da cromatografia, momento no qual as espécies foram separadas. As atividades encontradas em cada tempo foram corrigidas para um crescimento de $100 \%$.

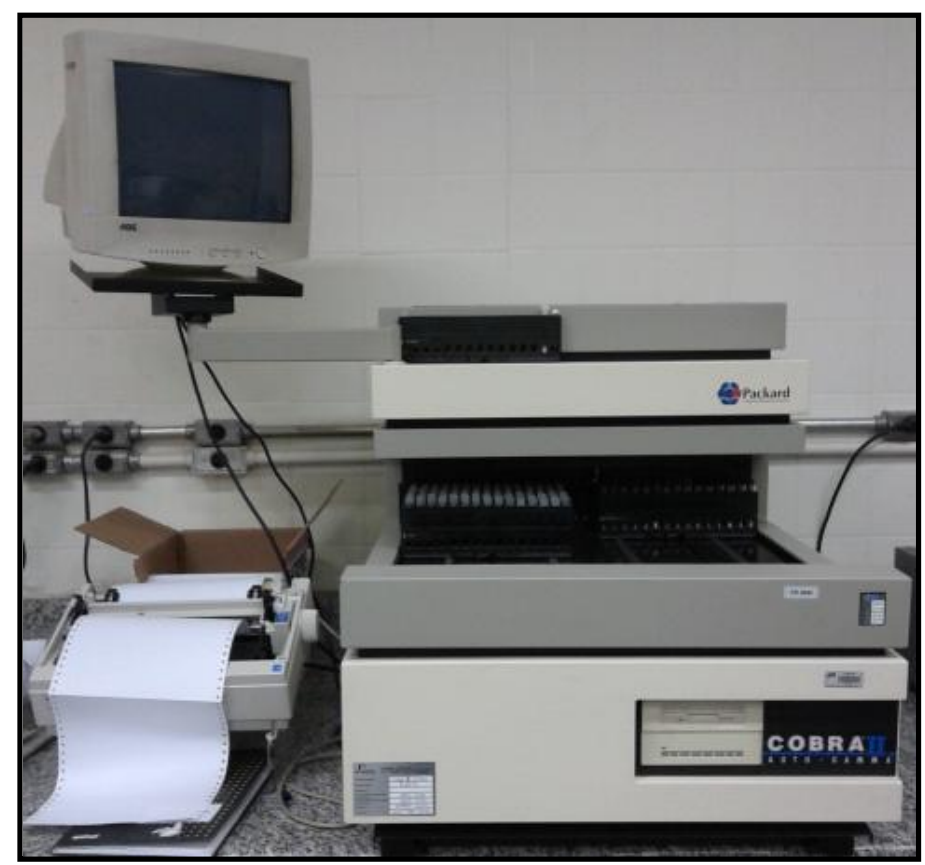

FIGURA 4.23 - Contador gama, modelo Cobra II ES5002 (PerkinElmer do Brasil Ltda.).

A eficiência $(\varepsilon)$ do contador gama foi calculada através da equação 4.15. Foi realizada a contagem no contador gama de uma atividade conhecida de ${ }^{68} \mathrm{Ga}$, previamente determinada através do detector de germânio hiperpuro.

$$
\varepsilon=\frac{\mathrm{cps}}{\mathrm{a}_{\gamma} \mathrm{dps}}
$$

Onde:

$\mathrm{dps}=$ atividade em desintegrações por segundo $(\mathrm{Bq})$

$\mathrm{cps}=$ contagens por segundo 
$\mathrm{a} \gamma=$ abundância gama do pico de energia de interesse (511 keV)

Assim como para o detector de germânio hiperpuro, limites de detecção LD e LQ do contador gama foram calculados para a energia de $511 \mathrm{keV}$.

Os limites LD foram calculados para diferentes tempos de contagem através da equação 4.16 (VANDEGRIFT et al., 1995). O LQ foi calculado pela equação 4.17 (CURRIE, 1968).

$$
\mathrm{LD}=4,65 \cdot \sqrt{\frac{\mathrm{BG}}{\mathrm{t} . \mathrm{I} . \varepsilon}}
$$

$B G=$ média de contagens do $B G$

$\mathrm{t}=$ tempo de contagem

$\mathrm{I}=$ abundância gama do pico de energia de interesse $(511 \mathrm{keV})$

$\varepsilon=$ eficiência do detector para a energia gama de interesse $(511 \mathrm{keV})$

$$
L Q=10 . \sigma
$$

$\sigma=$ desvio padrão da média das contagens do BG

Para avaliar a confiabilidade na utilização deste método para determinação da pureza radionuclídica do ${ }^{68} \mathrm{Ga}$, os resultados obtidos foram comparados com valores encontrados na análise, da mesma amostra de eluição, feita pelo método convencional, que realiza a recontagem da amostra 24 horas após a eluição.

A análise pelo método convencional foi realizada em dois equipamentos diferentes, detector de germânio hiperpuro e contador gama.

O contador gama é um contador tipo poço, composto por detectores de iodeto de sódio dopado com tálio (Nal[TI]). Possui alta sensibilidade devido à geometria do sistema, em que a amostra a ser analisada é introduzida no poço constituído pelo próprio cristal. O contador permite detectar atividades na faixa de nano a $\mu \mathrm{Ci}$. Os detectores de cintilação empregados nestes sistemas devem ser 
submetidos a controle periódico de resolução energética e linearidade, além da monitoração periódica do BG (LIMA et al., 2012).

\subsubsection{Imagem da coluna do gerador de ${ }^{68} \mathrm{Ge} /{ }^{68} \mathrm{Ga}$ no $\mu \mathrm{PET}$}

Foi realizada aquisição de imagem da coluna do gerador de ${ }^{68} \mathrm{Ge} /{ }^{68} \mathrm{Ga}$, G3, no equipamento $\mu \mathrm{PET}$ Albira, com objetivo de analisar a distribuição da adsorção do radionuclídeo ${ }^{68} \mathrm{Ge}$ no $\mathrm{TiO}_{2}$ contido na coluna. $\mathrm{O}$ tempo de aquisição de imagem foi de 10 minutos.

\subsubsection{Projeto de gerador com sistema a vácuo para eluição e purificação}

Para algumas eluições dos geradores G3 e G5 utilizou-se na saída dos geradores um cartucho cationico (Strata X-C Phenomenex) com o objetivo de avaliar a adsorção do ${ }^{68} \mathrm{Ga}$ no cartucho. Posteriormente, ${ }^{\circ}{ }^{68} \mathrm{Ga}$ foi eluído com solução de $\mathrm{HCl}$ 0,02 $\mathrm{mol} \mathrm{L}^{-1}$ preparada em acetona. Esse cartucho de troca iônica é utilizado nos módulos de síntese do DOTATATO- ${ }^{68} \mathrm{Ga}$ e DOTANOC- ${ }^{68} \mathrm{Ga}$ para purificação do ${ }^{68} \mathrm{Ga}$ antes da marcação dessas biomoléculas.

A partir desses estudos de purificação do ${ }^{68} \mathrm{Ga}$ durante a eluição foi desenvolvido um projeto de gerador com eluição a vácuo, que possui um cartucho de purificação acoplado ao sistema do gerador, fornecendo $0{ }^{68} \mathrm{Ga}$ já purificado. 


\section{RESULTADOS E DISCUSSÃO}

\subsection{Estudo do comportamento químico do Ge e do Ga nos materiais adsorvedores}

Tendo em vista a indisponibilidade do ${ }^{68} \mathrm{Ge}$ no início do desenvolvimento deste projeto, o estudo do comportamento químico do Ge e do $\mathrm{Ga}$ nos diferentes materiais adsorvedores foi realizado através do uso de traçadores, radioativo para o Ga e químico para o Ge. Essa alternativa mostrouse eficiente para a escolha dos materiais, além de contribuir para a redução de rejeitos radioativos, o que é muito importante, levando-se em conta que $0{ }^{68} \mathrm{Ge}$ tem uma meia-vida física de 271 dias.

$\mathrm{Na}$ etapa inicial do trabalho vários materiais adsorvedores foram selecionados para montagem de colunas cromatográficas com o objetivo de se estudar o comportamento químico do Ge e do ${ }^{67 / 68} \mathrm{Ga}$ nesses materiais, tendo em mente a concepção de um gerador, onde o radionuclídeo pai fique adsorvido no material da coluna e o radionuclídeo filho possa ser eluído.

As amostras contendo Ge foram analisadas por ICP-OES e os limites de detecção e quantificação para o Ge nesse equipamento foram: $L D=0,005 \mu \mathrm{g}$ $\mathrm{mL}^{-1}$ e $\mathrm{LQ}=0,017 \mu \mathrm{g} \mathrm{mL}^{-1}$. Esses valores foram determinados através das curvas de calibração demonstradas na FIG 5.1 . 


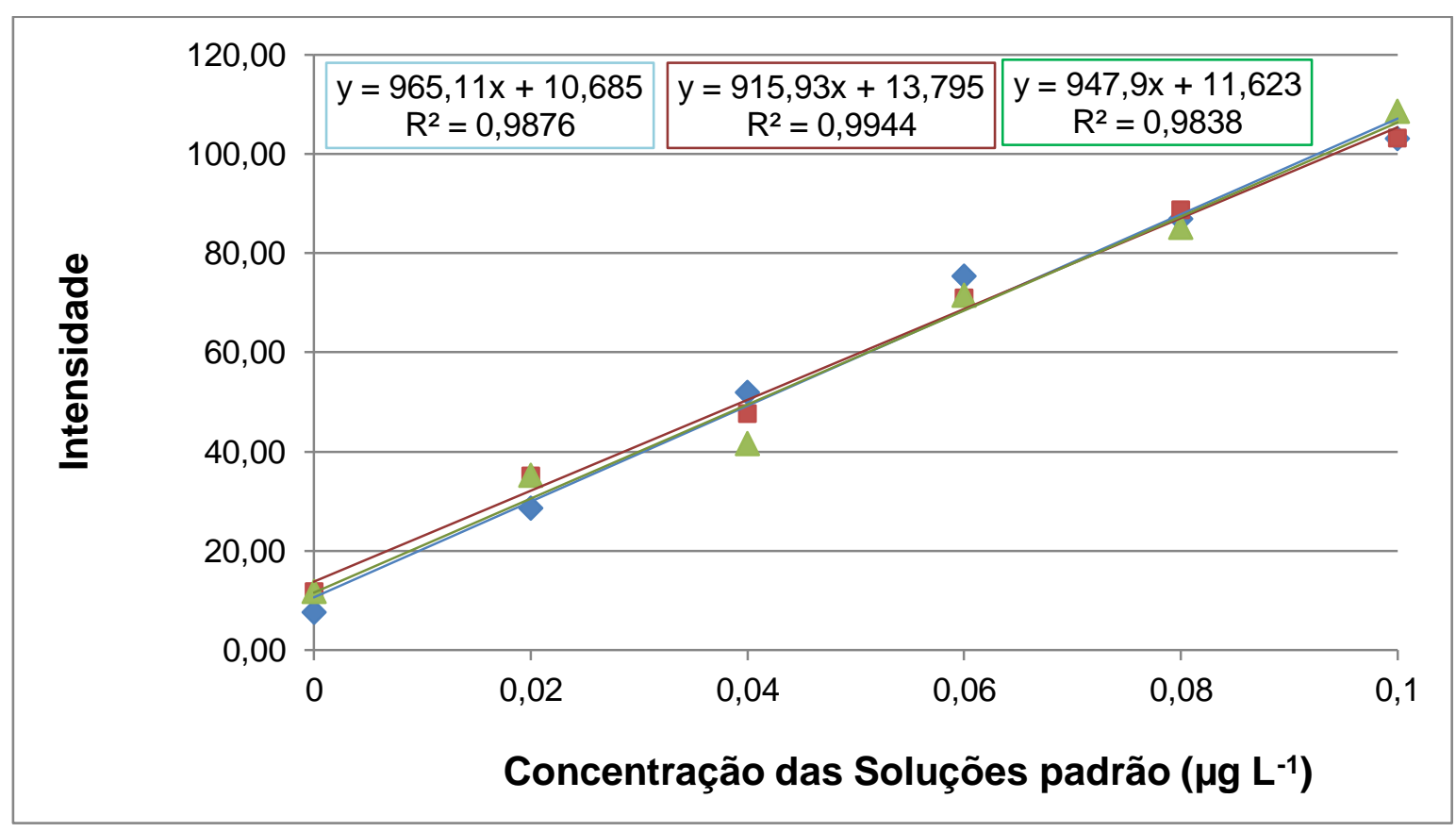

FIGURA 5.1 - Curvas de calibração do ICP-OES para o Ge, utilizadas para a determinação dos limites de detecção e quantificação.

Os resultados das colunas montadas com sistema de eluição a vácuo estão expressos por gráficos (FIG. 5.2 a 5.11) que mostram as porcentagens de cada elemento nos efluentes das simulações das eluições. Lembrando-se que cada elemento foi estudado separadamente nos materiais adsorvedores.

Já os resultados obtidos nos experimentos das colunas com sistema de eluição com pressão manual feito através de seringa estão mostrados nas TAB. 5.1 e 5.2 .

A porcentagem de $\mathrm{Ge}$ adsorvido nas colunas corresponde ao total carregado menos a massa que saiu no efluente após a percolação da solução carga e nos $10 \mathrm{~mL}$ de $\mathrm{HCl} 0,1 \mathrm{~mol} \mathrm{~L}{ }^{-1}$ fracionados (simulação da eluição do ${ }^{68} \mathrm{Ga}$ ). O efluente da solução carga está representado como fração zero nos gráficos. A porcentagem do ${ }^{67 / 68} \mathrm{Ga}$ que saiu da coluna corresponde a atividade que foi colocada menos a atividade retida na coluna.

Os pHs 1,5 e 4 para as soluções do condicionamento, da carga e de lavagem foram escolhidos para os estudos, pois em literatura é mostrado que uma alta adsorção do Ge nestes materiais começa a ocorrer com pH acima de 3,5 e a eluição do Ga ocorre com pH menor que 2 (MALYSHEV e SMIRNOV, 1975; (KOPECKÝ et al., 1973). Nestes valores de $\mathrm{pH}$ o Ge se encontra como um complexo de carga negativa e o Ga na sua forma catiônica. 
As FIG. 5.2, 5.3 e 5.4 mostram o comportamento do Ge e do Ga na coluna com $\mathrm{Al}_{2} \mathrm{O}_{3}$ ácida calcinada. Utilizando-se pH 1,5 para as soluções de condicionamento, carga e lavagem, $91 \%$ do Ga saiu no efluente. Ao realizar o experimento com $\circ \mathrm{Ge}$, nessas mesmas condições, foi obtido apenas $30 \%$ de retenção do elemento na coluna (FIG. 5.2).

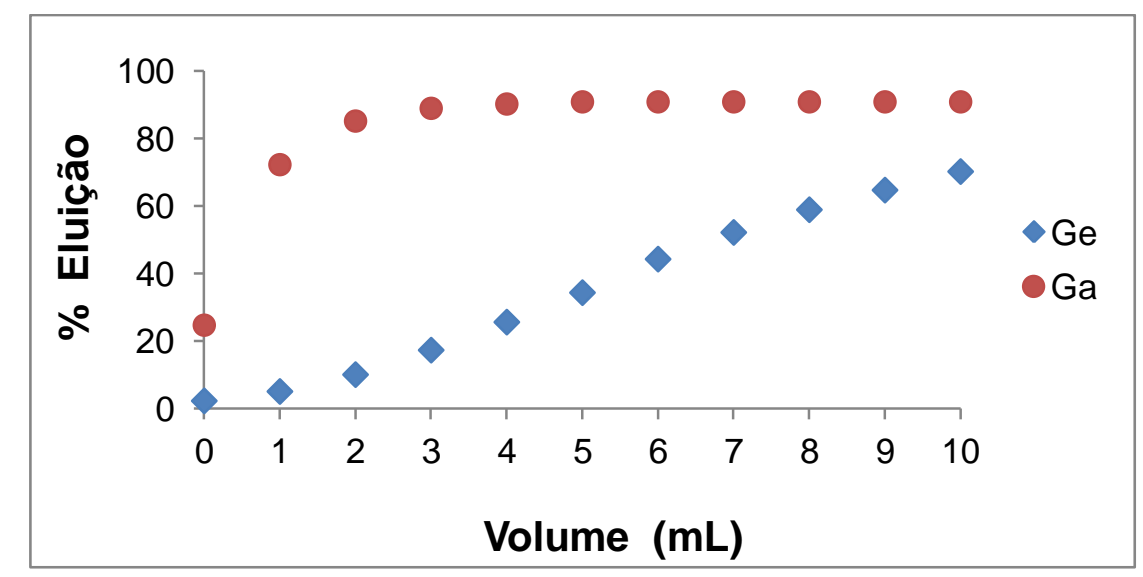

FIGURA 5.2 - Porcentagem de $\mathrm{Ge}$ e de Ga nas simulações das eluições das colunas com $\mathrm{Al}_{2} \mathrm{O}_{3}$ ácida calcinada utilizando $\mathrm{pH} 1,5$ para soluções de condicionamento, carga e lavagem.

Ao elevar o $\mathrm{pH}$ a 4 das soluções de condicionamento, carga e lavagem, houve uma retenção de $96 \%$ do Ge na coluna, porém nessas mesmas condições ocorre $100 \%$ de retenção do Ga (FIG. 5.3). Quando se utilizou pH 4 apenas para as soluções carga, $94 \%$ do Ga saiu no efluente e aproximadamente $80 \%$ de $\mathrm{Ge}$ ficou retido (FIG. 5.4). 


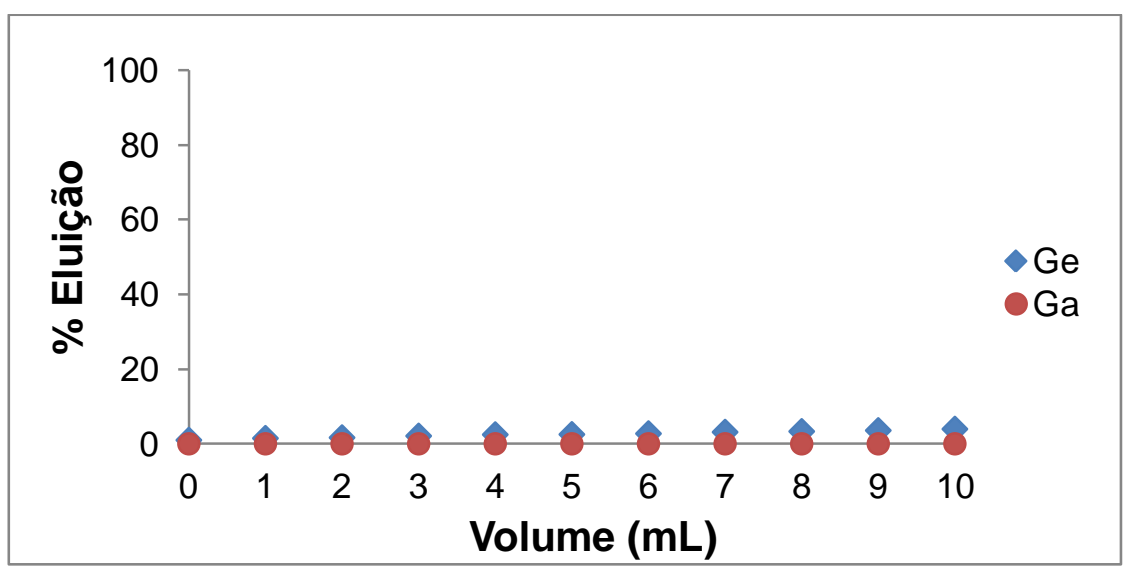

FIGURA 5.3 - Porcentagem de Ge e de Ga nas simulações das eluições das colunas com $\mathrm{Al}_{2} \mathrm{O}_{3}$ ácida calcinada utilizando $\mathrm{pH} 4$ para soluções de condicionamento, carga e lavagem.

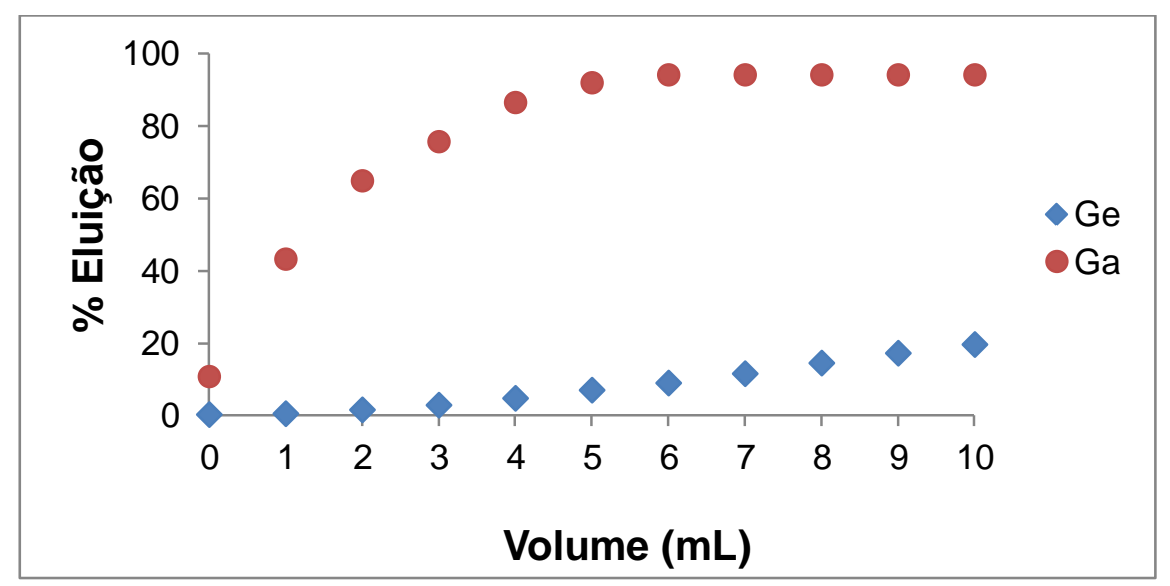

FIGURA 5.4 - Porcentagem de $\mathrm{Ge}$ e de Ga nas simulações das eluições das colunas com $\mathrm{Al}_{2} \mathrm{O}_{3}$ ácida calcinada utilizando $\mathrm{pH} 1,5$ para soluções de condicionamento e lavagem e pH 4 para carga.

Esses resultados mostram que a $\mathrm{Al}_{2} \mathrm{O}_{3}$ ácida calcinada, nas condições utilizadas nos três experimentos, não é um material adequado para promover simultaneamente, alta adsorção do Ge e uma eluição aceitável do Ga ( 70\%).

A FIG. 5.5 mostra o comportamento do Ge e do Ga nas colunas com $\mathrm{Al}_{2} \mathrm{O}_{3}$ básica. Para a realização dos experimentos foram utilizados $\mathrm{pH} 4$ para solução carga e pH 1,5 para o condicionamento e lavagem. A porcentagem de $\mathrm{Ge}$ retido na coluna foi de $98 \%$ e a porcentagem de Ga que saiu no efluente foi de 98\% (FIG. 5.5), resultados satisfatórios e melhores do que com a alumina ácida. 


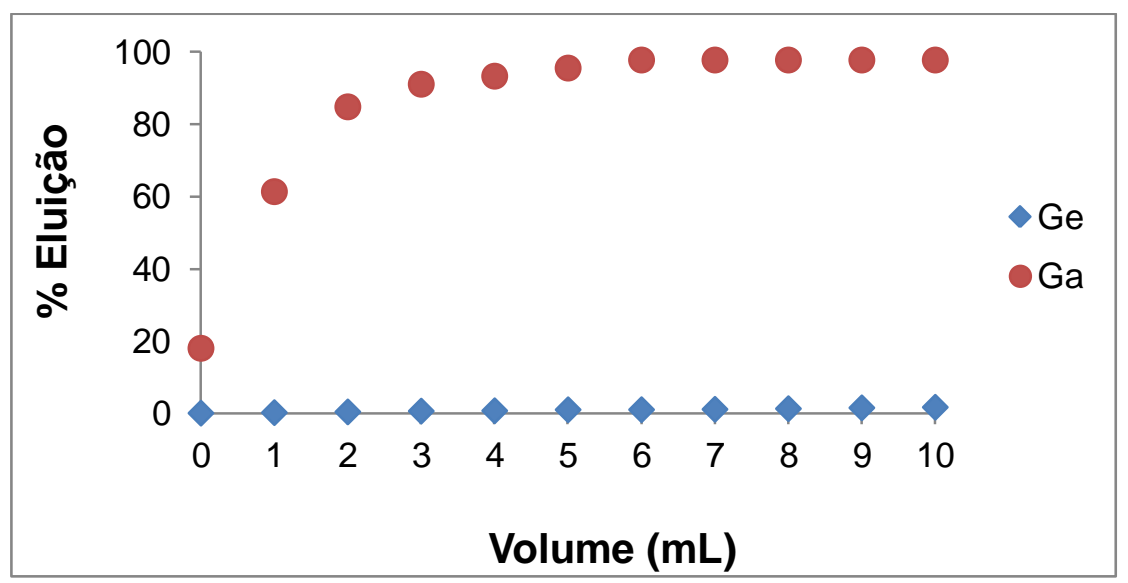

FIGURA 5.5 - Porcentagem de Ge e de Ga nas simulações das eluições das colunas com $\mathrm{Al}_{2} \mathrm{O}_{3}$ básica utilizando $\mathrm{pH} 1,5$ para soluções de condicionamento e lavagem e $\mathrm{pH} 4$ para carga.

As FIG. 5.6, 5.7, 5.8 e 5.9 mostram o comportamento químico do Ge e do $\mathrm{Ga}$ nas colunas com HZO. Utilizando-se pH 1,5 para as soluções de condicionamento, carga e lavagem, $82 \%$ do Ga saiu no efluente e $77 \%$ do $\mathrm{Ge}$ ficou retido na coluna (FIG. 5.6).

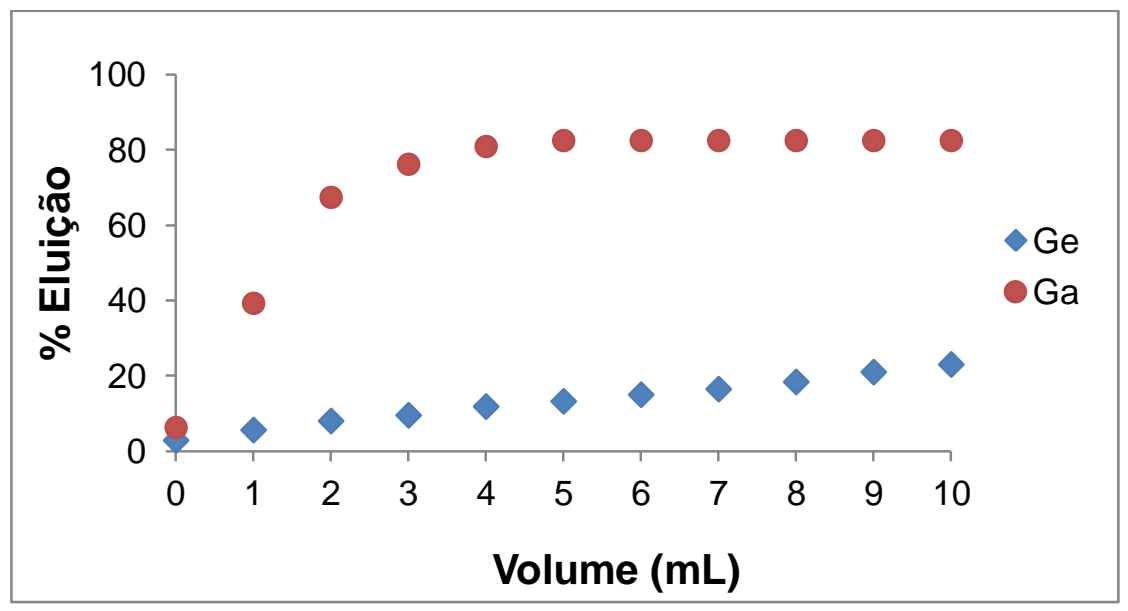

FIGURA 5.6 - Porcentagem de Ge e de Ga nas simulações das eluições das colunas com HZO utilizando pH 1,5 para soluções de condicionamento, carga e lavagem.

Assim como na coluna com $\mathrm{Al}_{2} \mathrm{O}_{3}$ ácida calcinada, a alteração do $\mathrm{pH}$ para 4 das soluções de condicionamento, carga e lavagem, gerou um aumento da retenção dos elementos na coluna. A adsorção do Ge aumentou para $96 \%$ e a saída do Ga foi nula (FIG. 5.7). 


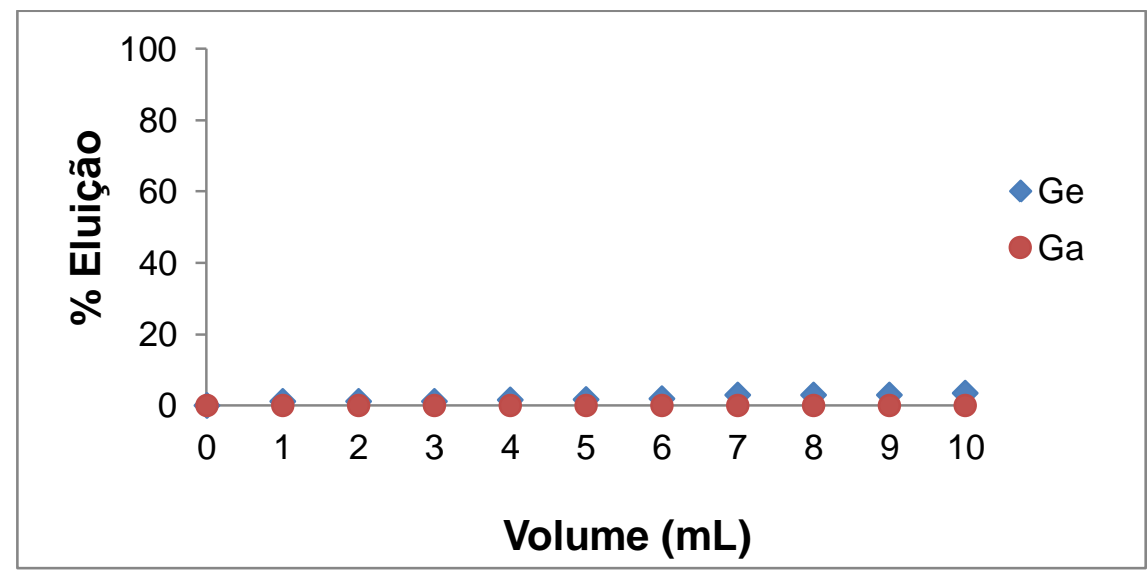

FIGURA 5.7 - Porcentagem de Ge e de Ga nas simulações das eluições das colunas com $\mathrm{HZO}$ utilizando $\mathrm{pH} 4$ para soluções de condicionamento, carga e lavagem.

Pode-se observar na FIG. 5.8 que ao utilizar pH 4 para as soluções do condicionamento e da carga e pH 1,5 para lavagem, a retenção do Ge na coluna se mantém por volta de $96 \%$ e a porcentagem de Ga no efluente subiu para $40 \%$.

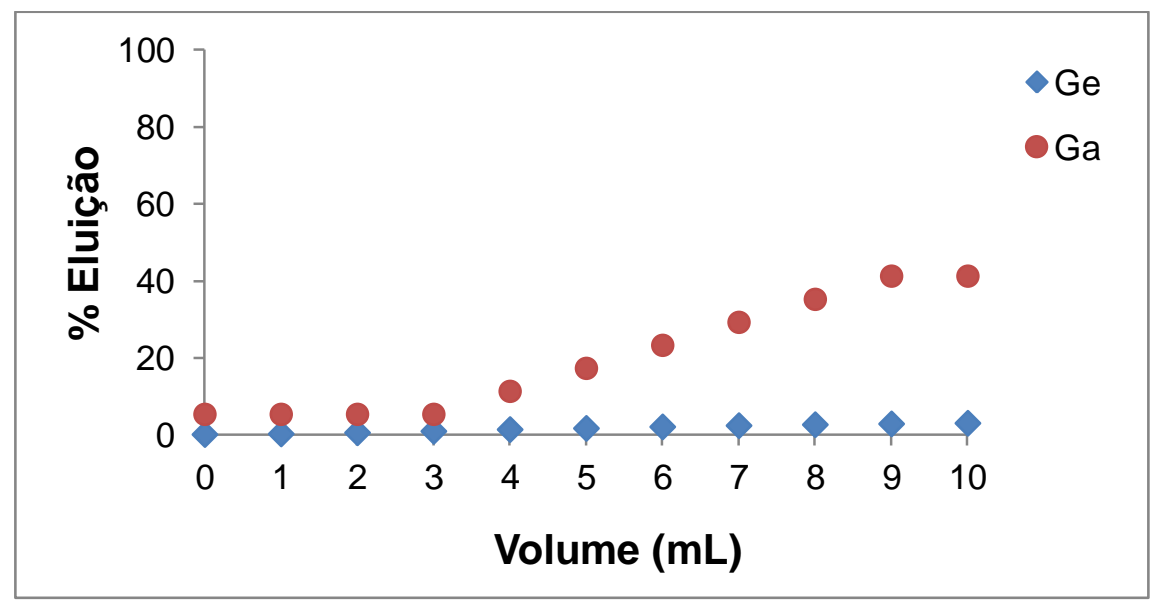

FIGURA 5.8 - Porcentagem de Ge e de Ga nas simulações das eluições das colunas com $\mathrm{HZO}$ utilizando $\mathrm{pH} 4$ para as soluções do condicionamento e carga e $\mathrm{pH} 1,5$ para lavagem.

Quando se utilizou pH 4 apenas para a solução carga, aproximadamente $90 \%$ do Ga saiu no efluente e $96 \%$ do Ge ficou adsorvido na coluna (FIG. 5.9). 


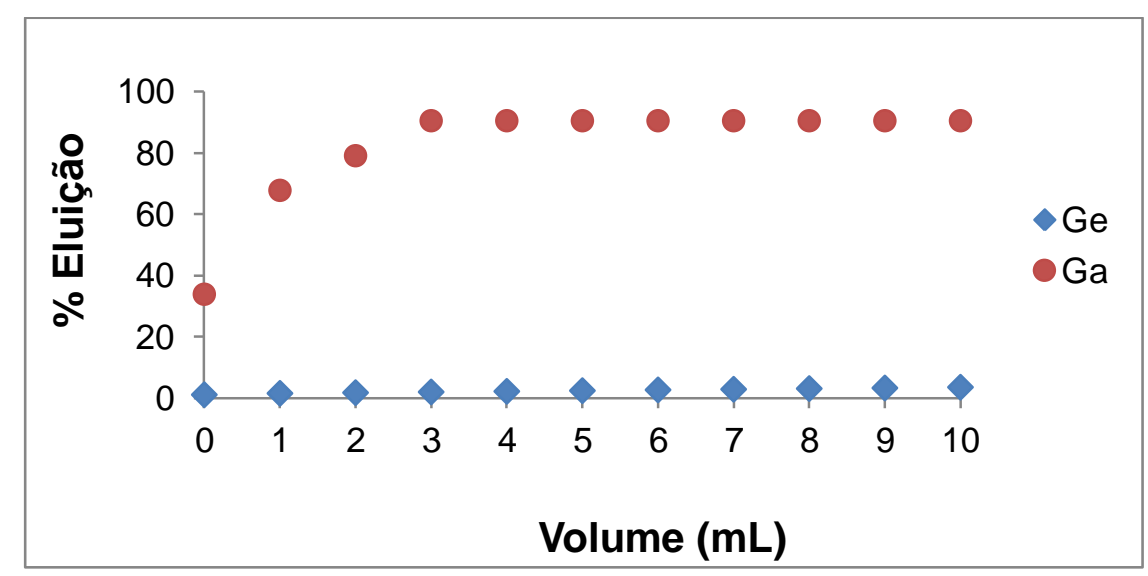

FIGURA 5.9 - Porcentagem de $\mathrm{Ge}$ e de $\mathrm{Ga}$ nas simulações das eluições das colunas com HZO utilizando $\mathrm{pH} \mathrm{1,5}$ para soluções de condicionamento e lavagem e $\mathrm{pH} 4$ para carga.

O comportamento do Ge e do Ga foi estudado na coluna de $\mathrm{ZrO}_{2} \mathrm{com}$ pH 4 para solução carga e pH 1,5 para o condicionamento e lavagem. A adsorção do Ge na coluna foi de aproximadamente 95\% e eluição de Ga > 95 \% (FIG. 5.10), resultado similar ao encontrado no estudo com HZO, 96\% (FIG. 5.9).

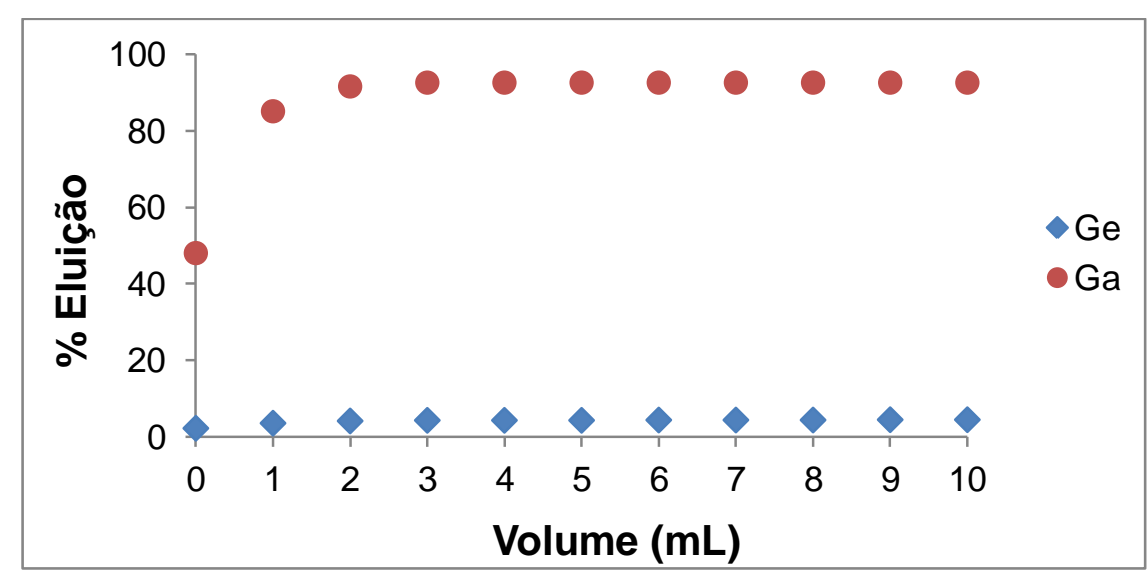

FIGURA 5.10 - Porcentagem de Ge e de Ga nas simulações das eluições das colunas com $\mathrm{ZrO}_{2}$ utilizando $\mathrm{pH} \mathrm{1,5}$ para soluções de condicionamento e lavagem e $\mathrm{pH} 4$ para carga.

A FIG. 5.11 mostra os resultados dos experimentos com $0 \mathrm{TiO}_{2}$ utilizando $\mathrm{pH} 4$ para solução carga e $\mathrm{pH}$ 1,5 para o condicionamento e lavagem. Nessas condições praticamente $100 \%$ do Ga saiu no efluente e $99 \%$ do Ge ficou adsorvido na coluna. 


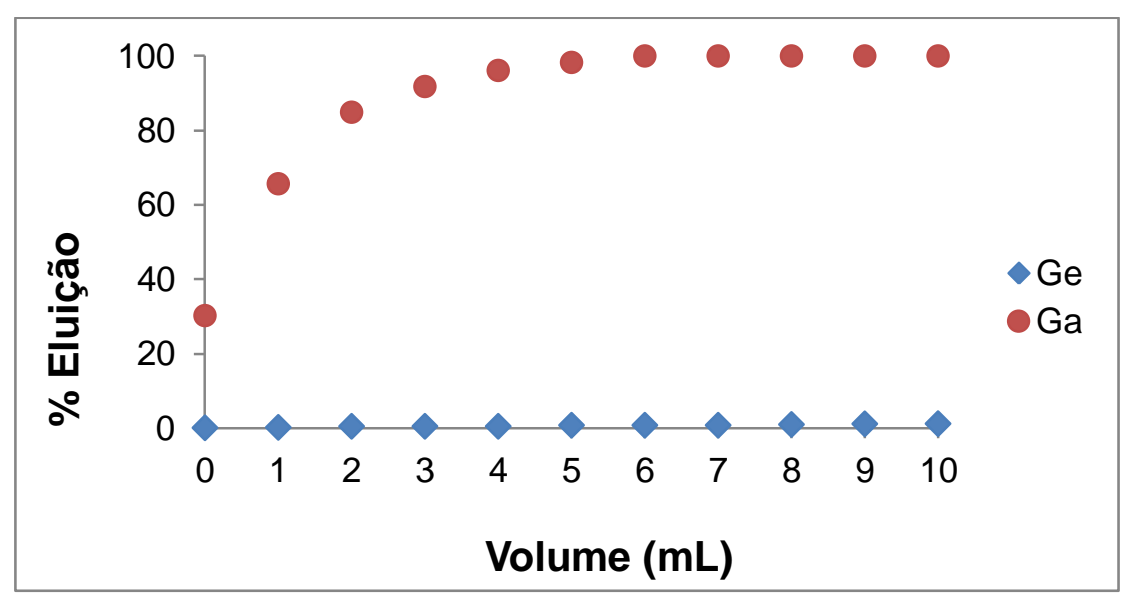

FIGURA 5.11 - Porcentagem de Ge e de Ga nas simulações das eluições das colunas com $\mathrm{TiO}_{2}$ utilizando $\mathrm{pH}$ 1,5 para soluções de condicionamento e lavagem e pH 4 para carga.

Foram realizadas simulações de 20 eluições com as colunas de $\mathrm{Al}_{2} \mathrm{O}_{3}$ básica, $\mathrm{HZO}$ e $\mathrm{TiO}_{2}$ para avaliar se o Ge realmente ficava adsorvido à coluna. $\mathrm{A}$ saída de $\mathrm{Ge}$ da coluna com $\mathrm{Al}_{2} \mathrm{O}_{3}$ básica foi de $6 \%$, na coluna com o $\mathrm{HZO}$ foi de 1 $\%$ e na coluna de $\mathrm{TiO}_{2}$ os valores foram menores que o LQ do equipamento.

A TAB. 5.1 mostra os resultados dos experimentos de adsorção do $\mathrm{Ge}$ no $\mathrm{TiO}_{2}$ seco a $100{ }^{\circ} \mathrm{C}, \mathrm{TiO}_{2}$ calcinado a $420{ }^{\circ} \mathrm{C}$ e no $\mathrm{SnO}_{2}$. A porcentagem de adsorção do $\mathrm{Ge}$ em $\mathrm{TiO}_{2}$ foi $\geq 99 \%$. Os resultados do estudo do comportamento do $\mathrm{Ge}$ no $\mathrm{SnO}_{2}$ apresentaram uma porcentagem de adsorção de no máximo $65 \%$.

TABELA 5.1 - Comportamento do Ge em diferentes materiais adsorvedores utilizando sistema de eluição com pressão manual, feito com seringa.

\begin{tabular}{lcccc}
\hline Adsorvedor & $\begin{array}{c}\mathbf{p H} \\
\text { condicionamento }\end{array}$ & $\begin{array}{c}\mathbf{p H} \\
\text { carga }\end{array}$ & $\begin{array}{c}\mathbf{p H} \\
\text { eluente }\end{array}$ & $\begin{array}{c}\text { \% Adsorção } \\
\mathbf{G e}\end{array}$ \\
\hline $\mathrm{TiO}_{2}$ não calcinado & 1,5 & 4 & 1,5 & 99 \\
$\mathrm{TiO}_{2}$ calcinado a $420^{\circ} \mathrm{C}$ & 1,5 & 1,5 & 1,5 & $\sim 100$ \\
$\mathrm{TiO}_{2}$ calcinado a $420^{\circ} \mathrm{C}$ & 1,5 & 4 & 1,5 & $\sim 100$ \\
$\mathrm{SnO}_{2}$ & 1,5 & 1,5 & 1,5 & 65 \\
$\mathrm{SnO}_{2}$ & 1,5 & 4 & 1,5 & 53 \\
\hline
\end{tabular}

Os experimentos realizados com as diferentes microesferas estão na tabela 5.2. Os melhores resultados foram alcançados com os experimentos de adsorção estáticos, onde a solução carga foi aquecida e deixada em contato com o material por mais de 24 horas. Esses resultados sugerem que para uma melhor 
adsorção do Ge é necessário o aquecimento do material ou possivelmente apenas um tempo maior de contato.

TABELA 5.2 - Estudo da adsorção do Ge em diferentes tipos de microesferas.

\begin{tabular}{lccccccc}
\hline Microesferas & $\begin{array}{c}\text { Massa do } \\
\text { Adsorvedor(g) }\end{array}$ & $\begin{array}{c}\text { Massa } \\
\text { Ge }(\boldsymbol{\mu g})\end{array}$ & $\begin{array}{c}\text { Carga } \\
(\mathbf{m L})\end{array}$ & $\begin{array}{c}\text { pH } \\
\text { carga }\end{array}$ & $\begin{array}{c}\text { pH } \\
\text { eluente }\end{array}$ & $\begin{array}{c}\text { \% Adsorção } \\
\text { Ge }\end{array}$ & $\begin{array}{c}\text { Tipo do } \\
\text { estudo }\end{array}$ \\
$\mathrm{ZrO}_{2}(\mathrm{CCTM})$ & 0,5 & 10 & 1 & 4 & 1.5 & 99 & estático \\
$\mathrm{ZrO}_{2} / \mathrm{Ti} 10 \%$ & 0,5 & 10 & 1 & 4 & 1.5 & 99 & estático \\
$\mathrm{ZrO}_{2} / \mathrm{Sn} \mathrm{10 \%}$ & 0,5 & 10 & 1 & 4 & 1,5 & 99 & estático \\
$\mathrm{Al}_{2} \mathrm{O}_{3} / \mathrm{Ti} 10 \%$ & 0,5 & 10 & 1 & 4 & 1,5 & 99 & estático \\
$\mathrm{Al}_{2} \mathrm{O}_{3} / \mathrm{Ti} \mathrm{10 \%}$ & $\mathbf{0 , 3}$ & $\mathbf{7 0}$ & $\mathbf{1}$ & $\mathbf{4}$ & $\mathbf{1 , 5}$ & $\mathbf{1 9}$ & dinâmico \\
$\mathrm{Al}_{2} \mathrm{O}_{3} / \mathrm{Ti} 10 \%$ & 0,3 & 70 & 1 & 4 & 1,5 & 75 & estático \\
$\mathrm{Al}_{2} \mathrm{O}_{3} / \mathrm{Sn} \mathrm{10 \%}$ & 0,5 & 10 & 1 & 4 & 1.5 & 97 & estático \\
$\mathrm{ZrO}_{2}(\mathrm{CCCH})$ & $\mathbf{1 , 0}$ & $\mathbf{4 6}$ & $\mathbf{1}$ & $\mathbf{1 , 5}$ & $\mathbf{1 , 5}$ & $\mathbf{1 3}$ & dinâmico \\
$\mathrm{ZrO}_{2}(\mathrm{CCCH})$ & 1,0 & 58 & 1 & 1,5 & 1,5 & 99 & estático \\
$\mathrm{ZrO}_{2}(\mathrm{CCCH})$ & 1,0 & 100 & 1 & 1,5 & 1,5 & 96 & estático \\
$\mathrm{Al}_{2} \mathrm{O}_{3}(\mathrm{CCCH})$ & 1,0 & 100 & 1 & 1,5 & 1,5 & 96 & estático \\
\hline
\end{tabular}

A porcentagem de adsorção de $\mathrm{Ge}$ nas microesferas de $\mathrm{ZrO}_{2}(\mathrm{CCCH})$ foi alta (99\%). Para avaliar se o Ge realmente ficava adsorvido nas microesferas, esse material foi transferido para uma coluna de vidro e foram feitas simulações de 20 eluições da coluna, onde saíram 3\% do Ge que estava adsorvido. Esse resultado mostra que é necessário a realização de mais estudos com este material.

$\mathrm{O}$ comportamento do ${ }^{68} \mathrm{Ga}$ foi estudado nas microesferas de $\mathrm{ZrO}_{2}$ $(\mathrm{CCCH})$ e $\mathrm{AlO}_{3}(\mathrm{CCCH})$ e alcançaram uma porcentagem de eluição de $99 \%$ e $68 \%$, respectivamente.

Os materiais que apresentaram melhor adsorção do Ge e eluição do ${ }^{68} \mathrm{Ga}$ foram o $\mathrm{TiO}_{2}$ e o $\mathrm{HZO}$. O $\mathrm{ZrO}_{2}$ mostrou-se promissor com uma adsorção > $95 \%$ de $\mathrm{Ge}$, mas o comportamento do ${ }^{68} \mathrm{Ga}$ nesse material ainda precisa ser estudado. 
As microesferas de $\mathrm{ZrO}_{2}$ (CCTM), $\mathrm{ZrO}_{2} / \mathrm{Ti} 10 \%, \mathrm{ZrO}_{2} / \mathrm{Sn} 10 \%, \mathrm{AlO}_{3} / \mathrm{Ti}$ $10 \%$ também apresentaram resultados iniciais promissores, mas outros estudos precisam ser realizados.

O material adsorvedor escolhido para a montagem do gerador ${ }^{68} \mathrm{Ge} /{ }^{68} \mathrm{Ga}$ foi o $\mathrm{TiO}_{2}$ por ter alcançado bons resultados de adsorção do $\mathrm{Ge}$, eluição do ${ }^{68} \mathrm{Ga}$ e nas simulações das eluições, onde a presença de Ge nas amostras estava abaixo do limite de detecção do equipamento.

\subsection{Caracterização do $\mathrm{TiO}_{2}$}

O dióxido de titânio pode apresentar três fases cristalinas diferentes: anatase, com estrutura tetragonal; rutilo, também com estrutura tetragonal; e broquita, com estrutura ortorrômbica (FIG. 5.12).

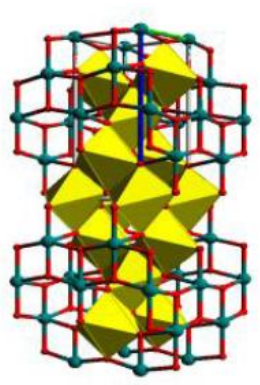

Anatase

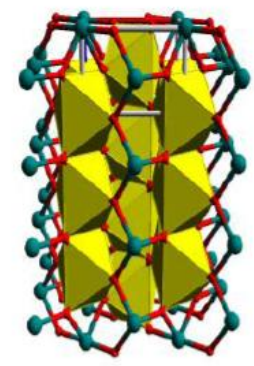

Rutilo

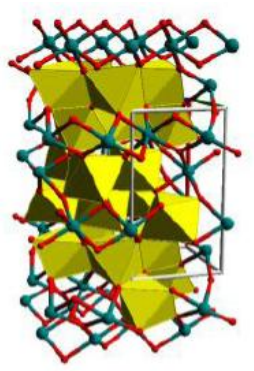

Broquita

FIGURA 5.12 - Estruturas cristalinas do $\mathrm{TiO}_{2}$ (BATISTA, 2010).

Dentre as três fases cristalinas, a mais estável termodinamicamente é a rutilo, que pode ser obtida a partir da conversão da anatase, a qual, por sua vez é a fase cristalina de maior fotoatividade. A broquita é a menos estudada dentre as três, apresentando pouca aplicabilidade, pouca disponibilidade natural, alto custo de produção e baixo valor comercial até o presente (BATISTA, 2010).

Neste trabalho, três tipos comerciais de $\mathrm{TiO}_{2}$ foram avaliados para montagem de colunas cromatográficas, Merck, Evonick-Degussa P-25 e P-90, mas a característica extremamente fina desses materiais impossibilitou a montagem das colunas. Por essa razão, optou-se pela preparação do óxido em 
laboratório, na tentativa de se obter um material com características adequadas para montagem de colunas.

A síntese do $\mathrm{TiO}_{2}$ pode ser feita por diferentes rotas, formando materiais particulados, filmes ou cristais. Essas rotas podem ser diferenciadas de acordo com o método utilizado para a formação dos materiais inorgânicos e podem ser separadas de acordo com a fase em que são executadas: fase gasosa ou fase líquida (BATISTA, 2010).

$\mathrm{Na}$ produção com fase gasosa os métodos mais empregados são a deposição de vapor químico (CVD - Chemical Vapour Deposition) e a oxidação em chama, sendo este o utilizado na produção do $\mathrm{TiO}_{2} \mathrm{P} 25$, comercializado pela Evonick-Degussa. Entretanto, os métodos de produção via fase líquida são os mais abordados na literatura, sendo os principais: precipitação homogênea, solgel, solvotérmicos, via emulsão e os eletroquímicos (BATISTA, 2010).

A rota de síntese do $\mathrm{TiO}_{2}$ utilizada neste trabalho foi via precipitação homogênea. Obteve-se um material adequado para montagem de colunas cromatográficas que se mostrou eficiente nos estudos de adsorção de $\mathrm{Ge} e$ eluição do $\mathrm{Ga}$, sendo o material de escolha para o preparo dos geradores de ${ }^{68} \mathrm{Ge} /{ }^{68} \mathrm{Ga}$. Porém, foi observado que os materiais produzidos apresentavam características diferentes, como o rendimento de síntese e a coloração do pó.

Foram preparados 10 lotes do $\mathrm{TiO}_{2}$ e o valor médio da diferença de massa, expressa em porcentagem, entre 0 valor teórico calculado pela estequiometria e a massa experimental foi de $119 \% \pm 47$.

Os valores de cada lote estão descritos na TAB. 5.3, assim como os volumes de $\mathrm{TiCl}_{3}$ utilizados na preparação de cada um deles. 
TABELA 5.3 - Volume de $\mathrm{TiCl}_{3}$ a $15 \%$ utilizado nas preparações dos lotes de $\mathrm{TiO}_{2}$, massa experimental do $\mathrm{TiO}_{2}$ e massa teórica do $\mathrm{TiO}_{2}$ calculada por estequiometria.

\begin{tabular}{|c|c|c|c|c|}
\hline Lote & $\begin{array}{c}\mathrm{TiCl}_{3} 15 \% \\
(\mathrm{~mL})\end{array}$ & $\begin{array}{c}\text { Massa }(\mathrm{g}) \mathrm{TiO}_{2} \\
\text { experimental }\end{array}$ & $\begin{array}{c}\text { Massa }(\mathrm{g}) \mathrm{TiO}_{2} \\
\text { teórica }\end{array}$ & $\begin{array}{l}\% \text { ( } \mathbf{M}_{\text {experimental }}- \\
\left.\mathbf{M}_{\text {teórica }}\right) / \mathbf{M}_{\text {teórica }}\end{array}$ \\
\hline 1 & 50 & 7,07 & 3,88 & 82 \\
\hline 2 & 50 & 6,15 & 3,88 & 58 \\
\hline 3 & 100 & 12,08 & 7,77 & 55 \\
\hline 4 & 100 & 16,66 & 7,77 & 114 \\
\hline 5 & 200 & 27,57 & 15,54 & 77 \\
\hline 6 & 200 & 48,80 & 15,54 & 214 \\
\hline 7 & 100 & 23,48 & 7,77 & 202 \\
\hline 8 & 100 & 18,09 & 7,77 & 133 \\
\hline 9 & 100 & $14,63^{*}$ & 7,77 & 88 \\
\hline 10 & 100 & 20,47 & 7,77 & 163 \\
\hline
\end{tabular}

* valor comprometido por perda de volume do material na hora da filtragem

Uma possível causa para essa diferença de massa obtida em relação à massa teórica pode ser explicada pela presença de água no material. O material apenas seco a $100{ }^{\circ} \mathrm{C}$ ainda possui uma mistura de hidróxido de titânio com óxido de titânio.

Considerando a formação de $\mathrm{Ti}(\mathrm{OH})_{3}$ para os cálculos estequiométricos, o valor médio da diferença de massa entre o valor teórico e a massa obtida seria de $77 \% \pm 38$ e não de $119 \% \pm 47$ como encontrado, considerando a formação de $\mathrm{TiO}_{2}$.

Outra informação relevante a ser considerada é que os lotes 1, 2, 3, 4 e 5 foram preparados com $\mathrm{TiCl}_{3}$ fora do prazo de validade e a solução apresentava uma camada amarelada na superfície, característica não observada na solução dentro do prazo de validade, utilizada para preparação dos lotes $6,7,8,9$ e 10.

A TAB. 5.4 apresenta a porcentagem de perda de massa do $\mathrm{TiO}_{2}$ dos lotes $4,5,6,7,8,9$ e 10 calcinados a $420^{\circ}$ por 3 horas. Os lotes 1,2 e 3 não foram calcinados.

A porcentagem média da perda de massa dos materiais foi de $22 \% \pm$ 9. Os materiais que apresentaram uma porcentagem de perda maior após a calcinação foram os dos lotes 4 e 5 , apresentando uma perda de $47 \%$ e $32 \%$, 
respectivamente. $\mathrm{O}$ uso de reagentes vencidos pode ter influenciado para esses resultados, caso tenha ocorrido alguma degradação do material.

A variação no modo de resfriamento do material após a calcinação foi estudada para os lotes 9 e 10. Para isso, cada lote foi dividido em duas partes. Uma das partes foi retirada do forno logo após o término da calcinação (resfriamento "rápido") e a outra foi retirada só no dia seguinte (resfriamento "lento"). Pode-se observar na TAB. 5.4 que a variação no modo de resfriamento não influenciou na porcentagem de perda dos materiais.

TABELA 5.4 - Porcentagem de perda da massa de $\mathrm{TiO}_{2}$ dos lotes 4, 5, 6, 7, 8, 9 e 10 após calcinação a $420^{\circ} \mathrm{C}$ e as condições de cada material.

\begin{tabular}{|c|c|c|c|c|}
\hline Lote & $\begin{array}{l}\text { Massa } \\
\text { (g) inicial }\end{array}$ & $\begin{array}{l}\text { Massa }(\mathrm{g}) \text { após } \\
\text { calcinação }\end{array}$ & $\begin{array}{c}\% \\
\text { perda }\end{array}$ & $\begin{array}{l}\text { Condições do material antes } \\
\text { da calcinação }\end{array}$ \\
\hline 4 & 8,00 & 4,25 & 47 & Não peneirado \\
\hline 5 & 10,00 & 6,79 & 32 & Não peneirado \\
\hline 6 & 4,00 & 3,60 & 10 & $\begin{array}{l}\text { Peneirado (149 a } 310 \mu \mathrm{m}) \text {, } \\
\text { lavado e condicionado }\end{array}$ \\
\hline 7 & 6,46 & 4,72 & 27 & Peneirado (149 a $310 \mu \mathrm{m})$ \\
\hline 8 & 18,09 & 17,14 & 5 & Não peneirado \\
\hline 9 & 3,50 & 2,88 & 18 & $\begin{array}{l}\text { Não peneirado. Resfriamento } \\
\text { "rápido" após calcinação }\end{array}$ \\
\hline 9 & 3,00 & 2,50 & 17 & $\begin{array}{l}\text { Não peneirado. Resfriamento } \\
\text { "lento" após calcinação }\end{array}$ \\
\hline 10 & 5,00 & 4,07 & 19 & $\begin{array}{l}\text { Não peneirado. Resfriamento } \\
\text { "rápido" após calcinação }\end{array}$ \\
\hline 10 & 5,00 & 3,91 & 22 & $\begin{array}{l}\text { Não peneirado. Resfriamento } \\
\text { "lento" após calcinação }\end{array}$ \\
\hline
\end{tabular}

Na TAB. 5.5 são apresentadas as características visuais dos materiais obtidos nos 10 lotes antes da calcinação e após a calcinação. 
TABELA 5.5 - Característica visual dos materiais obtidos nos 10 lotes.

\begin{tabular}{|c|c|c|}
\hline \multirow[t]{2}{*}{ Lote } & \multicolumn{2}{|c|}{ Característica visual dos produtos obtidos } \\
\hline & Seco & Calcinado \\
\hline 1 & Pó branco & - \\
\hline 2 & Pó branco & - \\
\hline 3 & Pó branco & - \\
\hline 4 & Pó branco & Pó amarelo \\
\hline 5 & Pó branco & $\begin{array}{c}\text { Pó amarelo bem claro calcinado a } 420^{\circ} \mathrm{C} \\
\text { e branco acinzentado a } 800^{\circ} \mathrm{C}\end{array}$ \\
\hline 6 & Pó amarelo claro & Pó amarelo \\
\hline 7 & Pó branco & Pó amarelo \\
\hline 8 & Pó branco & Pó amarelo \\
\hline $9 \mathrm{RR}$ & Pó branco & Pó amarelo \\
\hline $9 \mathrm{RL}$ & Pó branco & Pó amarelo \\
\hline $10 \mathrm{RR}$ & Pó branco & Pó amarelo \\
\hline $10 \mathrm{RL}$ & Pó branco & Pó amarelo \\
\hline
\end{tabular}

A calcinação favorece a formação de fases cristalinas no material e a mudança na coloração pode estar associada a essas fases. A formação das fases cristalinas será discutida no item 5.2.4.

\subsubsection{Distribuição granulométrica}

A análise da distribuição granulométrica, feita com os dados obtidos pelo peneiramento do material, foi realizada para os 10 lotes preparados. Já as análises feitas pelo analisador granulométrico CILAS foram realizadas apenas para o lote 4 , com o material seco a $100^{\circ} \mathrm{C}$ e com o material calcinado a $420^{\circ} \mathrm{C}$.

A calcinação é um tratamento térmico que pode causar alterações físico-químicas em um material. Quimicamente pode promover a perda de água, transformando, por exemplo, um hidróxido em óxido. Fisicamente, pode transformar um material amorfo em cristalino, assim como modificar o tamanho dos cristalitos desse material. Com isso, a distribuição granulométrica de um material pode ser alterada após o mesmo ser calcinado. O método de resfriamento após a calcinação também pode interferir nas características físicas do material.

Para os lotes 1, 2, 3 e 6 o peneiramento foi realizado com o material apenas seco, ou seja, não calcinado (NC). Para todos os outros lotes o 
peneiramento foi feito com o material calcinado (C) a $420{ }^{\circ} \mathrm{C}$. A temperatura de calcinação foi variada no lote $5 \mathrm{em} 420^{\circ} \mathrm{C}$ e $800^{\circ} \mathrm{C}$.

A FIG. 5.13 apresenta a distribuição granulométrica de todos os lotes após o peneiramento. Pode-se observar uma variação da distribuição granulométrica dos materiais entre os lotes produzidos, porém não é possível afirmar que essa variação foi ocasionada pela calcinação. O lote 3, por exemplo, que não foi calcinado, apresentou aproximadamente $10 \%$ a menos de partículas com tamanho $<60 \mu \mathrm{m}$, comparado ao lote 4 que foi calcinado.

A alteração da distribuição granulométrica de um lote para outro pode ser ocasionada tanto pelo tipo do material obtido quanto pela maceração feita neste material.

Comparando-se a alteração da distribuição granulométrica de um mesmo lote após a calcinação, pode-se observar nos resultados obtidos para o lote 10, que após a calcinação, com resfriamento "rápido", houve uma redução de aproximadamente $20 \%$ das partículas com tamanhos de 149 a $310 \mu \mathrm{m}$ (100 a 48 mesh). Por outro lado, não houve uma alteração significativa nessa mesma faixa granulométrica após a calcinação com resfriamento "lento". Portanto, nesse caso também não é possível afirmar que a calcinação proporcionou um aumento no tamanho da partícula. 


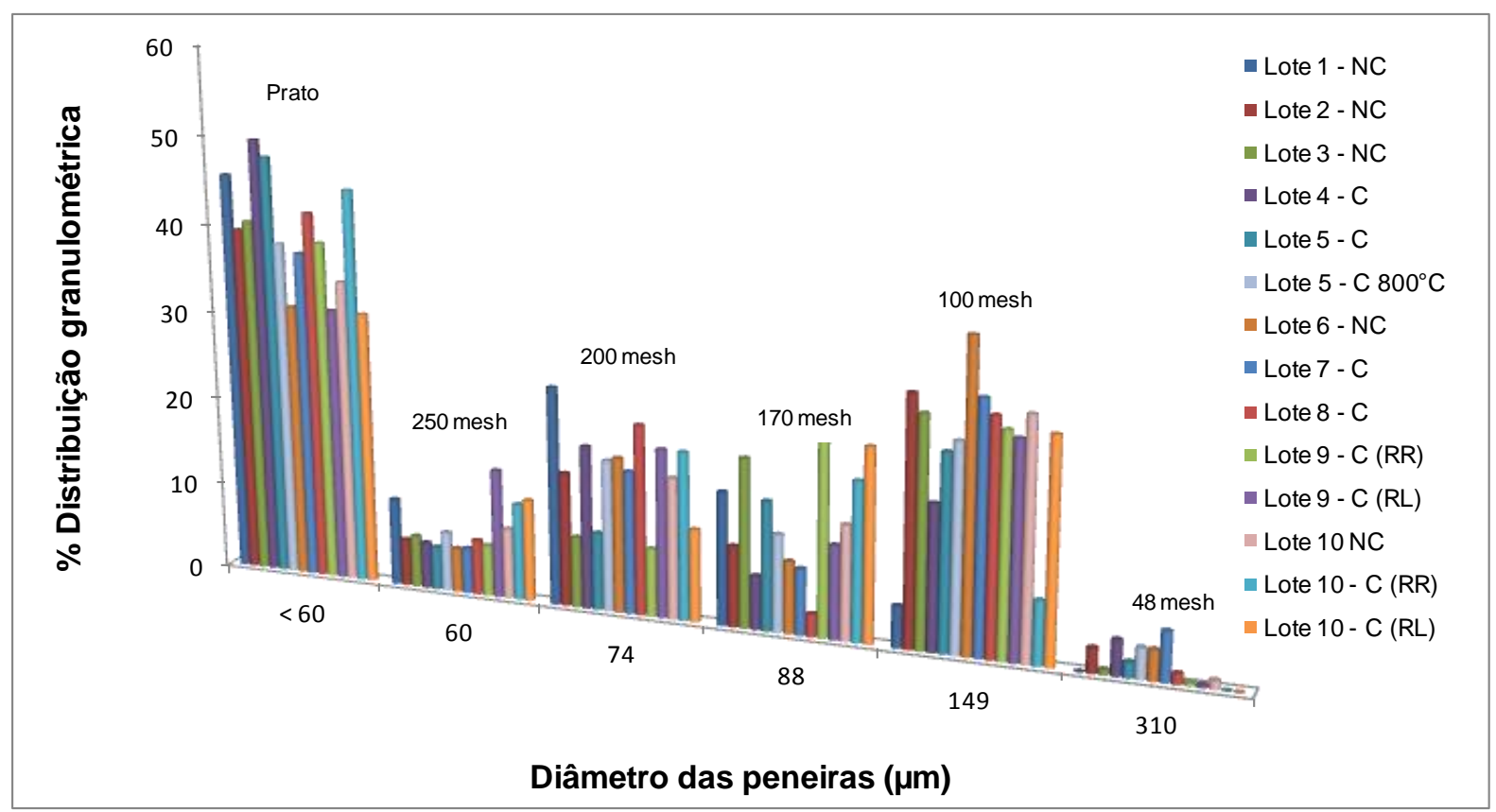

FIGURA 5.13 - Distribuição granulométrica de todos os lotes de $\mathrm{TiO}_{2}$ obtida após o peneiramento do material.

Uma análise mais refinada e precisa da distribuição granulométrica do $\mathrm{TiO}_{2}$ foi realizada para o lote 4 através de um analisador de distribuição granulométrica, CILAS.

A FIG. 5.14 mostra a análise da distribuição granulométrica do lote 4 seco a $100{ }^{\circ} \mathrm{C}$ realizada pelo analisador CILAS e a FIG. 5.15 mostra a análise do material calcinado a $420{ }^{\circ} \mathrm{C}$. Pode-se observar que houve um aumento no tamanho das partículas após a calcinação.

O diâmetro médio do material antes da calcinação era de 58,24 $\mu \mathrm{m}$, após a calcinação esse valor foi alterado para 117,75 $\mu \mathrm{m}$. Esse resultado mostra que nesse caso a calcinação ocasionou um aumento no tamanho da partícula. Porém, para afirmar que a calcinação realmente altera o tamanho da partícula, seriam necessárias mais análises de outros lotes. 


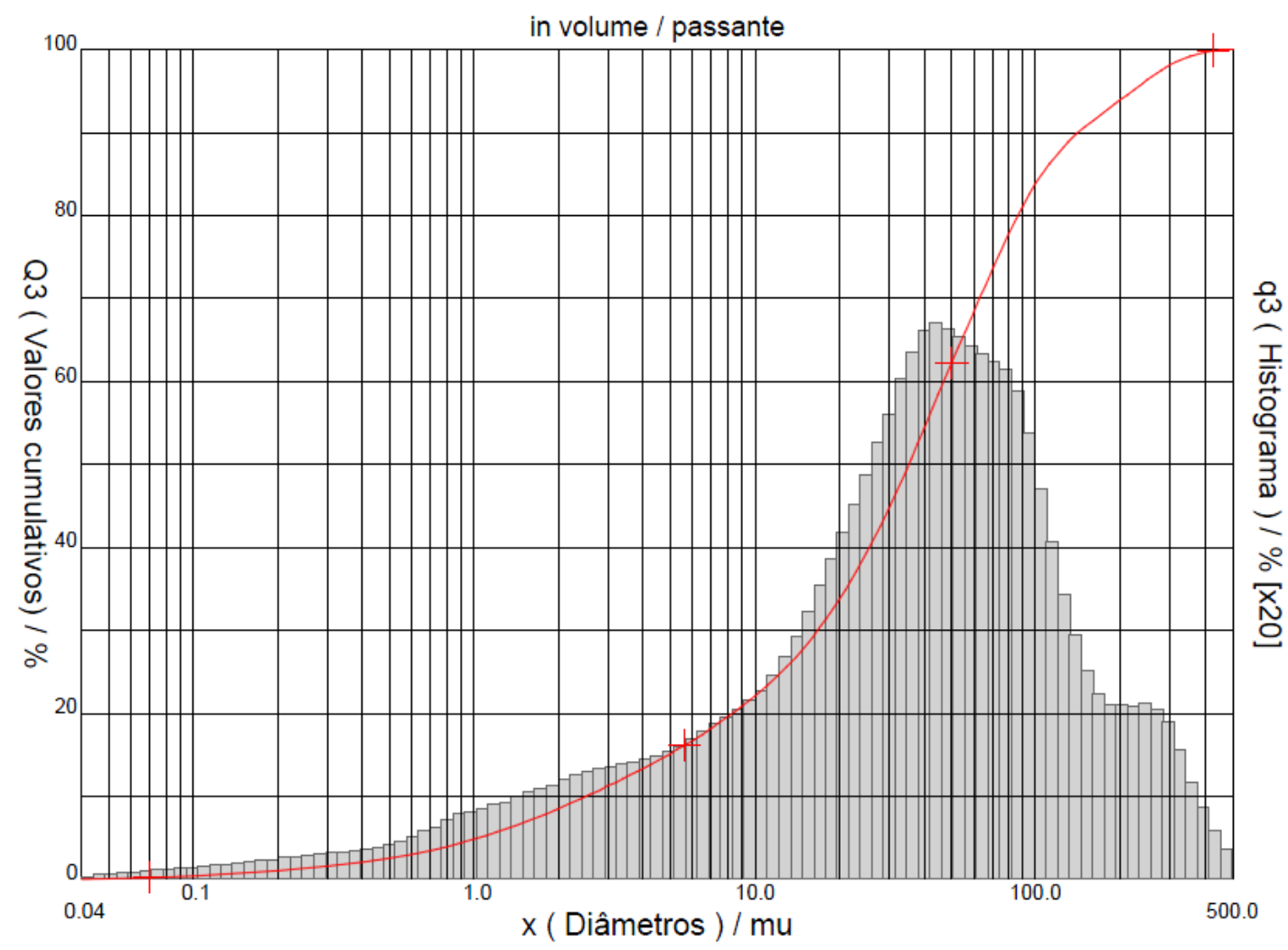

FIGURA 5.14 - Distribuição granulométrica do $\mathrm{TiO}_{2}$ (lote 4) seco a $100^{\circ} \mathrm{C}$.

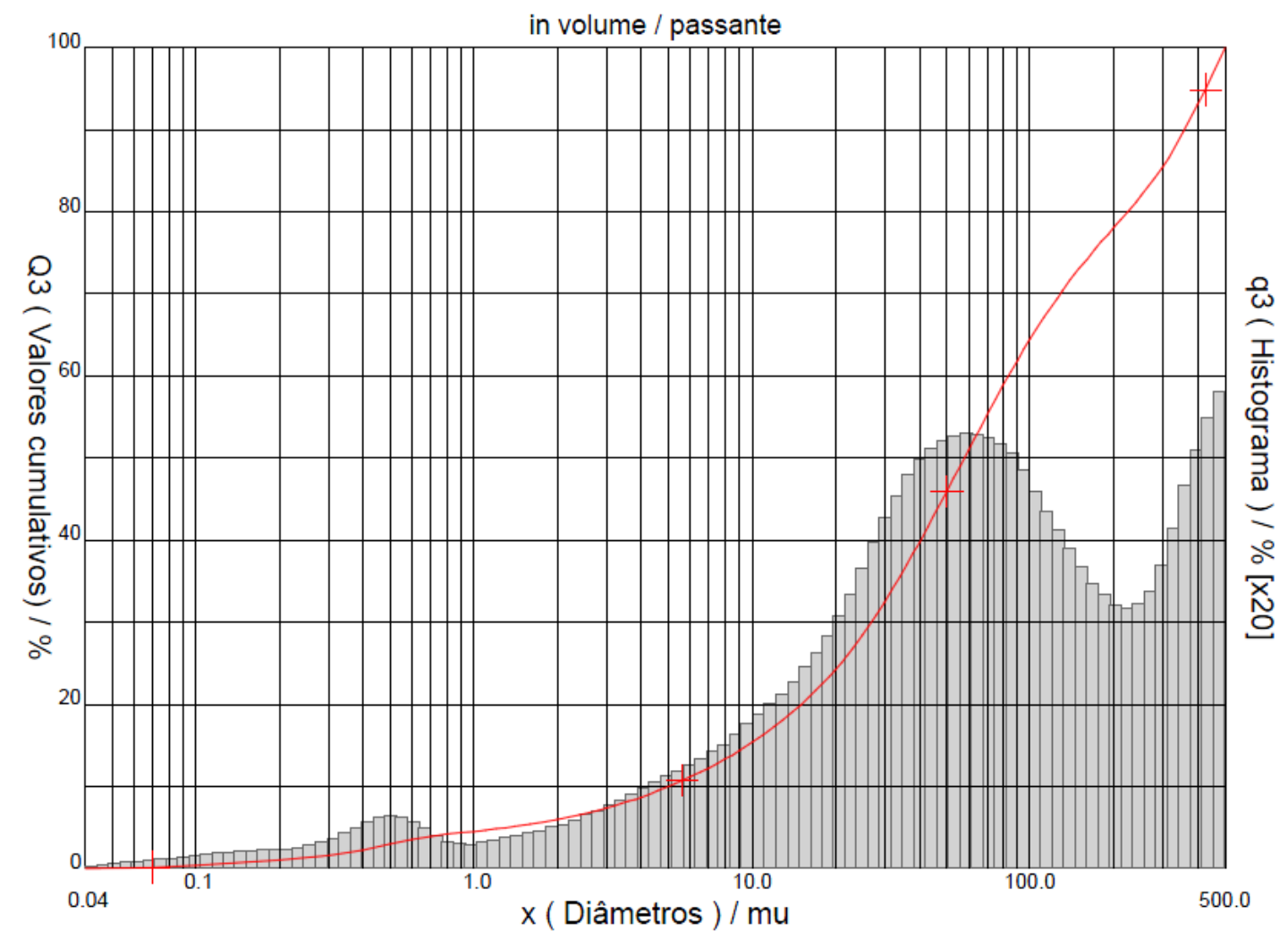

FIGURA 5.15 - Distribuição granulométrica do $\mathrm{TiO}_{2}$ (lote 4) calcinado a $420^{\circ} \mathrm{C}$. 
A TAB. 5.6 apresenta a porcentagem média encontrada em cada faixa granulométrica.

TABELA 5.6 - Porcentagem média de $\mathrm{TiO}_{2}$ obtido em cada faixa granulométrica após o peneiramento do material.

\begin{tabular}{ccc}
\hline $\begin{array}{c}\text { Tamanho da partícula } \\
(\mu \mathrm{m})\end{array}$ & $\begin{array}{c}\text { Tamanho da } \\
\text { partícula (mesh) }\end{array}$ & $\begin{array}{c}\% \text { Média de } \mathrm{TiO}_{2} \\
\text { obtido }\end{array}$ \\
\hline$<60$ & $>250$ & $40 \pm 5$ \\
$60-74$ & $250-200$ & $7 \pm 3$ \\
$74-88$ & $200-170$ & $16 \pm 4$ \\
$88-149$ & $170-100$ & $13 \pm 5$ \\
$149-310$ & $100-48$ & $22 \pm 6$ \\
$>310$ & $<48$ & $2 \pm 2$ \\
\hline
\end{tabular}

A faixa granulométrica do $\mathrm{TiO}_{2}$ utilizada para a realização dos experimentos foi de 149 a $310 \mu \mathrm{m}$, correspondendo a $(22 \pm 6) \%$ do material obtido. A granulometria da alumina utilizada nos geradores de ${ }^{99} \mathrm{Mo} /{ }^{99 \mathrm{~m}} \mathrm{Tc}$ produzidos pelo Centro de Radiofarmácia do IPEN-CNEN/SP é de no mínimo 99,20 $\mu \mathrm{m}$ (150 mesh). Como os experimentos deste trabalho foram realizados com as mesmas colunas de vidro utilizadas nos geradores de ${ }^{99} \mathrm{Mo} /{ }^{99 \mathrm{~m}} \mathrm{Tc}$, a faixa granulométrica escolhida para a realização dos experimentos foi de 149 a $310 \mu \mathrm{m}$ (100 a 48 mesh).

\subsubsection{Microscopia eletrônica de varredura e análise elementar}

As análises de microscopia e análises elementar foram realizadas para os lotes 3, 6, 7, 8 e para o $\mathrm{TiO}_{2} \mathrm{P} 90$ da Degussa. Para os materiais preparados em laboratório a análise foi realizada após o peneiramento e a faixa granulométrica utilizada foi de $149 \mu \mathrm{m}$ a $310 \mu \mathrm{m}$ (100 a 48 mesh).

\subsubsection{Microscopia eletrônica}

As micrografias do $\mathrm{TiO}_{2}$ dos lotes $3,6,7,8$ e do $\mathrm{TiO}_{2}$ comercial estão apresentadas nas FIG. 5.16, 5.17, 5.18, 5.19, 5.20 e 5.21.

A faixa granulométrica dos $\mathrm{TiO}_{2}$ preparados em laboratório utilizadas para análise foi de 149 a $310 \mu \mathrm{m}$ (100 a 48 mesh). Pode-se observar que as 
estruturas dos materiais sintetizados em laboratório são semelhantes, porém os lotes 7 e 8 (FIG. 5.18 e 5.19) apresentaram um tamanho de partícula maior que os materiais dos lotes 3 e 6 (FIG. 5.16 e 5.17 ).

Uma possível causa para essa diferença granulométrica foi um pequeno furo encontrado na peneira de $310 \mu \mathrm{m}$ (48 mesh) logo após a realização das análises. Mesmo assim optou-se por manter as análises dos lotes 7 e 8 no trabalho, pois posteriormente foram realizadas as análises elementares do material, sendo uma informação importante.

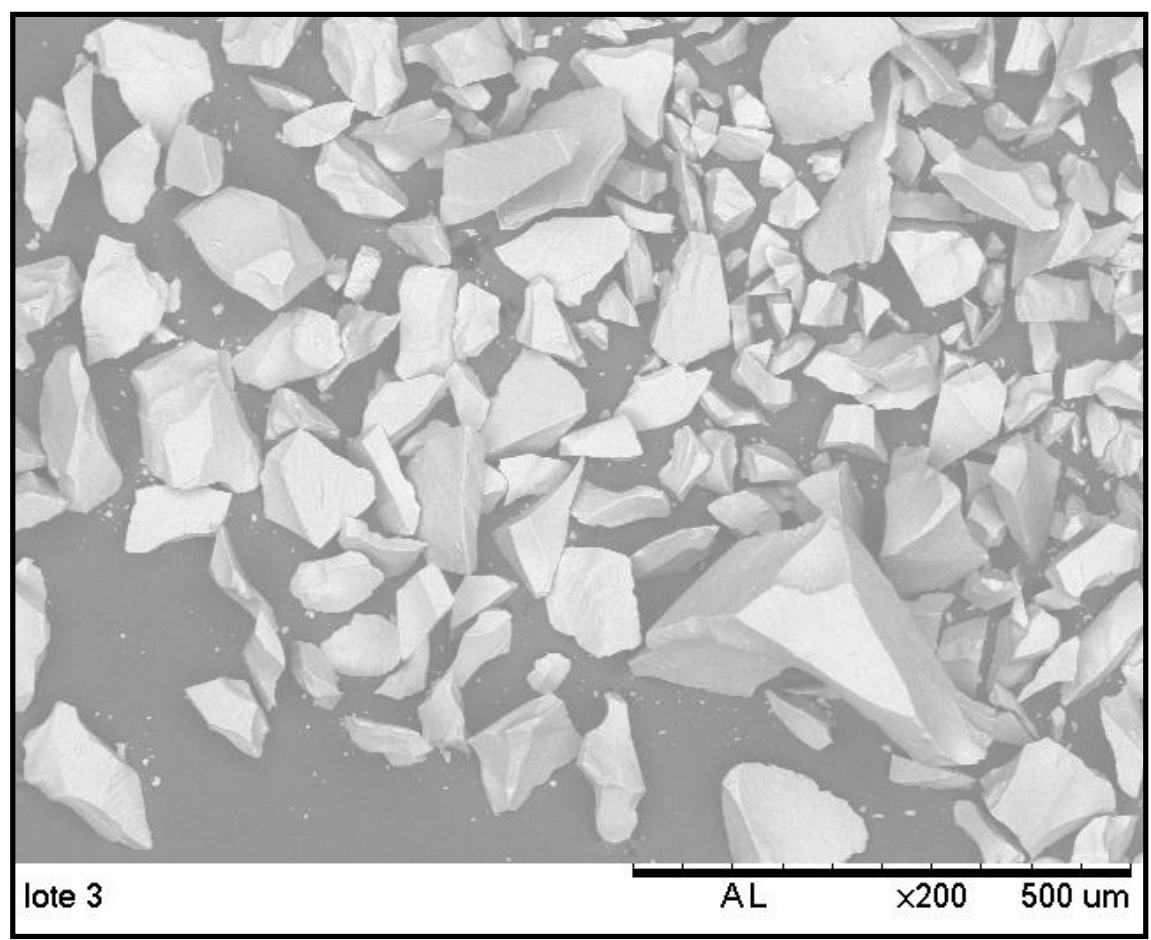

FIGURA 5.16 - Micrografia do $\mathrm{TiO}_{2}$ lote 3 seco a $100^{\circ} \mathrm{C}$. 


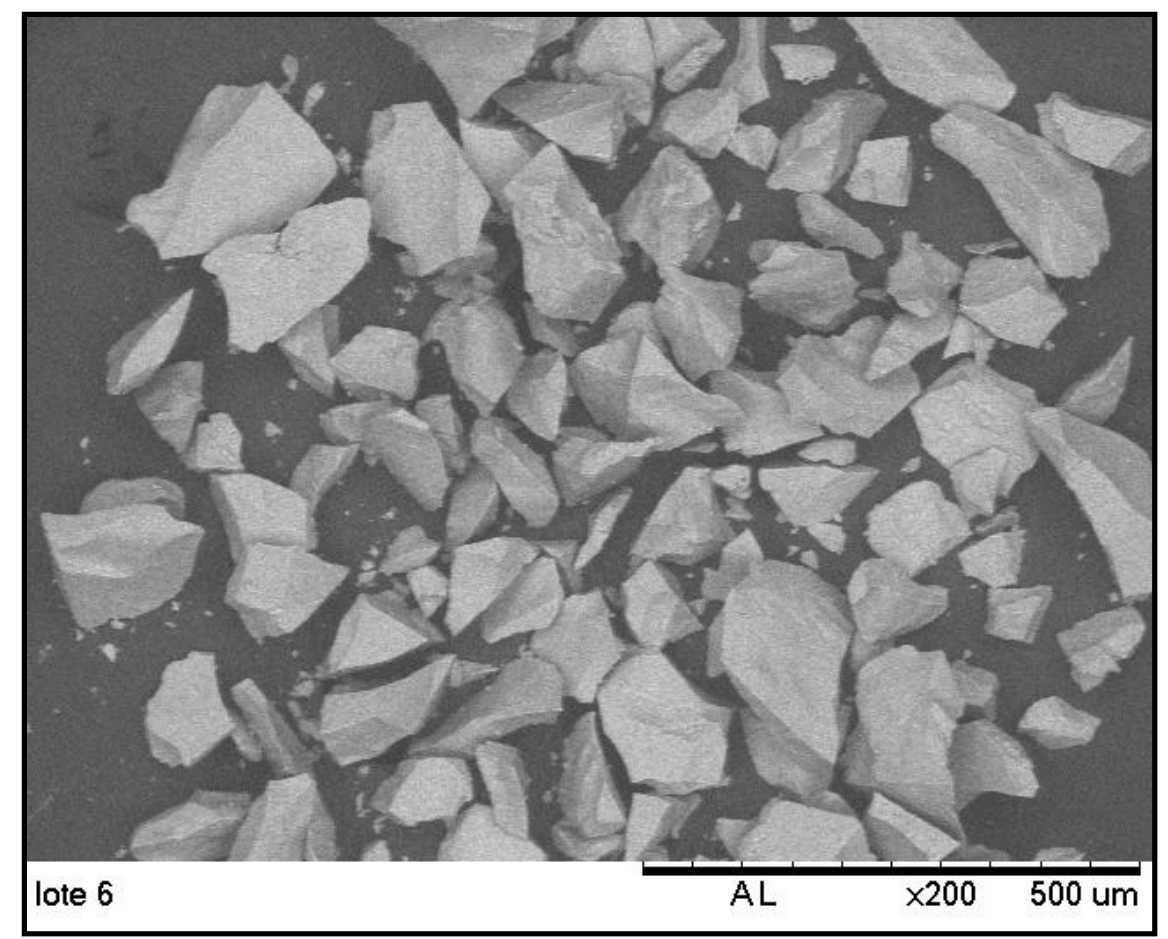

FIGURA 5.17 - Micrografia do $\mathrm{TiO}_{2}$ lote 6 seco a $100^{\circ} \mathrm{C}$ e calcinado a $420^{\circ} \mathrm{C}$.

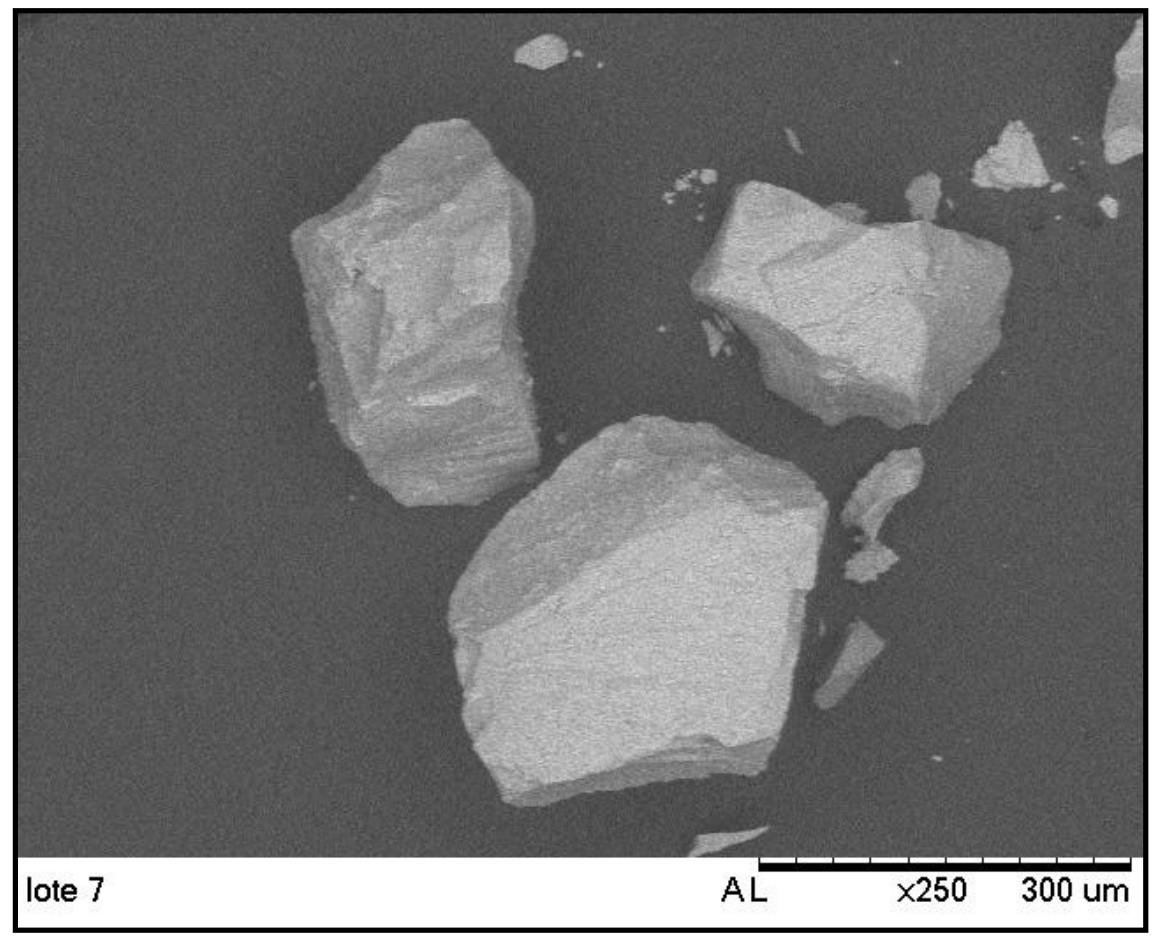

FIGURA 5.18 - Micrografia do $\mathrm{TiO}_{2}$ lote 7 seco a $100^{\circ} \mathrm{C}$ e calcinado a $420^{\circ} \mathrm{C}$. 


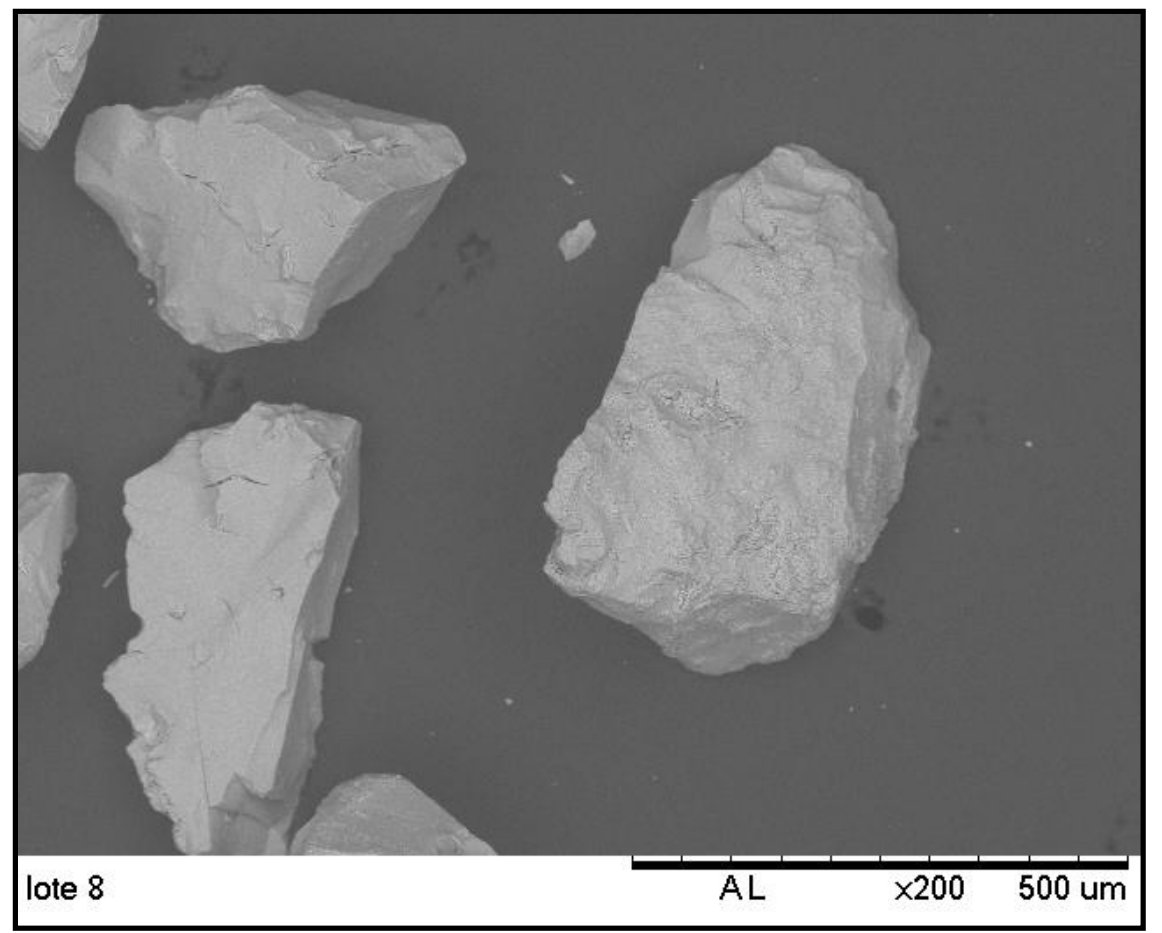

FIGURA 5.19 - Micrografia do $\mathrm{TiO}_{2}$ lote 8 seco a $100^{\circ} \mathrm{C}$ e calcinado a $420^{\circ} \mathrm{C}$.

As FIG. 5.20 e 5.21 mostram as micrografias do $\mathrm{TiO}_{2}$ comercial P90 da Degussa com aumento de 300 vezes e 4000 vezes. Pode-se observar aglomerados de partículas.

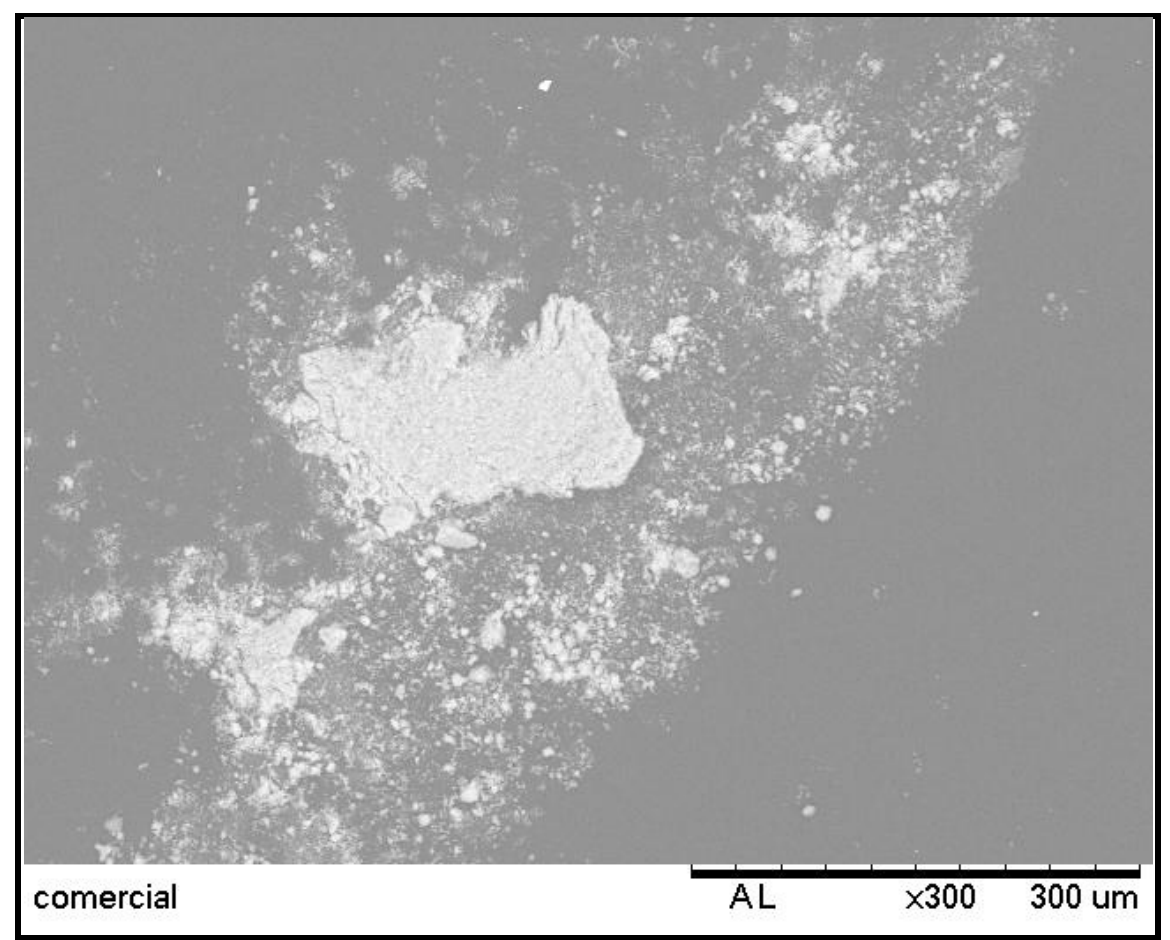

FIGURA 5.20 - Micrografia do $\mathrm{TiO}_{2} \mathrm{P} 90$ da Evonik Degussa (300x). 


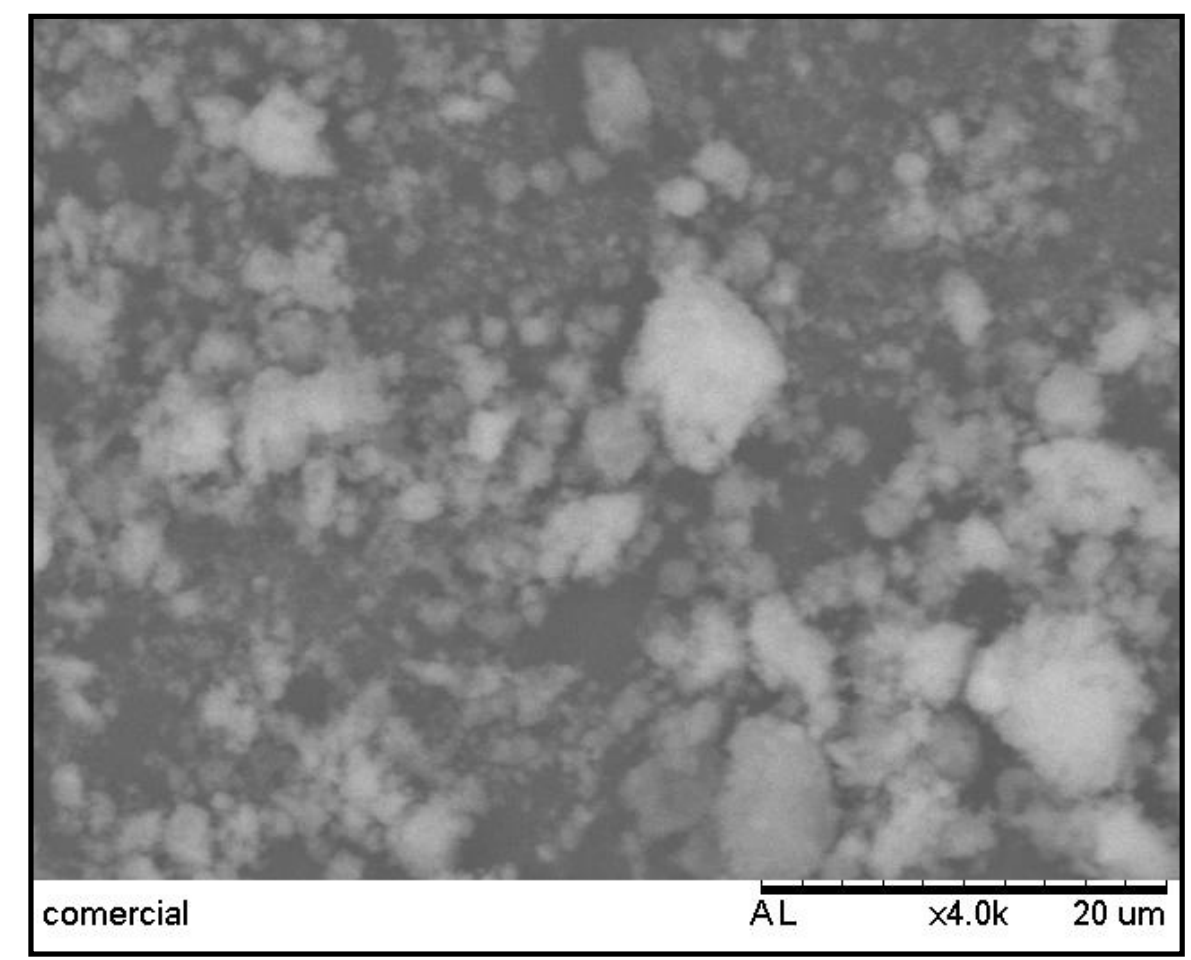

FIGURA 5.21 - Micrografia do $\mathrm{TiO}_{2}$ P90 da Evonik Degussa (4000x).

\subsubsection{Análise elementar}

Foram realizadas análises elementares dos $\mathrm{TiO}_{2}$ dos lotes 3, 6, 7 e 8 e do $\mathrm{TiO}_{2} \mathrm{P} 90$ da Degussa através do sistema EDS do microscópio.

A análise elementar do $\mathrm{TiO}_{2}$ do lote 3 é mostrada na FIG. 5.22, onde "A" apresenta a distribuição dos elementos na partícula selecionada para análise e "B" mostra o espectro dos elementos encontrados. Além do titânio, cloro, alumínio e oxigênio foram identificados. 


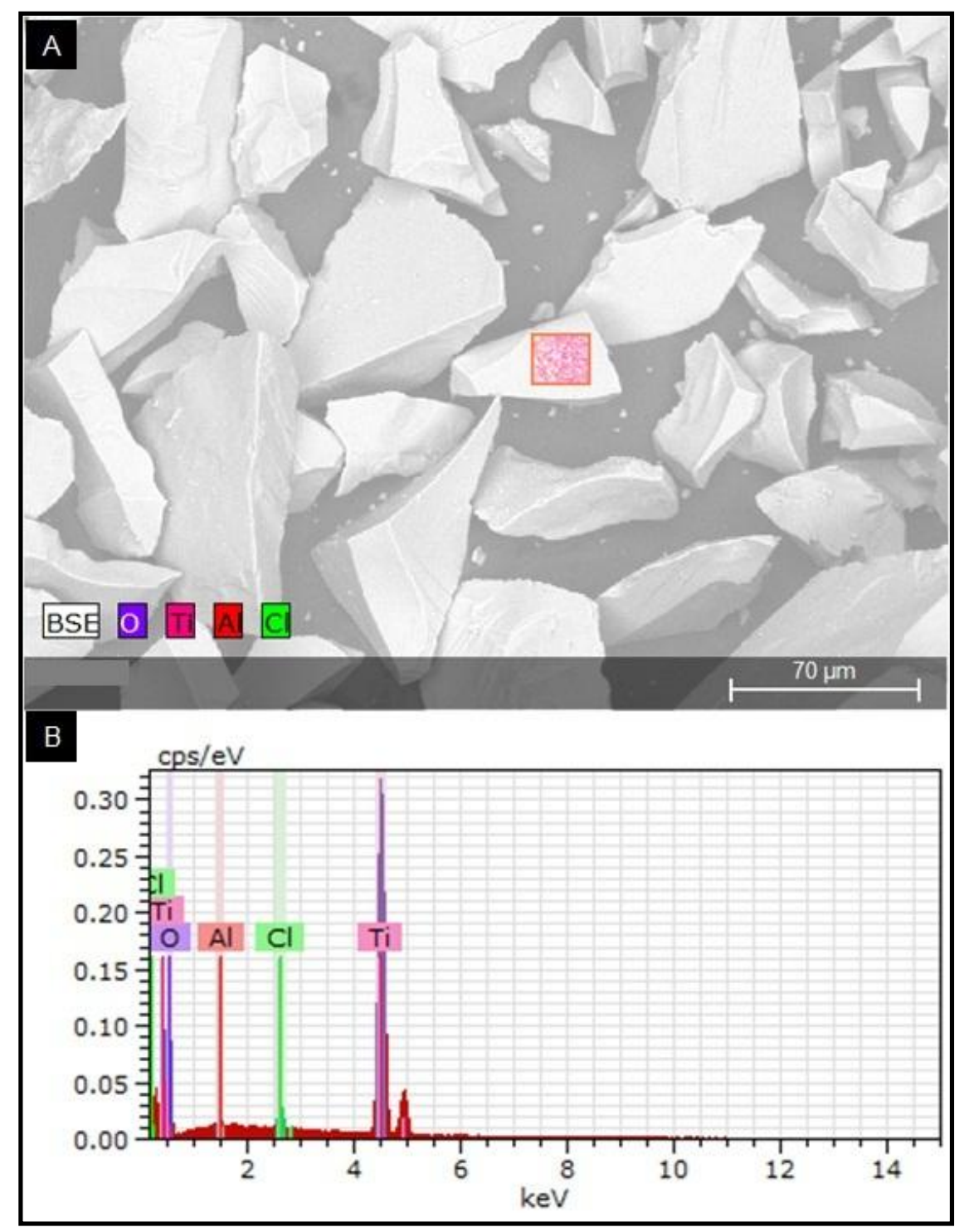

FIGURA 5.22 - Análise elementar do $\mathrm{TiO}_{2}$ lote $3\left(\operatorname{seco}\right.$ a $\left.100^{\circ} \mathrm{C}\right)$ feita pelo sistema EDS do microscópio. A) Distribuição elementar. B) Espectro dos elementos encontrados na amostra.

A FIG. 5.23 apresenta a quantificação dos elementos encontrados no $\mathrm{TiO}_{2}$ do lote 3. Sendo "A" o mapeamento da área para quantificação e "B" a porcentagem dos elementos encontrados. Foram quantificados apenas o titânio, cloro e alumínio. A amostra analisada apresentou $97,1 \%$ de titânio, 2,2\% de cloro e $0,6 \%$ de alumínio. 


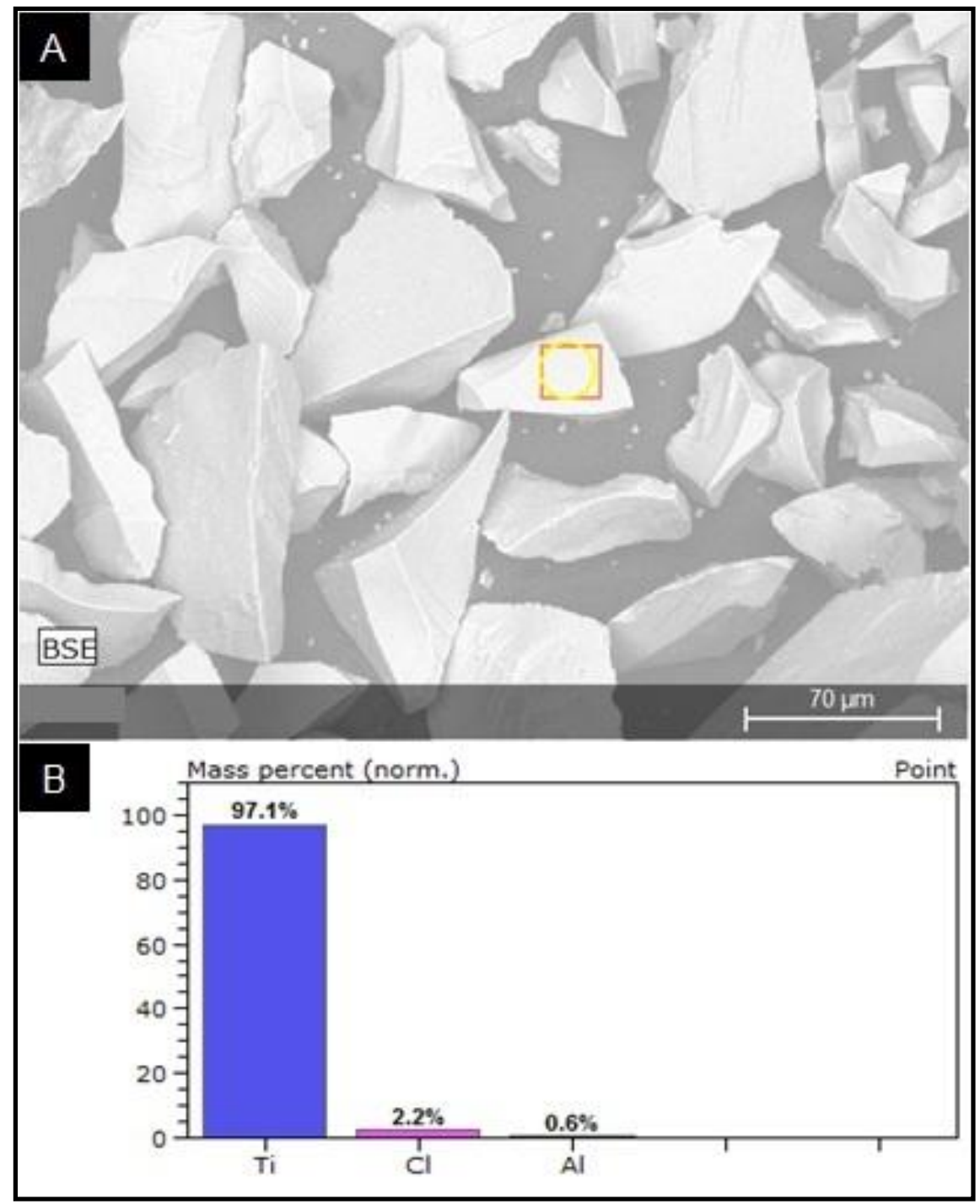

FIGURA 5.23 - Quantificação elementar do $\mathrm{TiO}_{2}$ lote 3 (seco a $100^{\circ} \mathrm{C}$ ) feita pelo sistema EDS do microscópio. A) Mapeamento da área para quantificação. B) Porcentagem dos elementos encontrados na amostra.

A FIG. 5.24 apresenta a análise elementar do $\mathrm{TiO}_{2}$ do lote 6 , onde foram encontrados apenas titânio e oxigênio na amostra. 


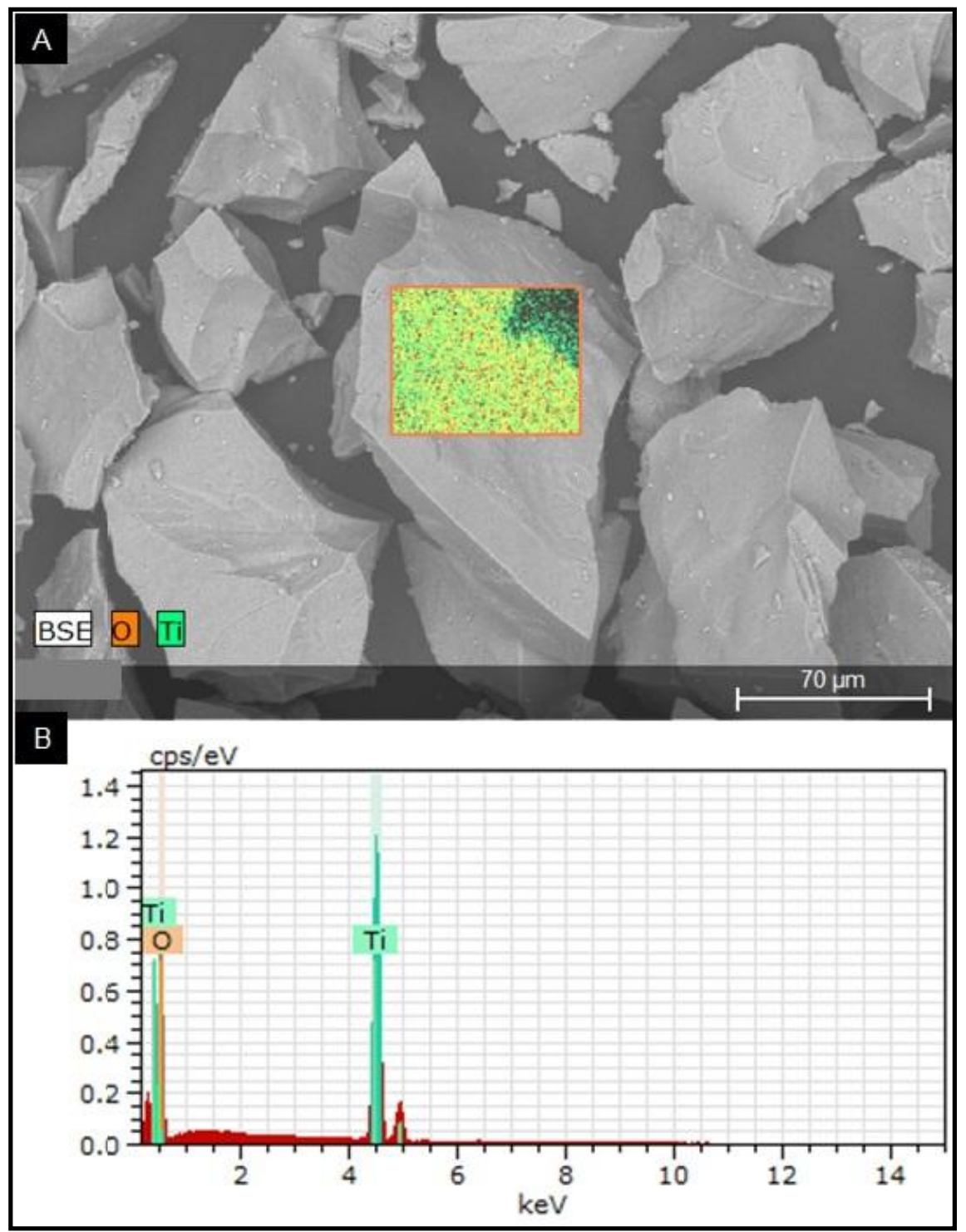

FIGURA 5.24 - Análise elementar do $\mathrm{TiO}_{2}$ lote 6 (seco a $100^{\circ} \mathrm{C}$ e calcinado a $420^{\circ} \mathrm{C}$ ) feita pelo sistema EDS do microscópio. A) Distribuição elementar. B) Espectro dos elementos encontrados na amostra.

A análise elementar do $\mathrm{TiO}_{2}$ do lote 7 está apresentada na FIG. 5.25. Além do titânio e oxigênio, foi encontrado cloro. 


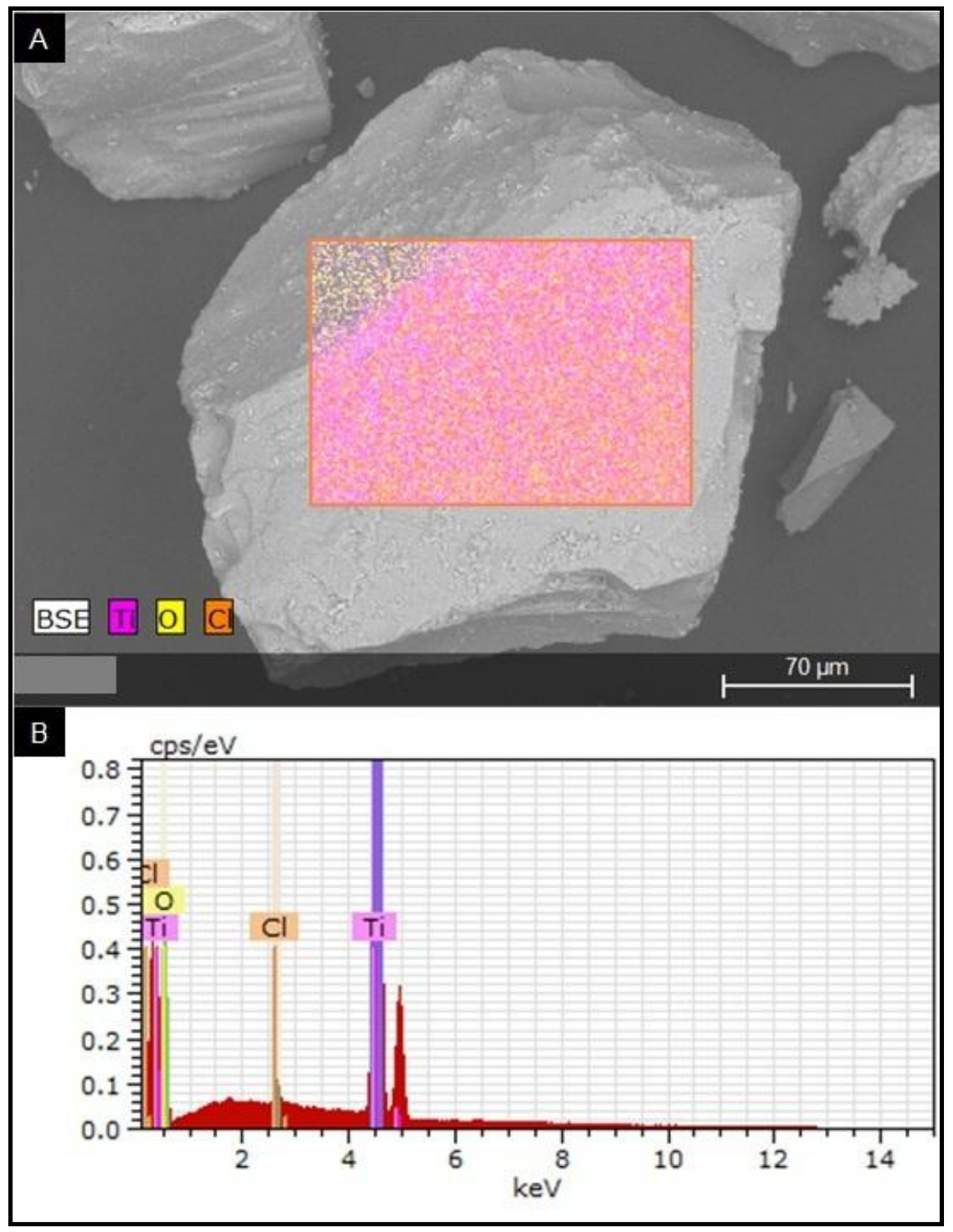

FIGURA 5.25 - Análise elementar do $\mathrm{TiO}_{2}$ lote 7 (seco a $100^{\circ} \mathrm{C}$ e calcinado a $420^{\circ} \mathrm{C}$ ) feita pelo sistema EDS do microscópio. A) Distribuição elementar. B) Espectro dos elementos encontrados na amostra.

A quantificação dos elementos encontrados no $\mathrm{TiO}_{2}$ do lote 7 está representada na FIG.26. Foram quantificados apenas o titânio e o cloro. A amostra analisada apresentou 99,1\% de titânio e 0,9 \% de cloro. 


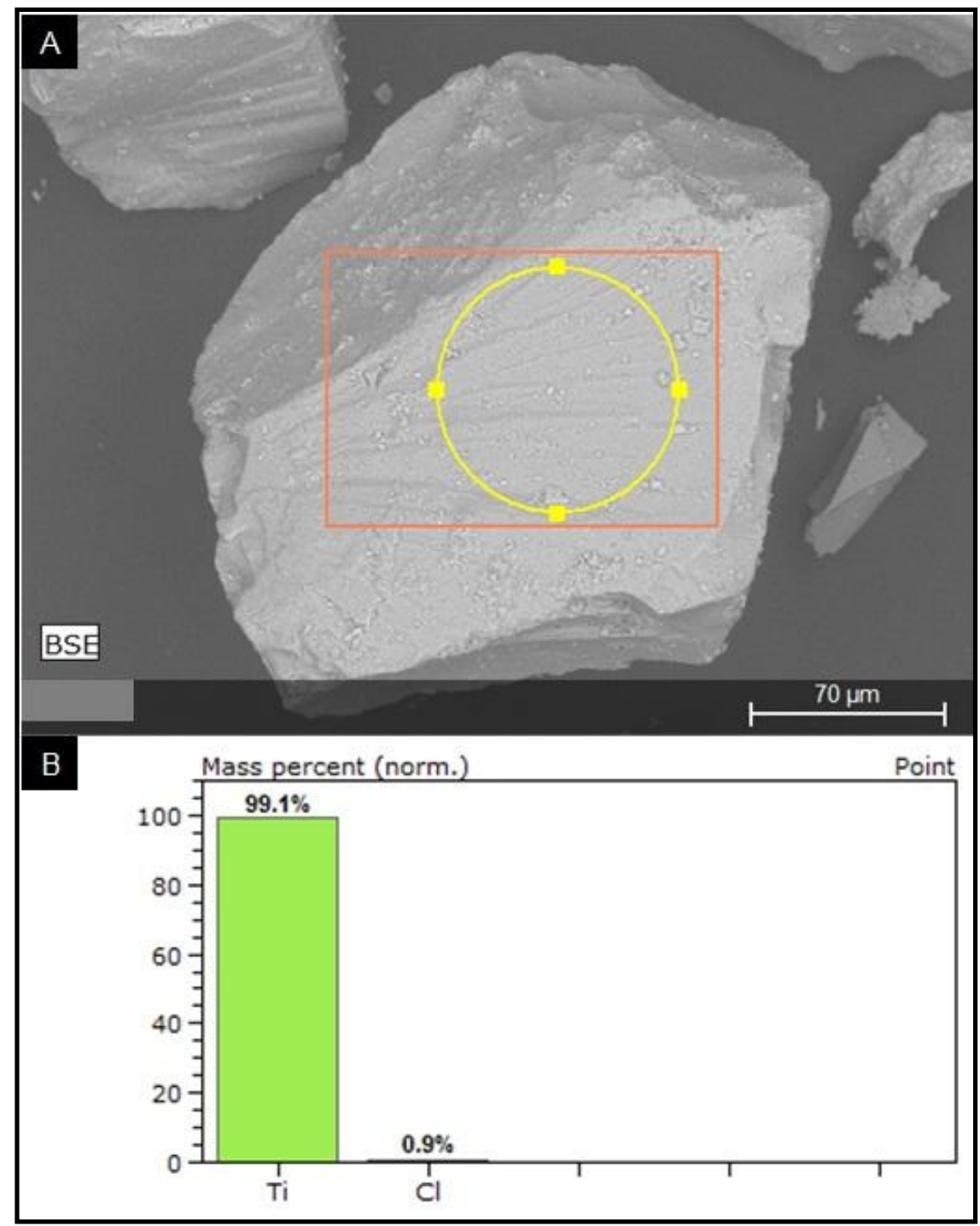

FIGURA 5.26 - Quantificação elementar do $\mathrm{TiO}_{2}$ lote 7 (seco a $100^{\circ} \mathrm{C}$ e calcinado a $420^{\circ} \mathrm{C}$ ) feita pelo sistema EDS do microscópio. A) Mapeamento da área para quantificação. B) Porcentagem dos elementos encontrados na amostra.

A FIG.5.27 mostra a análise elementar do $\mathrm{TiO}_{2}$ do lote 8. Os elementos identificados na amostra foram o titânio, cloro, silício, ferro e alumínio. 


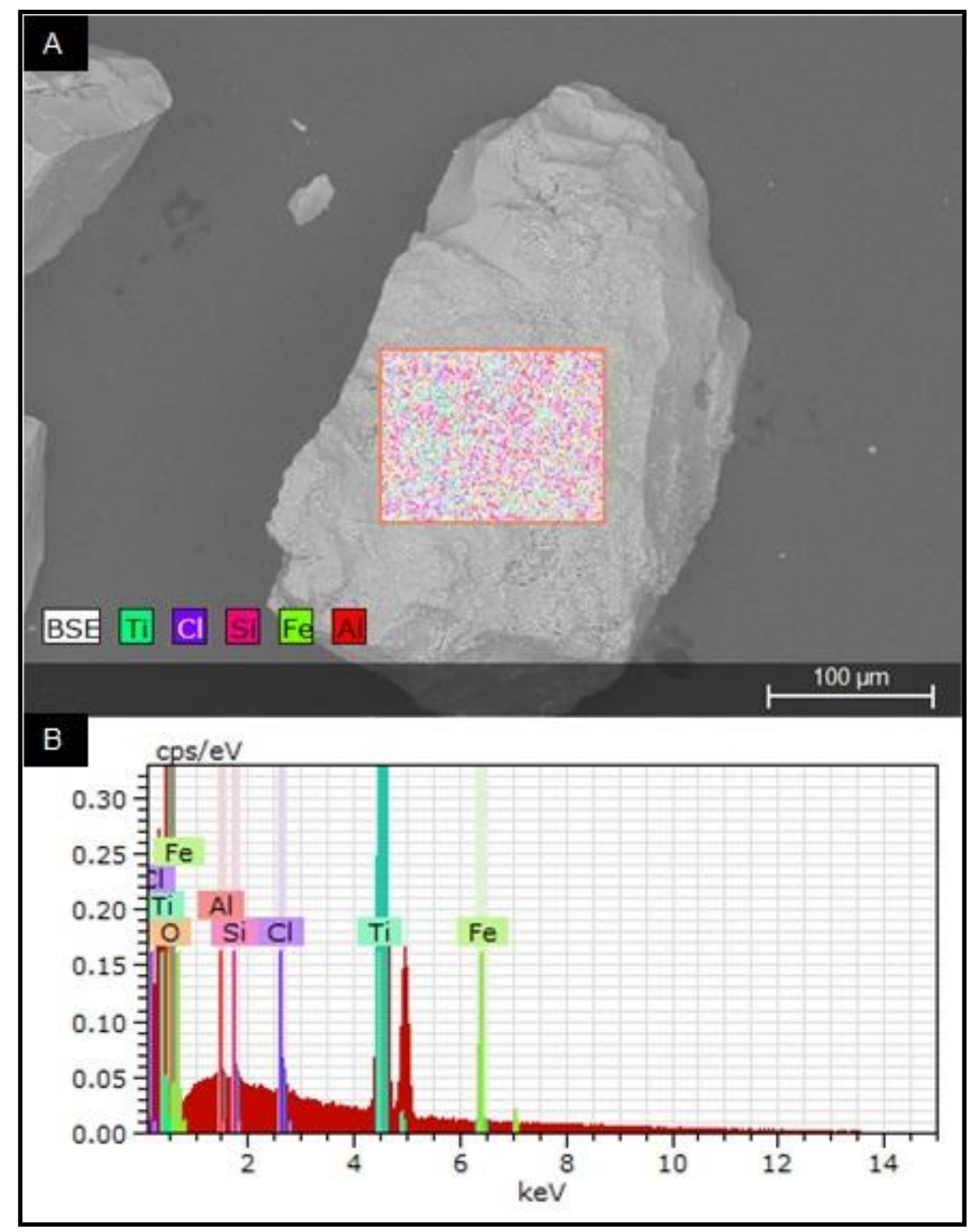

FIGURA 5.27 - Análise elementar do $\mathrm{TiO}_{2}$ lote 8 (seco a $100^{\circ} \mathrm{C}$ e calcinado a $420^{\circ} \mathrm{C}$ ) feita pelo sistema EDS do microscópio. A) Distribuição elementar. B) Espectro dos elementos encontrados na amostra.

A quantificação dos elementos encontrados no material do lote 8 está apresentada na FIG. 5.28. Na amostra analisada foram encontrados 98,2 \% de titânio, $0,9 \%$ de cloro, $0,5 \%$ de ferro e 0,4 \% de silício. O alumínio não foi quantificado. 


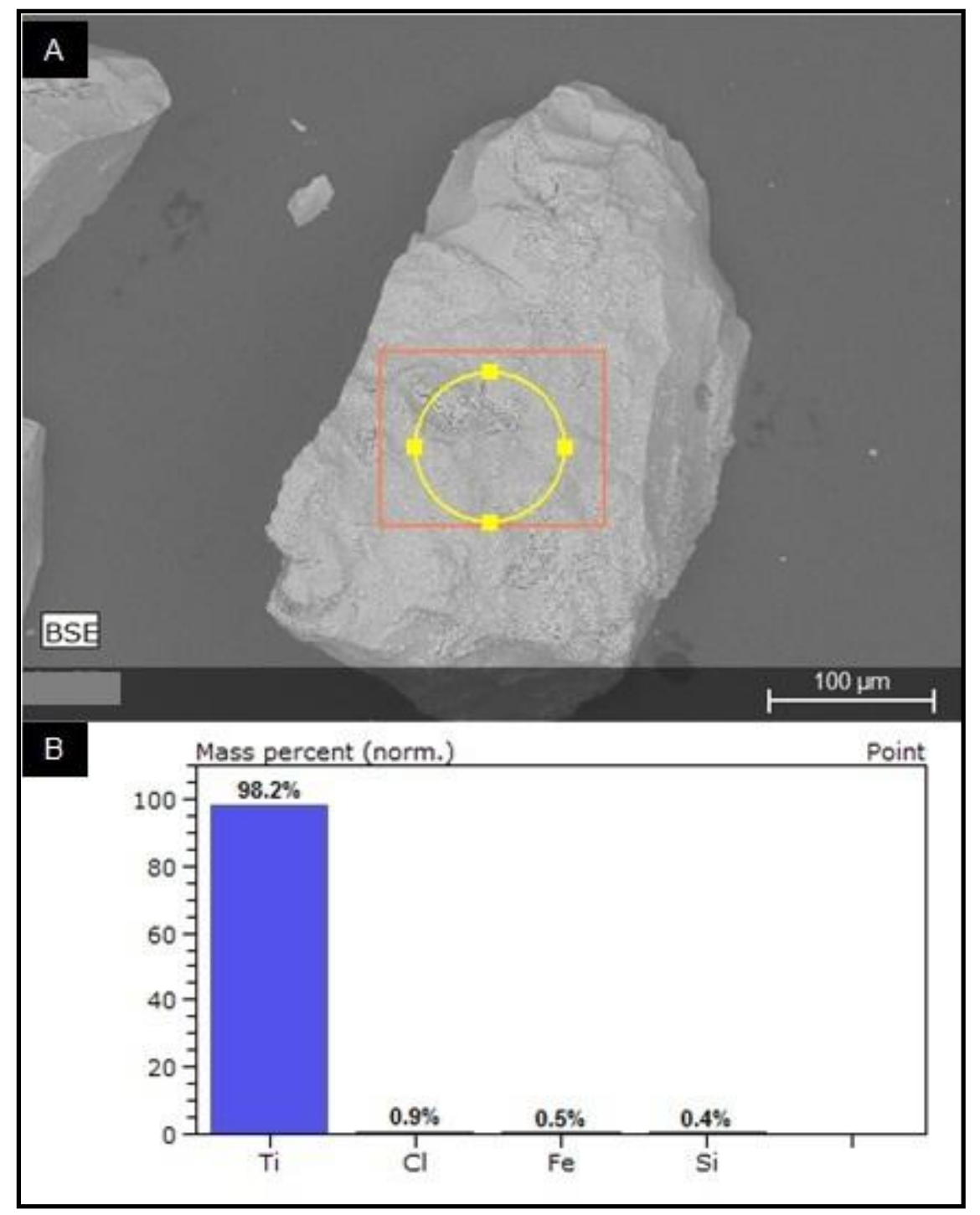

FIGURA 5.28 - Quantificação elementar do $\mathrm{TiO}_{2}$ lote $8\left(\right.$ seco a $100^{\circ} \mathrm{C}$ e calcinado a $420^{\circ} \mathrm{C}$ ) feita pelo sistema EDS do microscópio. A) Mapeamento da área para quantificação. B) Porcentagem dos elementos encontrados na amostra.

A FIG. 5.29 apresenta a análise elementar do $\mathrm{TiO}_{2} \mathrm{P} 90$ da Degussa. Além de titânio e oxigênio, foram encontrados na amostra, cloro, alumínio e silício. 


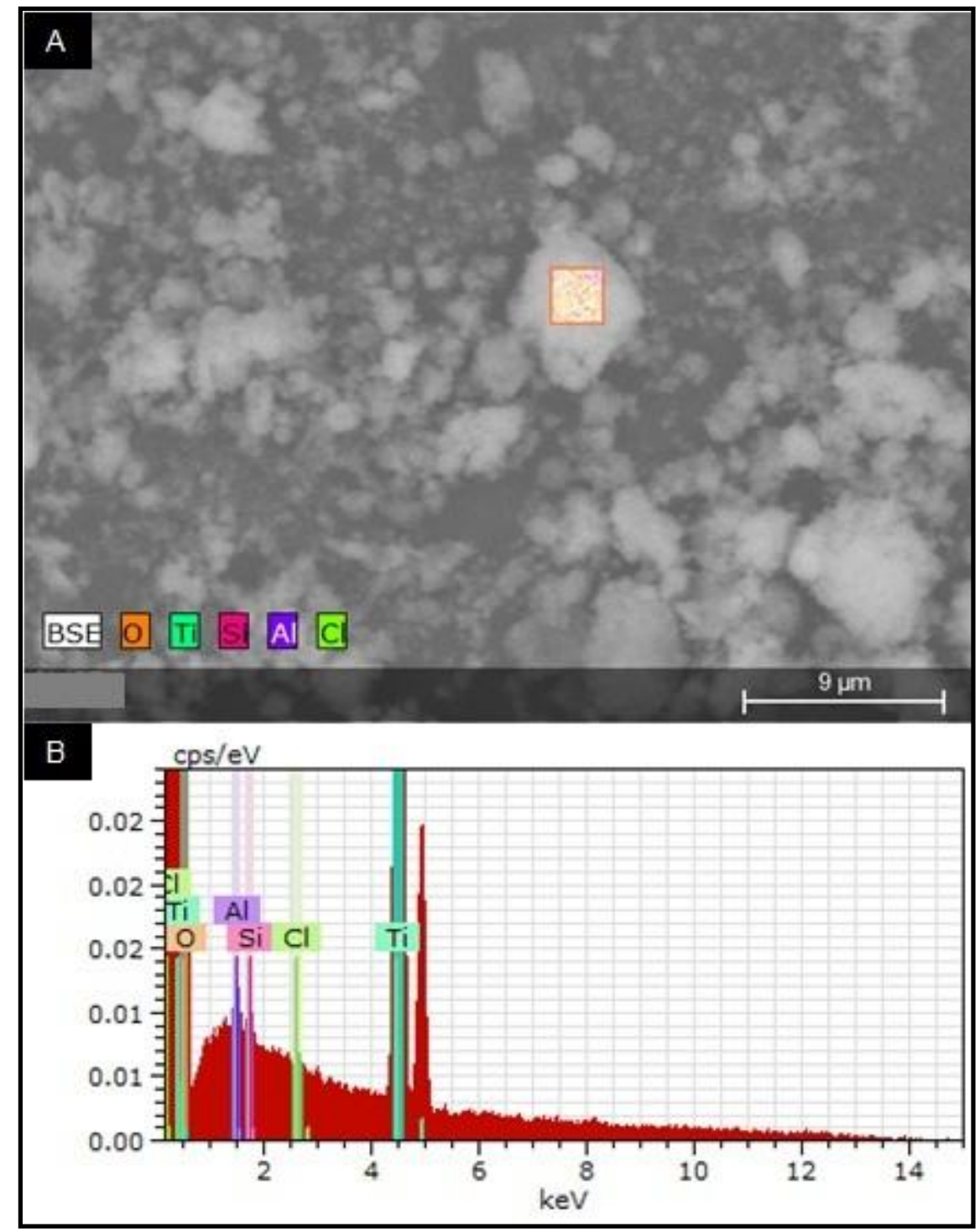

FIGURA 5.29 - Análise elementar do $\mathrm{TiO}_{2} \mathrm{P} 90$ da Evonik Degussa feita pelo sistema EDS do microscópio. A) Distribuição elementar. B) Espectro dos elementos encontrados na amostra.

A quantificação dos elementos encontrados na amostra do $\mathrm{TiO}_{2} \mathrm{P} 90$ da Degussa está representada na FIG. 5.30. 


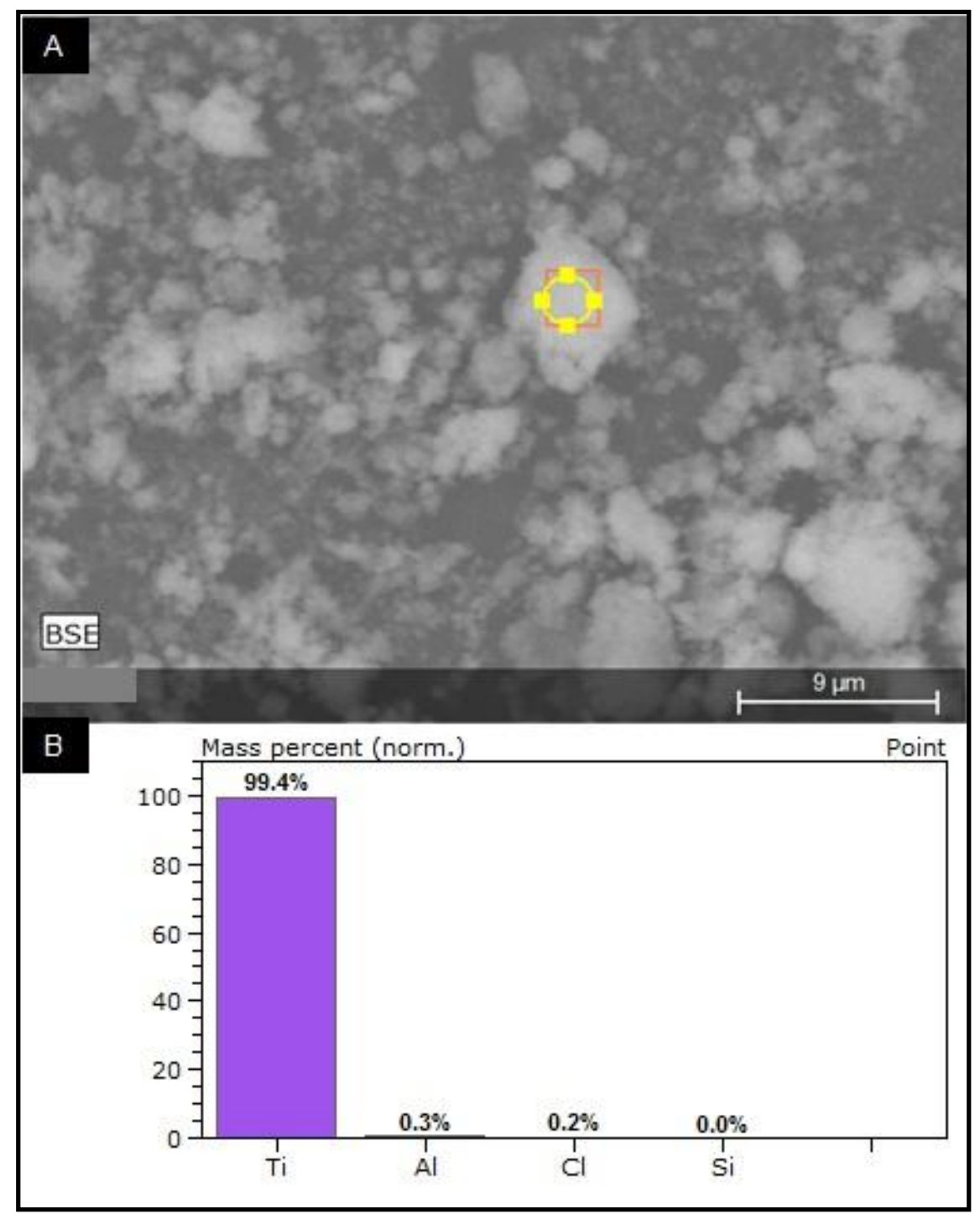

FIGURA 5.30 - Quantificação elementar do $\mathrm{TiO}_{2} \mathrm{P} 90$ da Evonik Degussa feita pelo sistema EDS do microscópio. A) Mapeamento da área para quantificação. B) Porcentagem dos elementos encontrados na amostra.

Foram encontrados $99,4 \%$ de titânio, 0,3 \% de alumínio, 0,2 \% de cloro e para o silício a quantificação deu $0,0 \%$, embora o pico desse elemento tenha aparecido na análise elementar.

A presença de cloro nas amostras de $\mathrm{TiO}_{2}$ pode ser explicada pela ineficiência do processo de lavagem do material durante o seu preparo. A lavagem do precipitado formado pela neutralização do $\mathrm{TiCl}_{3}$ por $\mathrm{NH}_{4} \mathrm{OH}$ tem como objetivo retirar os íons de cloro da solução, portanto é provável que a lavagem do material não foi suficiente para retirada desses íons da solução. 
Alumínio, ferro e silício podem ter origem das vidrarias e outros materiais utilizados para o preparo do $\mathrm{TiO}_{2}$, como as peneiras ou da água utilizada no processo de lavagem.

\subsubsection{Análise termogravimétrica (TG e DTA)}

O comportamento de decomposição térmica do $\mathrm{TiO}_{2}$ foi estudado usando a Termogravimetria (TG) e a Análise Térmica Diferencial (DTA). As análises térmicas foram realizadas no intervalo de temperatura de 20 a $800{ }^{\circ} \mathrm{C}$, com velocidade de aquecimento de $10^{\circ} \mathrm{C} / \mathrm{min}$. Foram analisados os $\mathrm{TiO}_{2}$ dos lotes $4\left(\right.$ seco a $\left.100^{\circ} \mathrm{C}\right), 9\left(\right.$ seco a $60^{\circ} \mathrm{C}$ e $\left.100^{\circ} \mathrm{C}\right)$ e 10 (seco a $\left.100^{\circ} \mathrm{C}\right)$.

As curvas de TG e DTA do $\mathrm{TiO}_{2}$, lote 4, estão apresentadas na FIG.5.31. A curva termogravimétrica apresentou três estágios de perda de massa. No primeiro estágio ocorreu uma perda de massa de aproximadamente $20 \%$, que corresponde à faixa de temperatura ambiente até $170^{\circ} \mathrm{C}$ e está relacionado a um pico endotérmico na curva de DTA, provavelmente ocasionado pela perda de água superficial do material. O segundo estágio corresponde a uma perda de massa mais discreta $(\sim 5 \%)$, que vai de $170^{\circ} \mathrm{C}$ até $280^{\circ} \mathrm{C}$, correspondendo a um pico exotérmico, provavelmente relacionado a reações de decomposição de intermediários. No último estágio ocorreu uma perda de $20 \%$ da massa, correspondendo à faixa de temperatura de $280^{\circ} \mathrm{C}$ a $400{ }^{\circ} \mathrm{C}$ e está relacionada a um pico endotérmico e à formação do óxido. A perda total de massa corresponde a $45 \%$. 


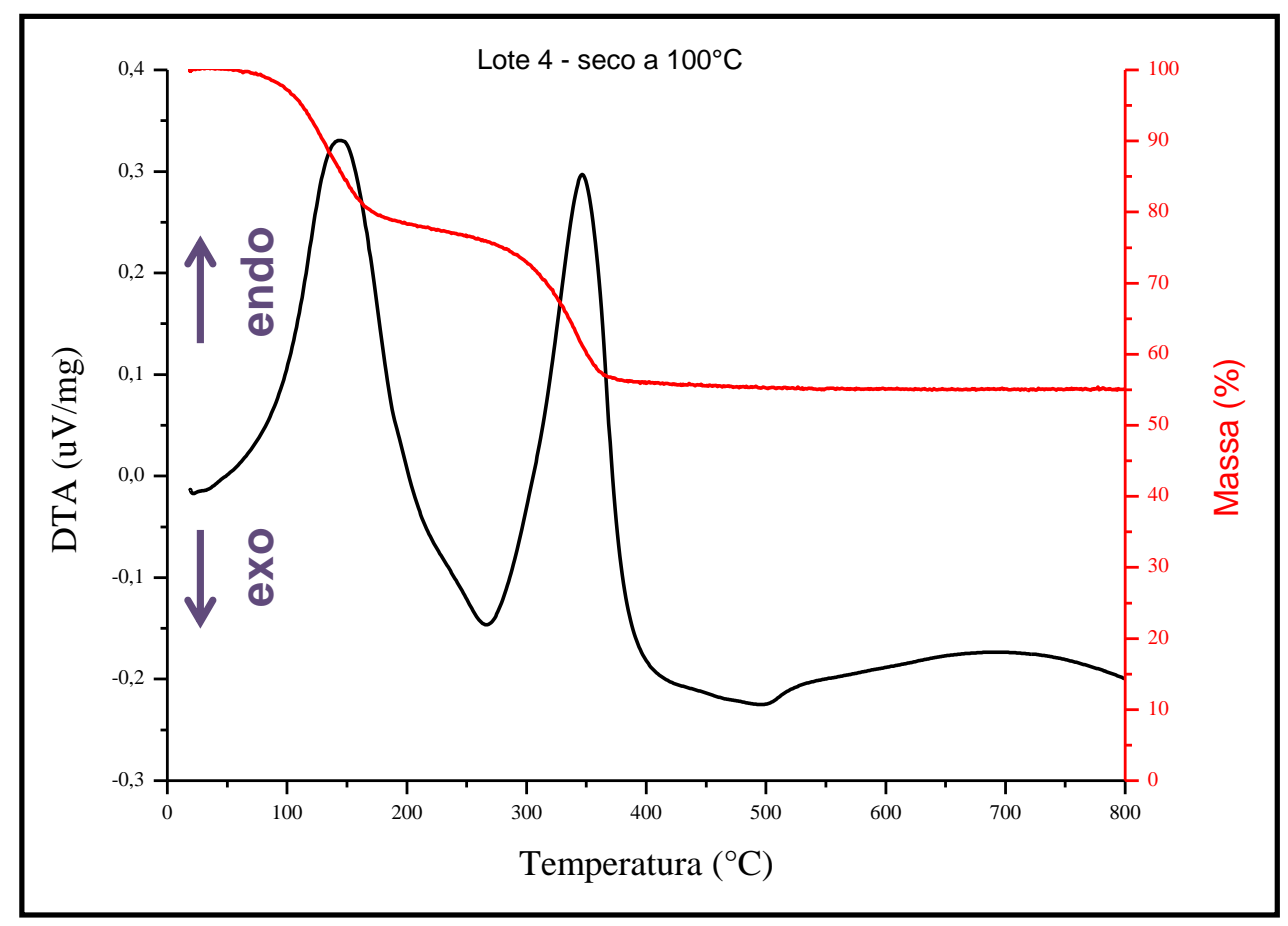

FIGURA 5.31 - Curva de TG e DTA do $\mathrm{TiO}_{2}$ lote 4 seco a $100{ }^{\circ} \mathrm{C}$.

A FIG. 5.32 mostra as curvas de TG e DTA do $\mathrm{TiO}_{2}$ do lote 9, seco a $60{ }^{\circ} \mathrm{C}$. A curva termogravimétrica apresentou três estágios de perda de massa, assim como observado na curva de TG do lote 4, porém com valores mais discretos. O primeiro estágio corresponde a uma perda de massa de aproximadamente $7 \%$, que corresponde à faixa de temperatura ambiente até 230 ${ }^{\circ} \mathrm{C}$ e está relacionado a um pico endotérmico na curva de DTA, provavelmente ocasionado pela perda de água superficial do material. O segundo estágio de perda de massa corresponde a aproximadamente $2 \%$ de perda, que vai de aproximadamente $230{ }^{\circ} \mathrm{C}$ até $380{ }^{\circ} \mathrm{C}$, correspondendo a um pico exotérmico, provavelmente relacionado a reações de decomposição de intermediários. No terceiro estágio pode-se observar uma perda por volta de $7 \%$ do material, correspondendo à faixa de temperatura de $370^{\circ} \mathrm{C}$ a $400{ }^{\circ} \mathrm{C}$ e está relacionada a um pico endotérmico e à formação do óxido. A perda total de massa corresponde a aproximadamente $16 \%$. 


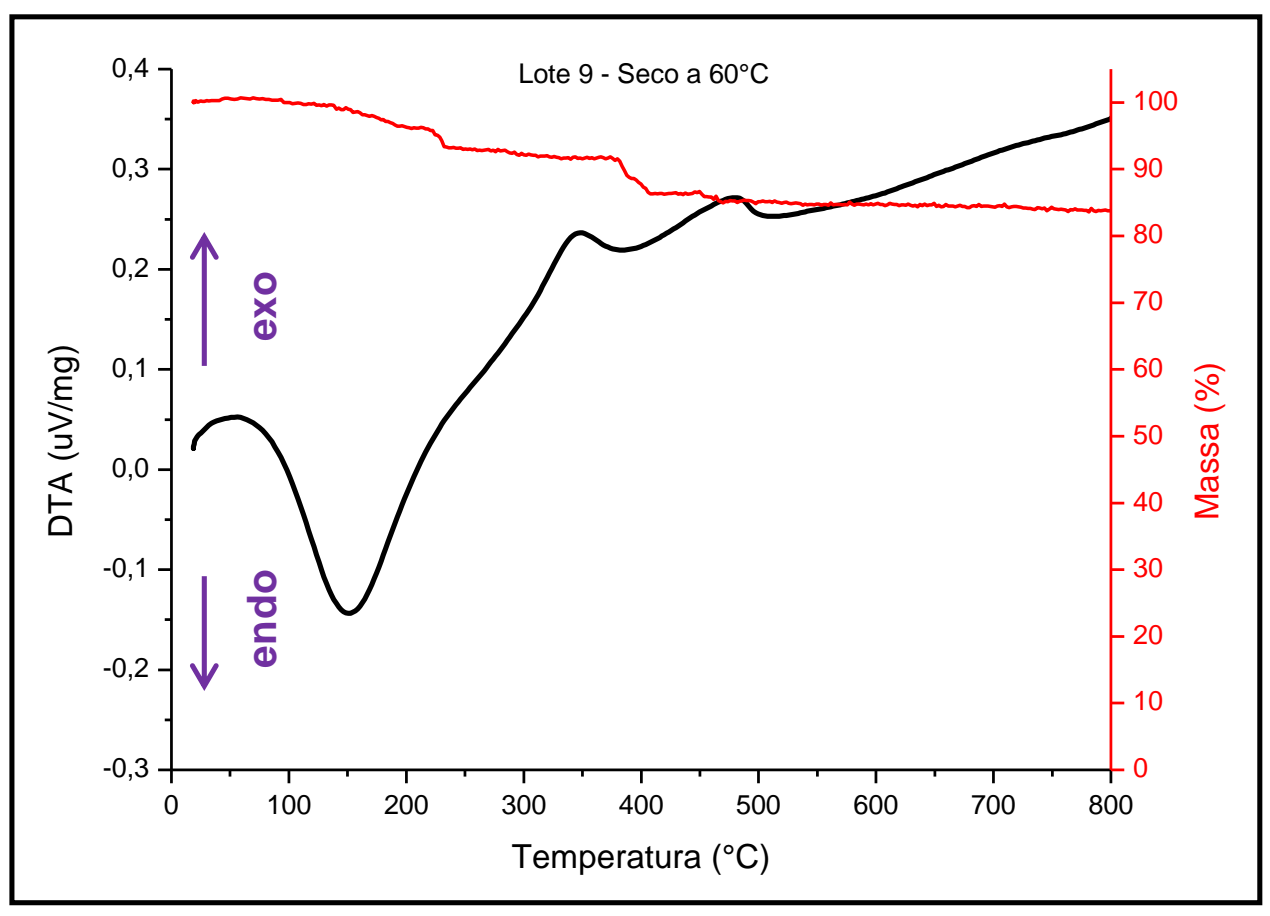

FIGURA 5.32 - Curva de TG e DTA do $\mathrm{TiO}_{2}$ lote 9 seco a $60^{\circ} \mathrm{C}$.

A curva termogravimétrica do $\mathrm{TiO}_{2}$ do lote 9 , seco a $100^{\circ} \mathrm{C}$, apresentou o mesmo perfil da curva do $\mathrm{TiO}_{2}$ seco a $60^{\circ} \mathrm{C}$, porém pode-se observar com clareza apenas dois estágios de perda de massa. O primeiro está associado a um pico endotérmico na curva de DTA e corresponde a aproximadamente $5 \%$ da perda de massa. No segundo estágio ocorreu uma perda de aproximadamente 4 $\%$, totalizando $9 \%$ de perda de massa do material (FIG. 5.33). A diferença na porcentagem da perda de massa do $\mathrm{TiO}_{2}$ seco a $60{ }^{\circ} \mathrm{C}$ para o seco a $100^{\circ} \mathrm{C}$, provavelmente está associada à presença de água no material.

A FIG. 5.34 apresenta as curvas de TG e DTA do $\mathrm{TiO}_{2}$ do lote 10 seco a $100{ }^{\circ} \mathrm{C}$. A curva termogravimétrica apresentou uma perda de massa de aproximadamente $26 \%$. O primeiro estágio de perda de massa corresponde a 15 $\%$ e está associado a um pico endotérmico da curva DTA, assim como nos outros materiais, provavelmente foi ocasionado pela perda de água superficial do material. Os próximos estágios de perda de massa correspondem a aproximadamente $11 \%$. 


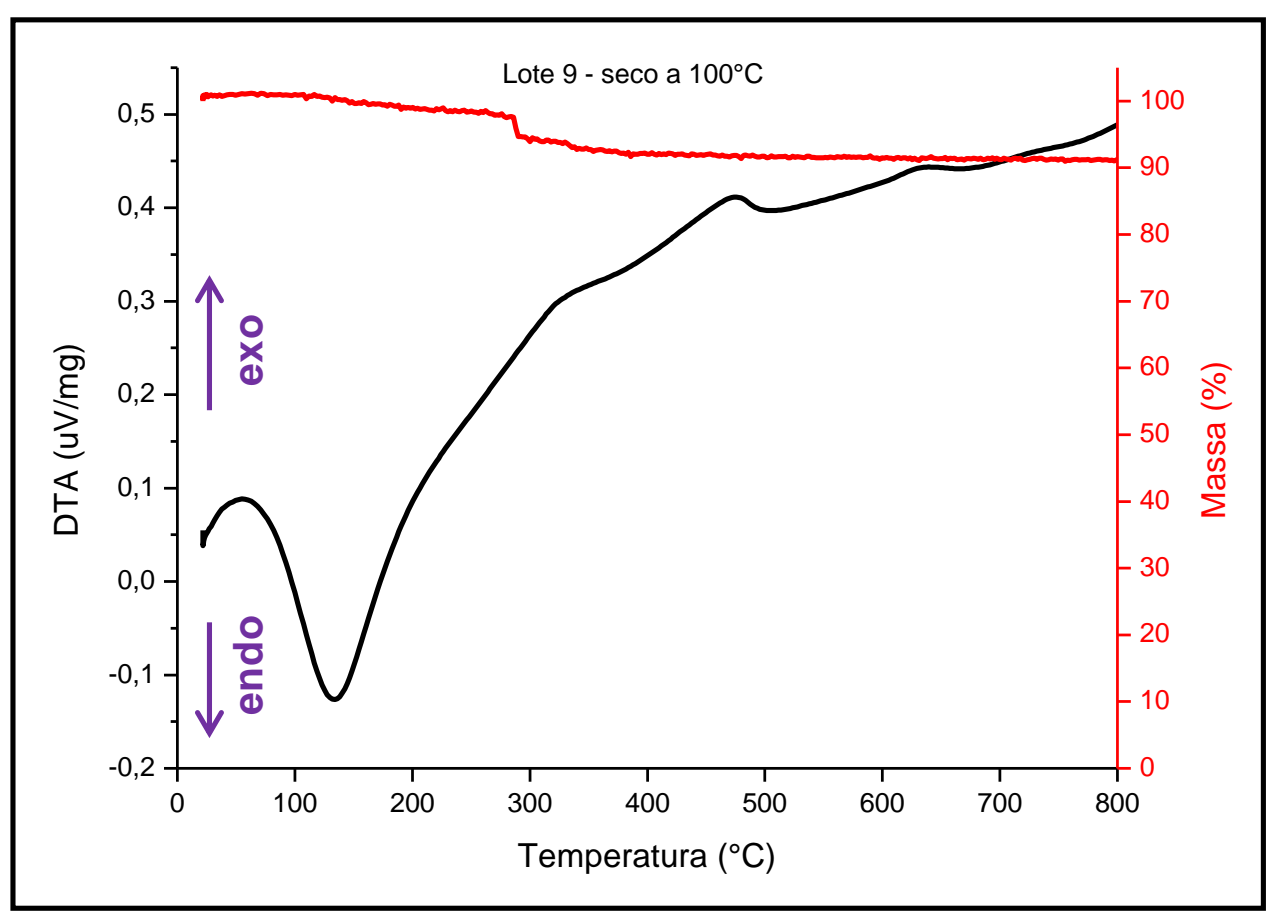

FIGURA 5.33 - Curva de TG e DTA do $\mathrm{TiO}_{2}$ lote 9 seco a $100{ }^{\circ} \mathrm{C}$.

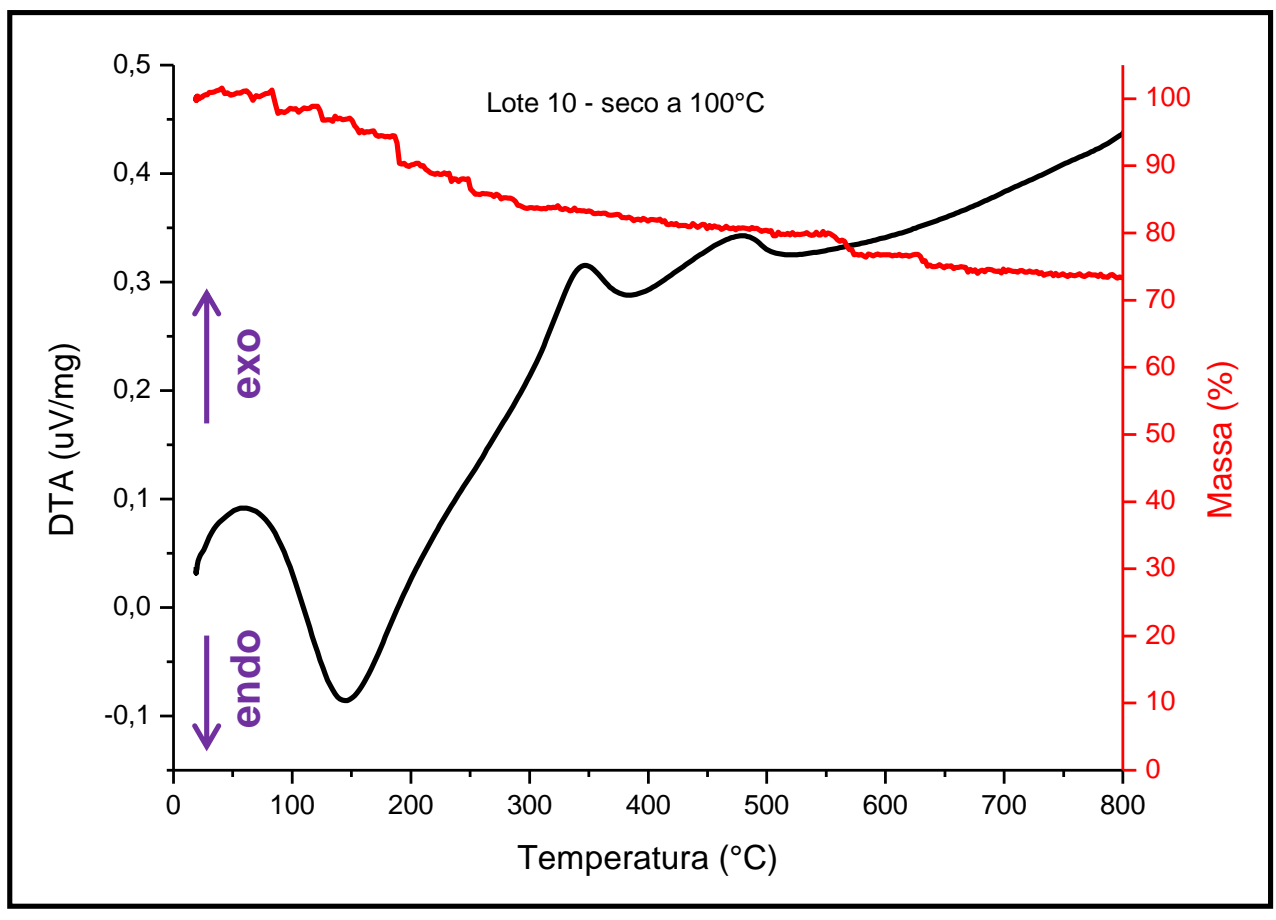

FIGURA 5.34 - Curva de TG e DTA do $\mathrm{TiO}_{2}$ lote 10 seco a $100^{\circ} \mathrm{C}$.

Com os resultados da análise termogravimétrica é possível concluir que a formação do $\mathrm{TiO}_{2}$ ocorre a partir de temperaturas acima de $400{ }^{\circ} \mathrm{C}$. A perda de massa do material com o aumento da temperatura indica a presença de $\mathrm{Ti}(\mathrm{OH})_{3}$, não sendo apropriado como trocador iônico, além de ser um material 
mais suscetível aos efeitos da radiólise quando utilizado para o preparo de geradores.

\subsubsection{Difração de raio $X$}

A FIG. 5.35 mostra o difratograma padrão do $\mathrm{TiO}_{2}$ com as fases anatase e rutilo e o difratograma obtido na análise do lote 6 calcinado a $420^{\circ} \mathrm{C}$. Pode-se observar que o material apresenta uma mistura das duas fases cristalinas.

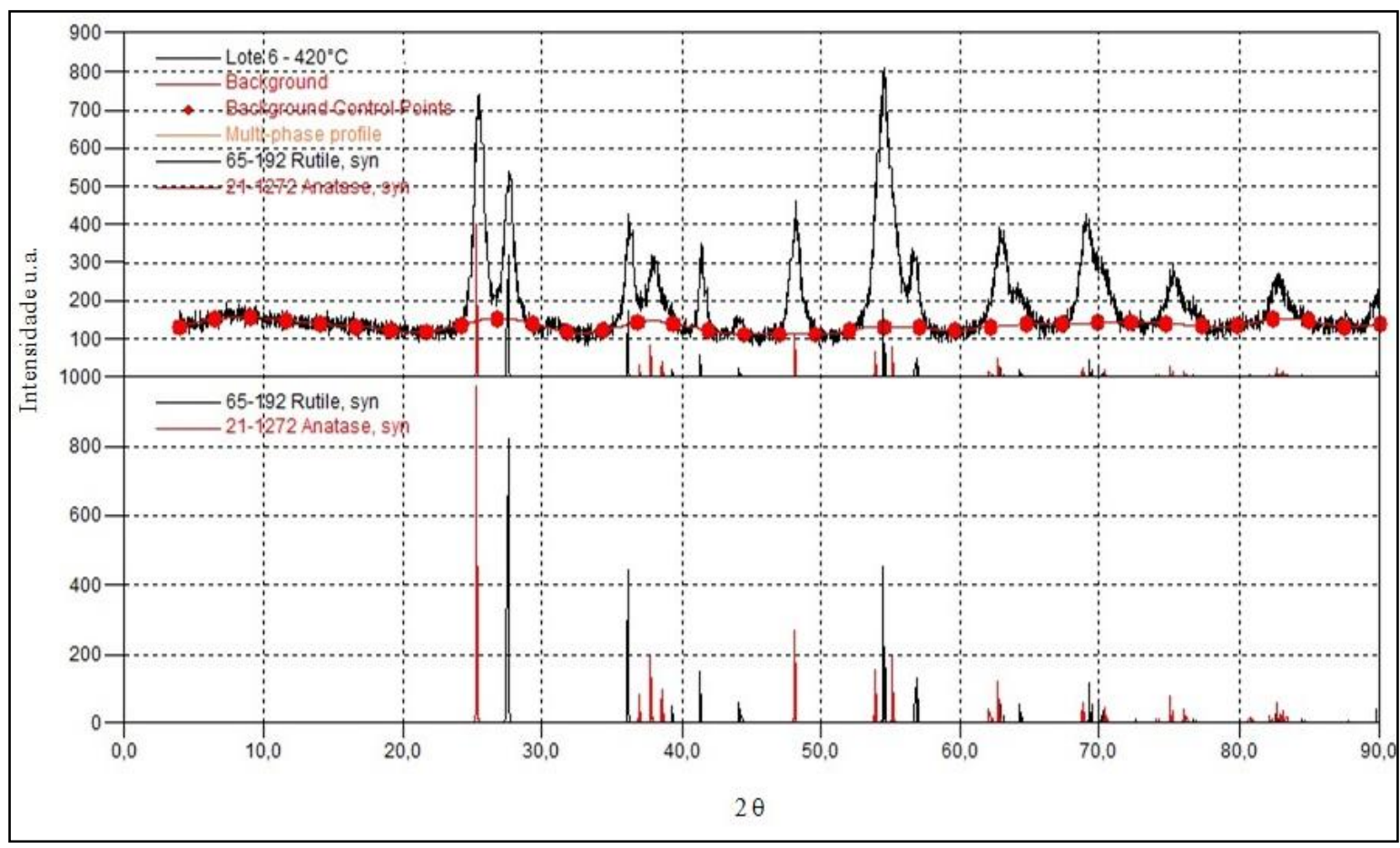

FIGURA 5.35 - Difratograma do $\mathrm{TiO}_{2}$ lote 6 (seco a $100^{\circ} \mathrm{C}$ e calcinado a $420^{\circ} \mathrm{C}$ ) e difratograma padrão do $\mathrm{TiO}_{2}$ com as fichas cristalográficas das fases anatase (JCPDS 21-1272) e rutilo (JCPDS 65-192).

A FIG. 5.36 mostra os difratogramas dos $\mathrm{TiO}_{2}$ dos lotes 3, 4, 5, 6, 7, 8 e do $\mathrm{TiO}_{2} \mathrm{P} 90$ da Degussa. Pode-se observar que os materiais que foram apenas secos a $100{ }^{\circ} \mathrm{C}$ (lotes 3 e 4) apresentam picos que correspondem ao $\mathrm{TiO}_{2}$ na fase anatase, porém com bases mais largas comparados aos que foram calcinados e ao material comercial, indicando tamanho do cristalito diferenciado. 
Os lotes 4 e 6 , calcinados a $420{ }^{\circ} \mathrm{C}$, foram os materiais que apresentaram picos mais evidentes da fase cristalina rutilo, comparados aos outros lotes que também foram calcinados a $420^{\circ} \mathrm{C}$.

A formação da fase rutilo ocasionada pelo aumento da temperatura de calcinação fica evidente com os difratogramas do lote 5. A amostra do material calcinada a $420^{\circ} \mathrm{C}$ apresentou picos característicos à fase anatase, já a amostra calcinada a $800^{\circ} \mathrm{C}$ apresentou picos da fase rutilo.

A calcinação promoveu a formação das fases cristalinas anatase e rutilo, porém observa-se que a formação da fase rutilo não foi evidente em todos os lotes calcinados a $420^{\circ} \mathrm{C}$, como pode ser visto nos difratogramas dos lotes $5 \mathrm{e}$ 8. Pode-se observar também que as proporções das fases anatase e rutilo não foram necessariamente iguais de um lote para outro, nessa mesma temperatura de calcinação, como é o caso dos lotes 4, 6 e 7.

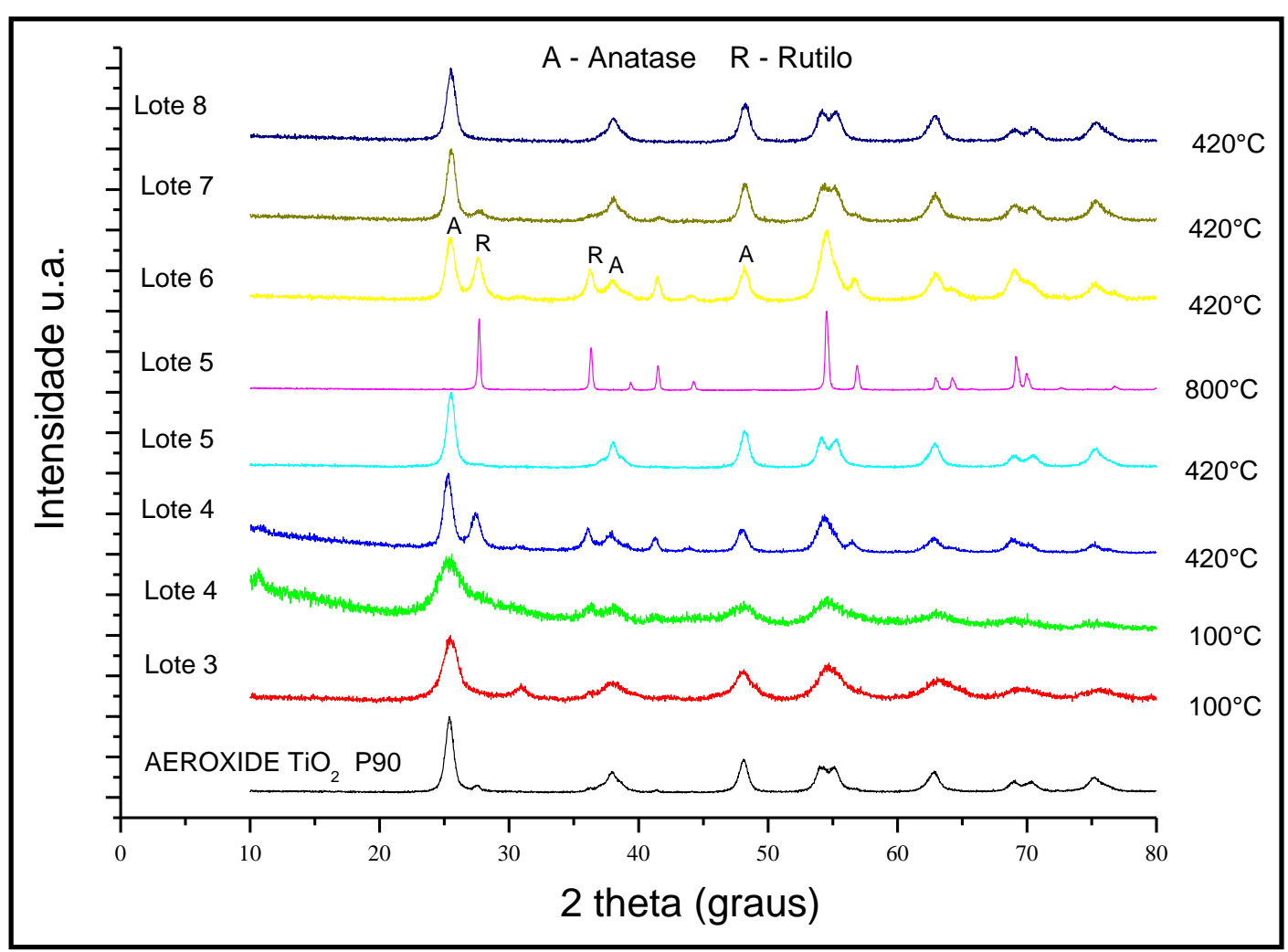

FIGURA 5.36 - Difratogramas de diferentes amostras de $\mathrm{TiO}_{2}$. AEROXIDE $\mathrm{TiO}_{2}$ P90 (Degussa), lote 3 e 4 secos a $100^{\circ} \mathrm{C}$, lote $4,6,7$ e 8 calcinados a $420^{\circ} \mathrm{C}$ e lote 5 calcinado a $420^{\circ} \mathrm{C}$ e $800^{\circ} \mathrm{C}$. 
O material não calcinado apresentou coloração branca, após a calcinação a $420^{\circ} \mathrm{C}$ ocorreu uma alteração da cor para amarelo-palha, que variou um pouco de tom, de um lote para outro. $\mathrm{O} \mathrm{TiO}_{2}$ calcinado a $800{ }^{\circ} \mathrm{C}$ ficou branco acinzentado. Aparentemente, a mudança da cor do material está associada à formação das fases cristalinas. Entretanto, a associação da cor do material com a fase cristalina em que ele se apresenta, vai depender do método pelo qual ele foi produzido. O $\mathrm{TiO}_{2} \mathrm{P90}$ da Degussa é um pó branco e como pode ser visto na FIG. 5.24 apresenta fases cristalinas anatase e rutilo em proporções semelhantes ao $\mathrm{TiO}_{2}$ do lote 7 , que é um material de cor amarelo-palha. Outra hipótese é que a coloração do material esteja associada ao estado de valência do óxido.

Além da temperatura de calcinação outros fatores também podem influenciar na formação das fases cristalinas, como por exemplo, o modo de resfriamento do material após a calcinação. Com os lotes 9 e 10 foram estudados dois métodos de resfriamento do material. Em um dos métodos, chamado de resfriamento rápido $(\mathrm{RR})$, o material foi retirado do forno logo após o término da calcinação. No outro método, resfriamento lento, o material foi deixado no forno até o mesmo apresentar temperatura menor que $110^{\circ} \mathrm{C}$.

A FIG. 5.37 mostra os difratogramas dos lotes 9 e 10 calcinados a 420 ${ }^{\circ} \mathrm{C}$ com resfriamento rápido e lento. Além dos difratogramas do lote 9 seco a $60 \mathrm{e}$ $100^{\circ} \mathrm{C}$ e do lote 10 seco a $100^{\circ} \mathrm{C}$. 


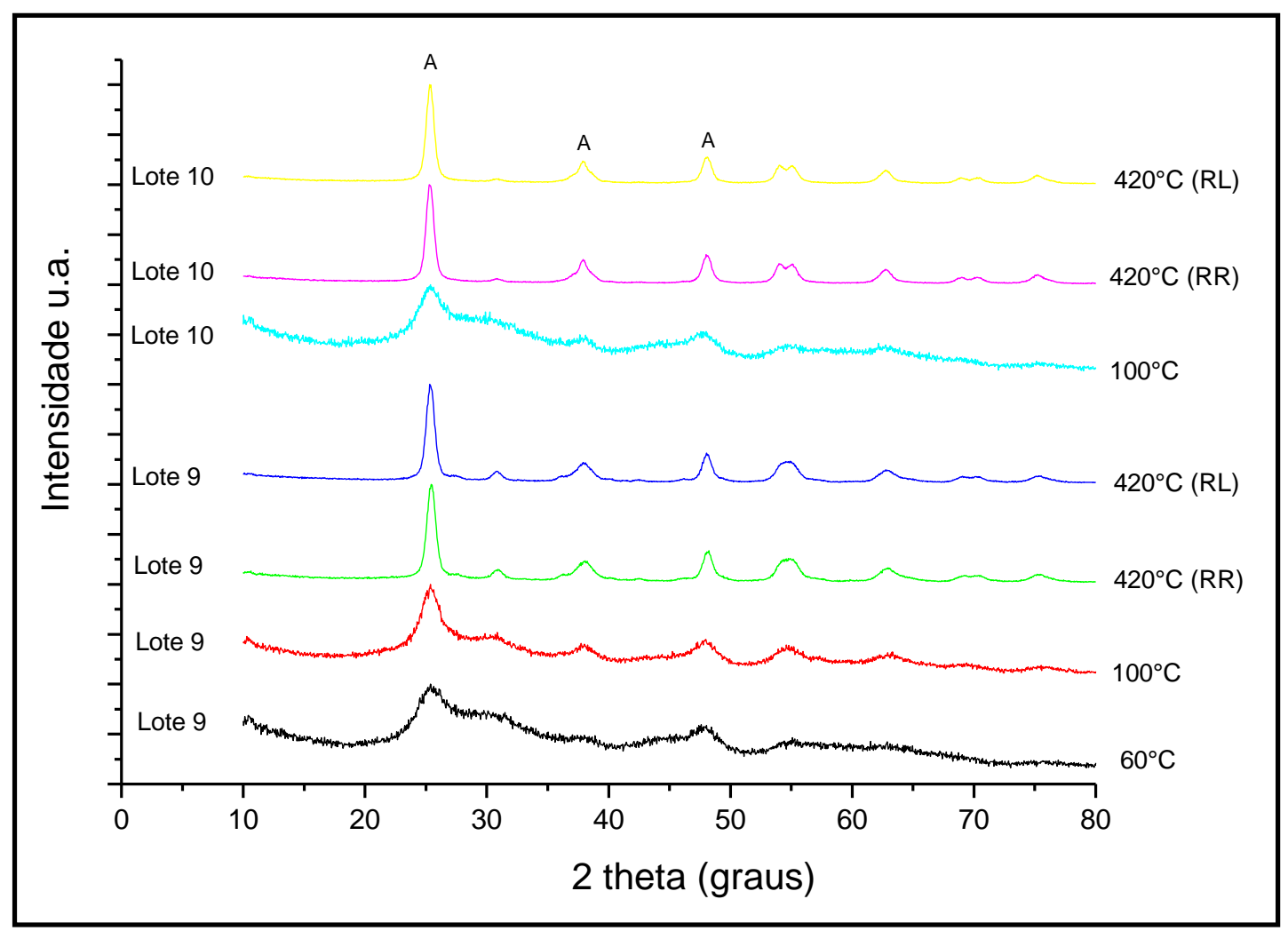

FIGURA 5.37 - Difratogramas dos $\mathrm{TiO}_{2}$ dos lotes 9 e 10. Lote 9: seco a $60^{\circ} \mathrm{C}$, $100^{\circ} \mathrm{C}$, calcinado a $420^{\circ} \mathrm{com}$ resfriamento rápido (RR) e resfriamento lento (RL). Lote 10: seco a $100^{\circ} \mathrm{C}$, calcinado a $420^{\circ}(\mathrm{RR})$ e $420^{\circ} \mathrm{C}(\mathrm{RL})$.

Pode-se observar que o tipo de resfriamento após a calcinação não alterou a formação da fase cristalina. Os materiais não calcinados apresentam picos pouco definidos, mostrando a presença de material amorfo. A calcinação promoveu a formação da fase cristalina anatase para ambos os lotes, porém é possível observar uma discreta formação da fase rutilo apenas no lote 9.

Os dois difratogramas do lote 9 apresentaram um pico próximo ao ângulo 30 que não é característico às fases anatase e rutilo do $\mathrm{TiO}_{2}$. Foi observado o mesmo pico no difratograma do lote 3 (FIG. 5.36). Esse pico pode estar relacionado a algum tipo de impureza no material. Através da análise elementar de uma amostra do $\mathrm{TiO}_{2}$ do lote 3 , foi possível identificar a presença de $2,2 \%$ de cloro e $0,6 \%$ de alumínio no material.

\subsubsection{Análise da área superficial específica (B.E.T.)}

A área superficial especifica de um material é uma característica importante que pode influenciar na sua capacidade de adsorção. $O$ valor pode 
variar de acordo com o modo de preparo do material e tratamento térmico realizado com o mesmo.

As análises foram feitas para os $\mathrm{TiO}_{2}$ dos lotes 4, 6, 7, 9, 10 e para o $\mathrm{TiO}_{2}$ comercial P90 da Degussa. Os resultados estão apresentados na TAB. 5.7.

TABELA 5.7 - Área superficial específica dos $\mathrm{TiO}_{2}$.

\begin{tabular}{ccc}
\hline Lotes & Tratamento térmico & ASE $\left(\mathbf{m}^{2} \mathbf{~}^{-1}\right)$ \\
\hline $\mathbf{4}$ & $100^{\circ} \mathrm{C}$ & 328 \\
$\mathbf{4}$ & $420^{\circ} \mathrm{C}$ & $76 \pm 7(\mathrm{n}=2)$ \\
$\mathbf{6}$ & $420^{\circ} \mathrm{C}$ & 68 \\
$\mathbf{7}$ & $420^{\circ} \mathrm{C}$ & 100 \\
$\mathbf{9}$ & $100^{\circ} \mathrm{C}$ & 166 \\
$\mathbf{9}$ & $420^{\circ} \mathrm{C}$ & 116 \\
$\mathbf{1 0}$ & $420^{\circ} \mathrm{C}$ & 84 \\
P90 Degussa & - & $191 \pm 16(\mathrm{n}=2)$ \\
\hline
\end{tabular}

Para as amostras do lote 4 calcinado e do $\mathrm{TiO}_{2} \mathrm{P90}$ foram realizadas duas análises e o valor informado na tabela é a média desses dois valores com o desvio médio dos mesmos.

Pode-se observar que a calcinação do lote 4 promoveu uma diminuição da área superficial especifica do material de $328 \mathrm{~m}^{2} \mathrm{~g}^{-1}$ para $76 \pm 7 \mathrm{~m}^{2} \mathrm{~g}^{-1}$. Essa redução de valores tão elevada não foi observada para o lote 9 após o tratamento térmico do material, que apenas seco a $100{ }^{\circ} \mathrm{C}$ apresentou área superficial específica de $166 \mathrm{~m}^{2} \mathrm{~g}^{-1}$ e após a calcinação esse valor foi para $116 \mathrm{~m}^{2} \mathrm{~g}^{-1}$. Embora seja esperada uma redução na área superficial específica do material após a calcinação, os valores elevados do lote 4 podem ser devido ao fato que os lotes 4 e 9 foram analisados em equipamentos diferentes e um dos procedimentos desta análise é o aquecimento inicial da amostra a pelo menos $200^{\circ} \mathrm{C}$, o que pode afetar a composição dos materiais.

Os materiais calcinados dos lotes 4,6 e 10 apresentaram valores similares da área superficial específica, $76 \pm 7,68$ e $84 \mathrm{~m}^{2} \mathrm{~g}^{-1}$ respectivamente.

A Evonik Degussa comercializa dois tipos de $\mathrm{TiO}_{2}$, o AEROXIDE $\mathrm{TiO}_{2}$ P25 e o P90. Segundo as especificações técnicas do produto P25, o mesmo apresenta área superficial específica de $50 \mathrm{~m}^{2} \mathrm{~g}^{-1}$, podendo variar de $35 \mathrm{a} 65 \mathrm{~m}^{2}$ $\mathrm{g}^{-1}$ e o P90 apresenta uma área superficial específica de $90 \mathrm{~m}^{2} \mathrm{~g}^{-1}$, com possível 
variação de 70 a $110 \mathrm{~m}^{2} \mathrm{~g}^{-1}$ (Evonik Specification 126/1; Evonik Specification 4505/1).

A análise realizada com o $\mathrm{TiO}_{2} \mathrm{P90}$ apresentou um resultado de área superficial específica do material de $191 \pm 16 \mathrm{~m}^{2} \mathrm{~g}^{-1}$, valor acima daquele informado pelo fabricante.

Os materiais preparados neste trabalho apresentaram valores de área superficial específica maiores que o $\mathrm{TiO}_{2} \mathrm{P} 25$ da Degussa, segundo os valores informados na ficha de especificação do produto (Evonik Specification 126/1).

Os óxidos de $\mathrm{TiO}_{2}$ comerciais são extremamente finos, característica que impossibilitou utilizá-los nas colunas cromatográficas.

\subsection{Preparo e avaliação dos geradores de ${ }^{68} \mathrm{Ge} /{ }^{68} \mathrm{Ga}$}

A adsorção do ${ }^{68} \mathrm{Ge}$ nas colunas com $\mathrm{TiO}_{2}$ dos geradores desenvolvidos neste trabalho foi $>99 \%$. As eficiências de eluição desses geradores (G1, G2, G3, G4 e G5) foram analisadas ao longo do tempo, assim como as eficiências de dois geradores comerciais: Obninsk (gerador comercial 1) e iThemba (gerador comercial 2).

A FIG. 5.37 mostra as eficiências de eluição dos geradores G1, G2, G3, G4 e G5 em relação ao tempo decorrido do carregamento do ${ }^{68} \mathrm{Ge}$ na coluna até o momento da eluição. A primeira eluição de todos os geradores apresentou baixa eficiência $(<40 \%)$, mas esse comportamento é normal até nos geradores comerciais, conforme pode ser observado na FIG. 5.38. 


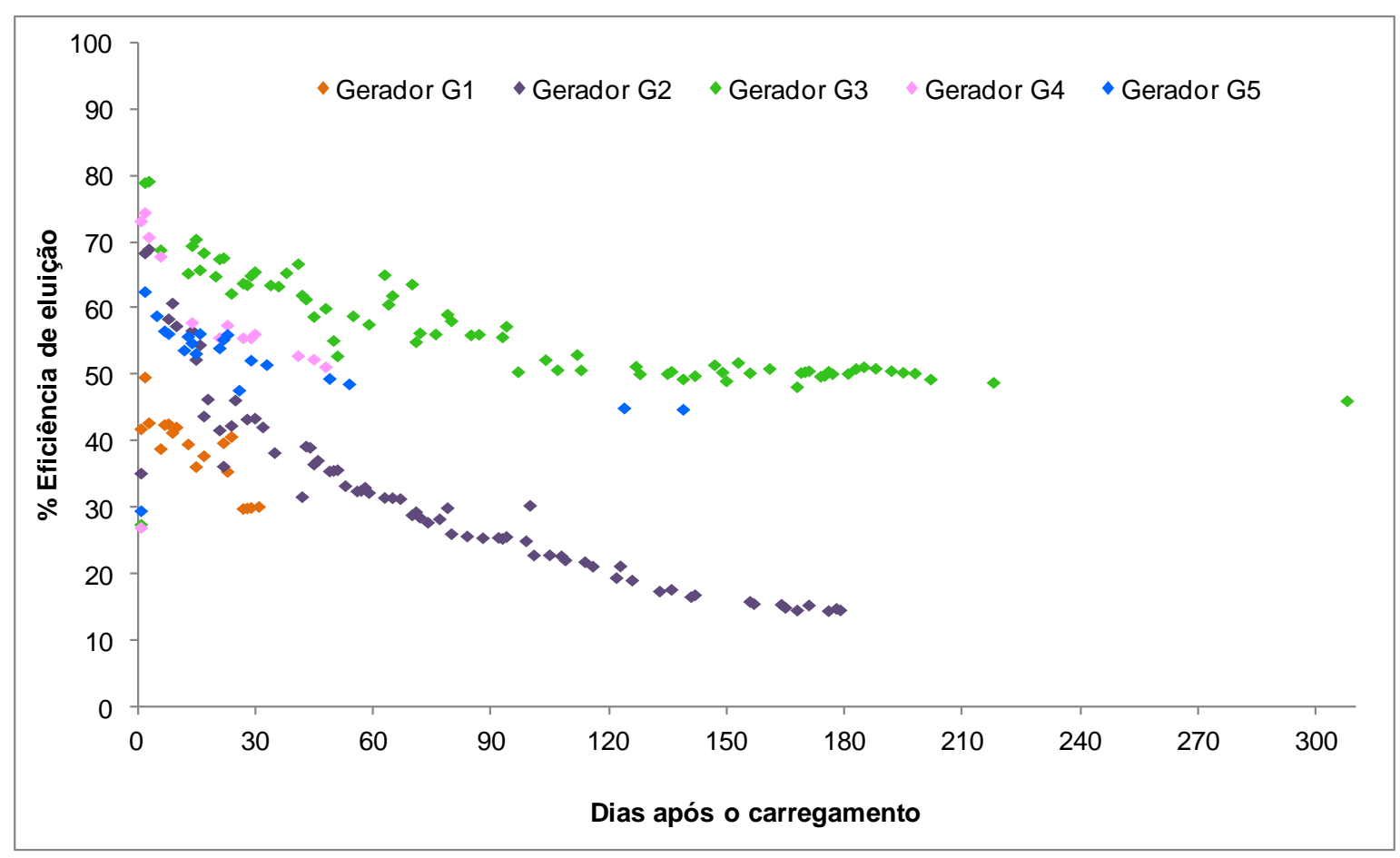

FIGURA 5.37 - Eficiência de eluição dos geradores G1, G2, G3, G4 e G5 em relação aos dias decorridos após o carregamento do ${ }^{68} \mathrm{Ge}$ na coluna.

Pode-se observar nas curvas de eficiência dos geradores G1 e G2 que em apenas 30 dias ocorreu uma redução maior que $20 \%$ na eficiência das eluições. Após a $12^{\mathrm{a}}$ eluição do gerador $\mathrm{G} 2$ foi acoplada uma torneira à mangueira de saída do gerador para manter a coluna úmida. $O$ gerador foi avaliado por mais 5 meses ( 71 eluições) e a sua eficiência de eluição caiu de 68 para $15 \%$.

A queda da eficiência dos geradores G1 e G2 para valores abaixo de $30 \%$ provavelmente ocorreu pelo fato das colunas terem sido mantidas secas por um longo período de tempo. A manutenção do adsorvedor úmido favorece o processo de troca iônica. Outro aspecto importante a ser considerado é que as colunas desses geradores foram montadas $\mathrm{com} \mathrm{TiO}_{2}$ não calcinado, o que significa que o material está mais suscetível aos efeitos da radiolise por provavelmente ainda conter moléculas de água na sua composição. Outra hipótese é a presença de $\mathrm{Ti}(\mathrm{OH})_{2}$ que não atua como trocador iônico.

O gerador G3 foi avaliado durante 10 meses (77 eluições) e apresentou eficiência de eluição de 79 a $46 \%$, resultado mais satisfatório do que os encontrados com os geradores G1 e G2. Essa melhora na eficiência de eluição provavelmente foi alcançada pelo uso do $\mathrm{TiO}_{2}$ calcinado e pela coluna ter sido 
mantida úmida. A torneira na saída do gerador ajudou a manter a coluna úmida, porém durante os meses de estudo, foi observado, umas três vezes, que a coluna do gerador estava seca. Isso pode ter comprometido a eficiência de eluição.

Os geradores G4 e G5 foram desenvolvidos com sistema de eluição a vácuo. Para tentar controlar a vazão e impedir a secagem da coluna, foi utilizado um dispositivo de plástico para comprimir a mangueira da saída do gerador, o mesmo utilizado em equipo de soro. A vazão obtida na eluição do gerador $\mathrm{G} 4$ foi de 3 a $4 \mathrm{~mL}$ por minuto e para o gerador $\mathrm{G} 5$ foi de $1,5 \mathrm{a} 2 \mathrm{~mL}$ por minuto.

Para o gerador G4, esse sistema foi avaliado durante 20 dias, porém devido aos níveis de contaminação de ${ }^{68} \mathrm{Ge}$ encontrados nas amostras das eluições estarem maiores do que os encontrados nos outros geradores (em eluições iniciais), o sistema a vácuo foi retirado e o gerador passou a ser eluído com pressão manual com seringa.

O gerador G5 foi avaliado por mais de 4 meses (20 eluições), apresentou eficiência de eluição inicial de aproximadamente $62 \%$, valor abaixo dos valores obtidos com os outros geradores nas eluições iniciais, porém após 4 meses a eficiência de eluição foi $>45 \%$, mesmo ficando dois meses sem ser eluído. Não realizar a eluição do gerador por um longo período de tempo pode promover uma queda na eficiência de eluição. Outro aspecto importante a ser observado é que a vazão obtida na eluição desse gerador foi menor que a do gerador G4 e dos geradores eluídos com pressão manual. A vazão é um parâmetro que também influencia na eficiência de eluição por ser um processo de troca iônica. Os dispositivos utilizados para tentar controlar a vazão não eram adequados para serem usados na montagem de geradores, pois não permitem um ajuste mais fino no controle da vazão, mas era o único dispositivo disponível para se estudar a viabilidade dos geradores eluídos com sistema a vácuo.

A FIG. 5.38 apresenta a porcentagem da eficiência de eluição em relação à quantidade de eluições dos geradores preparados neste trabalho e de dois geradores comerciais, gerador comercial 1, com coluna utilizando $\mathrm{TiO}_{2} \mathrm{e}$ gerador comercial 2, com coluna utilizando $\mathrm{SnO}_{2}$. 


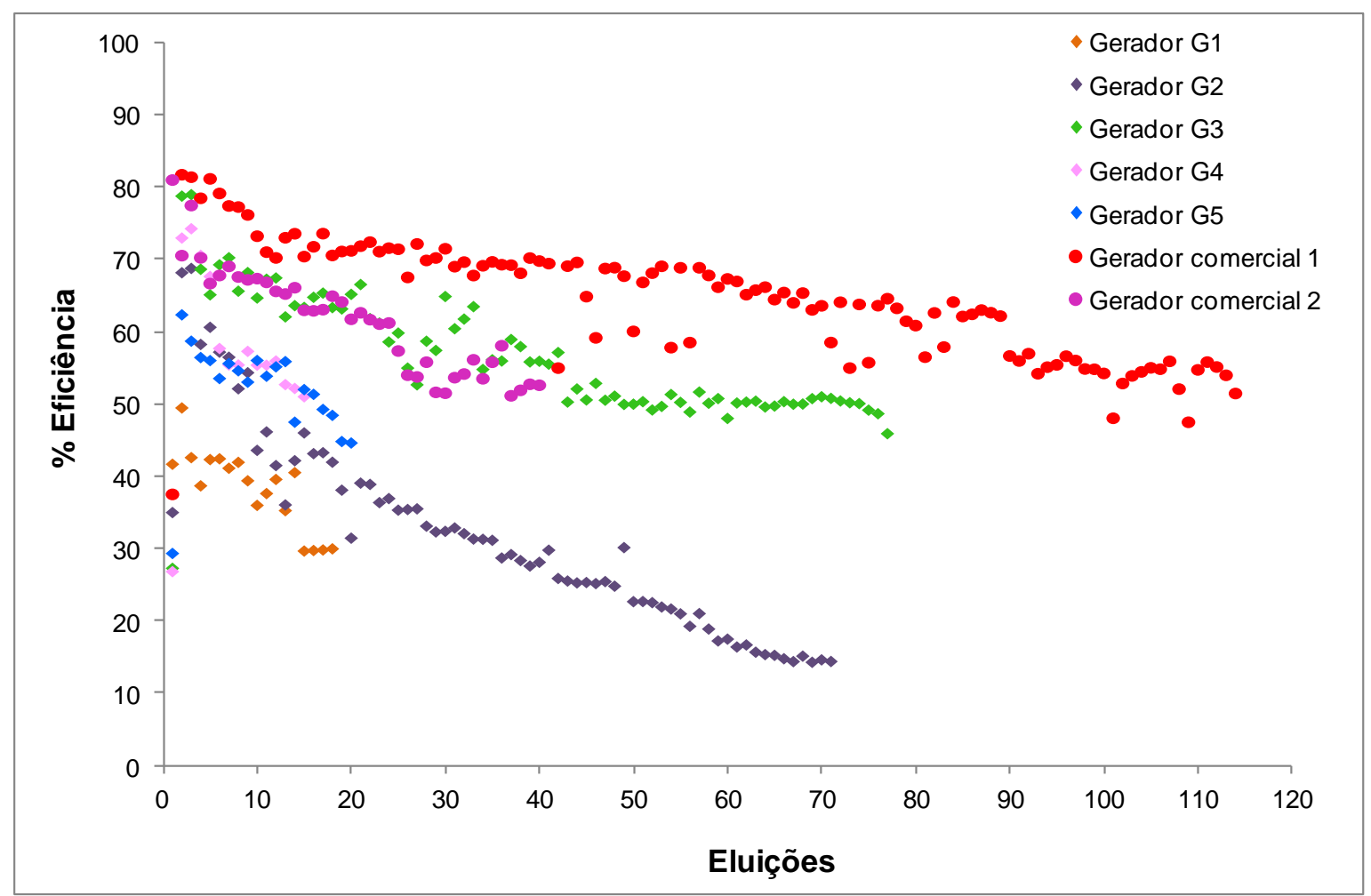

FIGURA 5.38 - Eficiência de eluição em relação à quantidade de eluições dos geradores preparados neste trabalho e dois geradores comerciais.

Pode-se observar pelo gráfico que a curva de eficiência de eluição do gerador G3 apresentou resultados similares ao gerador comercial 2. A vantagem de um gerador feito com coluna de $\mathrm{TiO}_{2}$ comparado a um gerador de $\mathrm{SnO}_{2}$ é a concentração da solução de $\mathrm{HCl}$ utilizada para eluição. Para o gerador de $\mathrm{TiO}_{2} \mathrm{a}$ eluição é feita com $\mathrm{HCl} 0,1 \mathrm{~mol} \mathrm{~L}^{-1}$, enquanto que para o gerador com coluna de $\mathrm{SnO}_{2}$ a eluição é feita com $\mathrm{HCl} 0,6 \mathrm{~mol} \mathrm{~L}^{-1}$. O ${ }^{68} \mathrm{Ga}$ em $\mathrm{pH} 1$ a 2 se apresenta em uma espécie química catiônica livre, ${ }^{68} \mathrm{Ga}^{+3}$, já em $\mathrm{pH}<1$ ocorre a formação de espécies aniônicas. Além disso, a quantidade de impurezas advindas do $\mathrm{HCl}$ podem diminuir.

Antes do preparo dos geradores com sistema de eluição a vácuo (G4 e G5), a viabilidade desse tipo de eluição foi estudada com o gerador comercial 1. O gerador apresentava baixa atividade (<111 MBq) e não era eluído há mais de um ano. Após esse período, foram realizadas 3 eluições com o sistema de pressão manual (90 a $93^{\mathrm{a}}$ eluição), que é do próprio gerador. Depois foram instaladas agulhas nas mangueiras de entrada e saída do gerador. Na mangueira de saída foi instalada uma torneira para tentar controlar a vazão da eluição e impedir a secagem da coluna. Essa tentativa de controlar a vazão apenas 
utilizando a torneira não foi prática, por isso para os geradores G4 e G5 tentou-se obter um controle maior da vazão da eluição utilizando os dispositivos para comprimir a mangueira da coluna.

O novo sistema não alterou a eficiência de eluição e os resultados podem ser observados na FIG. 5.39, que mostra a eficiência de eluição do gerador comercial 1 em relação aos dias decorridos do carregamento do ${ }^{68} \mathrm{Ge} e$ em uma escala maior apresenta os resultados das três eluições feitas com o sistema normal do gerador e os demais foram obtidos após a instalação do sistema de eluição a vácuo.

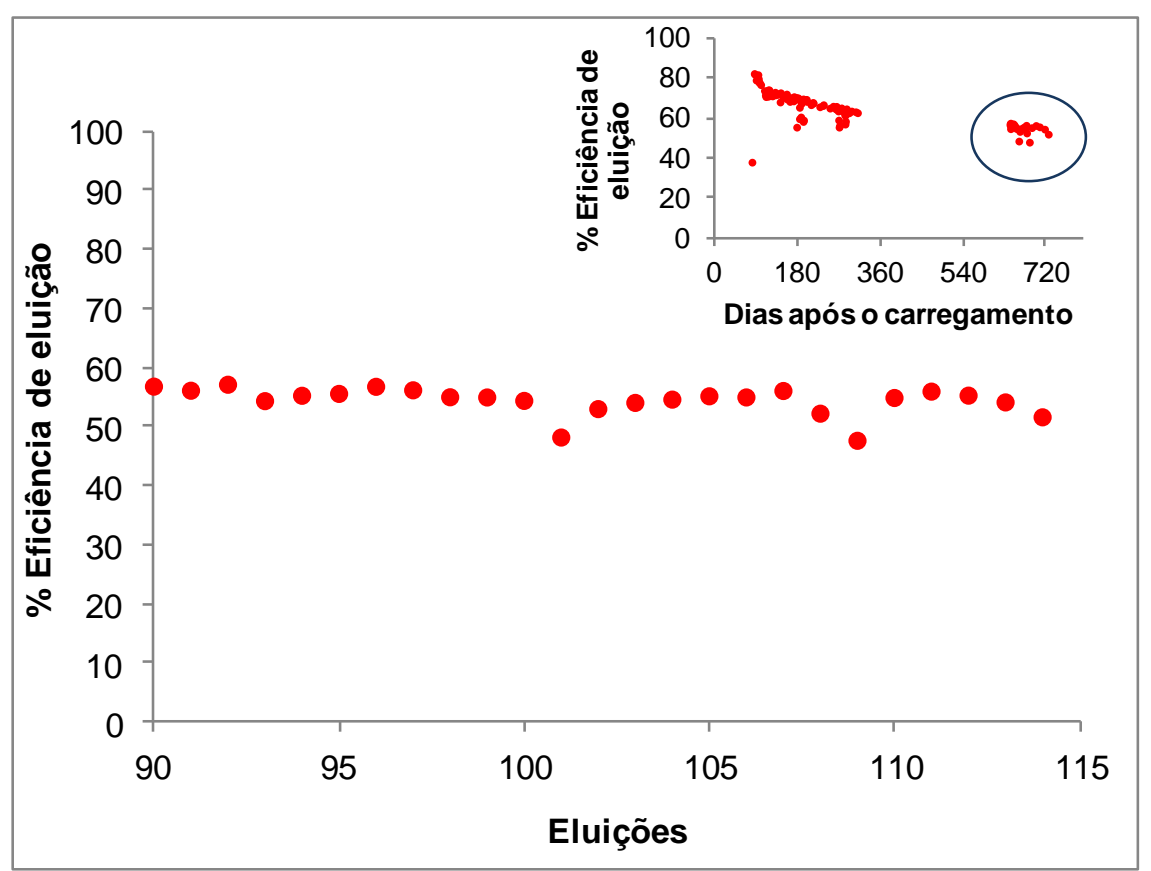

FIGURA 5.39 - Eficiência de eluição do gerador comercial 1 em relação aos dias decorridos do carregamento e a eficiência de eluição obtida com sistema de eluição a vácuo.

Segundo as especificações técnicas do gerador comercial Obninsk, a eficiência de eluição inicial do gerador é de aproximadamente $75 \%$, após 200 eluições pode ocorrer uma queda da eficiência, ficando por volta de $60 \%$. Outro gerador comercial que utiliza $\mathrm{TiO}_{2}$ como adsorvedor na coluna é o gerador IGG100 e segundo o fabricante esse sistema apresenta eficiência de eluição > 65 $\%$ (Technical Information Bulletin, 2013). 
Decristoforo (2012) avaliou seis geradores comerciais IGG100 até 1000 dias após a data de calibração. A média da eficiência observada dos geradores foi de $70 \%$, apresentando variação de 53 a $80 \%$.

Os resultados obtidos de eficiência de eluição dos geradores preparados neste trabalho (mantidos com a coluna úmida) se equiparam aos geradores comerciais, tanto com eluição feita por pressão quanto a vácuo. Em valores absolutos as eficiências foram menores no gerador G5, mas a vazão neste sistema foi sempre menor que nos sistemas com pressão.

Não foram encontrados trabalhos na literatura sobre geradores de ${ }^{68} \mathrm{Ge} /{ }^{68} \mathrm{Ga}$ utilizando coluna com $\mathrm{TiO}_{2}$ e sistema de eluição a vácuo. Os resultados obtidos neste trabalho com este novo sistema mostraram a viabilidade do desenvolvimento deste tipo de gerador, porém algumas adequações serão necessárias, como o uso de agulhas especiais e válvula adequada para o controle da vazão.

Além da eficiência de eluição, outro parâmetro importante para avaliar o desempenho de um gerador é o rendimento de eluição, que está relacionado à porcentagem de atividade eluída por volume e é determinado a partir do perfil de eluição do gerador, onde a atividade eluída é mensurada em cada mililitro utilizado na eluição.

Os perfis de eluição dos geradores G2 e G3 estão apresentados na FIG. 5.40 e o gráfico com os rendimentos de eluição de ambos geradores está representado na FIG. 5.41. Pode-se observar no perfil de eluição do gerador G2 que a maior parte da atividade foi eluída utilizando-se apenas $1 \mathrm{~mL}$ de $\mathrm{HCl} 0,1$ mol L $L^{-1}$ e o rendimento de eluição para $4 \mathrm{~mL}$ foi de aproximadamente $100 \%$. perfil de eluição do gerador G3 foi semelhante ao gerador G2 e um rendimento de eluição maior que $95 \%$ foi obtido com um volume de $6 \mathrm{~mL}$. 


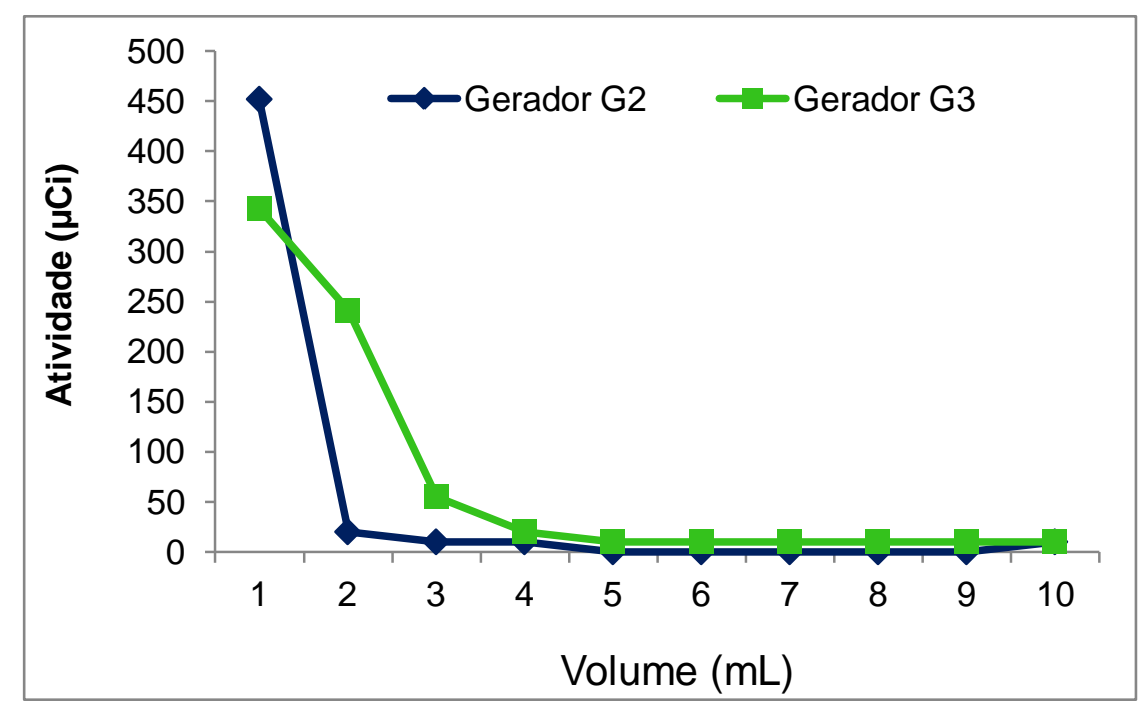

FIGURA 5.40 - Perfis de eluição dos geradores G2 e G3.

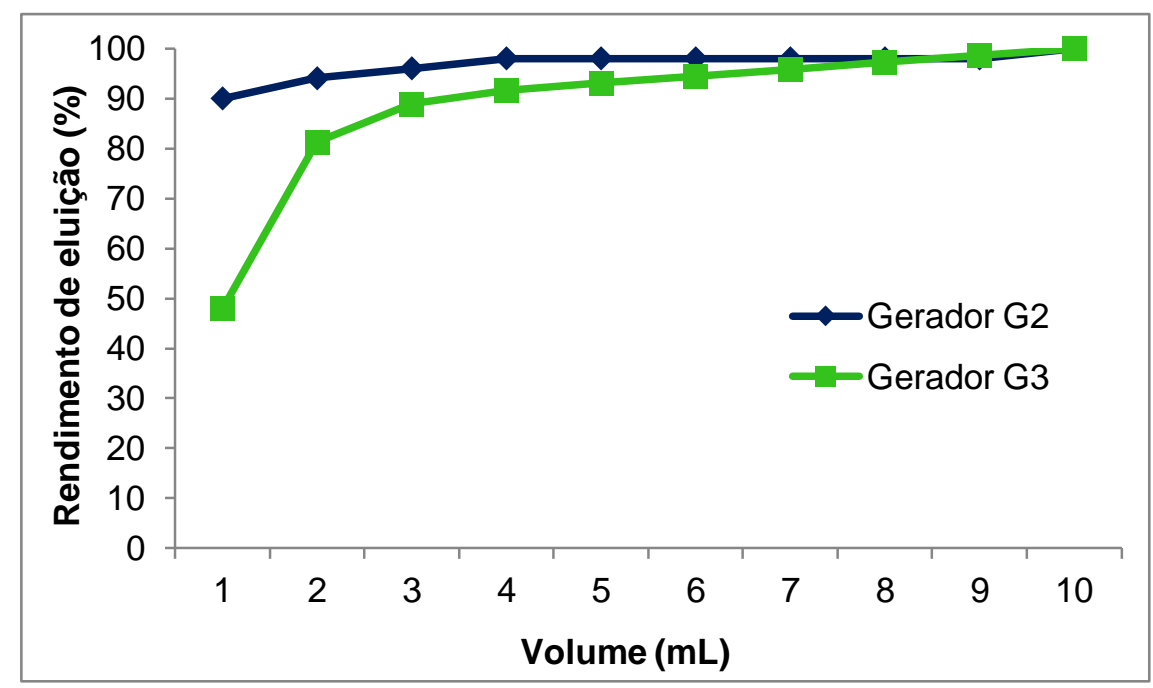

FIGURA 5.41 - Porcentagem de rendimento de eluição dos geradores G2 e G3.

A FIG. 5.42 mostra o perfil de eluição do gerador comercial 1 e a FIG. 5.43 apresenta a porcentagem de rendimento de eluição. Segundo as especificações técnicas desse gerador, $80 \%$ da atividade é eluída na primeira fração de $1 \mathrm{~mL}$ (Technical Information Bulletin, 2013). O perfil de eluição desse gerador foi avaliado em 5 frações de $2 \mathrm{~mL}$. 


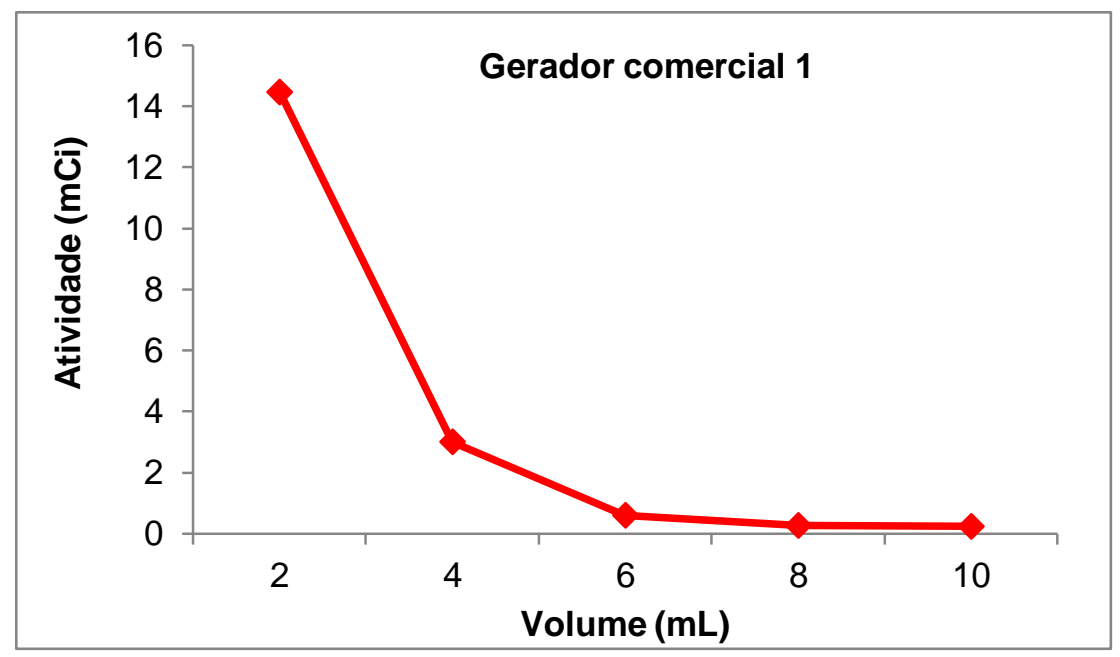

FIGURA 5.42 - Perfil de eluição do gerador comercial 1.

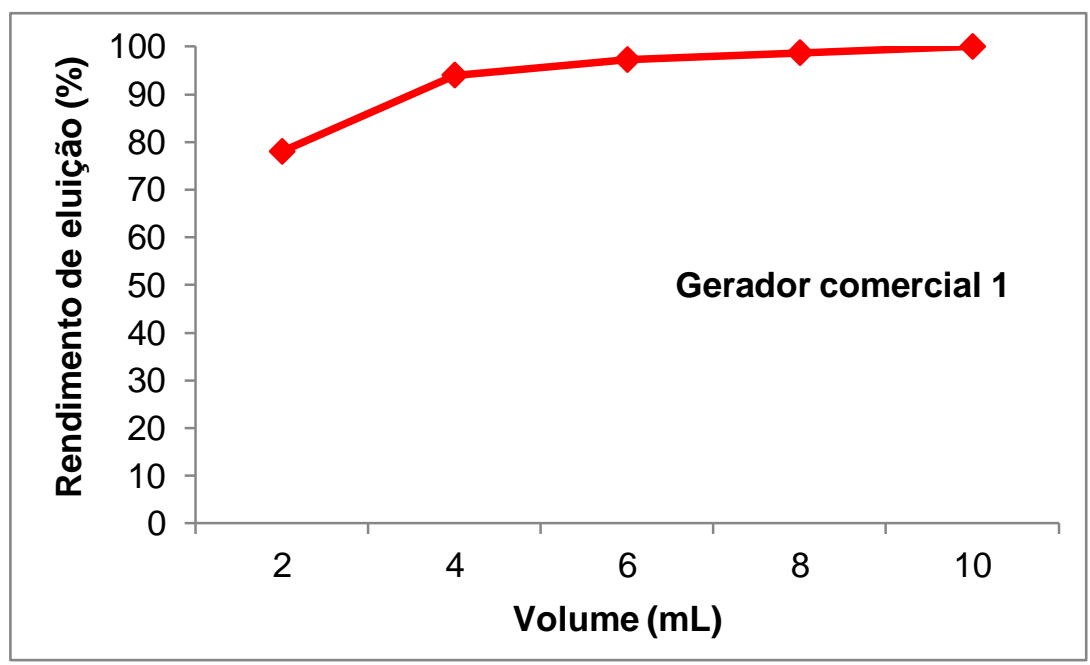

FIGURA 5.43 - Porcentagem de rendimento de eluição do gerador comercial 1.

Pode-se observar que aproximadamente $80 \%$ da atividade foi eluída na primeira fração e com $5 \mathrm{~mL}$ de $\mathrm{HCl} 0,1 \mathrm{~mol} \mathrm{~L}^{-1}$ foi obtido um rendimento de eluição > $95 \%$.

Segundo especificações técnicas do fabricante do gerador comercial 2 (iThemba), o rendimento de eluição do ${ }^{68} \mathrm{Ga}$ em $5 \mathrm{~mL}$ de $\mathrm{HCl} \mathrm{0,6} \mathrm{mol} \mathrm{L}{ }^{-1}$ não é < 80 \% (IDB HOLLAND bv. iThemba LABS, 2013). Nas FIG. 5.44 e 5.45 estão apresentados o perfil de eluição do gerador comercial 2 e a porcentagem de rendimento de eluição, respectivamente. Pode-se observar que um rendimento > $80 \%$ foi alcançado com $4 \mathrm{~mL}$ de $\mathrm{HCl} \mathrm{0,6} \mathrm{mol} \mathrm{L}^{-1}$. 


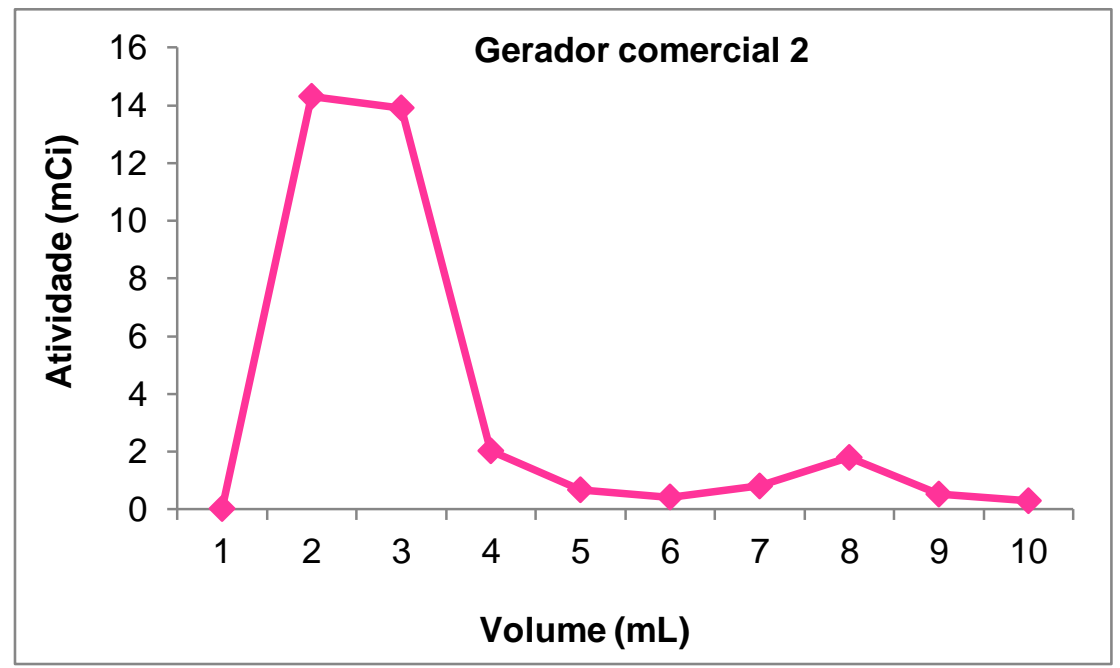

FIGURA 5.44 - Perfil de eluição do gerador comercial 2.

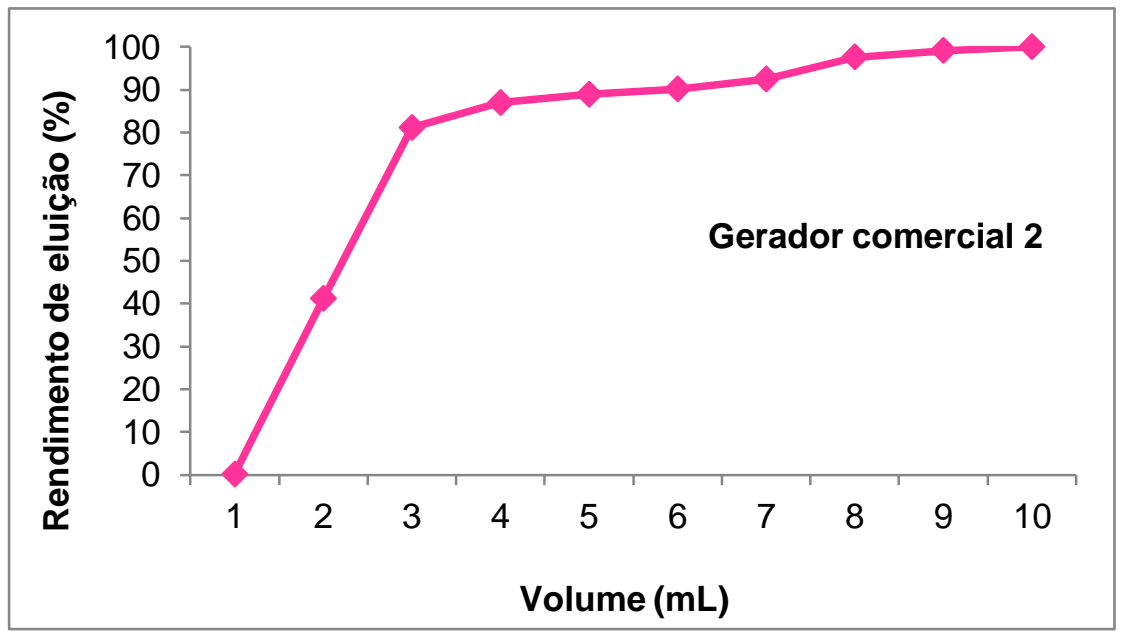

FIGURA 5.45 - Porcentagem de rendimento de eluição do gerador comercial 2.

\subsection{Controle de qualidade do ${ }^{68} \mathrm{Ga}$}

\subsubsection{Identificação dos fótons e identidade radionuclídica}

Os espectros obtidos nas contagens das amostras de eluições de todos os geradores preparados neste trabalho e dos geradores comerciais da Obninsk e iThemba, apresentaram apenas os picos de energia dos fótons característicos ao decaimento do ${ }^{68} \mathrm{Ga}, 511 \mathrm{keV}$ e $1077 \mathrm{keV}$.

A FIG. 5.46 representa o espectro obtido na contagem da amostra do gerador G5, mostrando o pico de $511 \mathrm{keV}$ e $1077 \mathrm{keV}$. 


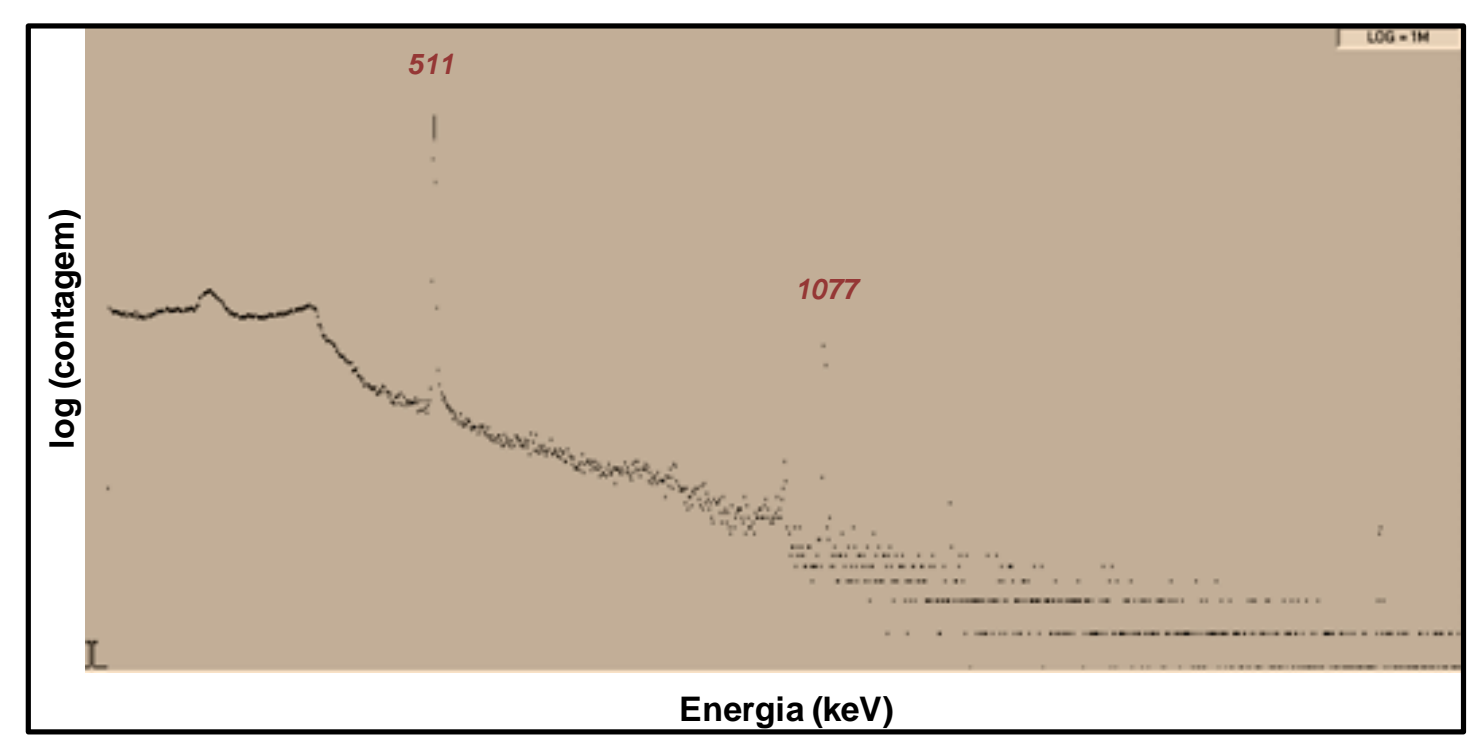

FIGURA 5.46 - Espectro obtido na contagem da amostra de eluição do gerador G5 no detector de germânio hiperpuro, mostrando os picos de energia dos fótons gama característicos ao ${ }^{68} \mathrm{Ga}(511 \mathrm{keV}$ e $1077 \mathrm{keV})$.

A identidade radionuclídica foi avaliada para as amostras dos geradores G3 e G5, desenvolvidos neste trabalho e para $0{ }^{68} \mathrm{Ga}$ eluído do gerador comercial 2 (iThemba).

A FIG. 5.47 mostra o gráfico da curva de decaimento do ${ }^{68} \mathrm{Ga}$ eluído do gerador G3. O valor encontrado para coeficiente angular da reta foi $-0,0099$, correspondendo à constante de decaimento $(\lambda)$. Através desse valor obteve-se um tempo de meia-vida física de 70 minutos.

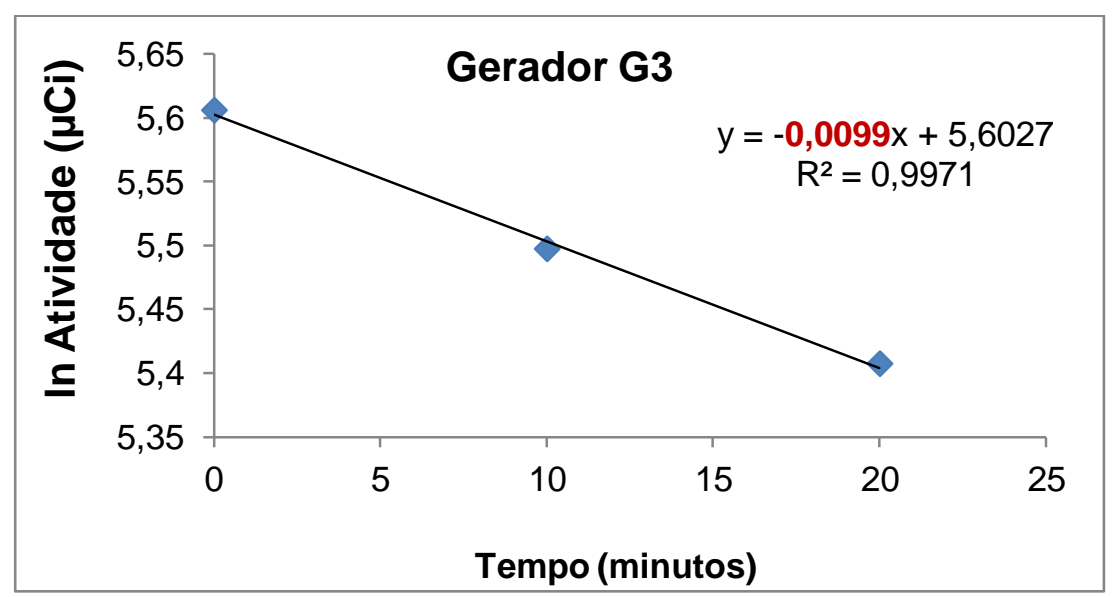

FIGURA 5.47 - Desintegração radioativa do ${ }^{68} \mathrm{Ga}$ obtido na eluição do gerador G3, desenvolvido neste trabalho. A escala do eixo da atividade está representada de maneira mono-log, mostrando a redução da atividade em função do tempo. 
As FIG. 5.48 e 5.49 mostram as curvas de decaimento das amostras de ${ }^{68} \mathrm{Ga}$ dos geradores $\mathrm{G} 5$ e gerador comercial 2 (iThemba), respectivamente. $\mathrm{O}$ tempo de meia-vida física calculado pelas curvas foram de 69,3 minutos e 66 minutos, respectivamente para os geradores G5 e gerador comercial 2.

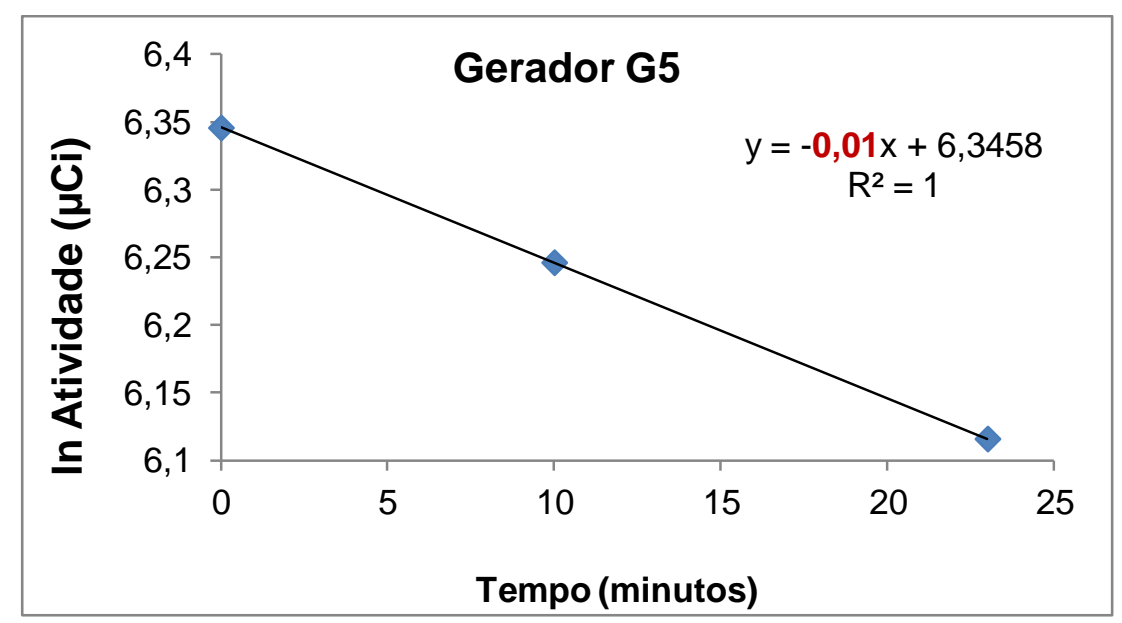

FIGURA 5.48 - Desintegração radioativa do ${ }^{68} \mathrm{Ga}$ obtido na eluição do gerador G5, desenvolvido neste trabalho. A escala do eixo da atividade está representada de maneira mono-log, mostrando a redução da atividade em função do tempo.

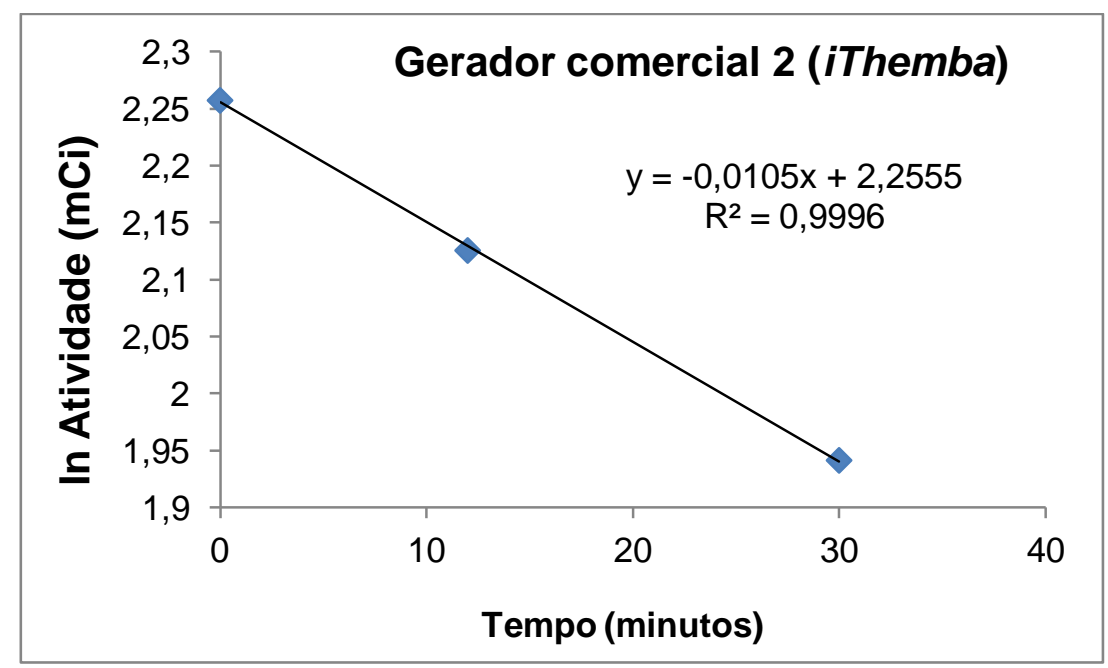

FIGURA 5.49 - Desintegração radioativa do ${ }^{68} \mathrm{Ga}$ obtido na eluição do gerador comercial 2 (iThemba). A escala do eixo da atividade está representada de maneira mono-log, mostrando a redução da atividade em função do tempo.

Os valores encontrados para a meia-vida física do ${ }^{68} \mathrm{Ga}$, eluído desses três geradores, estão dentro dos limites estabelecidos pela Farmacopeia Europeia, de 62 a 74 minutos. 


\subsubsection{Pureza radionuclídica}

A pureza radionuclídica do ${ }^{68} \mathrm{Ga}$ foi avaliada para as amostras das eluições dos geradores G2, G3, G4, G5 e dos geradores comerciais 1 (Obninsk) e 2 (iThemba), utilizando um detector de germânio hiperpuro.

As análises foram realizadas comparando-se a atividade do ${ }^{68} \mathrm{Ga}$ em uma amostra da eluição, feita com tempo de contagem de 1 minuto, com a atividade dessa mesma amostra, analisada 24 horas após a eluição, utilizando tempo de contagem de 20 minutos.

Embora a Farmacopeia Europeia preconize que a segunda contagem seja feita 48 horas após a eluição, pode-se observar pelo gráfico de decaimento radioativo do ${ }^{68} \mathrm{Ga}$, FIG. 5.50, que após 24 horas a atividade inicial desse radionuclídeo já decaiu para aproximadamente $10^{-5} \%$ dessa atividade, ficando abaixo do limite de atividade estabelecido para $0^{68} \mathrm{Ge}, 10^{-3} \%$, em relação ao ${ }^{68} \mathrm{Ga}$. Portanto, realizar a segunda contagem 24 horas após a eluição é um tempo adequado para se obter resultados confiáveis da pureza radionuclídica.

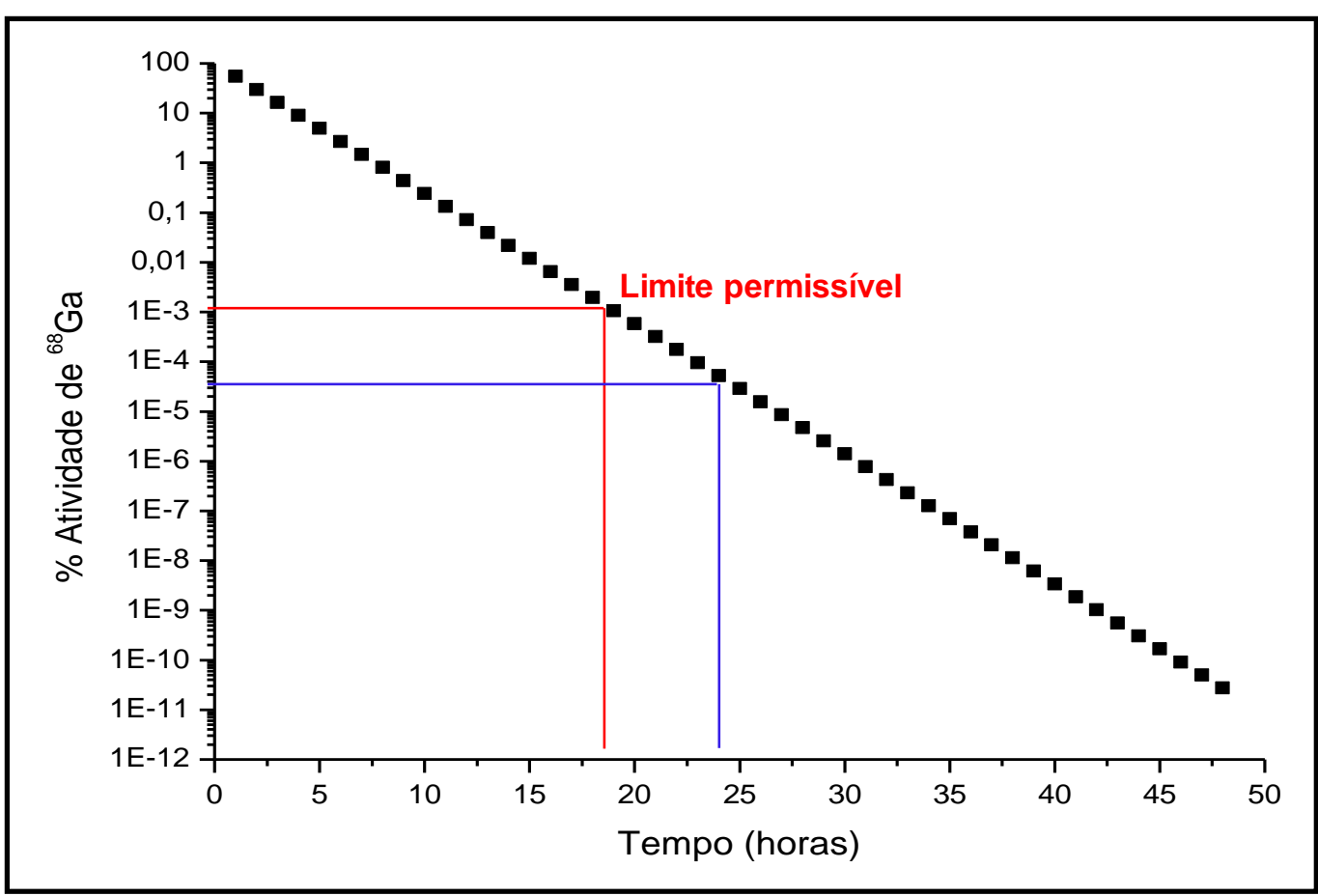

FIGURA 5.50 - Curva de decaimento do ${ }^{68} \mathrm{Ga}$ mostrando a porcentagem da atividade em relação ao tempo. 
Limites de detecção (LD) e quantificação (LD) do equipamento para a energia de $511 \mathrm{keV}$ foram calculados para os tempos de 20, 60 e 120 minutos de contagem. Esses cálculos foram feitos para as seis posições de contagem do detector.

Como o limite de contaminação de ${ }^{68} \mathrm{Ge}$ no ${ }^{68} \mathrm{Ga}$ é $10^{-3} \%$ da atividade do ${ }^{68} \mathrm{Ga}$, é necessário que se tenha uma atividade mínima de ${ }^{68} \mathrm{Ga}$ na amostra a ser analisada para que seja possível a detecção de $10^{-3} \%$ desse valor. Então, para cada LD e LQ calculado foi determinada uma atividade mínima de ${ }^{68} \mathrm{Ga}$ para realização da análise. Essa atividade mínima da amostra é referente ao horário da eluição e não à atividade no momento da análise. Portanto, todas as contagens realizadas para determinação da atividade de ${ }^{68} \mathrm{Ga}$ foram corrigidas para o horário da eluição.

As TAB. 5.8, 5.9 e 5.10 apresentam os resultados obtidos dos LD e LQ das seis posições de contagem do detector de germânio hiperpuro para os tempos de 20, 60 e 120 minutos, assim como as atividades mínimas de ${ }^{68} \mathrm{Ga}$ necessárias nas amostras a serem analisadas para que seja possível a detecção de $10^{-3} \%$ de ${ }^{68} \mathrm{Ge}$, levando em consideração tanto o LD quanto o LQ.

TABELA 5.8 - LD e LQ em seis posições do detector de germânio hiperpuro para a energia de $511 \mathrm{keV}$ com tempo de contagem de 20 minutos.

\begin{tabular}{ccccccc}
\hline $\begin{array}{c}\text { Posição } \\
\text { no } \\
\text { detector }\end{array}$ & $\begin{array}{c}\text { LD } \\
(\mathrm{Bq})\end{array}$ & $\begin{array}{c}\mathrm{LQ} \\
(\mathrm{Bq})\end{array}$ & $\begin{array}{c}\mathrm{LD} \\
(\mathrm{nCi})\end{array}$ & $\begin{array}{c}\mathrm{A}_{\min }{ }^{68} \mathrm{Ga} \\
(\mu \mathrm{Ci}) \text { para } \mathrm{LD}\end{array}$ & $\begin{array}{c}\mathrm{LQ} \\
(\mathrm{nCi})\end{array}$ & $\begin{array}{c}\mathrm{A}_{\min }{ }^{68} \mathrm{Ga}(\mu \mathrm{Ci}) \\
\text { para } \mathrm{LQ}\end{array}$ \\
P1 & 5 & 11 & 0,1 & 10 & 0,3 & 30 \\
P2 & 7 & 16 & 0,2 & 20 & 0,4 & 40 \\
P3 & 14 & 32 & 0,4 & 40 & 0,9 & 90 \\
P4 & 24 & 55 & 0,6 & 60 & 1,5 & 150 \\
P5 & 37 & 84 & 1,0 & 100 & 2,3 & 230 \\
P6 & 53 & 121 & 1,4 & 140 & 3,3 & 330 \\
\hline
\end{tabular}


TABELA 5.9 - LD e LQ em seis posições do detector de germânio hiperpuro para a energia de $511 \mathrm{keV}$ com tempo de contagem de 60 minutos.

\begin{tabular}{ccccccc}
\hline $\begin{array}{c}\text { Posição } \\
\text { no } \\
\text { detector }\end{array}$ & $\begin{array}{c}\text { LD } \\
(\mathrm{Bq})\end{array}$ & $\begin{array}{c}\mathrm{LQ} \\
\mathbf{( B q})\end{array}$ & $\begin{array}{c}\mathrm{LD} \\
(\mathrm{nCi})\end{array}$ & $\begin{array}{c}\mathrm{A}_{\min }{ }^{68}{ }^{68} \mathrm{Ga}(\mu \mathrm{Ci}) \\
\text { para } \mathrm{LD}\end{array}$ & $\begin{array}{c}\mathrm{LQ} \\
(\mathrm{nCi})\end{array}$ & $\begin{array}{c}\mathrm{A}_{\min }{ }^{68} \mathrm{Ga} \\
(\mu \mathrm{Ci})\end{array}$ para LQ \\
\hline P1 & 2 & 5 & 0,1 & 6 & 0,1 & 10 \\
P2 & 4 & 7 & 0,1 & 10 & 0,2 & 20 \\
P3 & 7 & 14 & 0,2 & 20 & 0,4 & 40 \\
P4 & 13 & 24 & 0,3 & 30 & 0,6 & 60 \\
P5 & 20 & 37 & 0,5 & 50 & 1,0 & 100 \\
P6 & 28 & 53 & 0,8 & 80 & 1,4 & 140 \\
\hline
\end{tabular}

TABELA 5.10 - LD e LQ em seis posições do detector de germânio hiperpuro para a energia de $511 \mathrm{keV}$ com tempo de contagem de 120 minutos.

\begin{tabular}{|c|c|c|c|c|c|c|}
\hline \multirow{2}{*}{$\begin{array}{l}\text { Posição } \\
\text { no } \\
\text { detector }\end{array}$} & \multicolumn{6}{|c|}{ Contagem de 120 minutos } \\
\hline & $\begin{array}{l}\mathrm{LD} \\
(\mathrm{Bq})\end{array}$ & $\begin{array}{l}\mathrm{LQ} \\
(\mathrm{Bq})\end{array}$ & $\begin{array}{l}\text { LD } \\
\text { (nCi) }\end{array}$ & $\begin{array}{c}A_{\min .}{ }^{68} \mathrm{Ga} \\
(\mu \mathrm{Ci}) \text { para } \mathrm{LD}\end{array}$ & $\begin{array}{l}\mathrm{LQ} \\
(\mathrm{nCi})\end{array}$ & $\begin{array}{c}A_{\min .}{ }^{68} \mathrm{Ga} \\
(\mu \mathrm{Ci}) \text { para } L Q\end{array}$ \\
\hline P1 & 2 & 3 & 0,04 & 4 & 0,10 & 10 \\
\hline P2 & 3 & 4 & 0,10 & 10 & 0,10 & 10 \\
\hline P3 & 5 & 9 & 0,10 & 10 & 0,20 & 20 \\
\hline P4 & 9 & 15 & 0,20 & 20 & 0,40 & 40 \\
\hline P5 & 13 & 23 & 0,40 & 40 & 0,60 & 60 \\
\hline P6 & 19 & 33 & 0,50 & 50 & 0,90 & 90 \\
\hline
\end{tabular}

Pode-se observar que o tempo de contagem de 20 minutos é adequado para se obter resultados satisfatórios na análise da pureza radionuclídica do ${ }^{68} \mathrm{Ga}$. $\mathrm{O}$ aumento do tempo de contagem para 60 e 120 minutos não resultou em valores de LD e LQ significantemente menores do que os encontrados com 20 minutos de contagem, nas posições P1, P2 e P3 do detector.

As amostras das eluições de todos geradores foram analisadas, com tempo de contagem de 20 minutos, na terceira posição do detector de germânio hiperpuro e todas continham atividade acima de $1480 \mathrm{kBq}(40 \mu \mathrm{Ci})$. Essa atividade é alta para o equipamento, pois o tempo morto ultrapassa os $20 \%$, então é necessário esperar o decaimento de pelo menos duas meia vidas física do radionuclídeo para se realizar a contagem no detector. Depois é necessário corrigir a atividade para a hora da eluição.

A FIG. 5.51 mostra as porcentagens de contaminação de ${ }^{68} \mathrm{Ge}$ encontradas nas amostras das eluições dos geradores. 


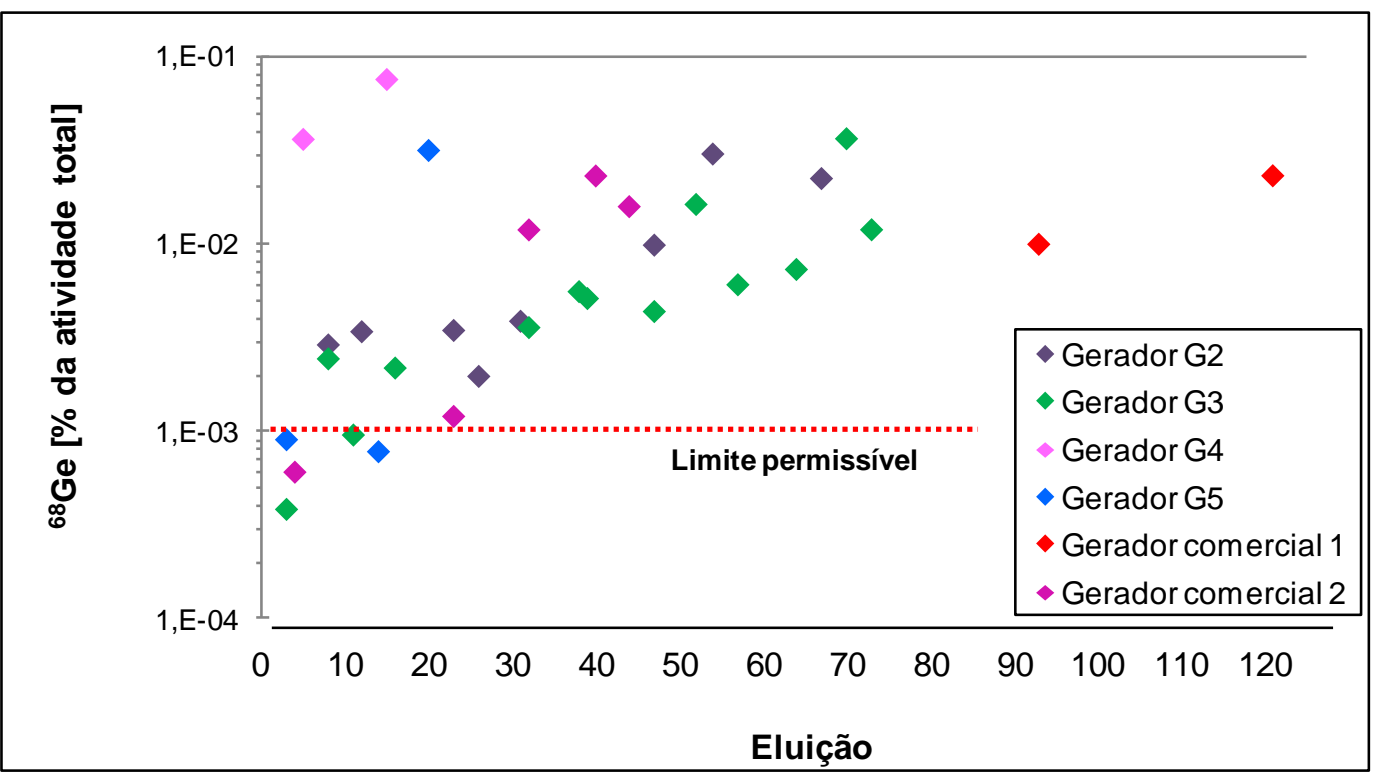

FIGURA 5.51 - Porcentagem de contaminação de ${ }^{68} \mathrm{Ge}$ no ${ }^{68} \mathrm{Ga}$ eluído dos geradores desenvolvidos neste trabalho e de dois geradores comerciais.

Apenas as primeiras eluições dos geradores G3, G5 e do gerador comercial 2 apresentaram níveis de contaminação de ${ }^{68} \mathrm{Ge}$ abaixo do determinado pela Farmacopeia Europeia, $10^{-3} \%$. Entretanto, este limite é válido, segundo a Farmacopeia, para soluções de ${ }^{68} \mathrm{Ga}$ prontas para a marcação e não para 0 eluído dos geradores. Em todos os geradores comerciais é necessário um processo de purificação que sempre diminui a contaminação com ${ }^{68} \mathrm{Ge}$.

Pode-se observar que os geradores desenvolvidos neste trabalho apresentaram níveis de contaminação de ${ }^{68} \mathrm{Ge}$ no eluato do ${ }^{68} \mathrm{Ga}$ similares aos níveis encontrados nas amostras das eluições dos geradores comerciais.

O estudo feito por Decristoforo (2012) em seis geradores comerciais (IGG100) relatou que os valores de contaminação de ${ }^{68} \mathrm{Ge}$ ficaram abaixo de $10^{-2} \%$.

É importante ressaltar que a altura da coluna utilizada no preparo do gerador pode interferir tanto na eficiência, quanto nos níveis de contaminação de ${ }^{68} \mathrm{Ge}$ nas amostras das eluições. Porém, este parâmetro não foi estudado e as colunas utilizadas nos geradores comerciais são mais altas que as utilizadas neste trabalho (FIG. 5.52). 


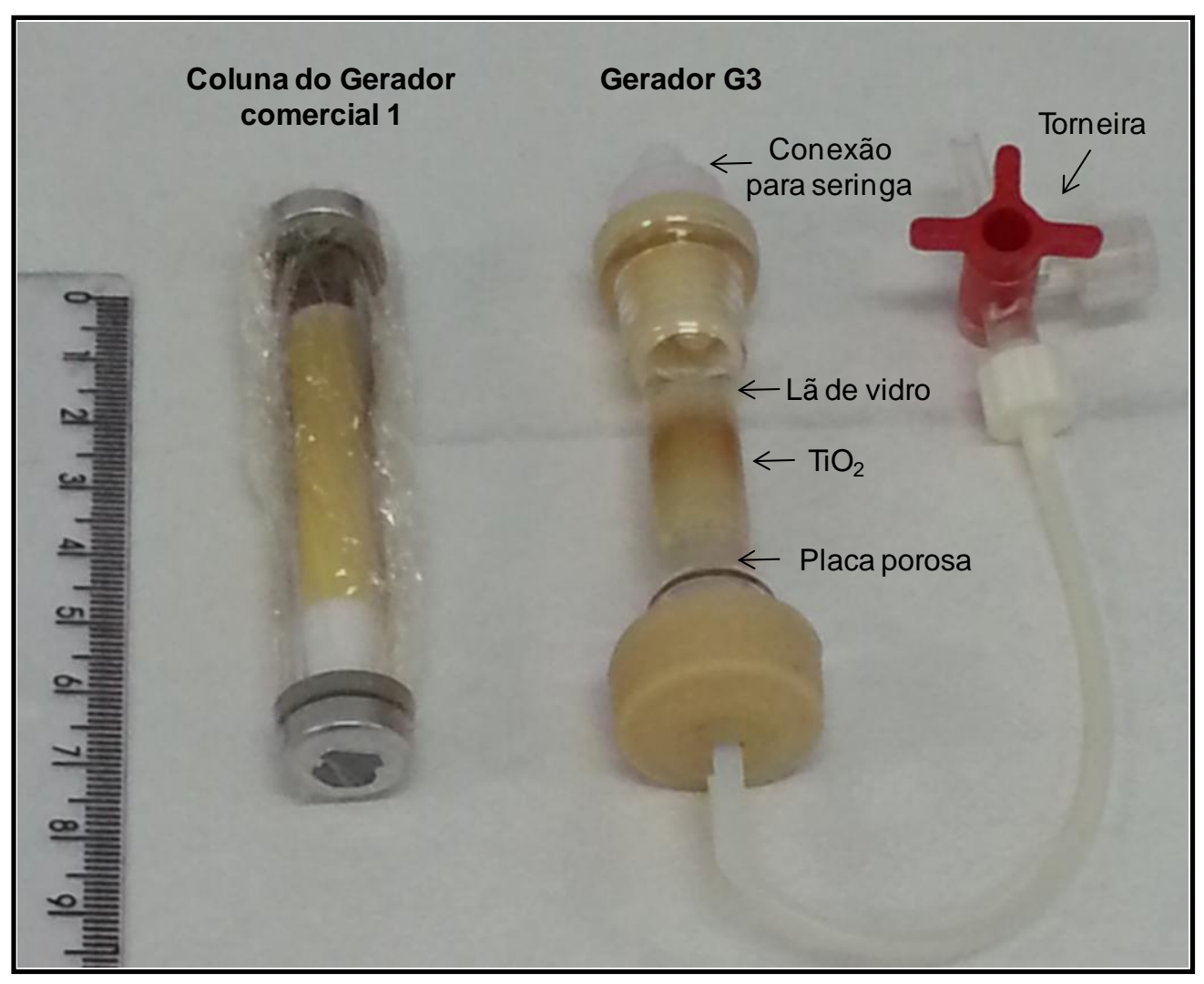

FIGURA 5.52 - Coluna utilizada no gerador comercial 1 (Obninsk) e coluna do gerador G3.

Outro ponto importante nesta análise é que a Farmacopeia Europeia não estabelece em que tempo a contaminação do ${ }^{68} \mathrm{Ga}$ deve ser determinada, se no fim da eluição, se após a purificação ou após a marcação. Neste trabalho foi estabelecido o tempo de eluição.

\subsubsection{Pureza radioquímica}

A pureza radioquímica foi determinada para $0{ }^{68} \mathrm{Ga}$ eluído do gerador G5. O valor encontrado foi de $95,7 \%$, o que está dentro do limite estabelecido pela Farmacopeia Europeia (> $95 \%$ ).

A FIG. 5.53 apresenta o cromatograma obtido na análise realizada com a solução referência $(A)$, mostrando o pico de maior atividade no segmento 1 da fita. Este resultado está de acordo com o informado pela Farmacopeia, que determina que para a solução referência $(A)$, o pico de maior atividade não pode ter $R_{f}>0,1$. 


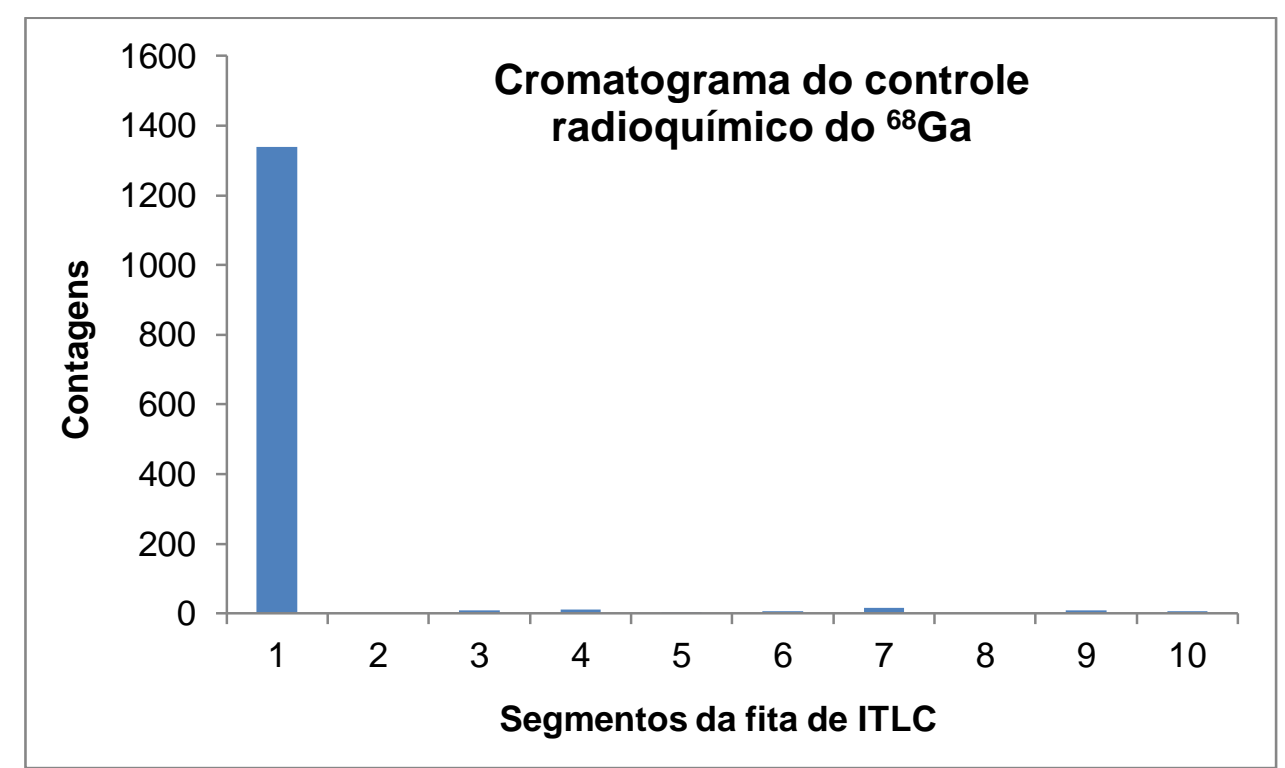

FIGURA 5.53 - Cromatograma do controle radioquímico do ${ }^{68} \mathrm{Ga}$ eluído do gerador G5.

A realização dessa análise, recomendada pela Farmacopeia Europeia, não determina realmente a pureza radioquímica do eluato, pois não avalia a porcentagem de ${ }^{68} \mathrm{Ga}$ na sua forma química desejada, ${ }^{68} \mathrm{Ga}^{3+}$. Essa análise na verdade simula a formação de outras espécies de ${ }^{68} \mathrm{Ga}$ que pode ocorrer durante o processo de marcação de uma biomolécula ou purificação do ${ }^{68} \mathrm{Ga}$, principalmente nos geradores preparados com trocadores orgânicos.

Por todos os trabalhos encontrados na literatura, pode-se afirmar que quando o ${ }^{68} \mathrm{Ga}$ é eluído em $\mathrm{HCl} 0,1 \mathrm{~mol} \mathrm{~L}^{-1}$ de um gerador com coluna preparada com um material inorgânico como $\circ \mathrm{TiO}_{2}$, a forma química eluída sempre será ${ }^{68} \mathrm{Ga}^{+3}$.

\subsubsection{Pureza química}

A análise dos contaminantes químicos dos eluatos de ${ }^{68} \mathrm{Ga}$ foi realizada por espectrometria de emissão óptica com plasma indutivamente acoplado (ICPOES) (Varian Vista-MPX).

Foram analisadas as amostras de eluição dos geradores G2, G3, G5 e do gerador comercial 2 (iThemba). Para os geradores desenvolvidos neste trabalho os metais analisados foram o $\mathrm{Ti}, \mathrm{Fe}, \mathrm{Zn}, \mathrm{Al}$ e $\mathrm{Ge}$ e para o gerador 
comercial, além desses elementos, o Sn também foi avaliado, pois o gerador é preparado com $\mathrm{SnO}_{2}$.

Os resultados encontrados para os geradores G2 $(n=47)$, G3 $(n=29)$, G5 $(n=7)$ e gerador comercial $2(n=13)$ encontram-se respectivamente nas TAB. 5.11, 5.12, 5.13 e 5.14. As tabelas informam qual eluição foi analisada para cada gerador e a concentração dos metais encontrada para cada uma delas.

TABELA 5.11 - Concentração $\mathrm{Ge}, \mathrm{Ti}, \mathrm{Fe}, \mathrm{Zn}$ e Al nas amostras das eluições do gerador $\mathrm{G} 2\left(\mathrm{TiO}_{2}\right.$ não calcinado).

\begin{tabular}{|c|c|c|c|c|c|}
\hline \multirow[b]{2}{*}{ Eluição } & \multicolumn{5}{|c|}{ Concentração $\left(\mu \mathrm{g} \mathrm{mL}^{-1}\right)$} \\
\hline & Ge & $\mathrm{Ti}$ & $\mathrm{Fe}$ & $\mathrm{Zn}$ & Al \\
\hline 2 & $<\mathrm{LQ}$ & 4,36 & 0,84 & 38,49 & 4,05 \\
\hline 3 & $<L Q$ & 5,25 & 0,59 & 9,51 & 1,65 \\
\hline 4 & $<L Q$ & 6,53 & 1,12 & 3,40 & 1,69 \\
\hline 5 & $<L Q$ & 7,25 & 0,44 & 1,05 & 1,00 \\
\hline 6 & $<L Q$ & 5,15 & 0,36 & 19,90 & 2,03 \\
\hline 7 & $<L Q$ & 7,65 & 0,39 & 23,88 & 2,31 \\
\hline 8 & $<L Q$ & 5,81 & 0,32 & 24,94 & 2,85 \\
\hline 9 & $<L Q$ & 6,55 & 0,26 & 2,89 & 1,37 \\
\hline 11 & $<L Q$ & 5,72 & 0,23 & 9,71 & 1,39 \\
\hline 12 & $<L Q$ & 5,53 & 0,24 & 13,23 & 1,67 \\
\hline 13 & $<L Q$ & 3,52 & 0,10 & 15,77 & 1,31 \\
\hline 14 & $<L Q$ & 5,18 & 0,19 & 1,04 & 0,83 \\
\hline 15 & $<L Q$ & 5,05 & 0,17 & 0,99 & 0,94 \\
\hline 16 & $<L Q$ & 5,40 & 0,24 & 1,85 & 0,84 \\
\hline 17 & $<\mathrm{LQ}$ & 5,44 & 0,21 & 14,84 & 1,89 \\
\hline 18 & $<\mathrm{LQ}$ & 5,54 & 0,39 & 37,45 & 3,69 \\
\hline 19 & $<\mathrm{LQ}$ & 5,54 & 0,35 & 26,93 & 3,24 \\
\hline 20 & $<\mathrm{LQ}$ & 11,57 & 0,10 & 0,64 & 0,97 \\
\hline 21 & $<\mathrm{LQ}$ & 5,93 & 0,08 & 0,08 & 0,73 \\
\hline 22 & $<L Q$ & 5,37 & 0,09 & 0,86 & 0,78 \\
\hline 23 & $<L Q$ & 5,38 & 0,07 & 0,03 & 0,86 \\
\hline 24 & $<L Q$ & 4,92 & 0,07 & 0,54 & 0,84 \\
\hline 25 & $<L Q$ & 6,82 & 0,19 & 18,33 & 2,41 \\
\hline 26 & $<L Q$ & 4,67 & 0,17 & 16,29 & 1,79 \\
\hline 27 & $<L Q$ & 5,47 & 0,07 & 0,45 & 0,51 \\
\hline 28 & $<L Q$ & 6,92 & 0,11 & 15,26 & 1,44 \\
\hline 29 & $<L Q$ & 8,43 & 0,07 & 0,00 & 0,80 \\
\hline 30 & $<\mathrm{LQ}$ & 6,26 & 0,09 & 1,34 & 1,12 \\
\hline
\end{tabular}


TABELA 5.11 - Concentração $\mathrm{Ge}, \mathrm{Ti}, \mathrm{Fe}, \mathrm{Zn}$ e Al nas amostras das eluições do gerador $\mathrm{G} 2\left(\mathrm{TiO}_{2}\right.$ não calcinado). Continuação.

\begin{tabular}{cccccc} 
& \multicolumn{5}{c}{ Concentração $\left(\boldsymbol{\mu g ~ \mathrm { mL } ^ { - 1 } )}\right.$} \\
Eluição & Ge & Ti & Fe & Zn & Al \\
\hline 31 & $<\mathrm{LQ}$ & 5,12 & 0,15 & 10,66 & 1,22 \\
32 & $<\mathrm{LQ}$ & 4,87 & 0,08 & 0,99 & 0,57 \\
33 & $<\mathrm{LQ}$ & 11,35 & 0,14 & 7,08 & 1,48 \\
34 & $<\mathrm{LQ}$ & 8,89 & 0,13 & 12,06 & 1,57 \\
35 & $<\mathrm{LQ}$ & 9,38 & 0,08 & 0,08 & 0,62 \\
36 & $<\mathrm{LQ}$ & 9,56 & 0,09 & 1,16 & 0,77 \\
37 & $<\mathrm{LQ}$ & 4,99 & 0,07 & 0,35 & 0,52 \\
38 & $<\mathrm{LQ}$ & 4,64 & 0,08 & 3,65 & 0,67 \\
41 & $<\mathrm{LQ}$ & 7,82 & 0,08 & 3,51 & 0,77 \\
42 & $<\mathrm{LQ}$ & 8,38 & 0,07 & 0,28 & 0,56 \\
44 & $<\mathrm{LQ}$ & 12,08 & 0,08 & 0,76 & 0,74 \\
45 & $<\mathrm{LQ}$ & 11,92 & 0,47 & 27,76 & 3,23 \\
48 & $<\mathrm{LQ}$ & 18,98 & 0,19 & 7,85 & 1,44 \\
53 & $<\mathrm{LQ}$ & 4,28 & 0,13 & 11,76 & 1,75 \\
55 & $<\mathrm{LQ}$ & 6,46 & 0,16 & 24,76 & 3,40 \\
57 & $<\mathrm{LQ}$ & 4,68 & 0,11 & 13,84 & 1,82 \\
60 & $<\mathrm{LQ}$ & 8,20 & 0,12 & 13,34 & 1,88 \\
64 & $<\mathrm{LQ}$ & 3,68 & 0,21 & 23,82 & 2,57 \\
70 & $<\mathrm{LQ}$ & 170,04 & 0,15 & 11,47 & 1,67 \\
\hline
\end{tabular}


TABELA 5.12 - Concentração $\mathrm{Ge}, \mathrm{Ti}, \mathrm{Fe}, \mathrm{Zn}$ e Al nas amostras das eluições do gerador $\mathrm{G} 3\left(\mathrm{TiO}_{2}\right.$ calcinado).

\begin{tabular}{|c|c|c|c|c|c|}
\hline \multirow[b]{2}{*}{ Eluição } & \multicolumn{5}{|c|}{ Concentração $\left(\mu \mathrm{g} \mathrm{mL}^{-1}\right)$} \\
\hline & $\mathrm{Ge}$ & $\mathrm{Ti}$ & $\mathrm{Fe}$ & $\mathrm{Zn}$ & Al \\
\hline 1 & $<L Q$ & 0,28 & 0,28 & 30,6 & 3,06 \\
\hline 2 & $<L Q$ & 0,34 & 0,60 & 14,3 & 1,89 \\
\hline 3 & $<\mathrm{LQ}$ & 0,35 & 0,50 & 3,5 & 0,81 \\
\hline 4 & $<L Q$ & 0,27 & 0,91 & 1,2 & 1,11 \\
\hline 5 & $<L Q$ & 0,22 & 0,45 & 20,7 & 2,74 \\
\hline 6 & $<L Q$ & 0,23 & 0,18 & 4,6 & 0,77 \\
\hline 7 & $<L Q$ & 0,24 & 0,26 & 9,6 & 1,51 \\
\hline 8 & $<L Q$ & 0,18 & 0,14 & 2,5 & 0,48 \\
\hline 9 & $<L Q$ & 0,18 & 0,15 & 9,4 & 0,58 \\
\hline 10 & $<L Q$ & 0,16 & 0,10 & 0,4 & 0,56 \\
\hline 11 & $<\mathrm{LQ}$ & 0,20 & 0,11 & 3,7 & 0,41 \\
\hline 12 & $<\mathrm{LQ}$ & 0,19 & 0,24 & 22,9 & 1,80 \\
\hline 13 & $<L Q$ & 0,16 & 0,11 & 2,2 & 0,74 \\
\hline 18 & $<L Q$ & 0,16 & 0,08 & 0,2 & 1,35 \\
\hline 21 & $<\mathrm{LQ}$ & 0,19 & 0,12 & 4,7 & 1,48 \\
\hline 26 & $<L Q$ & 0,15 & 0,07 & 0,4 & 1,06 \\
\hline 29 & $<L Q$ & 0,14 & 0,26 & 32,1 & 4,75 \\
\hline 32 & $<L Q$ & 0,14 & 0,14 & 23,2 & 2,96 \\
\hline 33 & $<L Q$ & 0,17 & 0,45 & 40,6 & 5,80 \\
\hline 36 & $<L Q$ & 0,12 & 0,15 & 12,9 & 2,10 \\
\hline 38 & $<L Q$ & 0,15 & 0,38 & 40,5 & 4,73 \\
\hline 39 & $<L Q$ & 0,22 & 0,16 & 15,8 & 2,41 \\
\hline 42 & $<L Q$ & 0,15 & 0,12 & 9,6 & 1,58 \\
\hline 45 & $<L Q$ & 0,10 & 0,24 & 24,5 & 3,00 \\
\hline 46 & $<L Q$ & 0,10 & 0,34 & 27,1 & 3,34 \\
\hline 49 & $<L Q$ & 0,11 & 0,18 & 18,7 & 2,17 \\
\hline 50 & $<L Q$ & 0,08 & 0,16 & 14,2 & 1,90 \\
\hline 53 & $<L Q$ & 0,09 & 0,14 & 13,8 & 1,70 \\
\hline 55 & $<L Q$ & 0,10 & 0,10 & 4,3 & 1,39 \\
\hline
\end{tabular}


TABELA 5.13 - Concentração $\mathrm{Ge}, \mathrm{Ti}, \mathrm{Fe}, \mathrm{Zn}$ e Al nas amostras das eluições do gerador G5.

\begin{tabular}{cccccc}
\hline & \multicolumn{5}{c}{ Concentração $\left(\mu \mathrm{g} \mathrm{mL}^{-1}\right)$} \\
Eluição & Ge & $\mathbf{T i}$ & $\mathbf{F e}$ & $\mathbf{Z n}$ & Al \\
\hline 2 & $<\mathrm{LQ}$ & 0,33 & 0,68 & 7,59 & 1,65 \\
3 & $<\mathrm{LQ}$ & 0,28 & 1,21 & 16,29 & 1,95 \\
6 & $<\mathrm{LQ}$ & 0,25 & 1,24 & 18,66 & 2,04 \\
13 & $<\mathrm{LQ}$ & 0,20 & 0,23 & 0,26 & 1,02 \\
16 & $<\mathrm{LQ}$ & 0,26 & 5,23 & 0,73 & 1,13 \\
18 & $<\mathrm{LQ}$ & 0,25 & 5,69 & 0,75 & 1,60 \\
20 & $<\mathrm{LQ}$ & 0,22 & 1,15 & 0,57 & 0,79 \\
\hline
\end{tabular}

TABELA 5.14 - Concentração Ge, Ti, Fe, Zn, Sn e Al nas amostras das eluições do gerador comercial 2 (iThemba).

\begin{tabular}{ccccccc}
\hline & \multicolumn{7}{c}{ Concentração $\left(\boldsymbol{\mu g} \mathbf{~ m L}^{-1}\right)$} & & \\
Eluição & Ge & $\mathbf{T i}$ & $\mathbf{F e}$ & $\mathbf{Z n}$ & $\mathbf{S n}$ & $\mathbf{A l}$ \\
\hline 1 & $<\mathrm{LQ}$ & 0,016 & 0,07 & 0,73 & 0,138 & 1,35 \\
4 & $<\mathrm{LQ}$ & 0,017 & 0,09 & 3,48 & 0,104 & 1,45 \\
7 & $<\mathrm{LQ}$ & 0,016 & 0,08 & 0,58 & 0,150 & 1,47 \\
11 & $<\mathrm{LQ}$ & 0,035 & 0,48 & 28,18 & 0,151 & 5,22 \\
13 & $<\mathrm{LQ}$ & 0,016 & 0,06 & 1,28 & 0,085 & 1,44 \\
15 & $<\mathrm{LQ}$ & 0,015 & 0,05 & 0,11 & 0,084 & 1,44 \\
17 & $<\mathrm{LQ}$ & 0,015 & 0,07 & 7,50 & 0,140 & 1,74 \\
20 & $<\mathrm{LQ}$ & 0,029 & 0,25 & 23,51 & 0,141 & 4,42 \\
22 & $<\mathrm{LQ}$ & 0,015 & 0,09 & 1,82 & 0,197 & 1,29 \\
23 & $<\mathrm{LQ}$ & 0,023 & 0,33 & 24,75 & 0,124 & 3,58 \\
25 & $<\mathrm{LQ}$ & 0,014 & 0,08 & 0,18 & 0,106 & 1,27 \\
27 & $<\mathrm{LQ}$ & 0,015 & 0,06 & 0,19 & 0,098 & 1,25 \\
28 & $<\mathrm{LQ}$ & 0,028 & 0,31 & 22,03 & 0,043 & 2,65 \\
\hline
\end{tabular}

A Farmacopeia Europeia determina limites apenas para os elementos $\mathrm{Fe}$ e $\mathrm{Zn}$ em solução de ${ }^{68} \mathrm{GaCl}_{3} \mathrm{com}$ a finalidade de radiomarcação. Os valores limites para esses metais são de $10 \mu \mathrm{g} / \mathrm{GBq}$.

Considerando-se um gerador de 1,11 GBq (30 mCi) eluído com $5 \mathrm{~mL}$, a concentração do ${ }^{68} \mathrm{Ga}$ é de $0,222 \mathrm{GBq} / \mathrm{mL}$. Assim, os limites para o $\mathrm{Fe}$ e para o Zn serão de $2,22 \mu \mathrm{g} \mathrm{mL}^{-1}$.

Os valores encontrados para o $\mathrm{Fe}$ nas análises das eluições dos geradores G2, G3 e comercial 2 estão abaixo desse limite, enquanto que para o gerador G5, das 7 amostras analisadas, 2 apresentaram níveis de contaminação 
acima dos limites estabelecidos, considerando a eluição de um gerador de 1,11 $\mathrm{GBq}(30 \mathrm{mCi})$. Esse resultado pode ser explicado pelo uso das agulhas metálicas nesse gerador que foi montado com sistema de eluição a vácuo.

As concentrações de $\mathrm{Zn}$ estão acima do limite em grande parte das amostras de todos os geradores. Embora $0{ }^{68} \mathrm{Ga}$ decaia $100 \%$ para o elemento Zn estável, esses níveis de contaminação não podem ser apenas referentes ao processo do decaimento. Uma atividade de $1850 \mathrm{MBq}(50 \mathrm{mCi})$ de ${ }^{68} \mathrm{Ga}$ daria origem a 1,22 ng de $\mathrm{Zn}$, sendo um valor muito abaixo dos níveis encontrados até nos geradores desenvolvidos neste trabalho, que foram carregados com menos de $74 \mathrm{MBq}(2 \mathrm{mCi})$ de ${ }^{68} \mathrm{Ge}$. Embora o nível de contaminantes encontrados nos reagentes utilizados fosse desprezível as possíveis fontes de contaminação seriam a água ou o $\mathrm{HCl}$ utilizados no preparo da solução para eluição, por um efeito de acúmulo no material adsorvedor. Outra possibilidade a ser investigada é a interferência de sinais entre os elementos durante a análise no ICP-OES. Esta contaminação com Zn foi observada em outros trabalhos do grupo (MARTINS, 2012).

Pode-se observar pelos resultados dos geradores G2, G3 e G5 (TAB. $5.11,5.12$ e 5.13) que houve uma contaminação maior de Ti nas amostras das eluições do gerador $\mathrm{G} 2$, que foi preparado $c o m \mathrm{TiO}_{2}$ não calcinado, chegando a níveis de contaminação de aproximadamente $170 \mu \mathrm{g} \mathrm{mL}^{-1}$. Isso pode ser explicado pela presença de $\mathrm{Ti}(\mathrm{OH})_{3}$ na composição, que é mais suscetível aos efeitos da radiólise e é mais solúvel que o $\mathrm{TiO}_{2}$. Essa é uma informação essencial que mostra a importância do uso do material calcinado no preparo dos geradores.

$O$ certificado de controle de qualidade do gerador da iThemba $L A B S$ especifica que a concentração de impurezas metálicas (Ga, Ge, Al, Sn, Ti, Cu, Zn,

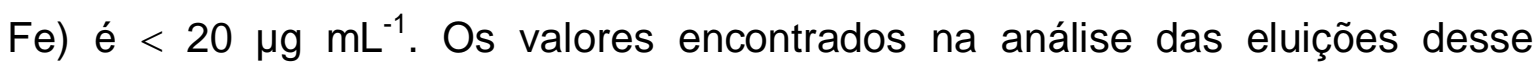
gerador (TAB. 5.14) para $\mathrm{Ge}, \mathrm{Ti}, \mathrm{Fe}, \mathrm{Sn}$ e Al estão dentro do informado pelo certificado do fabricante, apenas os níveis de $\mathrm{Zn}$ em algumas amostras apresentaram valores acima do especificado. Os níveis desses mesmos elementos analisados nas eluições dos geradores desenvolvidos neste trabalho, também ficaram abaixo de $20 \mu \mathrm{g} \mathrm{m}^{-1}$, com exceção do $\mathrm{Zn}$ para todos os geradores e do Ti para o gerador $\mathrm{G} 2$. 
Novamente, o valor preconizado pela Farmacopeia é para soluções de ${ }^{68} \mathrm{Ga}$ prontas para marcação, atualmente preparadas após purificação. Este processo reduz substancialmente as impurezas metálicas, sendo que as amostras de ${ }^{68} \mathrm{Ga}$ neste trabalho não foram purificadas.

\subsubsection{Medida do $\mathrm{pH}$}

A medida do $\mathrm{pH}$ foi realizada para amostras de todos os geradores desenvolvidos neste trabalho e para os geradores comerciais da Obninsk e iThemba. Todas as amostras apresentaram $\mathrm{pH}<2$, que é o limite estabelecido pela Farmacopeia Europeia.

\subsection{Determinação da pureza radionuclídia do ${ }^{68} \mathrm{Ga}$ por fitas cromatográficas}

\subsubsection{Seleção do sistema de separação}

O controle radionuclídico feito através de fitas cromatográficas é um método promissor, pois proporciona a separação das espécies, ${ }^{68} \mathrm{Ge}$ e ${ }^{68} \mathrm{Ga}$, fornecendo resultados muito mais rápidos comparado ao método tradicional, que necessita de pelo menos 24 horas para gerar o resultado.

Ao promover a separação das espécies, pelo sistema cromatográfico de fitas, é possível avaliar a atividade do ${ }^{68} \mathrm{Ge}$, através do crescimento do ${ }^{68} \mathrm{Ga}$, no segmento da fita referente ao ${ }^{68} \mathrm{Ge}$ e a atividade total da amostra pela atividade encontrada no segmento da fita referente ao ${ }^{68} \mathrm{Ga}$, que será recalculada para o horário da eluição.

Nesta etapa do trabalho vários sistemas cromatográficos foram avaliados na tentativa de se realizar a separação do ${ }^{68} \mathrm{Ge}$ e do ${ }^{68} \mathrm{Ga}$. Para esses estudos foram utilizadas amostras do próprio ${ }^{68} \mathrm{Ge}$ e as contagens dos segmentos das fitas foram realizadas no detector de germânio hiperpuro. Para todos os sistemas foram realizadas duas contagens, a primeira no dia que foi feita a cromatografia e a segunda contagem foi realizada no dia seguinte.

A TAB. 5.15 mostra os resultados encontrados com os dezenove sistemas cromatográficos avaliados, inclusive o sistema descrito por Eppard et al 
(2012), que utilizaram fita TLC e solvente $\mathrm{HCl} 2 \mathrm{~mol} \mathrm{~L}^{-1} /$ acetona (1:1) para separar ${ }^{68} \mathrm{Ge},{ }^{68} \mathrm{Ga}$ e DOTATOC- ${ }^{68} \mathrm{Ga}$, obtendo os seguintes $\mathrm{R}_{\mathrm{f}}:{ }^{68} \mathrm{Ge}=0,1 ;{ }^{68} \mathrm{Ga}$ $=1$ e DOTATOC ${ }^{-68} \mathrm{Ga}=0,4$.

TABELA 5.15 - $\mathrm{R}_{\mathrm{f}}$ do ${ }^{68} \mathrm{Ge}$ e do ${ }^{68} \mathrm{Ga}$ em diferentes sistemas cromatográficos.

\begin{tabular}{|c|c|c|c|c|}
\hline \multicolumn{3}{|c|}{ Sistema cromatográfico } & \multicolumn{2}{|c|}{$\mathbf{R}_{\mathrm{f}}$ das espécies } \\
\hline Suporte & Spot na fita & Solvente & ${ }^{68} \mathrm{Ge}$ & ${ }^{68} \mathrm{Ga}$ \\
\hline Whatman 3 & EDTA $0,1 \mathrm{~mol} \mathrm{~L}^{-1}$ & $\mathrm{CCl}_{4}$ saturado com HCl $6 \mathrm{~mol} \mathrm{~L}^{-1}$ & 0,1 & 0,1 \\
\hline Whatman 3 & EDTA $0,1 \mathrm{~mol} \mathrm{~L}^{-1}$ & Acetona & 0,1 & 0,1 \\
\hline Whatman 3 & - & Acetona & 0,1 & 0,1 \\
\hline TLC-SG-AI & - & Acetona & 0,1 & 0,1 \\
\hline Whatman 3 & EDTA $0,1 \mathrm{~mol} \mathrm{~L}^{-1}$ & $\mathrm{NaCl} 0,9 \%$ & $0,1-1,0$ & $0,1-1,0$ \\
\hline Whatman 3 & - & EDTA $0,1 \mathrm{~mol} \mathrm{~L}^{-1}$ & $0,1-1,0$ & $0,1-1,0$ \\
\hline TLC-SG-IB-F & - & EDTA $0,1 \mathrm{~mol} \mathrm{~L}^{-1}$ & $0,1-1,0$ & $0,1-1,0$ \\
\hline Whatman 3 & - & $\mathrm{HCl} 3 \mathrm{~mol} \mathrm{~L}^{-1} /$ butanol $(1: 1)$ & 0,1 & 0,1 \\
\hline Whatman 3 & - & Citrato de sódio $1 \mathrm{~mol} \mathrm{~L}^{-1}$ & $0,1-0,9$ & $0,1-0,9$ \\
\hline Whatman 3 & - & $\mathrm{HCl} 2 \mathrm{~mol} \mathrm{~L}^{-1} /$ acetona $(1: 1)$ & $0,8-0,9$ & $0,8-0,9$ \\
\hline Whatman 3 & EDTA $0,1 \mathrm{~mol} \mathrm{~L}^{-1}$ & $\mathrm{HCl} 2 \mathrm{~mol} \mathrm{~L}^{-1} /$ acetona $(1: 1)$ & $0,8-0,9$ & $0,8-0,9$ \\
\hline TLC-SG-IB-F & - & $\mathrm{HCl} 2 \mathrm{~mol} \mathrm{~L}^{-1} /$ acetona $(1: 1)$ & $0,1-0,2$ & $0,8-0,9$ \\
\hline ITLC & - & $\mathrm{HCl} 2 \mathrm{~mol} \mathrm{~L}^{-1} /$ acetona $(1: 1)$ & $0,1-0,9$ & 1,0 \\
\hline Whatman 3 & - & $\mathrm{HCl} 2 \mathrm{~mol} \mathrm{~L}^{-1} /$ Etanol (1:1) & $0,8-0,9$ & $0,8-0,9$ \\
\hline TLC-SG-IB-F & - & $\mathrm{HCl} 2 \mathrm{~mol} \mathrm{~L}^{-1} /$ Etanol (1:1) & $0,1-0,2$ & $0,8-0,9$ \\
\hline TLC-SG-IB-F & - & $\mathrm{HCl} 2 \mathrm{~mol} \mathrm{~L}^{-1} /$ Metanol (1:1) & $0,1-0,2$ & $0,1-0,9$ \\
\hline TLC-SG-IB-F & $\mathrm{HCl} 3 \mathrm{~mol} \mathrm{~L}^{-1}$ & Acetona & 0,1 & $0,5-0,6$ \\
\hline TLC-SG-IB-F & - & Acetona & 0,1 & 0,1 \\
\hline TLC-SG-IB-F & - & $\mathrm{HCl} 0,02 \mathrm{~mol} \mathrm{~L}^{-1}$ em acetona & $0,1-0,2$ & 0,4 \\
\hline
\end{tabular}

Os estudos realizados neste trabalho com o sistema descrito por Eppard et al. promoveram a separação do ${ }^{68} \mathrm{Ge}$ e do ${ }^{68} \mathrm{Ga}$, apresentando $\mathrm{R}_{\mathrm{f}} 0,1$ 0,2 para $\circ{ }^{68} \mathrm{Ge}$ e $R_{f} \quad 0,8-0,9$ para $\circ{ }^{68} \mathrm{Ga}$. Neste sistema cromatográfico, o solvente levou uma hora e vinte minutos para percorrer toda a fita. Na literatura não está especificado qual o tipo de fita TLC foi utilizada. Neste trabalho, utilizouse fita TLC-SG-IB-F. A FIG. 5.54 mostra a separação das espécies promovida por este sistema. 


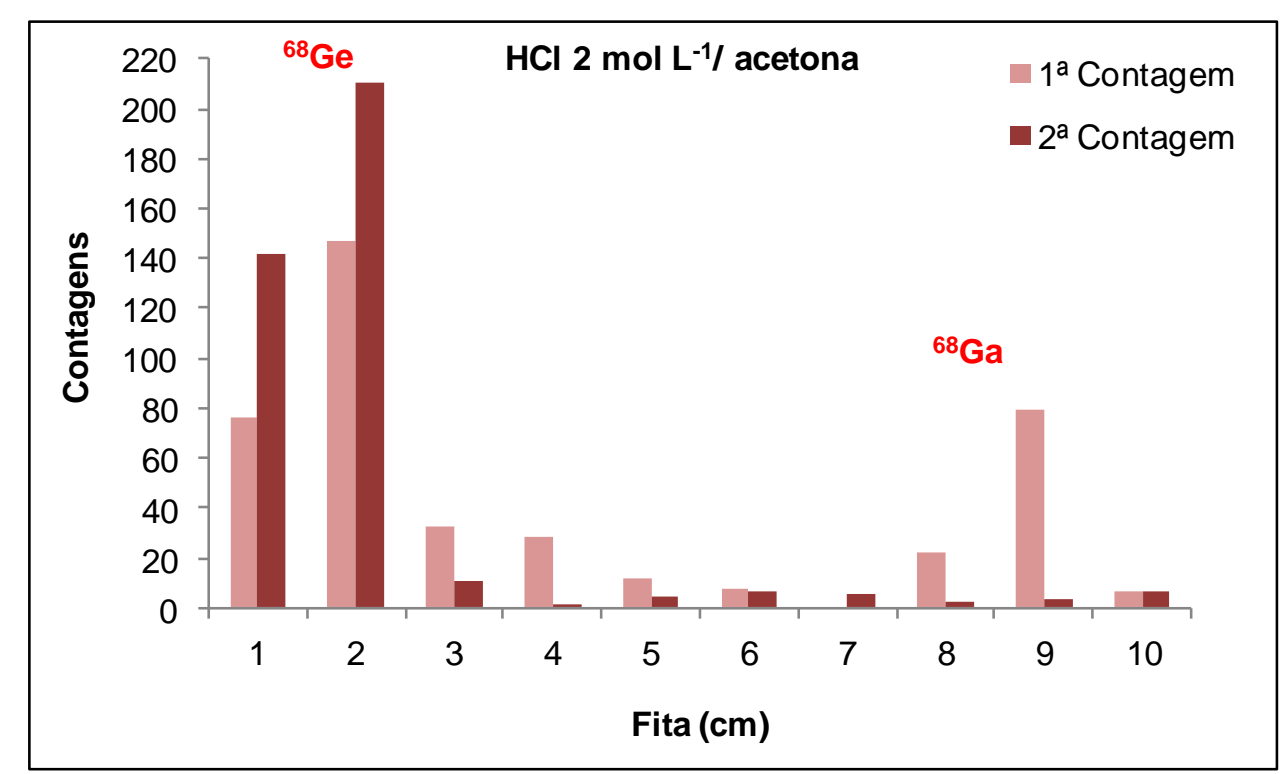

FIGURA 5.54 - Cromatograma do ${ }^{68} \mathrm{Ge}$ utilizando fita TLC-SG-IB-F e solvente $\mathrm{HCl} 2 \mathrm{~mol} \mathrm{~L}^{-1} /$ acetona (1:1) para separação de ${ }^{68} \mathrm{Ge} \mathrm{e}{ }^{68} \mathrm{Ga}$.

A primeira contagem foi realizada duas horas e vinte cinco minutos após o término da corrida do solvente. A atividade do ${ }^{68} \mathrm{Ga}$ já estava reduzida, mas é possível observar claramente um pico no $R_{f} 0,9$. O pico observado no $R_{f}$ $0,1-0,2$ é referente a atividade do ${ }^{68} \mathrm{Ga}$ vindo do decaimento do ${ }^{68} \mathrm{Ge}$. A segunda contagem da fita foi feita mais de 24 horas após a realização da cromatografia e mostra claramente o crescimento do pico no $R_{f}$ 0,1-0,2 correspondendo ao equilíbrio da atividade do ${ }^{68} \mathrm{Ga}$ com a do ${ }^{68} \mathrm{Ge}$.

O sistema que utilizou fita TLC-SG-IB-F com solvente $\mathrm{HCl} 2 \mathrm{~mol} \mathrm{~L}^{-1 /}$ etanol (1:1), proposto neste trabalho, apresentou o mesmo perfil de separação que o obtido pelo sistema que utilizou $\mathrm{HCl} 2 \mathrm{~mol} \mathrm{~L}^{-1} /$ acetona (1:1) (FIG. 5.54). Porém, o solvente levou duas horas e dez minutos para percorrer a fita, sendo uma desvantagem em relação ao sistema descrito por Eppard et al (2012), pois o que se busca no desenvolvimento de um método para determinação da pureza radionuclídica por fitas cromatográficas é a agilidade e rapidez no processo.

O outro sistema cromatográfico, desenvolvido de maneira inédita neste trabalho, que promoveu a separação do ${ }^{68} \mathrm{Ge}$ e do ${ }^{68} \mathrm{Ga}$ foi o que utilizou fita TLCSG-IB-F com spot de $\mathrm{HCl} 3 \mathrm{~mol} \mathrm{~L}^{-1}$ e acetona como solvente. Neste sistema o $\mathrm{R}_{f}$ encontrado para ${ }^{68} \mathrm{Ge}$ foi 0,1 e para $0^{68} \mathrm{Ga}, 0,5-0,6$. A vantagem desse sistema em relação ao desenvolvido por Eppard e colaboradores (2012) foi o tempo que o solvente levou para percorrer a fita, 30 minutos, praticamente uma 
hora a menos do que utilizando a mistura de $\mathrm{HCl} 2 \mathrm{~mol} \mathrm{~L}^{-1} /$ acetona (1:1). A FIG. 5.55 apresenta o cromatograma deste sistema.

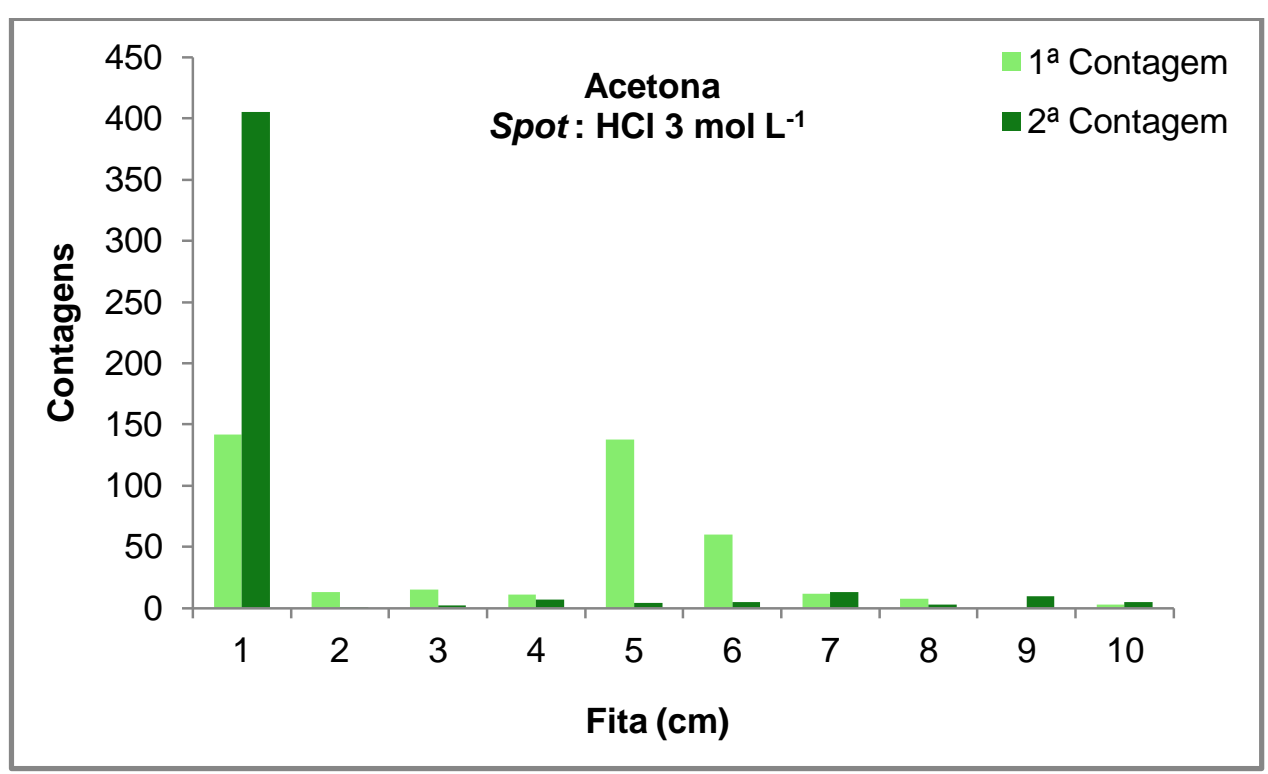

FIGURA 5.55 - Cromatograma do ${ }^{68} \mathrm{Ge}$ utilizando fita TLC-SG-IB-F com spot de $\mathrm{HCl} 3 \mathrm{~mol} \mathrm{~L}^{-1}$ e solvente acetona para separação de ${ }^{68} \mathrm{Ge}$ e ${ }^{68} \mathrm{Ga}$.

A primeira contagem foi realizada com uma hora e dez minutos após o término da corrida do solvente. A atividade do ${ }^{68} \mathrm{Ga}$ corresponde aos picos encontrados no $R_{f} 0,5-0,6$. O pico observado no $R_{f} 0,1$ é referente à atividade do ${ }^{68} \mathrm{Ga}$ vindo do decaimento do ${ }^{68} \mathrm{Ge}$. Após 24 horas foi realizada a segunda contagem, mostrando o crescimento do pico no $R_{f} 0,1$, correspondendo à atividade do ${ }^{68} \mathrm{Ge}$ que encontra-se em equilíbrio com o ${ }^{68} \mathrm{Ga}$.

Foram adquiridas imagens dessa fita cromatográfica no $\mu \mathrm{PET}$ para ilustrar a separação das duas espécies. As aquisições foram realizadas em 4 tempos diferentes contados a partir do final da cromatografia (FIG. 5.56). 


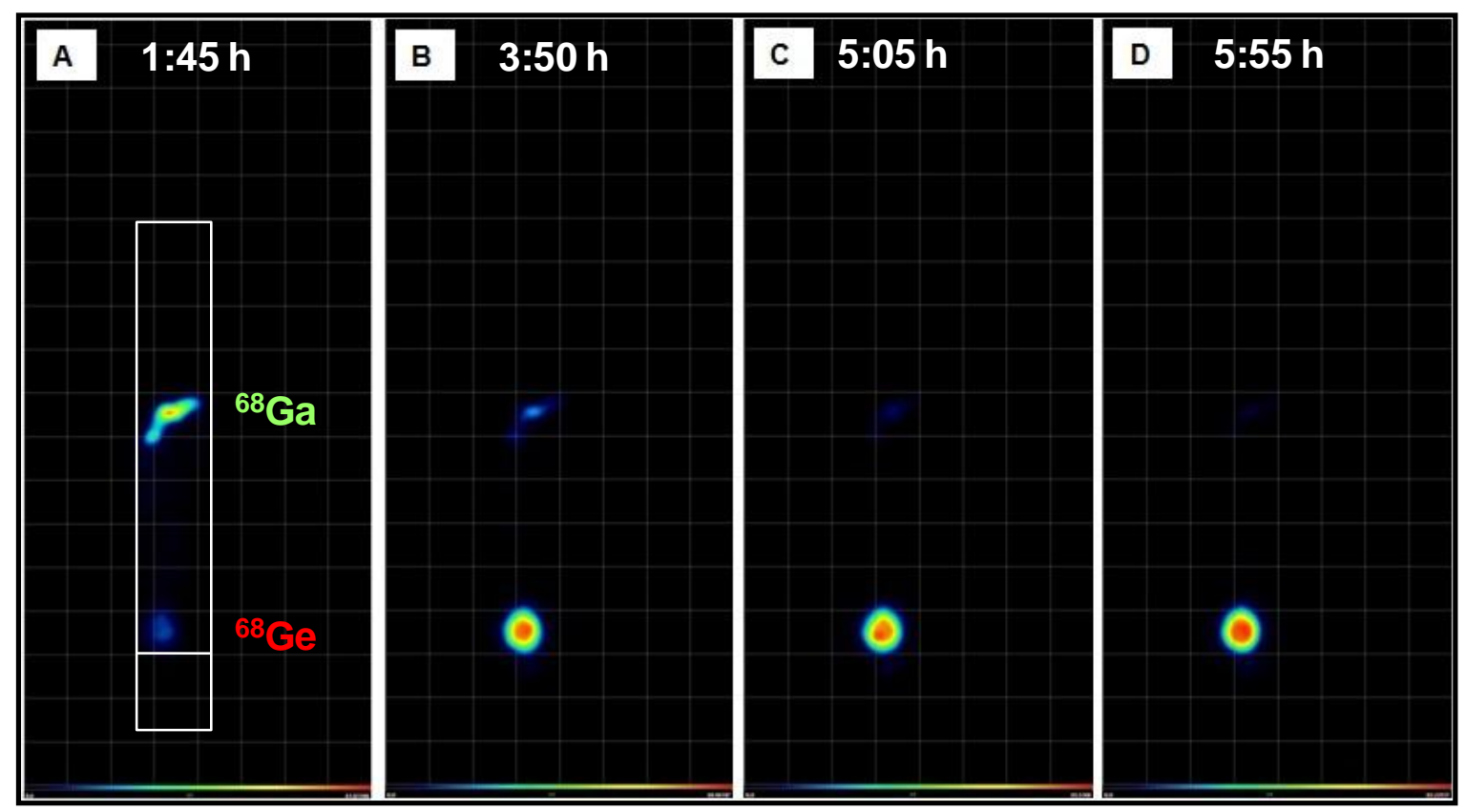

FIGURA 5.56 - Imagens de fita cromatográfica mostrando a separação do ${ }^{68} \mathrm{Ge}$ e do ${ }^{68} \mathrm{Ga}$ pelo sistema: fita TLC-SG-IB-F com spot de $\mathrm{HCl} 3 \mathrm{~mol} \mathrm{~L}^{-1}$ e solvente acetona. Aquisição em 4 tempos distintos contados após o término da cromatografia: (A) 1:45h; (B) 3:50h; (C) 5:05h; (D) 5:55h.

Além das imagens ilustrarem a separação das espécies na fita, mostram o decaimento da atividade do ${ }^{68} \mathrm{Ga}$ no $R_{f} 0,6$ e o crescimento da atividade ${ }^{68} \mathrm{Ga}$ vindo do decaimento do ${ }^{68} \mathrm{Ge}$ na origem da fita.

\subsubsection{Análise de amostra de ${ }^{68} \mathrm{Ga}$}

O sistema cromatográfico escolhido para análise da pureza radionuclídica do ${ }^{68} \mathrm{Ga}$ foi o desenvolvido neste trabalho, que utilizou fita TLC-SGIB-F com spot de $\mathrm{HCl} 3 \mathrm{~mol} \mathrm{~L}^{-1}$ e acetona como solvente.

Como as amostras analisadas por fitas cromatográficas precisam ter um volume reduzido ( $3 \mu \mathrm{L}$ ), é importante avaliar a concentração radioativa do ${ }^{68} \mathrm{Ga}$ de acordo com os LD e LQ do equipamento utilizado para a análise.

No caso do controle radionuclídico feito pelo método convencional não existe limitação para o volume da amostra de ${ }^{68} \mathrm{Ga}$, apenas da atividade a ser analisada. Dando como exemplo, o LD calculado para o detector de germânio hiperpuro para a energia de $511 \mathrm{keV}$, com tempo de contagem de 20 minutos na $3^{\text {a }}$ posição do equipamento, foi de $14 \mathrm{~Bq}(0,4 \mathrm{nCi})$. Portanto, nessas condições a amostra de ${ }^{68} \mathrm{Ga}$ a ser analisada precisa ter no mínimo $1480 \mathrm{kBq}$ (40 $\mu \mathrm{Ci}$ ) para 
ser possível a deteç̧ão de $10^{-3} \%$ dessa atividade. Se o controle radionuclidico fosse feito por fitas e a contagem realizada no detector de germânio hiperpuro, seria necessário ter $1480 \mathrm{kBq}(40 \mu \mathrm{Ci})$ de ${ }^{68} \mathrm{Ga}$ em um volume de aproximadamente $3 \mu \mathrm{L}$. Então, essa amostra teria que ter uma concentração radioativa de 493,21 MBq/ mL (13,33 mCi/ mL), o que corresponderia a eluição de um gerador de mais de $2200 \mathrm{MBq}$ (60 mCi), considerando a eluição feita com 5 $\mathrm{mL}$ de solução.

As fitas utilizadas para analisar a amostra de ${ }^{68} \mathrm{Ga}$ foram contadas no contador gama, já que este equipamento apresenta eficiência maior que o detector de germânio hiperpuro.

Para garantir que o equipamento seja capaz de detectar os níveis permissíveis de ${ }^{68} \mathrm{Ge}$ no ${ }^{68} \mathrm{Ga}$, utilizando um volume de no máximo $3 \mu \mathrm{L}$ de amostra do eluato, os LD do equipamento para energia de $511 \mathrm{keV}$ foram calculados para vários tempos de contagem. Para os cálculos foram considerados dois valores de $B G$, o valor informado pelo equipamento e a média de várias medidas do BG.

A TAB. 5.16 mostra os valores de LD do equipamento considerando o $B G$ informado pelo equipamento, enquanto que a TAB. 5.17 apresenta os resultados obtidos considerando para o cálculo o valor médio das medidas do BG.

Para o cálculo do $L Q$ foi utilizado apenas o valor médio das medidas do $\mathrm{BG}$ e o valor encontrado foi $3 \mathrm{~Bq}(0,081 \mathrm{nCi})$. Portanto a atividade mínima de ${ }^{68} \mathrm{Ga}$ necessária na amostra seria $303 \mathrm{kBq}(8,18 \mu \mathrm{Ci})$. 
TABELA 5.16 - Limites de detecção (LD) do contador gama para energia de 511 keV para diferentes tempos de contagem, utilizando para o cálculo o valor de BG informado pelo equipamento.

\begin{tabular}{|c|c|c|c|c|}
\hline $\begin{array}{l}\text { Tempo } \\
\text { ctg min. }\end{array}$ & LD (nCi) & $\operatorname{LD}(\mathrm{Bq})$ & $\begin{array}{c}A_{\text {min. }} \text { necessária } \\
\text { de }{ }^{68} \mathrm{Ga}(\mu \mathrm{Ci})\end{array}$ & $\begin{array}{c}\text { A }_{\text {min. }} \text { necessária } \\
\text { de }{ }^{68} \mathrm{Ga}(\mathrm{MBq})\end{array}$ \\
\hline 1 & 0,300 & 11,10 & 30,44 & 1,13 \\
\hline 2 & 0,150 & 5,55 & 15,22 & 0,56 \\
\hline 3 & 0,100 & 3,70 & 10,15 & 0,38 \\
\hline 4 & 0,076 & 2,81 & 7,61 & 0,28 \\
\hline 5 & 0,061 & 2,26 & 6,09 & 0,23 \\
\hline 6 & 0,051 & 1,89 & 5,07 & 0,19 \\
\hline 7 & 0,043 & 1,59 & 4,35 & 0,16 \\
\hline 8 & 0,038 & 1,41 & 3,81 & 0,14 \\
\hline 9 & 0,034 & 1,26 & 3,38 & 0,13 \\
\hline 10 & 0,030 & 1,11 & 3,04 & 0,11 \\
\hline 15 & 0,020 & 0,74 & 2,03 & 0,08 \\
\hline 30 & 0,010 & 0,37 & 1,02 & 0,04 \\
\hline
\end{tabular}

TABELA 5.17 - Limites de detecção (LD) do contador gama para energia de 511 keV para diferentes tempos de contagem, utilizando para o cálculo o valor médio das medidas do BG.

\begin{tabular}{|c|c|c|c|c|}
\hline $\begin{array}{l}\text { Tempo } \\
\text { ctg min. }\end{array}$ & LD (nCi) & $\operatorname{LD}(\mathrm{Bq})$ & $\begin{array}{c}A_{\min .} \text { necessária } \\
\text { de }{ }^{68} \mathrm{Ga}(\mu \mathrm{Ci})\end{array}$ & 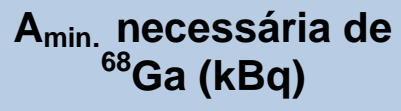 \\
\hline 1 & 0,073 & 2,70 & 7,25 & 270 \\
\hline 2 & 0,036 & 1,33 & 3,62 & 130 \\
\hline 3 & 0,024 & 0,89 & 2,41 & 90 \\
\hline 4 & 0,018 & 0,67 & 1,81 & 70 \\
\hline 5 & 0,015 & 0,56 & 1,45 & 50 \\
\hline 6 & 0,012 & 0,44 & 1,21 & 40 \\
\hline 7 & 0,010 & 0,37 & 1,03 & 40 \\
\hline 8 & 0,009 & 0,33 & 0,90 & 30 \\
\hline 9 & 0,008 & 0,30 & 0,80 & 30 \\
\hline 10 & 0,007 & 0,26 & 0,73 & 30 \\
\hline 15 & 0,005 & 0,19 & 0,48 & 20 \\
\hline 30 & 0,002 & 0,07 & 0,24 & 10 \\
\hline
\end{tabular}

Pode-se observar que os LD obtidos com o valor de BG informado pelo equipamento são maiores que os valores de LD encontrados através da contagem do BG. 
Para realização da análise foi utilizado $0^{68} \mathrm{Ga}$ eluído do gerador comercial 2 (iThemba), que foi eluído com volume de $5 \mathrm{~mL}$ de $\mathrm{HCl} 0,6 \mathrm{~mol} \mathrm{~L}^{-1}$, apresentando uma concentração radioativa de $70 \mathrm{MBq} / \mathrm{mL}(1,9 \mathrm{mCi} / \mathrm{mL})$.

As amostras aplicadas nas fitas (duplicata) foram de $3 \mu \mathrm{L}$, apresentando então uma atividade de aproximadamente $211 \mathrm{kBq}(5,7 \mu \mathrm{Ci})$. Após a realização da cromatografia foram realizadas 4 contagens dos segmentos das fitas em tempos distintos, contados a partir do inicio da análise, momento em que o solvente percorre a origem da fita e promove a separação das espécies. Os tempos analisados foram: $1^{\circ}$ ) 2 horas e 18 minutos; $2^{\circ}$ ) 3 horas e 22 minutos; $3^{\circ}$ ) 4 horas e 3 minutos e $\left.4^{\circ}\right) 25$ horas e 21 minutos.

Para a primeira contagem foi utilizado tempo de 1 minuto e para as demais contagens o tempo foi de 3 minutos.

Foram considerados os valores de LD obtidos através das contagens do $B G$ (TAB. 5.17) e não os valores obtidos utilizando o $B G$ informado pelo equipamento (TAB. 5.16). Portanto, para o tempo de contagem de 3 minutos, a atividade mínima necessária de ${ }^{68} \mathrm{Ga}$ na amostra seria de $90 \mathrm{kBq}(2,4 \mu \mathrm{Ci})$, valor abaixo do utilizado na amostra $(211 \mathrm{kBq})$, garantindo a viabilidade de detecção de ${ }^{68} \mathrm{Ge}$ nos limites permissíveis.

A FIG. 5.57 mostra as contagens dos segmentos das fitas nos 4 tempos estudados. Para determinação da atividade total da amostra de ${ }^{68} \mathrm{Ga}$ utilizada na análise foram considerados os valores de contagem obtidos no primeiro tempo de contagem (2:18 h). Foi realizada a soma das contagens dos segmentos 4, 5 e 6 e o valor encontrado foi corrigido para o horário da eluição. Este valor foi considerado como sendo a atividade total de ${ }^{68} \mathrm{Ga}$ da amostra aplicada na fita. 


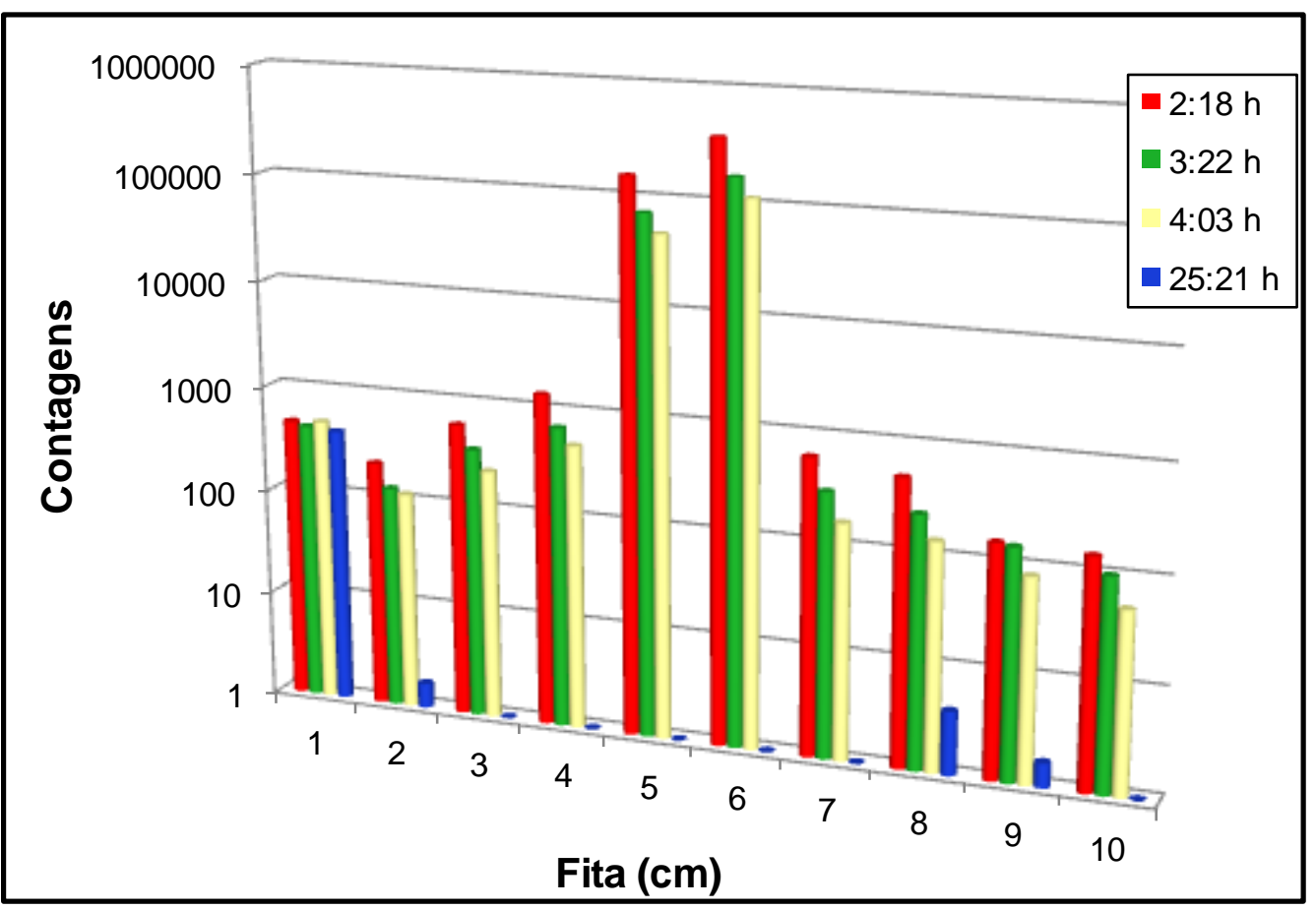

FIGURA 5.57 - Amostra de ${ }^{68} \mathrm{Ga}$ do gerador comercial 2 (iThemba) analisada por cromatografia, utilizando fita TLC-SG-IB-F com spot de $\mathrm{HCl} 3 \mathrm{~mol} \mathrm{~L}^{-1}$ e solvente acetona para separação de ${ }^{68} \mathrm{Ge} \mathrm{e}{ }^{68} \mathrm{Ga}$. Medida da atividade feita no contador gama em 4 tempos diferentes contados após o inicio da cromatografia.

Pode-se observar que a análise feita após 24 horas da realização da cromatografia apresenta contagem significativa apenas no primeiro segmento da fita. Os picos encontrados nos outros segmentos são valores de BG, neste tempo.

Para determinação da atividade de ${ }^{68} \mathrm{Ge}$, foram utilizadas as contagens encontradas no primeiro segmento da fita, que correspondem a atividade de ${ }^{68} \mathrm{Ga}$ vinda do decaimento do ${ }^{68} \mathrm{Ge}$. Para cada tempo estudado foi determinada a porcentagem do crescimento do ${ }^{68} \mathrm{Ga}$ e o valor encontrado foi corrigido para 0 crescimento de $100 \%$. A TAB. 5.18 mostra a porcentagem de crescimento do ${ }^{68} \mathrm{Ga}$ nos tempos utilizados para as contagens.

TABELA 5.18 - Porcentagem do crescimento do ${ }^{68} \mathrm{Ga}$ nos tempos utilizados para contagem das fitas.

\begin{tabular}{cc}
\hline $\begin{array}{c}\text { Tempo decorrido do inicio } \\
\text { da cromatografia }\end{array}$ & $\begin{array}{c}\text { Porcentagem de } \\
\text { crescimento do }{ }^{68} \mathbf{G a}\end{array}$ \\
$2: 18 \mathrm{~h}$ & 75,47 \\
$3: 22 \mathrm{~h}$ & 87,20 \\
$4: 03 \mathrm{~h}$ & 91,55 \\
$25: 21 \mathrm{~h}$ & 99,73 \\
\hline
\end{tabular}


Os valores encontrados de porcentagem de ${ }^{68} \mathrm{Ge}$ em cada tempo analisado estão mostrados na TAB. 5.19.

TABELA 5.19 - Porcentagem de ${ }^{68} \mathrm{Ge}$ nos diferentes tempos analisados após o inicio da cromatografia.

\begin{tabular}{ccc}
\hline $\begin{array}{c}\text { Tempo decorrido do } \\
\text { inicio da cromatografia }\end{array}$ & $\begin{array}{c}\%^{68} \mathrm{Ge} \\
\text { (média) }\end{array}$ & Desvio da média \\
$2: 18 \mathrm{~h}$ & $2,58 \cdot 10^{-2}$ & $\pm 0,0019$ \\
$3: 22 \mathrm{~h}$ & $2,20 \cdot 10^{-2}$ & - \\
$4: 03 \mathrm{~h}$ & $2,35 \cdot 10^{-2}$ & $\pm 0,0004$ \\
$25: 21 \mathrm{~h}$ & $1,90 \cdot 10^{-2}$ & $\pm 0,0006$ \\
\hline
\end{tabular}

Os valores encontrados para porcentagem de ${ }^{68} \mathrm{Ge}$ nesta mesma amostra usando o método convencional, utilizando o detector de germânio hiperpuro e o contador gama foram de $1,6.10^{-2} \%$ e $1,97.10^{-2} \%$, respectivamente. Esses valores são muito próximos aos encontrados pelo método de fitas cromatográficas, demonstrando a viabilidade do uso desse método, que traria uma resposta confiável da pureza radionuclídica em cerca de 2 horas após o fim da eluição.

Este método pode ser utilizado também para avaliar o nível de ${ }^{68} \mathrm{Ge}$ no produto marcado, como o DOTATATO- ${ }^{68} \mathrm{Ga}$.

\subsection{Imagem da coluna do gerador de ${ }^{68} \mathrm{Ge} /{ }^{68} \mathrm{Ga}$ no $\mu \mathrm{PET}$}

A FIG. 5.58 mostra uma imagem de corte sagital da coluna do gerador de ${ }^{68} \mathrm{Ge} /{ }^{68} \mathrm{Ga}$ (G3) adquirida no equipamento de $\mu \mathrm{PET}$. Sobre a imagem foi feita uma projeção de um desenho da coluna de vidro do gerador com as dimensões aproximadas ao tamanho real da coluna. 


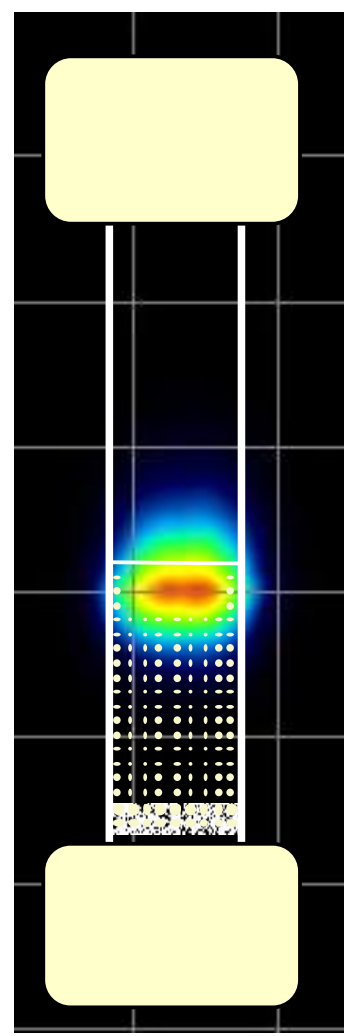

FIGURA 5.58 - Imagem da coluna do gerador de ${ }^{68} \mathrm{Ge} /{ }^{68} \mathrm{Ga}$ adquirida no equipamento $\mu \mathrm{PET}$ (corte sagital).

A FIG. 5.59 mostra uma imagem de corte axial com a sobreposição do desenho de um circulo representando o diâmetro da coluna de vidro.

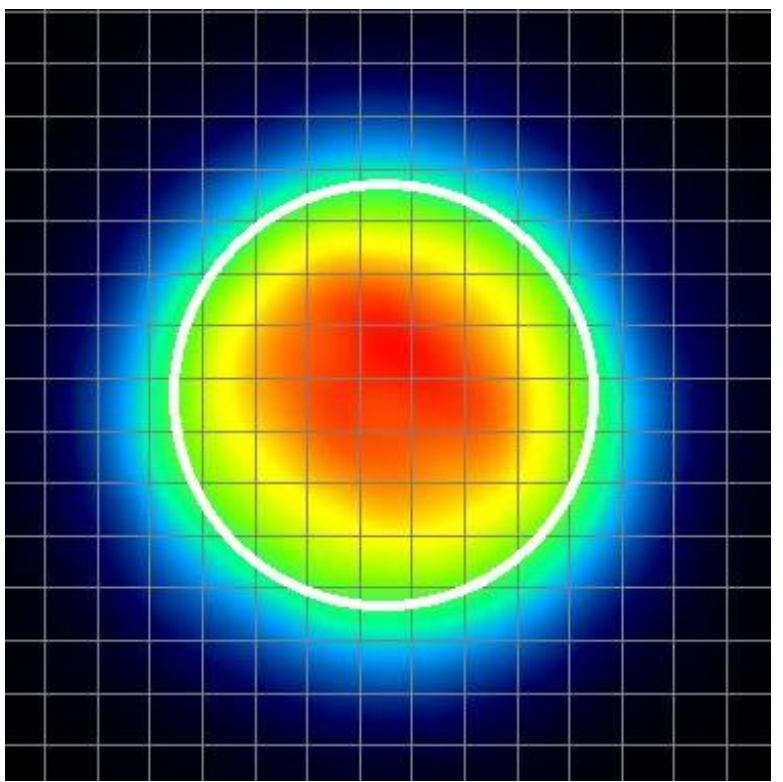

FIGURA 5.59 - Imagem da coluna do gerador de ${ }^{68} \mathrm{Ge} /{ }^{68} \mathrm{Ga}$ adquirida no equipamento $\mu$ PET (corte axial). 
O corte sagital mostra que a atividade do ${ }^{68} \mathrm{Ge}$ está concentrada na parte superior da coluna, comprovando sua eficiência em reter $0{ }^{68} \mathrm{Ge}$ e confirma a análise visual do efeito da radiação no adsorvedor $\left(\mathrm{TiO}_{2}\right)$ e no vidro da coluna (FIG. 5.52). No corte axial pode ser visto que $0{ }^{68} \mathrm{Ge}$ se distribuiu uniformemente ao longo do eixo (diâmetro) da coluna.

\subsection{Projeto de gerador com sistema de purificação feita a vácuo}

Até o presente momento, com as informações encontradas na literatura, nenhum gerador comercial fornece $0{ }^{68} \mathrm{Ga}$ em condições adequadas para marcação de biomoléculas e uso direto em seres humanos, considerando as BPF (Boas Práticas de Fabricação). A utilização dos geradores comerciais está vinculada ao uso dos módulos de síntese, onde ocorrem os processos de purificação e concentração do ${ }^{68} \mathrm{Ga}$, marcação da biomolécula e posterior purificação do marcado.

O desenvolvimento de um sistema que forneça, com praticidade, o ${ }^{68} \mathrm{Ga}$ em condições adequadas para marcação de biomoléculas, seria de grande importância para a aprovação desse sistema de gerador pelos órgãos regulatórios e também para o desenvolvimento de novos radiofármacos marcados com ${ }^{68} \mathrm{Ga}$, em particular os que vierem a ser desenvolvidos na forma de conjuntos de reativos liofilizados (kits).

A FIG. 5.60 mostra a ilustração do projeto do gerador com eluição a vácuo e sistema de purificação e concentração proposto neste trabalho. 


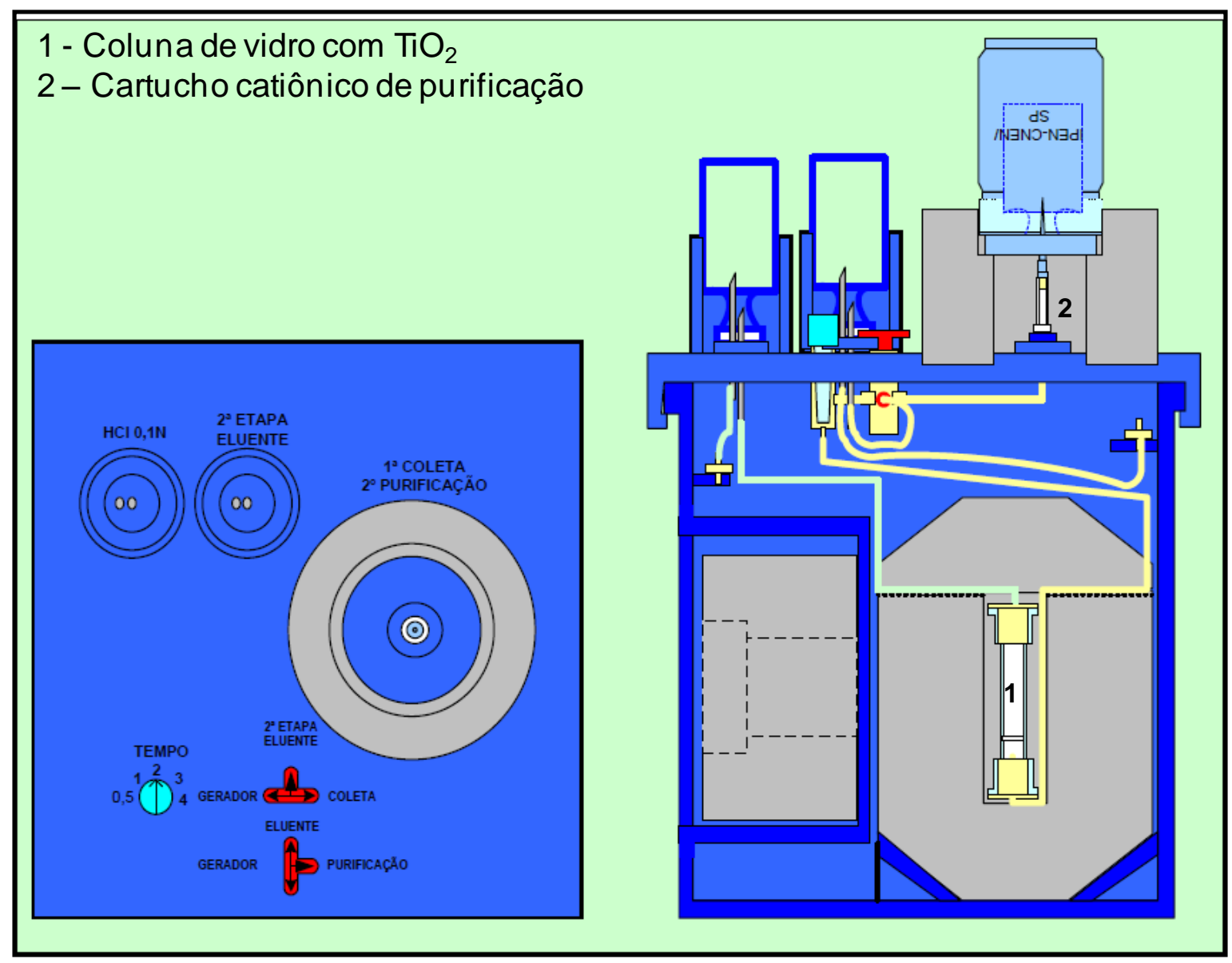

FIGURA 5.60 - Ilustração do gerador de ${ }^{68} \mathrm{Ge}-{ }^{68} \mathrm{Ga}$ com sistema a vácuo para eluição e purificação do ${ }^{68} \mathrm{Ga}$.

Esse gerador apresenta dois sistemas de eluição. No primeiro sistema (sistema primário) é feita a eluição do ${ }^{68} \mathrm{Ga}$ que está na coluna do gerador. Esta eluição será feita a vácuo controlado por uma válvula agulha de plástico. Após a eluição, o sistema primário é fechado por uma torneira de três vias (plástico). O ${ }^{68} \mathrm{Ga}$ ficará preso no cartucho catiônico e o efluente coletado no frasco a vácuo será descartado. Em outro compartimento do gerador, chamado de sistema

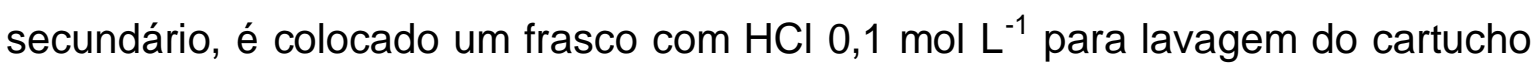
(retirada de contaminantes químicos). Novamente um frasco a vácuo é colocado no compartimento de coleta do gerador, para coletar a solução de lavagem. Após a lavagem do cartucho, um frasco com $1 \mathrm{~mL}$ de $\mathrm{HCl} \mathrm{0,02} \mathrm{mol} \mathrm{L}^{-1} /$ acetona é colocado na entrada do sistema secundário para eluir $0^{68} \mathrm{Ga}$ purificado que está preso no cartucho, sendo coletado em um outro frasco a vácuo. 


\section{CONCLUSÕES}

A partir dos resultados obtidos em cada etapa realizada neste trabalho, pode-se concluir:

A avaliação do comportamento químico do $G e$ e do Ga realizada separadamente através da utilização de traçadores, químico para o Ge e radioativo para o $\mathrm{Ga}$, foi uma alternativa eficiente para a escolha de um material adequado para o desenvolvimento dos geradores de ${ }^{68} \mathrm{Ge} /{ }^{68} \mathrm{Ga}$.

Dos materiais adsorvedores estudados, o que apresentou melhores resultados foi o $\mathrm{TiO}_{2}$. $\mathrm{O} \mathrm{ZrO}_{2}$ e as microesferas mostraram-se promissores, mas outros estudos precisam ser realizados com esses materiais.

A preparação do $\mathrm{TiO}_{2}$ foi eficaz para se obter um material adequado para montagem de colunas cromatográficas. Os resultados das análises de caracterização mostraram que o $\mathrm{TiO}_{2}$ calcinado a $420^{\circ} \mathrm{C}$ é mais adequado para 0 preparo de geradores, sendo mais resistente a processos de degradação. Concluiu-se também que a formação das fases cristalinas, anatase e rutilo, interferem na capacidade de adsorção do material. Porém, mais estudos precisam ser realizados para que se consiga determinar quais parâmetros do processo de síntese determinam a formação dessas fases e a proporção entre elas, além do tratamento térmico.

Dois tipos de geradores cromatográficos de ${ }^{68} \mathrm{Ge} /{ }^{68} \mathrm{Ga}$ foram desenvolvidos: geradores com sistema de eluição com pressão manual, feita através de seringa, similares aos geradores comerciais e geradores com sistema de eluição a vácuo, similar ao sistema de geradores de ${ }^{99} \mathrm{Mo} /{ }^{99 m} \mathrm{Tc}$, porém com controle da vazão e sistema de purificação. O sistema de eluição a vácuo é inédito para o desenvolvimento dos geradores de ${ }^{68} \mathrm{Ge} /{ }^{68} \mathrm{Ga}$ e pode contribuir para o preparo dos geradores dentro das Boas Práticas de Fabricação.

Os geradores desenvolvidos neste trabalho que apresentaram resultados mais promissores foram os geradores G3 e G5. Esses geradores foram preparados com $\mathrm{TiO}_{2}$ calcinado a $420^{\circ} \mathrm{C}$ e as colunas foram mantidas úmidas. 
O gerador G3, feito com sistema de eluição equivalente aos geradores comerciais, pressão manual feita com seringa, foi avaliado por 10 meses e a eficiência de eluição foi similar ao gerador comercial 2 (iThemba), variando de aproximadamente 50 a $80 \%$, com a vantagem de ser eluído com solução de $\mathrm{HCl}$

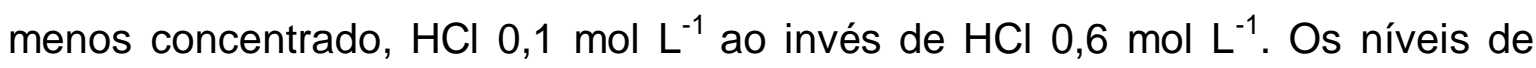
contaminação química e radionuclídica no eluato desse gerador foram similares aos encontrados nos geradores comerciais.

O gerador com sistema de eluição a vácuo, G5, apresentou eficiência de eluição entre 45 e $62 \%$, sendo menor que o gerador G3 (50 a 80\%), porém a vazão utilizada para eluição desse gerador foi de 1,5 a $2 \mathrm{~mL}$ por minuto, enquanto que no gerador G3 a vazão utilizada foi de 3 a $4 \mathrm{~mL}$ por minuto. Os níveis de contaminação de ${ }^{68} \mathrm{Ge}$ no eluato foram similares aos outros geradores, porém a contaminação química foi maior, devido ao uso de agulhas metálicas no sistema.

A metodologia inédita, proposta neste trabalho, para o controle da pureza radionuclídica do ${ }^{68} \mathrm{Ga}$, feita através de fitas cromatográficas, mostrou-se eficiente. Os valores obtidos na análise foram comparáveis aos valores encontrados pela metodologia convencional. Outra contribuição relevante em relação ao controle radionuclídico, foram os cálculos de limite de detecção e quantificação dos equipamentos utilizados na análise, mostrando a importância desse tipo de cuidado para realização de uma análise segura e eficaz.

Por fim, pode-se concluir que o objetivo principal do trabalho de desenvolver um gerador que disponibilize $0{ }^{68} \mathrm{Ga}$ com qualidade necessária para uso clínico pode ser alcançado quando o protótipo de gerador proposto for utilizado, pois possibilitará a purificação do eluato de maneira prática. É necessário também a avaliação desse protótipo utilizando atividades maiores de ${ }^{68} \mathrm{Ge}$ e realizando a marcação de peptídeos para comprovar a qualidade do eluato do gerador. 


\section{REFERÊNCIAS BIBLIOGRÁFICAS}

AARDANEH, K.; WALT, T. N. V. D. $\mathrm{Ga}_{2} \mathrm{O}$ for target, solvent extraction for radiochemical separation and $\mathrm{SnO} 2$ for the preparation of ${ }^{68} \mathrm{Ge} /{ }^{68} \mathrm{Ga}$ generator. $\boldsymbol{J}$. Radioanal. Nucl. Chem., v. 268, n.1, p. 25-32, 2006.

AHMAD, M. Comunicação pessoal. IAEA Technical Meeting on Developing techniques for small scale indigenous Molybdenum-99 production using low enriched uranium (LEU) fission or nêutron activation: Specific waste and quality issues. Santiago, Chile, 2010.

AMBE, S. ${ }^{68} \mathrm{Ge} /{ }^{68} \mathrm{Ga}$ Generator with Alpha-Ferric Oxide Support. Int. J. Appl. Radiat. Isot., v. 39, n.1, p. 49-51, 1988.

ANDRONOV, V.G.; BRUSKIN, A.B.; SEVAST'YANOVA, A.S.; KODINA, G.E., OCHKIN, A.V.; MYASOEDOVA, G.V. Sorption Conditioning of Eluate of ${ }^{68} \mathrm{Ge} /{ }^{68} \mathrm{Ga}$ for Medical Purposes. Radiokhimiya., v. 50, n. 5, p. 464-468, 2008.

ARINO, H.; SKRABA,W. J.; KRAMER, H.H. A New ${ }^{68} \mathrm{Ge} /{ }^{68} \mathrm{Ga}$ Radioisotope Generator System. Int. J. Appl. Radiat. Isot. v. 29, p.117-120, 1978.

BARRALL, R. C.; CHAKALIAN, V. M.; COLOMBETTI, L.G., FINSTON, R.A. Purity Tests of ${ }^{68} \mathrm{Ge}^{68} \mathrm{Ga}$ Generator. Int. J. Appl. Radiat. Isot., v. 22, p. 149-154, 1971.

BATISTA, P. S. Propriedades morfológicas e estruturais e rendimento quântico de geração de radicais hidroxila em amostras sintetizadas de dióxido de titânio. 2010. Tese (doutorado) - Universidade Federal de Uberlândia, Minas Gerais.

BENHONG, C.; ZONGQUAN, L.; YONGXIAN, W. ${ }^{68} \mathrm{Ge}-{ }^{68} \mathrm{Ga}$ with alpha-ferric oxide support in trigonal structure. J. Radioanal. Nucl. Chem., v. 238, n. 1-2, p. 175-177, 1998.

BRASIL. Resolução da Diretoria Colegiada $n^{\circ}$ 64, de 18 de dezembro de 2009. Brasília, DF: [sn], 2009. Disponível em: http://www.in.gov.br/visualiza/index.jsp?data=23/12/2009\&jornal=1\&pagina=73\&tot alArquivos=160. Acesso em: 10 abr. 2013.

CHAKRAVARTY, R.; SHUKLA, R.; RAM, R.; VENKATESH, M.; DASH, A.; TYAGI, A. K. Nanoceria-PAN Composite-Based Advanced Sorbent Material: A Major Step Forward in the Field of Clinical-Grade ${ }^{68} \mathrm{Ge} /{ }^{68} \mathrm{Ga}$ Generator. Appl Mat Interfaces, v. 2, n. 7, p. 2069-2075, 2010.

CHAKRAVARTY, R.; SHUKLA, R.; RAM, R.;TYAGI, A.; DASH, A.; VENKATESH, M. K. Development of a nano-zirconica based ${ }^{68} \mathrm{Ge} /{ }^{68} \mathrm{Ga}$ generator for biomedical applications. J. Nucl. Med. Biol., v. 38, p. 575-583, 2011.

CHENG, W.; JAO, Y.; LEE, C.; LO,A. Preparation of ${ }^{68} \mathrm{Ge} /{ }^{68} \mathrm{Ga}$ Generator with a binary Ga/Ag electropositions as solid target. J. Radioanal. Nucl. Chem., v. 245, n. 1 , p. $25-30,2000$. 
CURRIE, L. A. Limits for Qualitative Detection and Quantitative Determination: Application to Radiochemistry. Anal. Chem., v. 40, n. 3, p. 586-593, 1968.

DECRISTOFORO, C. Gallium-68 - A New Opportunity For PET Available From a Long Shelf life Generator - Automation and Applications. Current Radiopharmaceuticals, v. 5, pp 212-220, 2012.

EGAMEDIEV, S. K.; KHUJAEV, S.; MAMATKAZINA, A. K. Influence of preliminary treatment of aluminum oxide on the separation of ${ }^{68} \mathrm{Ge}-{ }^{68} \mathrm{Ga}$ radionuclide chain. $\boldsymbol{J}$. Radioanal. Nucl. Chem., v. 246, n. 3, p. 593-596, 2000.

EHRHARDT, G.J.; WELCH, M. J. A New Germanium-68/Gallium-68 Generator. J. Nucl. Med., v. 19, p. 925-929, 1978.

EPPARD, E.; LOKTIONOVA, N., RÖSCH, F. Quantitative online isolation of ${ }^{68} \mathrm{Ge}$ from ${ }^{68} \mathrm{Ge} /{ }^{68} \mathrm{Ga}$ generator eluates for purification and immediate quality control of breakthrough. Appl. Radiat. Isot., v. 82, p. 45-48, 2013.

EPPARD, E.; LOKTIONOVA, N.S.; ROESCH, F.; Quantitative determination of ${ }^{68} \mathrm{Ge}$ breakthrough of ${ }^{68} \mathrm{Ge} /{ }^{68} \mathrm{Ga}$ generators via TLC. Eur. J. Nucl. Med. Mol. Imaging. v. 39, p. S261-S262, 2012.

EUROPEAN DIRECTORATE FOR THE QUALITY OF MEDICINES AND HEALTHCARE. Gallium $\left({ }^{68} \mathrm{Ga}\right)$ chloride solution for radiolabelling. Ph. Eur. 7 , 7.8, 5643. julh. 2013.

Evonik industries. Specification 1261/1. AEROXIDE $\mathrm{TiO}_{2} \mathrm{P} 25$.

Evonik industries. Specification 4505/1. AEROXIDE $\mathrm{TiO}_{2} \mathrm{P90}$.

FERREIRA, R. M.; MARQUES, F. L. N. Radiofarmácia. In: HIRONAKA, F. H.; SAPIENZA, M. T.; ONO, C. R.; LIMA, M. S.; BUCHPIGUEL, C. A. (Ed.) Medicina Nuclear - Princípios e Aplicações. São Paulo, SP: Editora Atheneu, 2012. p. 5566.

FRÜH, R.S. Comunicação pessoal. Second Research Co-ordination Meeting (RCM) of the CRP. Romênia, abr. 2007.

GLEASON G.I. A Positron Cow. Int. J. Appl. Radiat. Isot., v. 8, p. 90-94, 1960.

GREEN, M. A.; WELCH, M.J. Gallium Radiopharmaceutical Chemistry. J. Nucl. Med. Biol., v. 16, n. 5, p. 435-448, 1989.

GREENE, M. W.; TUCKER, W. D. An Improved Gallium-68 Cow. Int. J. Appl. Radiat. Isot., v. 12, n. 1-2, p. 62-63, 1961.

IAEA Nuclear Data Section. Disponível em: http://www-nds.iaea.org/. Acesso em: agost. 2013.

IAEA. Production of Long Lived Parent Radionuclides for Generators: ${ }^{68}$ Ge, ${ }^{82} \mathrm{Sr},{ }^{90} \mathrm{Sr}$ and ${ }^{188} \mathrm{~W}$. IAEA Radioisotopes and radiopharmaceuticals series $\mathrm{n} \times 2$, 2010. 
IAEA. Quality Assurance for PET and PET/CT Systems, IAEA HUMAN HEALTH SERIES No. 1, 2009.

IAEA-TECDOC-1401. Quantifying uncertainty in nuclear analytical measurements. International Atomic Energy Agency, 2004.

IDB HOLLAND bv. iThemba LABS, África do Sul. ${ }^{68} \mathrm{Ga}$ generator. Disponível em: http://www.idb-holland.com/products/7/15_product_details_gallium-

68_generator.html. Acesso em: 09 nov. 2010.

ITG. The ITG Ga-68 Labelling Package: Ge-68/Ga-68 Generator \& Synthesis Module. ITG isotope technologies Garching GmbH. Disponível em: http://www.itggarching.de/index.php/products/generators/itg-ge-68-ga-68-generator. Acesso em: nov. 2011.

KHAN, M.U.; KHAN, S.; EL-REFAIE, S.; WIN, Z.; RUBELLO, D., AL-NAHHAS, A. Clinical indications for Gallium-68 positron emission tomography imaging. Eur $\boldsymbol{J}$ Surg Oncol, 2009. Article in press.

KOPECKÝ, P.; MUDROVÁ, B. ${ }^{68} \mathrm{Ge}-{ }^{68} \mathrm{Ga}$ Generator for the Production of ${ }^{68} \mathrm{Ga}$ in an lonic Form. Int. J. Appl. Radiat. Isot., v. 25, p. 263-268, 1974.

KOPECKÝ, P.; MUDROVÁ, B.; SVOBODA, K. The Study of conditions for the Preparation and Utilization of ${ }^{68} \mathrm{Ge}-{ }^{68} \mathrm{Ga}$ Generator. Int. J. Appl. Radiat. Isot., v. 24, p. 73-80, 1973.

LIMA, M.S.; GARCEZ, A. T.; PRANDO, S.; OLIVEIRA, M. A. Instrumentação e Processamento. In: HIRONAKA, F. H.; SAPIENZA, M. T.; ONO, C. R.; LIMA, M. S.; BUCHPIGUEL, C. A. (Ed.) Medicina Nuclear - Princípios e Aplicações. São Paulo, SP: Editora Atheneu, 2012. p. 25-53.

LOC' H, C., MAZIERE, B., COMAR, D. A new generator for ionic gallium-68. J. Nucl. Med., v. 21, p. 171-173, 1980.

MALYSHEV, K.V.; SMIRNOV, V.V. A Generator of Gallium-68 Based on Zirconium Hydroxide. Translated from Radiokhimiya, v. 17, n. 1, p. 137-140, 1975.

MARTINS, P. A. Desenvolvimento de método para separação química de gálio-67 pela técnica de difusão térmica. 2012. Tese (doutorado) - Instituto de Pesquisas Energéticas e Nucleares, São Paulo.

MIRZADEH, S.; LAMBRECHT, R.M. Radiochemistry of Germanium. J. Radioanal. Nucl. Chem., v. 202, p. 7-102, 1996.

NAKAYAMA, M.; HARATAKE, M.; KOISO, T.; ISHIBASHI, O.; HARADA, K.; NAKAYAMA, H.; SUGII, A.; YAHARA, S.; OHMOMO, Y.; ARANO, Y. Separation of ${ }^{68} \mathrm{Ga}$ from ${ }^{68} \mathrm{Ge}$ using a macroporous organic polymer containing $\mathrm{N}$ methylglucamine groups. Anal. Chim. Acta. v. 453, p. 135-141, 2002. 
NEIRINCKX, R.D.; DAVIS, M.A. Potential Column Chromatography for Ionic Ga68. II: Organic lon Exchangesrs. J. Nucl. Med., v. 21, p. 81-83, 1980.

NEIRINCKX, R.D.; DAVIS, M.A. Potential Column Chromatography Generators for Ionic Ga-68. I. Inorganic Substrates. J. Nucl. Med., v. 20, p. 1075-1079, 1979.

NEIRINCKX, R.D.; LAYNE, W.W.; SAWAN, S.P.; DAVIS, M.A. Development of an Ionic ${ }^{68} \mathrm{Ge} /{ }^{68} \mathrm{Ga}$ Generator III. Chelate Resins as Chromatographic Substrates for Germanium. Int. J. Appl. Radiat. Isot., v. 33, p. 259-266, 1982.

NEUMAIER, B.; FANI, M. ${ }^{68}$ Ga-Radiopharmaceuticals. In:

WESTER, H. J. Munich Molecular Imaging Handbook Series: Pharmaceutical Radiochemistry (I). Alemanha: Ed Scintomics Print Media and Publishing, 2010. v. 1, p. 103-126.

OLIVEIRA, P. R. Termogravimetria (TG) e Termogravimetria derivada (DTG). 2011. Acessado em: 03/2013. Disponível em: http://fasul.edu.br/pasta_professor/arquivos/54/8140_tg_-_dtg.pdf.

OLIVEIRA, R.; SANTOS, D.; FERREIRA, D.; COELHO, P.; VEIGA, F. Preparações radiofarmacêuticas e suas aplicações. Revista Brasileira de Ciências Farmaceuticas. v. 42, n. 2, 2006.

OSSO, J.; KNAPP, R. Principles and operation of radionuclide generators. In: THEOBALD, T. Sampson's Textbook of Radiopharmacy. Cornwall, Padstow: Pharmaceutical Press, 2011. 4. ed. p. 339-364.

PubMed. Palavra chave para pesquisa: $68 \mathrm{Ga}$ or Ga-68. Disponível em: http://www.ncbi.nlm.nih.gov/pubmed. Acesso em: agost. 2013.

REGO, J. A. Comunicação pessoal de Jorge Alberto Rego, em julho de 2013, recebida por correio eletrônico.

ROESCH, F.; RISS, P. J. The Renaissance of the ${ }^{68} \mathrm{Ge} /{ }^{68} \mathrm{Ga}$ Radionuclide Generator Iniciates New Developments in ${ }^{68} \mathrm{Ga}$ Radiopharmaceutical Chemistry. Current Topics in Medicinal Chemistry, v. 10, p. 1633-1668, 2010.

$\mathrm{ROSCH}, \mathrm{F}$. Past, present and future of $68 \mathrm{Ge} / 68 \mathrm{Ga}$ generators. Appl. Radiat. Isot., v. 76, p. 24-30, 2013.

SAHA, G. B. Fundamentals of Nuclear Pharmacy. 3.ed. Springer Verlag, 1992.

SBMN. 50 Anos da Sociedade Brasileira de Biologia, Medicina Nuclear e Imagem Molecular. Edição comemorativa da Sociedade Brasileira de Medicina Nuclear, 2011.

SCHUBIGER, P.A.; LEHMANN, L.; FRIEBE, M. PET Chemistry: The Driving Force in Molecular Imaging. Emst Schering Research Foundation Workshop 62. v. 64, p. 215-242. Ed Springer, 2007. 
SCHUHMACHER, J.; MAIER-BORST, W. A New ${ }^{68} \mathrm{Ge} /{ }^{68} \mathrm{Ga}$ Radioisotope Generator System for Production of ${ }^{68} \mathrm{Ga}$ in Dilute $\mathrm{HCl}^{*}$. Int. J. Appl. Radiat. Isot. v. 32, p. 31-36, 1981.

SEN, K.; BREEMAN, W. A.; WOLTERBEEK, H. T.; Choice of Inorganic Materials as ${ }^{68} \mathrm{Ge} /{ }^{68} \mathrm{Ga}$ Generator: An Intercomparison. Ion Exchange Letters. v. 4, p. 3243, 2011.

SKOOG, D. A.; HOLLER, F.J.; NIEMAN, T. A. Principles of Instrumental Analysis. 5.d. USA: Ed. Harcourt, 1998.

SUZUKI, K.N. Estudos de técnicas de concetração da atividade de ${ }^{99 m}$ Tc eluído de geradores de ${ }^{99}$ Mo/ ${ }^{99 m}$ Tc tipo gel. 2009. Tese (doutorado) - Instituto de Pesquisas Energéticas e Nucleares, São Paulo.

Technical Information Bulletin. ${ }^{68} \mathrm{Ge} /{ }^{68} \mathrm{Ga}$ Generator Comparison. Disponível em: http://www.ezag.com/fileadmin/ezag/user-

uploads/radiopharma/radiopharma/7131-

0037_Ga68_GeneratorInformation_Bulletin_customers.pdf. Acesso em: 26 mar. 2013.

THRALL, J. H. Medicina Nuclear. Tradução: Maria E. Penas. 2.d. Rio de Janeiro: Ed. Guanabara Koogan S.A., 2003.

VALLABHAJOSULA, S. Molecular Imaging: Radiopharmaceuticals for PET and SPECT. New York: Ed Springer, 2009.

VALLABHAJOSULA, S.; SOLNES, L.; VALLABHAJOSULA, B. A Broad Overview of Positron Emission Tomography Radiopharmaceuticals and Clinical Applications: What is New? Semin. Nucl. Med., v. 41, p. 246-264, 2011.

VANDEGRIFT, G. F.; WU, W. Discussion Guide for LEU-Modified Cintichem Process. p. 102, 1995.

VIEIRA, E.A. Análise Térmica. Programa de pós-graduação em engenharia metalúrgica e de materiais. Instituto Federal do Espírito Santo. Disponível em: $\mathrm{ftp}: / / \mathrm{ftp}$.cefetes.br/cursos/MetalurgiaMateriais/Estefano/caracterizacaomestrado/C ARACTERIZAO5.pdf. Acesso em: abr. 2013.

VIROLAINEN, S.; HEINONEN, J.; PAATERO, E. Selective recovery of germanium with $\mathrm{N}$-methylglucamine functional resin from sulfate solutions. Separation and Purification Technology. v. 104, p. 193-199, 2013.

VOLYNETS, M. P.; ERMAKOV, A. N.; FOMINA, T.V. "Thin-layer Chromatography in Inorganic analysis. 7 . Adsorption Behavior of Element Ions on Silica Gel in Aqueous-acetona Solutions of Hydrochloric Acid." Anal. Chem. of USSR., v. 25, p. 1599, 1970. Citado por MIRZADEH, S.; LAMBRECHT, R.M. Radiochemistry of Germanium. J Radio and Nucl Chem. v. 202, p. 7-102, 1996.

WOOD, S.A.; SAMSON, I.M. The aqueous geochemistry of gallium, germanium, indium and scandium. Ore Geology Reviews. v. 28, p. 57-102, 2006. 
YAMAGA, L. Palestra sobre "Resultados iniciais da pesquisa clínica com DOTATATO- ${ }^{68} \mathrm{Ga}$ " proferida pela Dra. Lilian Yamaga do Hospital Israelita Albert Einstein, no Centro de Radiofarmácia em abril de 2013.

YANG, Y,B.; JEONG, J.M.; KIM, Y. J.; CHOI, Y. J.; LEE, Y.; LEE, D.S.; CHUNG, J.; LEE, M. C. Formulation of ${ }^{68} \mathrm{Ga}$ BAPEN kit for myocardial positrón emission tomography imaging and biodistribution study. Nucl. Med. Biol., 2009. Article in press.

YANO, Y.; ANGER, H.O. A Gallium ${ }^{68}$ Positron Cow for Medical Use. J. Nucl. Med., v. 5, p. 485-488, 1964. 